\title{
THE IMPACT OF THE EURO ON FINANCIAL MARKETS
}

by Lorenzo Cappiello, Peter Hördahl, Arjan Kadareja and Simone Manganelli comments by Xavier Vives and Bruno Gerard 


\title{
WORKING PAPER SERIES
}

NO 598 / MARCH 2006

PROCEEDINGS OF JUNE 2005 WORKSHOP ON WHAT EFFECTS IS EMU HAVING ON THE EURO AREA AND ITS MEMBER COUNTRIES?

\section{THE IMPACT OF THE EURO ON FINANCIAL MARKETS}

\author{
by Lorenzo Cappiello?, \\ Peter Hördahl', \\ Arjan Kadareja ${ }^{2}$ \\ and Simone Manganelli ${ }^{2}$ \\ comments by Xavier Vives \\ and Bruno Gerard
}

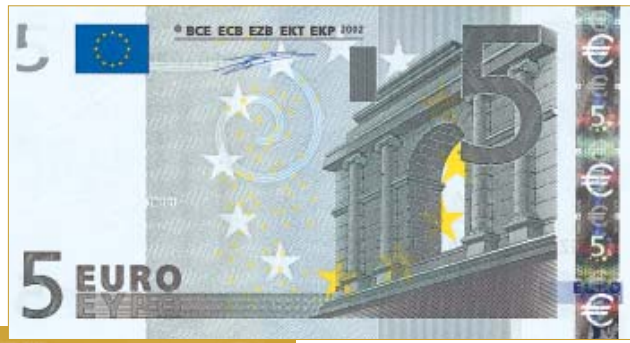

This paper can be downloaded without charge from http://www.ecb.int or from the Social Science Research Network electronic library at http://ssrn.com/abstract_id $=887087$ 


\section{PREFACE}

On 16 and 17 June 2005, the ECB has hosted a Conference on "What Effects is EMU Having on the Euro Area and its Member Countries?” One and a half decade after the start of the European Economic and Monetary Union (EMU) and more than six years after the launch of the euro, the aim of the conference was to assess what can be learned about the impact of economic and monetary integration and how it has benefited the euro area and its member countries.

The conference brought together academics, central bankers and policy makers to discuss the existing empirical evidence on changes brought about, either directly or indirectly, by EMU and, in particular, the introduction of the euro in five main areas:

Area 1. Trade integration;

Area 2. Structural reforms in product and labour markets;

Area 3. Financial integration;

Area 4. Business cycles synchronisation and economic specialisation; and

Area 5. Inflation persistence and inflation differentials.

Lead presenters for each of the aforementioned areas had been asked to put together - and interpret - all the available information, flag any open questions, and also discuss the implications in their respective field of expertise. With the benefit of hindsight, lead presenters and discussants have also addressed some initial presumptions with the evidence that has accumulated thus far.

In order to exchange information and ideas on the above effects, and increase mutual awareness of ongoing work in the diverse areas, we deemed it useful to issue the five leading presentations, together with the accompanying discussions, in the ECB Working Paper Series.

Otmar Issing

Member of the Executive Board
Francesco Paolo Mongelli Conference Organiser
Juan Luis Vega

Conference Organiser

\footnotetext{
(C) European Central Bank, 2006

Address

Kaiserstrasse 29

60311 Frankfurt am Main, Germany

Postal address

Postfach 160319

60066 Frankfurt am Main, Germany

Telephone

+496913440

Internet

http://www.ecb.int

Fax

+496913446000

Telex

411144 ecb d

All rights reserved.

Any reproduction, publication and reprint in the form of a different publication, whether printed or produced electronically, in whole or in part, is permitted only with the explicit written authorisation of the ECB or the author(s).

The views expressed in this paper do not necessarily reflect those of the European Central Bank. 


\section{CONTENTS}

Abstract 4

Non-technical summary 5

1. Introduction

2. Asset return dynamics before and after the euro: The impact on stock and bond markets

2.1 Asset return correlation and financial integration

2.2 Data

2.3 Correlation and volatility dynamics

2.3.1 Estimation approach

2.3.2 Results

2.4 Structural changes in co-movements

2.4.1 Estimation and testing approach

2.4.2 Results

3. Asset pricing before and after the euro: The behaviour of the term structure

3.1 The HTV model

3.2 Impact of the euro on fundamentals

3.3 Impact of the euro on term premia

4. Conclusions

References

Appendices

A The multivariate dynamic conditional correlation (DCC) GARCH model for asset returns

B The quantile regression approach for comovements in asset returns

C The affine macro-finance term structure model

Tables and figures

Comments by Xavier Vives

Comments by Bruno Gerard

European Central Bank Working Paper Series 


\begin{abstract}
We assess whether the euro had an impact first on the degree of integration of European financial markets, and, second, on the euro area term structure. We propose two methodologies to measure integration: one relies on time-varying GARCH correlations, and the other one on a regression quantile-based codependence measure. We document an overall increase in co-movements in both equity and bond euro area markets, suggesting that integration has progressed since the introduction of the euro. However, while the correlations in bond markets reaches almost one for all euro area countries, co-movements in equity markets are much lower and the increase is limited to large euro area economies only. In the second part of the paper, we focus on the asset pricing implications of the euro. Specifically, we use a dynamic no-arbitrage term structure model to examine the risk - return trade-off in the term structure of interest rates before and after the introduction of the euro. The analysis shows that while the average level of term premia seems little changed following the euro introduction, the variability of premia has been reduced as a result of smaller macro shocks during the euro period. Moreover, the macro factors that were found to be important in explaining the dynamics of premia before the introduction of the euro continue to play a key role in this respect also thereafter.
\end{abstract}

KEY WORDS: Financial markets, euro, financial integration, volatility, conditional correlation, term structure, fundamentals, risk premia

JEL CLASSIFICATION: F36, G12, E43, E44, C22 
Non-technical summary

This paper studies the impact of the euro on European stock and government bond markets. We first investigate whether the introduction of the euro had an impact on the degree of integration of European financial markets. We then analyse to which extent the common monetary policy significantly changed the dynamics and the determinants of the euro area term structure.

To study integration, we argue that the progressive elimination of trade barriers, capital controls and exchange rate risks should lead to an increase in comovements of firms' returns. Therefore, measures of co-movements are linked to the degree of financial integration.

We measure co-movements using two different methodologies. One relies on the estimation of a time-varying correlation. The other one is based on the estimation of the conditional probability that a return falls below a given threshold, when another return is also falling below the same threshold. The two methodologies are complementary: the first provides a short run picture of the correlation evolution, while the second is used to analyse changes in long run co-movements before and after the introduction of the euro.

We document an overall increase in co-movements in both equity and bond euro area markets, suggesting that integration has progressed since the introduction of the single currency. However, while the correlations in bond markets reaches almost one for all euro area countries, co-movements in equity markets are much lower and the increase is limited to large euro area economies only. We control for the impact of global factors by including in the analysis other non euro area countries, in particular, Japan, the UK and the US. As for equity markets, our findings suggest the presence of a common "cross Atlantic" factor, in that co-movements across large EU countries and the US increase by a comparable magnitude. Co-movements with Japan and small EU economies, instead, remain generally very low. As for bond markets, we find strong evidence that the single currency was a major factor in fostering integration in the euro area. We emphasise two results. First, unlike the equity markets, bond markets almost reach the level of perfect integration in both small and large euro area economies. Second, while we continue to observe a "cross Atlantic" integration process, the increase in co-movements for non euro area economies is much less pronounced. Japan continues to exhibit weak links with the rest of the countries in our sample.

With respect to the impact of the euro on the term structure, our results suggest that the behaviour of term premia is different now compared to before the introduction of the euro, and that this is due partly to changes in the dynamics of the macro state variables, and partly to changes in the market's required compensation for risk associated with these macro factors. However, we also find that average premia remain little changed after the euro's introduction, while there seems to have been a reduction in the variability of premia during the euro period. Moreover, we conclude that the macro factors that were found to be important in explaining the dynamics of premia before the euro continue to play a key role in this respect also after the single currency was introduced. 


\section{Introduction}

The launch of the euro in January 1999 has generated a large debate among researchers, policymakers and market participants about the effects of the single currency on financial markets. This paper studies the impact of the euro on European stock and government bond markets. By analysing return dynamics and asset pricing, we address two sets of questions. First, we investigate whether the introduction of the euro had an impact on the degree of integration of European financial markets. Second, we analyse whether the common monetary policy significantly changed the dynamics and the determinants of the euro area term structure.

There are a number of papers that study financial integration exploiting the implication of asset pricing models (see, for instance, Bekaert and Harvey, 1995, and Hardouvelis, Malliaropulos and Priestley, 2006). A possible problem inherent in this approach is that the choice of the asset pricing model may affect the final results. We employ, instead, a factor model for market returns which distinguishes between global and local components. Differently from previous studies on integration, we do not estimate the model itself nor its loading factors.

To study integration we follow the intuition of Cappiello, Gérard, Kadareja and Manganelli (2005), who show how measures of co-movements are linked to the degree of financial integration. The idea is that, as trade barriers and capital controls are removed within an economic area, firms' cash flows will become more subject to common shocks. Ceteris paribus this, coupled with the elimination of exchange rate risk, implies an increase in co-movements of firms' returns.

We propose two methodologies to measure co-movements. The first one is a time-varying GARCH correlation, along the lines of Engle (2002) and Cappiello, Engle and Sheppard (2003). The second one is a regression quantile-based codependence estimate, as suggested by Cappiello, Gérard and Manganelli (2005). The two methodologies are complementary in the sense that GARCH-based measures provide a short run picture of the correlation evolution, while regression quantile-based measures are used to analyse changes in long run co-movements before and after the euro.

We document an overall increase in co-movements in both equity and bond euro area markets, suggesting that integration has progressed since the introduction of the single currency. However, while the correlations in bond markets reaches almost one for all euro area countries, co-movements in equity markets are much lower and the increase is limited to large euro area economies only. We control for the 
impact of global factors by including in the analysis other non euro area countries, in particular, Japan, the UK and the US. As for equity markets, our findings suggest the presence of a common "cross Atlantic" factor, in that co-movements across large EU countries and the US increase by a comparable magnitude. Co-movements with Japan and small EU economies, instead, remain generally very low. As for bond markets, we find strong evidence that the single currency was a major factor in fostering integration in the euro area. We emphasise two results. First, unlike the equity markets, bond markets almost reach the level of perfect integration in both small and large euro area economies. Second, while we continue to observe a "cross Atlantic" integration process, the increase in co-movements for non euro area economies is much less pronounced. Japan continues to exhibit weak links with the rest of the countries in our sample.

In the second part of the paper, we focus on the effects of the euro on the term structure of interest rates, with particular emphasis on whether there have been significant changes in risk premia on yields of various maturities. Specifically, using the affine macro-finance model of Hördahl, Tristani and Vestin (2005a) we investigate whether the dynamic behaviour of macroeconomic risk factors that are relevant for the term structure have changed with the single currency. We also examine whether the market has changed the way it prices these risk factors in bonds.

We find that the behaviour of term premia is different now compared to before the introduction of the euro, and that this is due partly to changes in the dynamics of the macro state variables, and partly to changes in the way the market requires compensation for bearing risk associated with these macro factors. However, we also find that while these changes seem to have resulted in a reduction in the variability of premia during the euro period, average premia remain little changed. Moreover, with respect to the determinants of the time-varying portion of premia, we conclude that the macro factors that were found to be important in explaining the dynamics of premia before the euro continue to play a key role in this respect also after the single currency was introduced. The results of this second part of the paper are relevant for a variety of monetary policy issues.

The paper is structured as follows. In section 2, we analyse the impact of the euro on the dynamics of asset returns in equity and bond markets. Section 3 examines the risk - return trade-off in the term structure of interest rates before and after the introduction of the euro. Section 4 concludes. Details about the three models used in the analyses can be found in the appendices. 


\section{Asset return dynamics before and after the euro: The impact on stock and bond markets}

In this section we propose a set of measures to assess the effects of the euro on bond and stock markets. Following Cappiello, Gérard, Kadareja and Manganelli (henceforth CGKM) (2005), we first show how measures of co-movement can be linked to the degree of financial integration. We then propose two measures of comovement: (i) a time-varying GARCH-type correlation and (ii) a regression quantilebased codependence measure. The two approaches are robust to the well-know heteroskedasticity problem that plagues naïve correlation measures (see, for instance, Forbes and Rigobon, 2002). The two methodologies are complementary in the sense that GARCH-based measures provide a high-frequency picture of the correlation evolution, while with the measures based on regression quantiles we can analyse changes in correlations over the long run. Finally, through a simple visual inspection, we also check whether the euro had any major effect on equity and bond markets volatilities.

\subsection{Asset return correlation and financial integration}

As shown by CGKM, there is a relationship between correlation and integration. The relationship is derived from a model for returns which distinguishes between global and local factors. Progress in integration is associated with an increase in the proportion of returns' variance explained by the global factor vis-à-vis local factors.

This reflects the intuition that, as a country moves from being closed to an open status, the impact of foreign factors on domestic firms' cash flows increases. Hence the removal of trade barriers and the elimination of exchange rate risk within a region should be accompanied by an increase in co-movements of firms' returns. In short, increased co-movements in financial asset returns are consistent with greater integration and economic interdependence.

In line with this discussion, we model returns in a national market as follows:

$$
r_{i t}=\beta_{i t} G_{t}+e_{i t},
$$

where $r_{i t}$ is the return on asset $i, \beta_{i t}$ the exposure at time $t$ of asset $i$ to the global factor $G_{t}$, and $e_{i t}$ the idiosyncratic risk of asset $i$ assumed to be orthogonal to the global factor and to asset $j$ idiosyncratic risk. 
The volatility of country $i$ 's returns can be decomposed as $\sigma_{r_{i t}}^{2}=\beta_{i t}^{2} \sigma_{G t}^{2}+\sigma_{e_{i t}}^{2}$. A measure of integration which formalises the preceding discussion is given by the amount of variance explained by the global factor: ${ }^{1}$

$$
\phi_{i t} \equiv \frac{\beta_{i t}^{2} \sigma_{G t}^{2}}{\sigma_{r_{i t}}^{2}} .
$$

If markets are perfectly segmented the variance explained by the global factor is equal to zero and therefore $\phi_{i t}=0$. On the other hand, if markets are perfectly integrated, most of the source of variation will come from the global factor and $\phi_{i t} \simeq 1$. In general, higher values of $\phi_{i t}$ imply a higher degree of integration.

CGKM show that there is a precise link between standard correlation measures and the integration indicators $\phi_{i t}$ and $\phi_{j t}$ :

$$
\rho_{i j t}=\operatorname{sign}\left(\beta_{i t} \beta_{j t}\right) \sqrt{\phi_{i t} \phi_{j t}} \quad \forall i, j \text { and } i \neq j .
$$

The above decomposition indicates that the correlation is proportional to our integration indicators which, in turn, represent the amount of the total variance explained by the global component.

To assess the impact of the euro, it is necessary to test for changes in correlations. These tests need to account for time variation in the moments of the returns distribution and departure from normality. Since changes in volatilities before and after the introduction of the euro could result in an estimation bias, a simple comparison between correlations over the two periods could lead to a spurious outcome.

To solve this issue, we use two different, yet complementary, modelling strategies, both robust to heteroscedasticity problems. The first model is the Dynamic Conditional Correlation (DCC) Generalised Autoregressive Conditionally Heteroskedastic (GARCH) process introduced by Engle (2002). The second approach is based on the "co-movement box" of Cappiello, Gérard and Manganelli (2005). The DCC GARCH model allows us to check the behaviour of both volatilities and correlations over time, and in particular after the introduction of the euro. This model, however, is fully parametric, since it assumes a dynamic for second moments and a specific distribution for asset returns. The co-movement box, on the other hand, is a semi-parametric approach and does not need any assumption on the distribution of returns. Differently from the DCC GARCH model, which estimates correlations at a relatively high frequency, co-movement box measures provide a direct test for changes in correlation before and after the introduction of the euro.

${ }^{1}$ See CGKM for further details. 


\subsection{Data}

We analyse returns on (i) equity market indices and (ii) ten-year government bonds. Equity indices include Austria, Belgium, Finland, France, Germany, Greece, Ireland, Italy, the Netherlands, Portugal, Spain, as well as the Eurostoxx50. Data on 10-year government bonds are available for all the countries listed above, except Portugal. The sample covers the period from January 9th, 1987 to October 21st, 2005. Data on the Greek equity price index, and the Belgian and Finnish 10-year government bond are only available from January 10th 1992. Countries which do not belong to the euro area (such as Denmark, Japan, Sweden, the United Kingdom, and the United States) are also included in the analysis since they will be used as control.

We use Global Financial Data indices at weekly frequency. Equity indices are market-value-weighted and include dividends. As for government bonds, we use yields to maturities. The use of weekly data reduces the asynchronicity effects due to different opening hours, national holidays and administrative closures.

Equity and government bond returns are continuously compounded. Bond returns are computed with the following formula:

$$
\begin{aligned}
r_{b t} & =p_{b t}-p_{b t-1} \\
& =n\left(y_{t-1}-y_{t}\right),
\end{aligned}
$$

where $r_{b t}$ denotes the (weekly) returns on bonds, $p_{b t}$ the log price of the bond, $p_{b t} \equiv \ln \left(P_{b t}\right), y_{t}$ the $\log$ of the gross yield to maturity, $y_{t} \equiv \ln \left(1+Y_{b t}\right)$, and $n$ the maturity, which, in our case, is ten year. ${ }^{2}$

Table 1 reports data summary statistics. As expected, equity markets exhibit higher average returns and standard deviations than bond markets. Both series tend to be negatively skewed and leptokurtic. Non-normality is confirmed by the Jera-Barque test statistics.

Tables 2a-2d report unconditional correlations for the full sample period, and three sub-periods: The first runs from January 1987 to December 1998, the second from January 1992 to December 1998 and the third from January 1999 to October 2005. This choice mirrors the samples used for estimating conditional correlations and long-run comovements. Three stylised facts emerge from these tables. First,

\footnotetext{
${ }^{2}$ Yields are constructed to keep maturity constant at each observation.
} 
correlations over the full sample period are very low between equity and bond markets. However, the break-down by sub-periods reveals that correlations were positive before 1998 and turned negative afterwards. This could be related to the burst of the bubble in equity markets in early 2000s and the associated flight-to-quality phenomenon. Second, full sample intra-asset correlations are roughly comparable, but the sub-sample correlations increase remarkably since 1999, especially for bonds, where return correlations approache one. Third, the euro area asset returns are overall more correlated with the US than Japan and increasingly so after 1999.

\subsection{Correlation and volatility dynamics}

\subsubsection{Estimation approach}

The DCC GARCH model of Engle (2002) exploits the decomposition of the covariance matrix, which can be written as the product of a correlation matrix and diagonal matrices of standard deviations. The estimation of the conditional second moments is based on a two step procedure. In the first step univariate volatility models are estimated for each asset return. The standard deviations obtained in the first stage are utilised to standardise asset returns, which, in the second step, will be used to estimate the conditional correlation matrix. ${ }^{3}$ In line with Sheppard (2002) and Cappiello, Engle and Sheppard (2003), among others, we estimate a flexible version of the original scalar DCC GARCH process of Engle (2002). In our specification the dynamics of correlation is not parametrized with single news impact and smoothing parameters but with diagonal coefficient matrices. We also accommodate second moment asymmetries typical of financial time series. The formulae for conditional correlations and variances of asset returns are given in equations (17) and (18)-(20) of Appendix A , respectively. We refer to Appendix A for further technical details.

\subsubsection{Results}

In this section we describe the estimation results obtained with the multivariate diagonal DCC GARCH model. We use weekly data from January 1987 to October 2005. We plot conditional variances and correlations for equity and bond returns on EU countries. US and Japanese time varying second moments are also reported. We first analyse equity markets and next we move to bond markets.

\footnotetext{
${ }^{3}$ In fact, there is an intermediate step which involves the estimation of the long run correlation matrix (see Cappiello, Engle and Sheppard, 2003, for further details).
} 
Due to the multi-stage procedure of the DCC GARCH process, we first estimate three univariate volatility models for each return series, (i) the GARCH model of Bollerslev (1986), (ii) the Exponential GARCH (EGARCH) model of Nelson (1991), and (iii) the GJR-GARCH of Glosten, Jagannathan and Runkle (1993). Next, we select the model which best fit the data according to the Schwartz information criterion. Table 3 reports the selected GARCH specifications and their estimated parameters. Apart from Austria and Finland, all equity markets show asymmetry in conditional volatility. As for bonds, instead, only four markets out of 12 (France, Italy, Spain and the US) require asymmetric GARCH specifications. This is in line with previous findings (see, for instance, Cappiello, Engle and Sheppard, 2003). Parameter estimates for the correlation dynamics are reported in Table 4 and are almost all significantly different from zero. Correlation is highly persistent and, differently from the univariate models, both equities and bonds exhibit asymmetry.

Equities Figure 1 plots, for euro area economies, weighted average conditional correlations between equity returns. ${ }^{4}$ We observe an overall increase in the level of conditional correlation in the second of the 1990s, with a major boost in 1998. This may be due to the considerable reduction in the exchange rate risk which occurred on 3 May 1998, when the announcement of irrevocable exchange rates was made. We also distinguish between "large" (France, Germany, Italy, the Netherlands and Spain) and "small" (Austria, Belgium, Finland, Ireland and Portugal) economies. This breakdown reveals that most of the increase in correlation is driven by the largest countries, while the correlation in the smallest remains roughly unchanged. Details about each country-pair time-varying correlations can be found in figures 2 , 3 and 4 and confirm the results from the aggregate plots.

To understand whether this increase in correlations is euro area specific or reflects a more global phenomenon, figure 5 plots the conditional correlations between returns on Eurostoxx50 and selected non-euro area equity market indices (Denmark, Japan, Sweden, the UK and the US). We observe a similar increase in correlations starting in the second half of 1990s for the non-euro area EU countries and the US, while correlations with Japan remain low. This suggests that the stronger equity market co-movements are a cross-Atlantic feature rather than euro area specific.

\footnotetext{
${ }^{4}$ Conditional correlations of each euro area country pair is weighted by the fraction of its GDP relative to the total euro area GDP. In the computation we use the 2003 GDP levels.
} 
Figures 9-11 plot conditional variances for returns on equity markets. Stock market volatilities for the euro area, US and UK reflect major global shocks, like the ERM crisis in 1992, the Asian-Russian-Latin America crises, the burst of the equity market bubble, the terrorist attack on September 11 2001, the American corporate scandals and the Iraq war. Overall world equity markets seem to become more volatile starting from the Asian crisis.

Bonds Euro area bond markets have witnessed a dramatic increase in integration with the introduction of the single currency. Figure 6 shows the weighted average conditional correlations between returns on 10-year government bonds for Germany and other euro area economies. ${ }^{5}$ Correlations, which hovered around 0.4 in the first half of the 1990s, steadily increased thereafter and reached almost one after 1999. Despite the elimination of exchange rate risk and the common monetary policy, government bond markets are not perfectly correlated. This reflects the existence of remaining domestic liquidity and credit risk premia.

A striking difference with respect to the equity market analysis is that the increase in correlations occurred for both large and small economies. Figure 7 reports single correlations for each country pair and confirm the overall results of figure 6. The international comparison proposed in figure 8 suggests another remarkable difference vis-à-vis the equity markets. Cross Atlantic correlations increase but not to the same extent as the euro area countries. After 1999 correlations between Sweden, Denmark and the UK versus Germany stabilize around 0.85. Correlations between Germany, the UK and the US reach a somewhat lower upper bound around 0.75. Finally, correlations involving Japan remain low and unchanged, similarly to equity markets.

As for the bond markets (see figures 12 and 13), volatility is clearly decreasing over the second portion of the sample.

\subsection{Structural changes in co-movements}

\subsubsection{Estimation and testing approach}

Let $y_{t}$ and $x_{t}$ denote two different random variables. Let $q_{\theta t}^{Y}$ be the time $t \theta$-quantile of the conditional distribution of $y_{t}$. Analogously, for $x_{t}$, we define $q_{\theta t}^{X}$. Our basic

\footnotetext{
${ }^{5}$ Similarly to equity markets,.conditional correlations of each euro area country pair is weighted by the fraction of its GDP relative to the total euro area GDP. In the computation we use the 2003 GDP levels.
} 
tool of analysis is the conditional probability $p_{t}(\theta) \equiv \operatorname{Pr}\left(y_{t} \leq q_{\theta t}^{Y} \mid x_{t} \leq q_{\theta t}^{X}\right)$. For any given quantile, it gives the probability of observing a joint tail event in the two markets, which is a direct measure of market co-movement. ${ }^{6}$

The characteristics of $p_{t}(\theta)$ can be conveniently analysed in what we call the "co-movement box" (see Figure 14). The co-movement box is a square with unit side, where $p_{t}(\theta)$ is plotted against $\theta$. The shape of $p_{t}(\theta)$ will generally depend on the characteristics of the joint distribution of the random variables $x_{t}$ and $y_{t}$, and therefore for generic distributions it can be derived only by numerical simulation. There are, however, three important special cases that do not require any simulation: 1) perfect positive correlation, 2) independence and 3) perfect negative correlation. If two markets are independent, which implies $\rho_{Y X}=0, p_{t}(\theta)$ will be piece-wise linear, with slope equal to one, for $\theta \in(0,0.5)$, and slope equal to minus one, for $\theta \in(0.5,1)$. When there is perfect positive correlation between $x_{t}$ and $y_{t}$ (i.e. $\left.\rho_{Y X}=1\right), p_{t}(\theta)$ is a flat line that takes on unit value. Under this scenario, the two markets essentially reduce to one. The polar case occurs for perfect negative correlation, i.e. $\rho_{Y X}=-1$. In this case $p_{t}(\theta)$ is always equal to zero: when the realization of $y_{t}$ is in the lower tail of its distribution, the realization of $x_{t}$ is always in the upper tail of its own distribution and conversely. We refer to the appendix for a more analytical description of the model.

This discussion suggests that the shape of $p_{t}(\theta)$ provides key insights about the dependence between two random variables $x_{t}$ and $y_{t}$. Indeed, $p_{t}(\theta)$ satisfies some basic desirable properties (independence, co-monotonicity and counter-monotonicity), as summarized in Theorem 1 of Cappiello, Gérard and Manganelli (2005). In general, the higher $p_{t}(\theta)$ the higher the codependence between the two random variables.

These conditional probabilities of co-movements can be estimated over different periods. In the present application, we consider the six years before and after the introduction of the euro. When the conditional probabilities for these two different periods are plotted in the same graph, differences in the intensity of co-movements can be identified directly. In particular, an upward shift of these curves would be consistent with an increased integration in the euro area after the introduction of the single currency.

\footnotetext{
${ }^{6}$ For $\theta>0.5$ we consider $\operatorname{Pr}\left(y_{t}>q_{\theta t}^{Y} \mid x_{t}>q_{\theta t}^{X}\right)$, i.e., the probability of a jont upper tail event.
} 


\subsubsection{Results}

In this section we describe the estimation results obtained with the co-movement box. We use weekly data from January 1992 to October 2005. The sample is split in two at 1 January 1999 to compare probabilities of co-movement before and after the introduction of the single currency. Like in the GARCH sub-section, we first plot co-movement boxes for equity and bond returns on EU countries. For international comparison, we also look at co-movements with US and Japanese markets. We first analyse equity markets and next we move to bond markets.

Equities Figure 15 plots weighted average probabilities of co-movements between returns on equity market indices for the euro area economies. Overall, co-movements increase after the introduction of the single currency. The distinction between large and small euro area economies, however, reveals that most of the increase is driven by the large member states. Co-movements in small economies remain practically unchanged. This confirms the results obtained with the GARCH correlation analysis.

Details about each country-pair co-movements (together with $95 \%$ confidence bands) can be found in figures 16, 17 and 18. Table 5a quantifies these average probabilities of co-movements for each country pair, before and after 1999. Formal statistical tests for differences in probabilities of co-movements between the pre-euro and euro periods are reported in table $6 \mathrm{a}$. For the sake of completeness, we show results for the left and right parts of the distribution, together with the entire quantile range. These results confirm that the visual increase in co-movement observed in figure 15 are statistically significant mainly for the large euro area country pairs.

A somewhat puzzling result is that some countries historically linked, such as the couples Austria-Germany or Belgium-Netherlands, show no significant increase in co-movement after 1999. A plausible explanation is that these country pairs already exhibited very low exchange rate volatility before the introduction of the single currency. At same time, within the group of "small" countries, Finland has made significant progress in integration with the large euro area economies. This could be due to the presence of multi-national companies (such as Nokia), which are particularly exposed to international shocks. ${ }^{7}$

For international comparison, we plot in figure 19 probabilities of co-movements

\footnotetext{
${ }^{7}$ In 2004, Nokia's market capitalisation represented about $60 \%$ of the whole Finnish stock exchange.
} 
between returns on the Eurostoxx50 and non euro area equity market indices (Denmark, Japan, Sweden, the UK and the US). We observe a significant increase in co-movement between euro area on one side and Sweden, the UK and the US on the other, reaching levels comparable to those of the largest euro area economies. As for the pairs euro area-Japan and US-Japan, figures 19c and 19f show that there are no significant changes in co-movements before and after 1999. Tables 5b and 6b broadly confirm these results for pairs between large euro area economies, Japan, the UK and the US.

Overall, these results, in line with the GARCH findings, suggest that common "cross Atlantic" factors drive co-movements in equity markets. Although comovements between Eurostoxx50, the UK or the US have increased after 1999, they tend to be higher within large euro area economies. For example, after the introduction of the euro, the co-movements for the pairs Germany-UK or Germany-US are smaller than each individual co-movement between Germany and the other large euro area economies (see table 5b). Co-movements with Japan, instead, remain very low with respect to all the other countries considered in the analysis.

Bonds Figure 20 presents the average co-movements between the returns on 10year government bonds of euro area economies and the German benchmark. We observe a sharp increase in co-movement after the introduction of the single currency. The fact that the probability of co-movement reaches almost one - the level of perfect integration - suggests that the euro has been a major driver of integration in this market. Differently from the equity markets, the increase in co-movement occurs for both large and small economies. Moreover, after 1999, the level of integration for bond markets is higher than that of (large) equity markets. These results are consistent with those found with the GARCH methodology in the previous subsection. The fact that the probability of co-movement is not perfectly one may be due to remaining liquidity differentials and to different national credit risks. Details of each country pair can be found in figure 21 and table 8. Interestingly, the probability lines become flatter, suggesting that the introduction of the euro increased not only overall correlations, but also the degree of co-movement in the upper and lower tails of the distribution.

The impact of the euro appears even more evidently in international comparisons. Figure 22 and table 8 indicate that, despite an overall increase, co-movements are always higher within euro area economy pairs than between couples where 
non euro area countries are included. Consistently with the equity market results, Japanese bond market continues to show very weak links with the rest of the economies in our sample.

\section{Asset pricing before and after the euro: The behav- iour of the term structure}

Next, we try to shed some light on the asset pricing implications of the euro by examining the risk - return trade-off in the term structure of interest rates before and after the introduction of the single currency. Specifically, we focus on whether there has been significant changes in risk premia on yields of various maturities following the introduction of the euro. We employ the affine macro-finance model of Hördahl, Tristani and Vestin (2005) (HTV model hereafter) to investigate whether the dynamic behaviour of macroeconomic risk factors that are relevant for the term structure have changed with the single currency. The HTV model was developed specifically to improve the understanding of how macroeconomic factors drive movements in the term structure of interest rates and how they affect the behaviour of risk premia embedded in observed yields. The model also allows us to examine whether the market has changed the way it prices macroeconomic risk factors in bonds. Hence, we should be able to determine not only whether term structure risk premia have changed after the introduction of the euro, but also to provide some insight into whether any such changes are due to different dynamics in the state variables that determine yields and/or to shifts in the compensation required by investors for bearing risk associated with these state variables.

\subsection{The HTV model}

Building on the work of Piazzesi (2003) and Ang and Piazzesi (2003), the HTV model provides a framework where a small structural model of the macro economy, which includes forward-looking elements, is combined with an arbitrage-free model of bond yields. Specifically, it provides a dynamic term structure model entirely based on macroeconomic factors, which allows for an explicit feedback from the short term monetary policy rate to macroeconomic variables. Three key macroeconomic variables - inflation, the output gap and the short term policy interest rate - are jointly modelled to obtain an endogenous description of the dynamics of the short term rate. Based on this, term structure risk premia are explicitly modelled in order 
to capture the dynamics of the entire term structure. Bond yields and term premia are affine functions of the macroeconomic state variables, and are therefore of the same form as in the "pure finance" affine term structure literature - e.g. Dai and Singleton, (2000, 2003) and Duffie and Kan (1996) - which in recent years has made tremendous progress in terms of modelling the term structure of interest rates.

The approach used by HTV to jointly model the macroeconomy and the term structure is presented below. The main assumption is that aggregate macroeconomic relationships can be described using a linear framework. A stylized structural model, that may be motivated by the fact that it could be derived from first principles, is used to describe the macroeconomy. While too stylized to provide a fully-satisfactory account of macroeconomic dynamics, Hördahl et al. (2005) find that the model does capture the central features of the dynamics of key macroeconomic variables and that it serves very well as a foundation for the pricing of bonds. The model of the economy includes an equation which describe the evolution of inflation, $\pi_{t}$, and an equation for the output gap, $x_{t}$ :

$$
\begin{aligned}
& \pi_{t}=\mu_{\pi} E_{t}\left[\pi_{t+1}\right]+\left(1-\mu_{\pi}\right) \pi_{t-1}+\delta_{x} x_{t}+\varepsilon_{t}^{\pi}, \\
& x_{t}=\mu_{x} E_{t} x_{t+1}+\left(1-\mu_{x}\right) x_{t-1}-\zeta_{r}\left(r_{t}-E_{t}\left[\pi_{t+1}\right]\right)+\varepsilon_{t}^{x} .
\end{aligned}
$$

The output gap term in the inflation equation implies that prices are set as a mark-up on marginal cost, while the expected inflation term is due to the assumption of price stickiness, and the lags capture inflation inertia. The output gap equation provides a description of the dynamics of aggregate demand, which is assumed to be affected by movements in the short term real interest rate, and in which the forward looking term should capture the intertemporal smoothing motives characterizing consumption. The equations above, which are commonly interpreted as appropriate to describe yearly data, are recast the monthly frequency to better fit the data used in the empirical application ${ }^{8}$ see the Appendix.

In order to solve for the rational expectations equilibrium, the model assumes that the central bank follows a simple forward-looking Taylor rule, in which the central bank sets the nominal short rate according to

$$
r_{t}=(1-\rho)\left(\beta\left(E_{t}\left[\pi_{t+1}\right]-\pi_{t}^{*}\right)+\gamma x_{t}\right)+\rho r_{t-1}+\eta_{t}
$$

${ }^{8}$ This recasting of the mopel is done along the lines of Rudebusch (2002); see Hördahl et al. (2005) for specific details. 
where $\pi_{t}^{*}$ is a perceived inflation target and $\eta_{t}$ is a "monetary policy shock". ${ }^{9}$ Finally, the inflation target, which is unobservable, is postulated to follow an $\operatorname{AR}(1)$ process

$$
\pi_{t}^{*}=\phi_{\pi} \pi_{t-1}^{*}+u_{\pi, t}
$$

where $u_{\pi, t}$ is a normal disturbance with constant variance uncorrelated with the other structural shocks, which in turn are also assumed to be mutually uncorrelated. ${ }^{10}$

In order to solve the model, it is written in the general form

$$
\left[\begin{array}{c}
\mathbf{X}_{1, t+1} \\
E_{t} \mathbf{X}_{2, t+1}
\end{array}\right]=\mathbf{H}\left[\begin{array}{l}
\mathbf{X}_{1, t} \\
\mathbf{X}_{2, t}
\end{array}\right]+\mathbf{K} r_{t}+\left[\begin{array}{c}
\boldsymbol{\xi}_{1, t+1} \\
\mathbf{0}
\end{array}\right]
$$

where $\mathbf{X}_{1}$ is the vector of predetermined variables, in this case including lags of $x, \pi$, and $r$, as well as the contemporaneous values of the inflation target $\pi^{*}$ and the shocks $\eta, \varepsilon^{\pi}$, and $\varepsilon^{x} . \mathbf{X}_{2}$ includes the variables which are not predetermined, which in this model are the contemporaneous values of $x$ and $\pi$, and forward-looking expectations of these variables; $r_{t}$ is the policy instrument and $\boldsymbol{\xi}_{1}$ is a vector of shocks.

The model can be solved numerically following standard methods - in the empirical implementation the method proposed by Söderlind (1999) is used. The solution provides two matrices $\mathbf{M}$ and $\mathbf{C}$ such that

$$
\mathbf{X}_{1, t}=\mathbf{M X}_{1, t-1}+\boldsymbol{\xi}_{1, t}
$$

and

$$
\mathbf{X}_{2, t}=\mathbf{C X}_{1, t}
$$

This also allows the short term interest rate to be written as $r_{t}=\boldsymbol{\Delta}^{\prime} \mathbf{X}_{1, t}$, where $\boldsymbol{\Delta}$ follows from the assumed policy rule in combination with the model solution.

Finally, the term structure of interest rates is determined from the assumed structure of the macroeconomy. The system above expresses the short term interest rate as a linear function of the vector $\mathbf{X}_{1}$, which in turn follows a first order Gaussian VAR. This structure is formally equivalent to that on which affine models

\footnotetext{
${ }^{9}$ The choice of a simple rule instead of a solution of the model under full commitment or discretion can be motivated by the fact that the estimates include bond prices, which will reflect investors' perceptions of monetary policy.

${ }^{10} \mathrm{In}$ addition, it is assumed that the three macro shocks are normally distributed with constant variance.
} 
are normally built. Hence, the term structure is derived by imposing the assumption of absence of arbitrage opportunities, and by specifying a process for the stochastic discount factor. Specifically, following the standard dynamic arbitrage-free term structure literature the pricing kernel $m_{t+1}$, which prices all nominal bonds in the economy, is defined as $m_{t+1}=\exp \left(-r_{t}\right) \psi_{t+1} / \psi_{t}$, where $\psi_{t+1}$ is assumed to follow the log-normal process $\psi_{t+1}=\psi_{t} \exp \left(-\frac{1}{2} \lambda_{t}^{\prime} \lambda_{t}-\lambda_{t}^{\prime} \boldsymbol{\xi}_{1, t+1}\right)$, and where $\lambda_{t}$ is the vector of market prices of risk associated with the underlying sources of uncertainty in the economy. Following Duffee (2002) it is assumed that the market prices of risk are affine in the state vector

$$
\lambda_{t}=\lambda_{0}+\lambda_{1} \mathbf{X}_{1, t}
$$

so that the market's required compensation for bearing risk can vary with the state of the economy. ${ }^{11}$ The macroeconomic model, coupled with the assumptions on the pricing kernel, implies that the continuously compounded yield $y_{t}^{n}$ on an $n$-period zero coupon bond is given by

$$
y_{t}^{n}=A_{n}+B_{n}^{\prime} \mathbf{X}_{1, t},
$$

where the $A_{n}$ and $B_{n}^{\prime}$ matrices can be derived recursively (see the Appendix).

\subsection{Impact of the euro on fundamentals}

We are interested in comparing the dynamics and the determinants of the euro area term structure before and after the introduction of the euro. However, limitations in data complicates the practical implementation of such a comparison. An obvious problem is that prior to 1998 a euro term structure did not exist. While a synthetic euro term structure can be constructed, it is not obvious how to go about doing this and, moreover, it is not clear whether such a synthetic yield curve would be an appropriate measure of the curve that we are actually interested in. For example, major differences in the macroeconomic environment and in the monetary policy pursued by different countries prior to the gradual harmonization that paved the way for the euro, meant that yields in these countries also differed substantially and that their dynamics were different. Moreover, it could be argued that it is not particularly meaningful to apply a dynamic no-arbitrage model to data consisting

\footnotetext{
${ }^{11}$ To be precise, rather than building the term structure directly on the reduced form of the macro model, bond yields are written as a specific function of the state vector $\mathbf{X}_{1, t}$. This allows yields to be expressed as functions of the levels of the macro variables, rather than of their shocks; see Hördahl et al. (2005) for details.
} 
of a synthetic mix of various interest rates, since such a mix was never traded in actual markets.

This latter problem also applies to data after the introduction of the euro. While differences between yields have been drastically reduced compared to the pre-euro period, small but non-negligible yield differences continue to persist, and there is no obvious or uncontroversial way of aggregating yields. In fact, for various segments of the government yield curve, the market seems to have chosen government bonds from different countries as benchmarks for those segments. However, when taking the euro term structure as a whole, the market appears to view the euro swap curve as the appropriate benchmark.

These considerations leads us to our choice of yield data for the empirical implementation. Rather than aggregating national yield data, we rely on data from the German bond market, which, at least to some extent, seems to have been a benchmark for European bond markets as a whole. Moreover, while most other countries that subsequently adopted the euro experienced periods of more or less severe currency crises and associated interest rate turbulence, Germany, as the anchor of ERM, did not. Hence, by using German yield data before 1999, we believe that we largely avoid including intra-area currency effects on the term structure, which are not the focus of this analysis. For comparability, and also for the reasons mentioned above, we continue to use German yield data also after the introduction of the euro.

As for the macro data, for the pre-euro period we rely on German inflation (measured as monthly year-on-year CPI inflation) and a measure of the German output gap (deviations of log-industrial production from a recursively estimated quadratic trend; see Hördahl et al. (2005) for details). Similar measures of inflation and the output gap are used after 1998, but now the data refers to the euro area instead of Germany. ${ }^{12}$ The reason that we rely on euro area macro data instead of German data after the introduction of the euro is that monetary policy plays a key role in the HTV model, and the monetary policy of the ECB is based on aggregate euro area macroeconomic variables rather than the macroeconomic situation in any individual member state.

The first step of the analysis is simply to compare estimates of the HTV model before and after the introduction of the euro. For the pre-euro period, we rely on

\footnotetext{
${ }^{12}$ Inflation is measured as monthly year-on-year euro area HICP inflation and the output gap is constructed similar to the German gap, using national industrial production figures weighted by GDP.
} 
the estimates presented in Hördahl et al. (2005), which refer to the period January 1975 - December 1998. The more recent sub-sample covers the period January 1999 - December 2004. Apart from the macro data described above, zero-coupon yields for six maturities are included in the estimations: 1, 3, 6, 12, 36 and 84 months to maturity. All data are monthly.

Parameter estimates are obtained using the maximum likelihood method, and the variance-covariance matrix of the parameters is based on the Jacobian, which is calculated analytically. We start by looking at whether the parameter estimates obtained for the euro sample are significantly different from the values found for the pre-euro sample. A Likelihood-Ratio test based on estimates where the parameters are kept fixed relative to estimates where all parameters are allowed to change after the introduction of the euro results in an overwhelming rejection of the null hypothesis that the parameters are unchanged ( $p$-value less than 0.001).

We can also examine whether this rejection is due to changes in the parameters that govern the dynamics of the macro state variables, or to changes in the market-price-of-risk parameters, or both. Testing the subset of macro parameters separately using an LR test also results in a strong rejection of the null hypothesis: the LR statistic is 152.49 whereas the $5 \%$ critical value is 26.30 . This would suggest that the dynamic behaviour of key macroeconomic variables has changed after the introduction of the euro. The following displays the macro parameter estimates before and after the euro:

$$
\begin{aligned}
& \pi_{t}^{\text {pre-euro }}=\underset{(0.011)}{0.132} E_{t}\left[\pi_{t+1}\right]+(1-0.132) \pi_{t-1}+\underset{\left(0.054 \times 10^{-2}\right)}{0.038 \times 10^{-2}} x_{t}+, \varepsilon_{t}^{\pi} \quad \sigma_{\pi} \times 10^{2}=\underset{(0.001)}{0.022}, \\
& \pi_{t}^{\text {euro }}=\underset{(0.054)}{0.152} E_{t}\left[\pi_{t+1}\right]+(1-0.152) \pi_{t-1}+\underset{\left(1.028 \times 10^{-2}\right)}{0.905 \times 10^{-2}} x_{t}+\varepsilon_{t}^{\pi} \quad \sigma_{\pi} \times 10^{2}=\underset{(0.002)}{0.015} \\
& x_{t}^{\text {pre-euro }}=\underset{(0.029)}{0.303} E_{t} x_{t+1}+(1-0.303) x_{t-1}-\underset{(0.023)}{0.027}\left(r_{t}-E_{t}\left[\pi_{t+1}\right]\right)+, \varepsilon_{t}^{x} \quad \sigma_{x} \times 10^{2}=\underset{(0.004)}{0.097}, \\
& x_{t}^{\text {euro }}=\underset{(0.159)}{0.396 E_{t}} x_{t+1}+(1-0.396) x_{t-1}-\underset{(0.123)}{0.109}\left(r_{t}-E_{t}\left[\pi_{t+1}\right]\right)+, \varepsilon_{t}^{x} \quad \sigma_{x} \times 10^{2}=\underset{(0.005)}{0.041}, \\
& r_{t}^{\text {pre-euro }}=(1-0.976)\left(\underset{(0.855)}{2.087}\left(E_{t}\left[\pi_{t+1}\right]-\pi_{t}^{*}\right)+\underset{(0.925)}{1.243 x_{t}}\right)+\underset{(0.015)}{0.976 r_{t-1}}+\eta_{t} \quad \sigma_{\eta} \times 10^{2}=\underset{(0.001)}{0.040}, \\
& r_{t}^{\text {euro }}=(1-0.925)\left(\underset{(0.044)}{1.016}\left(E_{t}\left[\pi_{t+1}\right]-\pi_{t}^{*}\right)+\underset{(0.459)}{0.404} x_{t}\right)+\underset{(0.052)}{0.925 r_{t-1}}+, \eta_{t} \quad \sigma_{\eta} \times 10^{2}=\underset{(0.002)}{0.014} .
\end{aligned}
$$

We notice several differences associated with the introduction of the single cur- 
rency. First, the volatility of macroeconomic shocks is substantially smaller after the introduction of the euro. Second, during the euro period there is a greater sensitivity of the output gap to the real interest rate and substantially larger elasticity of inflation to the output gap. Third, as seen from the Taylor equation, short rates react less strongly to inflation expectations and the output gap than before. All these results reflect a more effective monetary policy (see figure 24.1). However, caution is necessary in the interpretation of our results, since coefficients are estimated with less precision over the euro period. The shorter sample size for the euro period may be responsible for the bigger parameter standard errors.

\subsection{Impact of the euro on term premia}

Applying an LR test to check whether the estimated market-price-of-risk parameters have changed after the introduction of the euro reveals that not only the macro parameters are statistically different in the two sub-samples, but also the parameters that determine how risk factors are priced in the term structure are significantly different before and after the euro. ${ }^{13}$ Hence, it would seem that the behaviour of term premia is different now compared to before the introduction of the euro, and that this is due partly to changes in the dynamics of the macro state variables, and partly to changes in the way the market requires compensation for bearing risk associated with these macro factors.

However, it turns out that, despite these significant changes to the estimates, average premia are virtually identical before and after the euro introduction. figure 24.2 shows the term structure of average yield premia during the pre-euro period (1975-1998) and during the euro period (1999-2004). The yield premium can be viewed as the component of zero-coupon bond yields that are not due to expectations of future interest rates - i.e. the difference between observed yields and the yields that would prevail if the expectations hypothesis of the term structure of interest rates were to hold; ${ }^{14}$ Appendix $\mathrm{C}$ provides a definition based on the HTV model. The third curve in figure 24.2, labelled "reprojected", shows the impact of changes to the price of risk parameters by displaying the counterfactual average yield premia that would be obtained during the euro period if macro dynamics were allowed to differ from the pre-euro period, but if, at the same time, the market price of risk

\footnotetext{
${ }^{13}$ The LR statistic is 80.85 and the $5 \%$ critical value is 23.69 .

${ }^{14}$ More precisely, the yield premium would be the difference between observed yields and yields given by (a pure version of) the unbiased expectations hypothesis.
} 
parameters $\left(\lambda_{0}\right.$ and $\left.\lambda_{1}\right)$ were held constant at the estimated pre-euro values. It is clear from the figure that the price of risk parameters have adjusted in such a way that they offset the (average) effect of the changed macro dynamics.

Figure 24.2 provides only a partial characterization of term premia before and after the euro, in that it merely shows the unconditional picture. To investigate the conditional characteristics in the two subperiods, we proceed in two steps. First, we ask whether there are any changes in the initial response of premia to various macroeconomic shocks, as compared to the steady state. Second, we look at the estimated time-varying premia in each sample and investigate which macro factors seem most important in explaining the evolution of premia over time.

Figures 24.3-24.6 displays the initial response (i.e. one-month ahead) of yield premia to one standard deviation shocks to each of the four macro variables (inflation target; monetary policy rate; inflation; output gap) for all maturities up to 7 years. As before, we show the estimated response for the pre-euro period, the euro period, as well as the reprojected response during the euro period in the case where we allow the macro dynamics to change as of 1999, but keep the market prices of risk unchanged. The overall picture is that the impact responses for the euro period tend to be more muted than during the pre-euro period. The reprojections show that the changes to the market prices of risk are mainly important for the impact of inflation target shocks, whereas they have a limited effect for monetary policy and inflation shocks, and a negligible effect on the response of premia to output shocks. It should be noted here, however, that the market prices of risk are estimated with a relatively low degree of precision, in particular for the euro sample, which is substantially shorter than the pre-euro sample. In any case, given the results in figure 24.2, one may conclude that while the overall level of yield premia seems little changed after the introduction of the euro, the variability of premia have been reduced as a result of smaller macro shocks on average during the euro period.

The second step of the analysis of conditional features of premia is to examine the estimated time-series of yield premia and their main determinants before and after the introduction of the euro. Figure 24.7 show the evolution of de-meaned yield premia for the 1-year and the 7-year maturities,and the most important macro-based components of these premia during the pre-euro period, while figure 24.8 shows the same thing for the euro period. Comparing figure 24.7 with figure 24.8 , it is clear that premia have indeed become less variable after the euro's introduction, as was suggested above: while the estimated time-varying component of 1-year yield premia 
varied between $-1.5 \%$ and $+1.5 \%$ before the euro, they fluctuated between $-0.5 \%$ and $+0.5 \%$ thereafter; for 7 -year premia the range was $\pm 2 \%$ in the pre-euro period vs. $\pm 0.25 \%$ in the euro period. Again, it should be noted that the average premia remained the same during the two sub-periods.

With respect to the determinants of the time-varying portion of premia, the bottom line is that despite large differences in the magnitude of estimated premia, the macro factors that were found to be important in explaining the dynamics of premia before the introduction of the euro continue to play a key role in this respect also thereafter. More specifically, at the 1-year horizon, the largest fraction of the time-varying yield premium both before and after the introduction of the euro is due to interest rate risk, i.e. the possibility of monetary policy shocks. However, while 1-year pre-euro yield premia were decreasing in the level of the short-term interest rate, the opposite seems to be the case after the euro was introduced. The second most important component of the time varying yield premium at 1-year maturities is inflation target risk. The target premium is increasing in the level of the inflation target in both sub-samples.

At the 7-year horizon, the most important determinant of the time varying component of the yield premium is risk associated with the inflation target. At this maturity, the inflation target premium is negatively correlated with the level of the inflation target both before and after the euro, although the influence of the target is smaller after 1998. When the target is high, the yield premium is lower than average and investors are relatively more willing to hold 7-year bonds, possibly reflecting investors' confidence that the target will revert back to lower levels in the long run. The second most relevant factor for the variable component of 7-year yield premia is output gap risk. Specifically, booms tend to make investors more willing to hold long term bonds, thereby reducing premia, while investors require a larger bond premium during recessions. This result holds both before and after the introduction of the euro.

\section{Conclusions}

In this paper we investigate first whether the introduction of the euro had an impact on the degree of integration of European financial markets. Second, we analyse whether the common monetary policy significantly changed the dynamics and the determinants of the euro area term structure of interest rates. 
Our results suggest an overall increase in the integration of both equity and bond euro area markets since the introduction of the single currency. However, while the integration is very advanced for all euro area government bond markets, as for equity markets it seems to lag behind, and progress limited to large euro area economies. Controlling for the impact of global factors, we find evidence of a common "cross Atlantic" component, in that integration across large EU countries and the US increases. Japan and small EU economies, instead, remain generally very little integrated with the other countries. As for bond markets, we find that the single currency was a major factor in fostering integration, which, unlike the equity markets, increases substiantially in both small and large euro area economies. Moreover, while we continue to observe the presence of "cross Atlantic" factors, progress in integration for non euro area economies is less pronounced. Japan continues to exhibit weak links with the rest of the countries in our sample.

With respect to the impact of the euro on the term structure, our results suggest that the behaviour of term premia is different now compared to before the introduction of the euro, and that this is due partly to changes in the dynamics of the macro state variables, and partly to changes in the market's required compensation for risk associated with these macro factors. However, we also find that average premia remain little changed after the euro's introduction, while there seems to have been a reduction in the variability of premia during the euro period. Moreover, we conclude that the macro factors that were found to be important in explaining the dynamics of premia before the euro continue to play a key role in this respect also after the single currency was introduced. 


\section{References}

[1] Ang, A. and M. Piazzesi, 2003, "A No-Arbitrage Vector Autoregression of Term Structure Dynamics with Macroeconomic and Latent Variables," Journal of Monetary Economics, 50(4), 745-787.

[2] Bekaert, G, and C. Harvey, 1995, "Time-Varying World Market Integration," Journal of Finance, 50 (2), 403-444.

[3] Bekaert, G, and G. Wu, 2000, "Asymmetric Volatility and Risk in Equity Markets," Review of Financial Studies, 13 (1), 1-42.

[4] Bollerslev, T., 1986, "Generalized Autoregressive Conditional Heteroskedasticity," Journal of Econometrics, 31(3), 307-327.

[5] Bollerslev, T., 1990, "Modelling the Coherence in Short Run Nominal Exchange Rates: A Multivariate Generalized ARCH Model," Review of Economics and Statistics, 72(3), 498-505.

[6] Bollerslev, T. and J.M. Wooldridge, 1992, "Quasi-Maximum Likelihood Estimation and Inference in Dynamic Models with Time-Varying Covariance," Econometric Reviews, 11(2), 143-172.

[7] Cappiello, L., R.F. Engle and Sheppard, 2003, "Asymmetric Dynamics in the Correlations of Global Equity and Bond Returns," ECB Working Paper No. 204, January.

[8] Cappiello, L., B. Gérard and S. Manganelli, 2005, "Measuring Comovements by Regression Quantiles," ECB Working Paper No. 501, July.

[9] Cappiello, L., B. Gérard, A. Kadareja and S. Manganelli, 2006, "Financial Integration of New EU Member States," ECB mimeo.

[10] Dai, Q. and K.J. Singleton, 2000, "Specification Analysis of Affine Term Structure Models," Journal of Finance, 55(5), 1943-1978.

[11] Dai, Q. and K.J. Singleton, 2003, "Term Structure Modeling in Theory and Reality," Review of Financial Studies, 16(3), 631-678.

[12] Ding, Z. and R. F. Engle, 2001, "Large Scale Conditional Covariance Matrix Modelling, Estimation and Testing," Academia Economic Papers 29 (2), 157184.

[13] Duffie, D. and R. Kan, 1996, "A Yield-Factor Model of Interest Rates," Mathematical Finance, 6(4), 379-406. 
[14] Engle, R. F., 2002, "Dynamic Conditional Correlation - A Simple Class of Multivariate GARCH Models," Journal of Business and Economic Statistics, 20(3), 339-350.

[15] Engle, R. F. and K. Kroner, 1995, "Multivariate Simultaneous GARCH," Econometric Theory 11 (1), 122-150.

[16] Engle, R. F. and S. Manganelli, 2004, "CAViAR: Conditional Autoregressive Value at Risk by Regression Quantiles," Journal of Business and Economic Statistics, 22(2), 367-381.

[17] Engle, R. F. and K. Sheppard, 2001, "Theoretical and Empirical Properties of Dynamic Conditional Correlation MVGARCH," UCSD Working Paper No. 2001-15.

[18] Forbes, K. J., and R. Rigobon, 2002, "No Contagion, only Interdependence: Measuring Stock Market Comovements," Journal of Finance, 57 (5), 2223-2261.

[19] Glosten, L.R., R. Jagannathan, and D.E. Runkle, 1993, "On the Relation between the Expected Value and the Variance of the Nominal Excess Return on Stocks," Journal of Finance, 48(5), 1779-1801.

[20] Hardouvelis, G.A., D. Malliaropulos, and R. Priestley, 2006, "EMU and European Stock Market Integration," Journal of Business, 79 (1), 365-392.

[21] Hördahl, P., O. Tristani and D. Vestin (2005a), "A Joint Econometric Model of Macroeconomic and Term Structure Dynamics," ECB Working Paper No. 405, forthcoming Journal of Econometrics.

[22] Kroner, K. F., and V. K. Ng, 1998, "Modeling asymmetric comovements of assets returns," Review of Financial Studies, 11 (4), 817-44.

[23] Nelson, D.B., 1991, "Conditional Heteroskedasticity in Asset Returns: A New Approach," Econometrica, 59(2), 347-370.

[24] Piazzesi, M., 2003, "Bond Yields and the Federal Reserve," forthcoming, Journal of Political Economy.

[25] Sheppard, K., 2002, "Understanding the Dynamics of Equity Covariance," mimeo, UCSD.

[26] Söderlind, P., 1999, "Solution and Estimation of RE Macromodels with Optimal Policy," European Economic Review, 43(4-6), 813-823. 


\section{A The Dynamic Conditional Correlation (DCC) GARCH model for asset returns}

Multivariate GARCH models have been widely used to study second moment interrelations among economic and financial variables. Typically, in addition to volatilities, these specifications model the time evolution of asset return covariances. A well known example is given by the so-called Baba, Engle, Kraft and Kroner (or simply BEKK) GARCH process (see Engle and Kroner, 1995). Recently, Engle (2002) has introduced the Dynamic Conditional Correlation (DCC) GARCH model, which is particularly well suited to analyse correlation dynamics among asset returns.

Let $\mathbf{R}_{t} \equiv\left\{r_{i, t}\right\}$ be a $s \times 1$ vector of asset returns,which is assumed to be conditionally normal with mean zero and covariance matrix $\mathbf{H}_{t} \equiv\left\{h_{i j, t}\right\}$ :

$$
\mathbf{R}_{t} \mid \Im_{t-1} \sim N\left(\mathbf{0}, \mathbf{H}_{t}\right)
$$

where $\Im_{t-1}$ is the information set available at time $t-1$.

The covariance matrix $\mathbf{H}_{t}$ can be decomposed as follows (see, for instance, Bollerslev, 1990):

$$
\mathbf{H}_{t}=\mathbf{D}_{t} \mathbf{P}_{t} \mathbf{D}_{t}
$$

where $\mathbf{D}_{t}$ is a diagonal matrix containing the conditional standard deviations relative to the $s$ asset returns, i.e. $\mathbf{D}_{t} \equiv \operatorname{diag}\left\{\sqrt{h_{i i, t}}\right\}$, while $\mathbf{P}_{t}$ is the time-varying correlation matrix. $\mathbf{P}_{t}$ is a symmetric matrix with ones on the main diagonal and conditional correlation coefficients on the off-diagonal elements, i.e. $\mathbf{P}_{t} \equiv\left\{\rho_{i j, t}\right\}$.

The estimation of the conditional covariance matrix $\mathbf{H}_{t}$ is based on a three step procedure. First, univariate volatility models $\sqrt{h_{i i, t}}$ are estimated for each asset return. Akaike and Schwartz information criteria permit to select the volatility model that fits the data best. In the second step asset returns are standardised by the estimated standard deviations resulting from the first stage:

$$
\varepsilon_{t}=\mathbf{D}_{t}^{-1} \mathbf{R}_{t}
$$

where $\varepsilon_{t}$ is the $s \times 1$ vector of standardised residuals. Next unconditional correlations are estimated and used for the intercept parameters of the conditional correlation. Finally, coefficients of the correlation dynamics are estimated conditional on the correlation intercept coefficients. The conditional correlation matrix between stan- 
dardised residuals will read as follows:

$$
\mathbf{P}_{t}=E\left(\varepsilon_{t} \varepsilon_{t}^{\prime} \mid \Im_{t-1}\right)
$$

In the original DCC model suggested by Engle (2002), when the system is covariance stationary (see Ding and Engle, 2001), the dynamics of correlation evolve as a scalar process with a single news impact parameter and a single smoothing parameter:

$$
\begin{gathered}
\mathbf{Q}_{t}=\overline{\mathbf{Q}}(1-a-b)+a \varepsilon_{t-1} \boldsymbol{\varepsilon}_{t-1}^{\prime}+b \mathbf{Q}_{t-1} \\
\mathbf{P}_{t}=\operatorname{diag}\left\{\mathbf{Q}_{t}\right\}^{-1 / 2} \mathbf{Q}_{t} \operatorname{diag}\left\{\mathbf{Q}_{t}\right\}^{-1 / 2}
\end{gathered}
$$

where $\overline{\mathbf{Q}}$ is the unconditional correlation matrix of the standardised error terms, $\overline{\mathbf{Q}}=E\left(\varepsilon_{t} \varepsilon_{t}^{\prime}\right)$, and $\operatorname{diag}\left\{\mathbf{Q}_{t}\right\}$ is a diagonal matrix with the $i$ th diagonal element of $\mathbf{Q}_{t} \equiv\left\{q_{i i, t}\right\}$ on its $i$ th position. Provided that $\mathbf{Q}_{t}$ is positive definite, $\operatorname{diag}\left\{\mathbf{Q}_{t}\right\}^{1 / 2}$ guarantees $\mathbf{P}_{t}$ be a correlation matrix with ones on the main diagonal and every other off-diagonal elements less than or equal to one in absolute value.

The specification described by equation (14) does not allow for asset specific news and smoothing parameters. A more flexible model, which however is parsimonious in the number of coefficients to estimate, is represented by the diagonal DCC GARCH model, where the scalars $a$ and $b$ are replaced by diagonal matrices $\mathbf{A}$ and B:

$$
\mathbf{Q}_{t}=\left(\overline{\mathbf{Q}}-\mathbf{A}^{\prime} \overline{\mathbf{Q}} \mathbf{A}-\mathbf{B}^{\prime} \overline{\mathbf{Q}} \mathbf{B}\right)+\mathbf{A}^{\prime} \varepsilon_{t-1} \varepsilon_{t-1}^{\prime} \mathbf{A}+\mathbf{B}^{\prime} \mathbf{Q}_{t-1} \mathbf{B},
$$

or, equivalently,

$$
\mathbf{Q}_{t}=\overline{\mathbf{Q}} \odot\left(\iota \iota^{\prime}-\mathbf{a a}^{\prime}-\mathbf{b b}^{\prime}\right)+\mathbf{a} \mathbf{a}^{\prime} \odot \varepsilon_{t-1} \varepsilon_{t-1}^{\prime}+\mathbf{b b}^{\prime} \odot \mathbf{Q}_{t-1} .
$$

In equation $(16) \odot$ is the Hadamard (element by element) product, $\iota$ a vector of ones, and $\mathbf{a}$ and $\mathbf{b}$ are vectors containing the diagonal elements of the matrices $\mathbf{A}$ and $\mathbf{B}$, respectively.

For $\overline{\mathbf{Q}}$, since expectations are infeasible, they are replaced by sample analogs, $T^{-1} \sum_{t=1}^{T} \varepsilon_{t} \varepsilon_{t}^{\prime}$. Engle and Sheppard (2001) show that, given that $\rho_{i j, t}=q_{i j, t} / \sqrt{q_{i i, t} q_{j j, t}}$ is the typical element of $\mathbf{P}_{t}$, this matrix will necessarily be a correlation matrix by the Cauchy-Schwartz inequality. 


\section{A.1 Asymmetries}

It is well documented that volatility of equity returns increases more after a negative shock than after a positive shock of the same magnitude. Asymmetric effects have also been recently found in conditional covariances and correlations. As for returns on bonds, the evidence about asymmetric second moments is, instead, mixed (see, for instance, Kroner and Ng, 1998, Bekaert and Wu, 2000, and Cappiello, Engle and Sheppard, 2003). In line with this literature, we enrich the process described by equation (16) introducing a term able to capture asymmetry in conditional correlations, $\mathbf{g g}^{\prime} \odot \boldsymbol{\eta}_{t-1} \boldsymbol{\eta}_{t-1}^{\prime}$. $\mathbf{g}$ is a vector of unknown parameters, whose elements can be thought of as the diagonal coefficients of a corresponding $\mathbf{G}$ matrix. The generic $i$ element of $\boldsymbol{\eta}_{t}$ is defined as $\eta_{i t} \equiv I\left(\varepsilon_{i t}<0\right) \varepsilon_{i t}$, where $I(\cdot)$ is an indicator function which takes on value one if the argument is true and zero otherwise. Assuming that the resulting covariance process is stationary, equation (16) can be written as:

$\mathbf{Q}_{t}=\overline{\mathbf{Q}} \odot\left(\iota \iota^{\prime}-\mathbf{a} \mathbf{a}^{\prime}-\mathbf{b b}^{\prime}\right)-\overline{\mathbf{H}} \odot \mathbf{g g} \mathbf{g}^{\prime}+\mathbf{a} \mathbf{a}^{\prime} \odot \varepsilon_{t-1} \varepsilon_{t-1}^{\prime}+\mathbf{b b}^{\prime} \odot \mathbf{Q}_{t-1}+\mathbf{g g}^{\prime} \odot \boldsymbol{\eta}_{t-1} \boldsymbol{\eta}_{t-1}^{\prime}$,

where $\overline{\mathbf{H}}=E\left(\boldsymbol{\eta}_{t} \boldsymbol{\eta}_{t}^{\prime}\right)$. Similarly to $\overline{\mathbf{Q}}$, we replace $\overline{\mathbf{H}}$ with its sample analog, $T^{-1} \sum_{t=1}^{T} \boldsymbol{\eta}_{t} \boldsymbol{\eta}_{t}^{\prime}$.

\section{A.2 Univariate volatility models}

As pointed out in Engle and Sheppard (2001), any univariate GARCH model which is covariance stationary and assumes normally distributed errors (irrespective of the true error distribution) can be used to model the variances, as the model is estimated in three steps. For each asset we select a univariate volatility model among three possible specifications: (i) the GARCH model of Bollerslev (1986), (ii) the Exponential GARCH (EGARCH) model of Nelson (1991) and (iii) the GJR-GARCH of Glosten, Jagannathan and Runkle (1993). While the symmetric traditional GARCH process elegantly captures volatility clustering, it does not allow negative and positive past shocks to have a different impact on conditional second moments. The effect of the sign of lagged innovations is accommodated with the EGARCH and GJR-GARCH models. In line with the assumptions on asset returns (see equation (12)), the three processes read as follows:

$$
G A R C H: h_{i, t}=\alpha_{0}+\alpha_{1} r_{i, t-1}^{2}+\alpha_{2} h_{i, t-1}
$$




$$
\begin{gathered}
E G A R C H: \ln \left(h_{i, t}\right)=\alpha_{0}+\alpha_{1}\left(\left|v_{i, t-1}\right|-E\left|v_{i, t-1}\right|\right)+\gamma v_{i, t-1}+\alpha_{2} \ln \left(h_{i, t-1}\right), \\
\text { GJR-GARCH: } h_{i, t}=\alpha_{0}+\alpha_{1} r_{i, t-1}^{2}+\gamma I\left(r_{i, t-1}<0\right) r_{i, t-1}^{2}+\alpha_{2} h_{i, t-1} .
\end{gathered}
$$

In equation (19) the term $v_{i, t}$ is i.i.d. with zero mean and unit variance and can be thought of as the $i$ th element of the $s \times 1$ vector $\mathbf{Y}_{t}=\mathbf{H}_{t}^{-1 / 2} \mathbf{R}_{t}$. The EGARCH parametrization accommodates the asymmetric relation between asset returns and volatility, since the conditional variance depends on both the size and the sign of $v_{i, t}$. Similar to the traditional GARCH representation (18), the term $\alpha_{1}\left(\left|v_{i, t-1}\right|-E\left|v_{i, t-1}\right|\right)$ captures the magnitude effect. The term $\gamma v_{i, t-1}$, instead, allows the conditional variance to respond asymmetrically to the sign of lagged return innovations. Under the assumption that returns are normally distributed, $E\left|v_{i, t}\right|=\sqrt{2 / \pi}$ (see Nelson, 1991, for further details).

In equation (20) $I(\cdot)$, as before, represents an indicator function. The only difference with the traditional GARCH process in (18) is the inclusion of the term $\gamma I\left(r_{i, t-1}<0\right) r_{i, t-1}^{2}$, which accommodates the asymmetric volatility effect.

\section{A.3 The likelihood function}

Under the assumption of normality, the log likelihood function of the DCC GARCH model can be expressed as follows (see Engle, 2002, for further details):

$$
\begin{aligned}
L & =-\frac{1}{2} \sum_{t=1}^{T}\left[s \ln (2 \pi)+\ln \left(\left|\mathbf{H}_{t}\right|\right)+\mathbf{R}_{t}^{\prime} \mathbf{H}_{t}^{-1} \mathbf{R}_{t}\right] \\
& =-\frac{1}{2} \sum_{t=1}^{T}\left[s \ln (2 \pi)+\ln \left(\left|\mathbf{D}_{t} \mathbf{P}_{t} \mathbf{D}_{t}\right|\right)+\mathbf{R}_{t}^{\prime} \mathbf{D}_{t}^{-1} \mathbf{P}_{t}^{-1} \mathbf{D}_{t}^{-1} \mathbf{R}_{t}\right] \\
& =-\frac{1}{2} \sum_{t=1}^{T}\left[s \ln (2 \pi)+2 \ln \left(\left|\mathbf{D}_{t}\right|\right)+\ln \left(\left|\mathbf{P}_{t}\right|\right)+\boldsymbol{\varepsilon}_{t}^{\prime} \mathbf{P}_{t}^{-1} \varepsilon_{t}\right]
\end{aligned}
$$

Since the estimation of the DCC GARCH model is based on a three step procedure, maximising the log likelihood function (21) gives consistent but inefficient estimates of the vector of unknown parameters. Engle and Sheppard (2001) provide the asymptotic theory associate with this estimation procedure. This is consistent with the Quasi Maximum Likelihood (QML) methodology of Bollerslev and Wooldridge (1992), which gives standard errors robust to departure from normality. 


\section{B The quantile regression approach for comovements in asset returns}

In this section we describe the formal framework that allows us to fill the "comovement box". Let $y_{t}$ and $x_{t}$ denote two different random variables. Let $q_{\theta t}^{Y}$ be the time $t$ $\theta$-quantile of the conditional distribution of $y_{t}$. Analogously, for $x_{t}$, we define $q_{\theta t}^{X}$.

Denote the conditional cumulative joint distribution of the two random variables by $F_{t}(y, x)$. Define $F_{t}^{-}(y \mid x) \equiv \operatorname{Pr}\left(y_{t} \leq y \mid x_{t} \leq x\right)$ and $F_{t}^{+}(y \mid x) \equiv \operatorname{Pr}\left(y_{t} \geq y \mid\right.$ $\left.x_{t} \geq x\right)$. Our basic tool of analysis is the following conditional probability:

$$
p_{t}(\theta) \equiv\left\{\begin{array}{ll}
F_{t}^{-}\left(q_{\theta t}^{Y} \mid q_{\theta t}^{X}\right) & \text { if } \theta \leq 0.5 \\
F_{t}^{+}\left(q_{\theta t}^{Y} \mid q_{\theta t}^{X}\right) & \text { if } \theta>0.5
\end{array} .\right.
$$

This conditional probability represents an effective way to summarizes the characteristics of $F_{t}(y, x)$.

If we think of $\left\{x_{t}\right\}_{t=1}^{T}$ and $\left\{y_{t}\right\}_{t=1}^{T}$ as the time series returns of two different markets, for each quantile $\theta, p_{t}(\theta)$ measures the probability that, at time $t$, the return on market $Y$ will fall below (or above) its $\theta$-quantile, conditional on the same event occurring in market $X$.

$p_{t}(\theta)$ satisfies some basic desirable properties (such as independence, co-monotonic ity $_{\text {. }}$ and counter-monotonicity), as summarized in theorem 1 of Cappiello, Gérard and Manganelli (2005). While $p_{t}(\theta)$ can be used to measure the dependence between different markets, the interest of the researcher often lies in testing whether this dependence has changed over time. Market integration is an important case in point. If increased integration can be associated to stronger co-movements between markets, one can test for changes in integration by testing if the conditional probability of co-movements between two markets increases after institutional changes fostering greater openness and integration.

The framework of the co-movement box can be used to formalize this intuition. Let $p^{I}(\theta) \equiv I^{-1} \sum_{t \in\{\text { Integration period }\}} p_{t}(\theta)$ and $p^{S}(\theta) \equiv S^{-1} \sum_{t \in\{\text { Segmented period }\}} p_{t}(\theta)$, where $I$ and $S$ denote the number of observations in segmented and integrated periods respectively. We adopt the following working definition of increased integration:

Definition 1 (Integration) - Integration increases if $\delta(0,1)=\int_{0}^{1}\left[p^{I}(\theta)-p^{S}(\theta)\right] d \theta>$ 0 .

$\delta(0,1)$ measures the area between the average conditional probabilities $p^{I}(\theta)$ and $p^{S}(\theta)$. 
Constructing the co-movement box and testing for differences in the probability of co-movement requires several steps. First, we estimate the univariate quantiles associated to the return series of interest, using the CAViaR model by Engle and Manganelli (2004). Second, we construct, for each series and for each quantile, indicator variables which are equal to one if the observed return is lower than this quantile and zero otherwise. Finally, we regress the $\theta$-quantile indicator variable of country $Y$ on the $\theta$-quantile indicator variable of country $X$, interacted with time dummies which identify periods of greater integration. These regression coefficients will provide a direct estimate of the conditional probabilities of co-movements and of their changes across regimes.

The average conditional probability $p_{t}(\theta)$ can be estimated by running the following regression:

$$
I_{t}^{Y X}\left(\hat{\beta}_{\theta_{i}}\right)=\alpha_{\theta_{i}}^{1}+\alpha_{\theta_{i}}^{2} D_{t}^{I}+\tilde{\epsilon}_{t} .
$$

where $I_{t}^{Y X}\left(\hat{\beta}_{\theta_{i}}\right) \equiv I\left(y_{t} \leq q_{t}^{Y}\left(\hat{\beta}_{\theta_{i} Y}\right)\right) \cdot I\left(x_{t} \leq q_{t}^{X}\left(\hat{\beta}_{\theta_{i} X}\right)\right)$ for each $\theta_{i}$ quantile, $q_{t}^{Y}\left(\hat{\beta}_{\theta_{i} Y}\right)$ and $q_{t}^{X}\left(\hat{\beta}_{\theta_{i} X}\right)$ denote the estimated quantiles, and $D_{t}^{I}$ is the dummy for the integration period.

Cappiello, Gérard and Manganelli (2004) show that the OLS estimators of regression (23) are asymptotically consistent estimators of the average conditional probability $p_{t}(\theta)$ in the non-integrated and integrated regimes and provide estimators for their standard errors:

$$
\begin{aligned}
& \hat{\tilde{\alpha}}_{\theta_{i}}^{1} \stackrel{p}{\rightarrow} E\left[p_{t}\left(\theta_{i}\right) \mid \text { segmented period }\right] \equiv p^{S}\left(\theta_{i}\right) \quad i=1, \ldots, m, \\
& \hat{\tilde{\alpha}}_{\theta_{i}}^{1}+\hat{\tilde{\alpha}}_{\theta_{i}}^{2} \stackrel{p}{\rightarrow} E\left[p_{t}\left(\theta_{i}\right) \mid \text { integrated period }\right] \equiv p^{I}\left(\theta_{i}\right) \quad i=1, \ldots, m \text {. }
\end{aligned}
$$

$\hat{\tilde{\alpha}}_{\theta_{i}}^{1}$ is the parameter associated with constant and, as such, it converges to the average probabilities in the segmented period. Similarly, since $\hat{\tilde{\alpha}}_{\theta_{i}}^{2}$ is the coefficient of $D_{t}^{I}$, the sum of $\hat{\tilde{\alpha}}_{\theta_{i}}^{1}+\hat{\tilde{\alpha}}_{\theta_{i}}^{2}$ converges in probability to the average co-movement likelihood under the integration regime. Testing for an increase in the conditional co-movement likelihood across two regimes is equivalent to testing for the null that $\alpha_{\theta_{i}}^{2}$ is equal to zero. Indeed, it is only when $\alpha_{\theta_{i}}^{2}=0$ that the two conditional probabilities coincide. If $\alpha_{\theta_{i}}^{2}$ is greater than zero, the conditional probability during the integration regime will be higher than the conditional probability during the segmentation regime. 


\section{The affine macro-finance term structure model}

The Hördahl, Tristani and Vestin (2005) model, as described by Equations (5) - (7), when recast to suit monthly data is

$$
\begin{aligned}
\pi_{t} & =\frac{\mu_{\pi}}{12} \sum_{i=1}^{12} E_{t}\left[\pi_{t+i}\right]+\left(1-\mu_{\pi}\right) \sum_{i=1}^{3} \delta_{\pi i} \pi_{t-i}+\delta_{x} x_{t}+\varepsilon_{t}^{\pi} \\
x_{t} & =\frac{\mu_{x}}{12} \sum_{i=1}^{12} E_{t}\left[x_{t+i}\right]+\left(1-\mu_{x}\right) \sum_{i=1}^{3} \zeta_{x i} x_{t-i}-\zeta_{r}\left(r_{t}-E_{t}\left[\pi_{t+11}\right]\right)+\varepsilon_{t}^{x} \\
r_{t} & =(1-\rho)\left(\beta\left(E_{t}\left[\pi_{t+11}\right]-\pi_{t}^{*}\right)+\gamma x_{t}\right)+\rho r_{t-1}+\eta_{t}
\end{aligned}
$$

The model is solved by formulating it in the state space form

$$
\left[\begin{array}{c}
\mathbf{X}_{1, t+1} \\
E_{t} \mathbf{X}_{2, t+1}
\end{array}\right]=\mathbf{H}\left[\begin{array}{l}
\mathbf{X}_{1, t} \\
\mathbf{X}_{2, t}
\end{array}\right]+\mathbf{K} r_{t}+\left[\begin{array}{c}
\boldsymbol{\xi}_{1, t+1} \\
\mathbf{0}
\end{array}\right]
$$

where $\mathbf{X}_{1}$ is the following vector of predetermined variables:

$$
\mathbf{X}_{1 t}=\left[x_{t-1}, x_{t-2}, x_{t-3}, \pi_{t-1}, \pi_{t-2}, \pi_{t-3}, \pi_{t}^{*}, \eta_{t}, \varepsilon_{t}^{\pi}, \varepsilon_{t}^{x}, r_{t-1}\right]^{\prime},
$$

and $\mathbf{X}_{2}$ are the non-predetermined variables:

$$
\mathbf{X}_{2 t}=\left[E_{t} x_{t+11}, \ldots, E_{t} x_{t+1}, x_{t}, E_{t} \pi_{t+11}, \ldots, E_{t} \pi_{t+1}, \pi_{t}\right]^{\prime}
$$

For the pricing of bonds, the transformed vector $\mathbf{Z}_{t}$ defined as

$$
\mathbf{Z}_{t}=\left[x_{t-1}, x_{t-2}, x_{t-3}, \pi_{t-1}, \pi_{t-2}, \pi_{t-3}, \pi_{t}^{*}, r_{t}, \pi_{t}, x_{t}, r_{t-1}\right]^{\prime}
$$

is used. Using the solution $\mathbf{X}_{2, t}=\mathbf{C X}_{1, t}, \mathbf{Z}_{t}$ can be written as $\mathbf{Z}_{t}=\hat{\mathbf{D}} \mathbf{X}_{1, t}$. Given the definition of $r_{t}$ and $\xi_{t+1}$, the pricing kernel $m_{t+1}=\exp \left(-r_{t}\right) \frac{\xi_{t+1}}{\xi_{t}}$ can be written as

$$
m_{t+1}=\exp \left(-\overline{\boldsymbol{\Delta}}^{\prime} \mathbf{Z}_{t}-\frac{1}{2} \lambda_{t}^{\prime} \lambda_{t}-\lambda_{t}^{\prime} \varepsilon_{1, t+1}\right)
$$

by using $r_{t}=\overline{\boldsymbol{\Delta}}^{\prime} \mathbf{Z}_{t}$ with $\overline{\boldsymbol{\Delta}}^{\prime}=[\underset{1 \times 7}{\mathbf{0}}, 1, \underset{1 \times 3}{\mathbf{0}}]$.

That this set-up will deliver bond prices that are exponential affine functions of $\mathbf{X}_{1, t}$. Since $\mathbf{Z}_{t}$ is an affine transformation of $\mathbf{X}_{1, t}$, bond prices can be written as

$$
p_{t}^{n}=\exp \left(\bar{A}_{n}+\bar{B}_{n}^{\prime} \mathbf{Z}_{t}\right)
$$

where the coefficients $\bar{A}_{n}$ and $\bar{B}_{n}$ have to be determined. 
The price of a one-period bond at time $t$ is $p_{t}^{1}=E_{t}\left[m_{t+1}\right]=\exp \left(-\overline{\boldsymbol{\Delta}}^{\prime} \mathbf{Z}_{t}\right)$, so that $\bar{A}_{1}=0$ and $\bar{B}_{1}=-\overline{\boldsymbol{\Delta}}$. The pricing kernel (29) and the postulated form of bond prices (30) can be used to rewrite the equation for the price of an $(n+1)$-period bond $p_{t}^{n+1}=E_{t}\left[m_{t+1} p_{t+1}^{n}\right]$ as

$p_{t}^{n+1}=\exp \left(\bar{A}_{n}-\bar{B}_{n}^{\prime} \hat{\mathbf{D}} \Sigma \lambda_{0}+\frac{1}{2} \bar{B}_{n}^{\prime} \hat{\mathbf{D}} \Sigma \Sigma^{\prime} \hat{\mathbf{D}}^{\prime} \bar{B}_{n}+\left(\bar{B}_{n}^{\prime} \hat{\mathbf{D}} \mathbf{M} \hat{\mathbf{D}}^{-1}-\overline{\boldsymbol{\Delta}}^{\prime}-\bar{B}_{n}^{\prime} \hat{\mathbf{D}} \Sigma \lambda_{1}\right) \mathbf{Z}_{t}\right)$

The bond-pricing coefficients for any maturity $n$ can therefore be found using the recursion

$$
\begin{aligned}
\bar{A}_{n+1} & =\bar{A}_{n}-\bar{B}_{n}^{\prime} \hat{\mathbf{D}} \Sigma \lambda_{0}+\frac{1}{2} \bar{B}_{n}^{\prime} \hat{\mathbf{D}} \Sigma \Sigma^{\prime} \hat{\mathbf{D}}^{\prime} \bar{B}_{n} \\
\bar{B}_{n+1}^{\prime} & =\bar{B}_{n}^{\prime} \hat{\mathbf{D}}\left(\mathbf{M} \hat{\mathbf{D}}^{-1}-\Sigma \lambda_{1}\right)-\overline{\boldsymbol{\Delta}}^{\prime}
\end{aligned}
$$

initialized at $\bar{A}_{1}=0$ and $\bar{B}_{1}=-\overline{\boldsymbol{\Delta}}$.

Term premia are obtained as follows, where a distinction is made between holding premia, forward premia, and yield premia.

The one-period holding premium $e_{n, t}$ on an $n$-period bond purchased at $t$ is defined as the expected holding return of that bond over one period, less the riskfree rate:

$$
e_{n, t}=E_{t}\left[\ln \left(p_{t+1}^{n-1}\right)-\ln \left(p_{t}^{n}\right)\right]-r_{t}
$$

Using the bond pricing equation, this can be written as

$$
e_{n, t}=\left(\bar{B}_{n-1}^{\prime} \hat{\mathbf{D}} \Sigma \lambda_{0}-\frac{1}{2} \bar{B}_{n-1}^{\prime} \hat{\mathbf{D}} \Sigma \Sigma^{\prime} \hat{\mathbf{D}}^{\prime} \bar{B}_{n-1}\right)+\left(\bar{B}_{n-1}^{\prime} \hat{\mathbf{D}} \Sigma \lambda_{1}\right) \mathbf{Z}_{t} .
$$

The one-period forward premium $\psi_{n, t}$ at $t$ for maturity $n$ is defined as the difference between the implied one-period forward rate $n$ periods ahead, $f_{n, t}$, less the corresponding expected one-period interest rate:

$$
\psi_{n, t}=f_{n, t}-E_{t}\left[r_{t+n}\right]
$$

The implied forward rate is given by

$$
\begin{aligned}
f_{n, t} & =\ln \left(p_{t}^{n}\right)-\ln \left(p_{t}^{n+1}\right) \\
& =\left(\bar{B}_{n}^{\prime} \hat{\mathbf{D}} \Sigma \lambda_{0}-\frac{1}{2} \bar{B}_{n}^{\prime} \hat{\mathbf{D}} \Sigma \Sigma^{\prime} \hat{\mathbf{D}}^{\prime} \bar{B}_{n}\right)+\left[\bar{B}_{n}^{\prime}-\bar{B}_{n}^{\prime} \hat{\mathbf{D}}\left(\mathbf{M} \hat{\mathbf{D}}^{-1}-\Sigma \lambda_{1}\right)+\overline{\boldsymbol{\Delta}}^{\prime}\right] \mathbf{Z}_{t}
\end{aligned}
$$


while the expected short rate is

$$
E_{t}\left[r_{t+n}\right]=\overline{\boldsymbol{\Delta}}^{\prime} \hat{\mathbf{D}} \mathbf{M}^{n} \hat{\mathbf{D}}^{-1} \mathbf{Z}_{t}
$$

The one-month forward premium is therefore

$$
\begin{aligned}
\psi_{n, t}= & f_{n, t}-E_{t}\left[r_{t+n}\right] \\
= & \left(\bar{B}_{n}^{\prime} \hat{\mathbf{D}} \Sigma \lambda_{0}-\frac{1}{2} \bar{B}_{n}^{\prime} \hat{\mathbf{D}} \Sigma \Sigma^{\prime} \hat{\mathbf{D}}^{\prime} \bar{B}_{n}\right)+ \\
& {\left[\bar{B}_{n}^{\prime}-\bar{B}_{n}^{\prime} \hat{\mathbf{D}}\left(\mathbf{M} \hat{\mathbf{D}}^{-1}-\Sigma \lambda_{1}\right)+\overline{\mathbf{\Delta}}^{\prime}\left(I-\hat{\mathbf{D}} \mathbf{M}^{n} \hat{\mathbf{D}}^{-1}\right)\right] \mathbf{Z}_{t} }
\end{aligned}
$$

The $n$-maturity yield premium at $t, \omega_{n, t}$, can be defined as the average of the forward premia up until $t+n-1$, i.e. $\omega_{n, t}=\frac{1}{n} \sum_{i=0}^{n-1} \psi_{n, t}$. This is given by

$$
\begin{aligned}
\omega_{n, t}= & \frac{1}{n} \sum_{i=0}^{n-1}\left[\bar{B}_{i}^{\prime} \hat{\mathbf{D}} \Sigma \lambda_{0}-\frac{1}{2} \bar{B}_{i}^{\prime} \hat{\mathbf{D}} \Sigma \Sigma^{\prime} \hat{\mathbf{D}}^{\prime} \bar{B}_{i}+\right. \\
& \left.\left(\bar{B}_{i}^{\prime}-\bar{B}_{i}^{\prime} \hat{\mathbf{D}}\left(\mathbf{M} \hat{\mathbf{D}}^{-1}-\Sigma \lambda_{1}\right)+\overline{\boldsymbol{\Delta}}^{\prime}\left(I-\hat{\mathbf{D}}^{i} \hat{\mathbf{D}}^{-1}\right)\right) \mathbf{Z}_{t}\right]
\end{aligned}
$$


Table 1: Descriptive statistics of returns on equity market indices and 10-year government bonds

This table reports summary statistics relative to weekly returns on 17 equity market indiceś and 14 10-year government bonds. The equity indices refer to Austria (AT), Belgium (BE) Denmark (DK), Finland (FI), France (FR), Germany (DE), Greece (GR), Ireland (IE) Italy (IT), Japan (JP), the Netherlands (NL), Portugal (PT), Spain (ES), Sweden (SE), the United Kingdom (UK), the United States (US), as well as the Eurostoxx50 (EU). Data on 10-year government bonds are available for all the countries listed above, except Portugal. The sample covers the period from January 9th, 1987 to October 21st, 2005. Data on the Greek equity price index, and the Belgian and Finnish 10-year government bond are only available from January 10th 1992. Therefore, they are reported in the separate table $1 \mathrm{~b}$. The superscripts "S" and "B" stand for stocks and bonds, respectively. Equity market indices and 10-year government bond yields are from Global Financial Data. Mean and Standard Deviation are annualized and in percentage. Min. and Max represent the weekly minimum and maximum retuns and are in percentage. The Jarque-Bera (J-B) test for normalit combines excess skewness and kurtosis and is asymptotically distributed as $\chi_{m}^{2}$ with $m=2$ degrees of freedom.

Table 1a - Sample period: January 198\%-October 2005

\begin{tabular}{|c|c|c|c|c|c|c|c|}
\hline Asset & Mean & Max. & Min. & Std. Dev. & Skewness & Kurtosis & J-Bera \\
\hline $\mathrm{DE}^{\mathrm{S}}$ & 3.53 & 11.21 & -12.60 & 0.18 & -0.45 & 5.40 & 268 \\
\hline $\mathbf{F R}^{\mathrm{S}}$ & 5.76 & 10.64 & -12.71 & 0.17 & -0.35 & 4.83 & 156 \\
\hline $\mathbf{U K}^{\mathrm{S}}$ & 5.52 & 9.51 & -24.61 & 0.15 & -1.69 & 21.14 & 13910 \\
\hline $\mathrm{IT}^{\mathrm{S}}$ & 3.95 & 15.95 & -16.30 & 0.20 & -0.18 & 5.82 & 330 \\
\hline$N^{S}$ & 6.51 & 14.93 & -14.17 & 0.17 & -0.72 & 7.74 & 1001 \\
\hline $\mathbf{E S}^{\mathbf{S}}$ & 8.24 & 11.74 & -19.20 & 0.19 & -0.50 & 7.41 & 835 \\
\hline $\mathrm{SE}^{\mathrm{S}}$ & 9.50 & 17.06 & -15.41 & 0.20 & -0.29 & 6.37 & 478 \\
\hline $\mathbf{A T}^{\mathrm{S}}$ & 7.82 & 13.64 & -13.74 & 0.16 & -0.29 & 7.64 & 891 \\
\hline $\mathrm{BE}^{\mathrm{S}}$ & 6.69 & 11.13 & -13.31 & 0.15 & -0.50 & 7.31 & 800 \\
\hline $\mathbf{D K}^{\mathrm{S}}$ & 9.09 & 7.81 & -12.68 & 0.14 & -0.52 & 5.78 & 359 \\
\hline $\mathbf{F I}^{\mathrm{S}}$ & 9.75 & 16.84 & -22.07 & 0.27 & -0.42 & 6.09 & 420 \\
\hline $\mathrm{IE}^{\mathrm{S}}$ & 8.85 & 10.46 & -19.79 & 0.18 & -1.16 & 9.82 & 2120 \\
\hline $\mathbf{P T}^{\mathrm{S}}$ & 7.40 & 16.37 & -18.02 & 0.20 & 0.18 & 11.32 & 2835 \\
\hline $\mathbf{J} \mathbf{P}^{\mathrm{S}}$ & -1.81 & 11.05 & -12.50 & 0.20 & -0.20 & 4.65 & 118 \\
\hline $\mathbf{U S} \mathbf{S}^{\mathbf{S}}$ & 7.74 & 7.49 & -13.01 & 0.15 & -0.71 & 6.80 & 672 \\
\hline $\mathbf{E} \mathbf{U}^{\mathrm{S}}$ & 6.77 & 13.59 & -12.57 & 0.18 & -0.30 & 5.69 & 310 \\
\hline $\mathbf{D E}^{\mathrm{B}}$ & 1.34 & 4.67 & -5.37 & 0.07 & -0.40 & 5.29 & 240 \\
\hline $\mathbf{F R}^{\mathrm{B}}$ & 2.51 & 15.85 & -10.33 & 0.09 & 1.29 & 34.52 & 40854 \\
\hline $\mathbf{U K}^{\mathbf{B}}$ & 2.95 & 7.19 & -5.34 & 0.10 & 0.07 & 5.14 & 188 \\
\hline $\mathbf{I T}^{\mathbf{B}}$ & 2.97 & 7.29 & -9.17 & 0.11 & -0.86 & 10.03 & 2141 \\
\hline $\mathbf{N L}^{\mathrm{B}}$ & 1.46 & 5.88 & -4.13 & 0.06 & -0.12 & 5.45 & 248 \\
\hline $\mathbf{E S}^{\mathbf{B}}$ & 4.28 & 9.76 & -10.85 & 0.11 & -0.86 & 12.12 & 3522 \\
\hline $\mathbf{S E}^{\mathrm{B}}$ & 4.18 & 8.22 & -8.08 & 0.10 & -0.49 & 6.80 & 629 \\
\hline$A T^{B}$ & 1.94 & 3.26 & -4.22 & 0.06 & -0.46 & 5.05 & 206 \\
\hline $\mathbf{D K}^{\mathrm{B}}$ & 4.07 & 8.53 & -7.00 & 0.09 & -0.20 & 8.48 & 1232 \\
\hline $\mathbf{I E}^{\mathrm{B}}$ & 4.39 & 6.72 & -6.76 & 0.09 & -0.41 & 7.00 & 682 \\
\hline $\mathbf{J P}^{\mathbf{B}}$ & 1.89 & 5.49 & -5.08 & 0.07 & -0.42 & 6.90 & 649 \\
\hline $\mathbf{U} \mathbf{S}^{\mathbf{B}}$ & 1.26 & 11.40 & -5.45 & 0.09 & 0.31 & 8.67 & 1327 \\
\hline
\end{tabular}

Table $1 b$ - Sample period: January 1992-October 2005

\begin{tabular}{lccccccc}
\multicolumn{1}{c}{ Asset } & Mean & Max. & Min. & Std. Dev. Skewness & Kurtosis & J-Bera \\
$\mathbf{B E}^{\mathbf{B}}$ & 3.60 & 3.15 & -4.31 & 0.27 & 0.41 & 7.89 & 738.09 \\
$\mathbf{F I}^{\mathbf{B}}$ & 5.53 & 7.33 & -8.96 & 0.07 & -0.43 & 4.07 & 57.18 \\
$\mathbf{G R}^{\mathbf{S}}$ & 9.72 & 22.22 & -19.54 & 0.09 & -0.84 & 8.84 & 1108.37 \\
\hline
\end{tabular}


Table 2a: Return unconditional correlations over the whole sample period, January 1987 - October 2005

This table reports return unconditional correlations over the whole sample period, from January 9th, 1987 to October 21st, 2005. Correlations are computed on weekly returns of 16 equity market indices and 12 10-year government bonds. The equity indices refer to Austria (AT), Belgium (BE), Denmark (DK), Finland (FI), France (FR), Germany (DE), Ireland (IE), Italy (IT), Japan (JP), the Netherlands (NL), Portugal (PT), Spain (ES), Sweden (SE), the United Kingdom (UK), the United States (US), as well as the Eurostoxx50 (EU). Data on 10-year government bonds are available for all the countries listed above, except Belgium, Finland and Portugal. The superscripts "S" and "B" stand for stocks and bonds, respectively.

\begin{tabular}{|c|c|c|c|c|c|c|c|c|c|c|c|c|c|c|c|c|}
\hline & $\mathrm{DE}^{\mathrm{S}}$ & $\mathrm{FR}^{\mathrm{S}}$ & $\mathbf{U K}^{\mathrm{S}}$ & $\mathbf{I T}^{\mathrm{S}}$ & $\mathrm{NL}^{\mathrm{S}}$ & $\mathbf{E S}^{\mathbf{S}}$ & $\mathrm{SE}^{\mathrm{S}}$ & $\mathrm{AT}^{\mathrm{S}}$ & $\mathbf{B E}^{\mathrm{S}}$ & $\mathrm{DK}^{\mathrm{S}}$ & $\mathrm{FI}^{\mathrm{S}}$ & $\mathrm{IE}^{\mathrm{S}}$ & $\mathbf{P T}^{\mathrm{S}}$ & $\mathbf{J P}^{\mathrm{S}}$ & $\mathbf{U S}^{\mathbf{S}}$ & $\mathbf{E U}^{\mathbf{S}}$ \\
\hline${ }^{\mathrm{S}}$ & & 0.78 & 0.65 & 0.63 & 0.79 & 0.65 & 0.68 & 0.50 & 0.66 & 0.55 & 0.52 & 0.55 & 0.32 & 0.35 & 0.58 & 0.91 \\
\hline $\mathbf{F R} \mathbf{R}^{\mathrm{S}}$ & & & 0.65 & 0.62 & 0.77 & 0.67 & 0.64 & 0.42 & 0.67 & 0.50 & 0.52 & 0.52 & 0.32 & 0.35 & 0.57 & 0.88 \\
\hline $\mathbf{U} \mathbf{K}^{\mathrm{S}}$ & & & & 0.54 & 0.75 & 0.61 & 0.60 & 0.39 & 0.57 & 0.48 & 0.47 & 0.66 & 0.34 & 0.37 & 0.61 & 0.74 \\
\hline IT $^{S}$ & & & & & 0.61 & 0.57 & 0.54 & 0.38 & 0.52 & 0.50 & 0.43 & 0.47 & 0.29 & 0.30 & 0.42 & 0.70 \\
\hline $\mathbf{N L}^{\mathrm{S}}$ & & & & & & 0.65 & 0.64 & 0.40 & 0.71 & 0.55 & 0.51 & 0.60 & 0.31 & 0.35 & 0.63 & 0.89 \\
\hline $\mathbf{E S}^{\mathbf{S}}$ & & & & & & & 0.63 & 0.44 & 0.59 & 0.48 & 0.44 & 0.54 & 0.35 & 0.36 & 0.50 & 0.74 \\
\hline $\mathbf{S E}^{\mathrm{S}}$ & & & & & & & & 0.37 & 0.52 & 0.51 & 0.62 & 0.53 & 0.38 & 0.36 & 0.53 & 0.71 \\
\hline $\mathbf{A} \mathbf{T}^{\mathrm{S}}$ & & & & & & & & & 0.42 & 0.33 & 0.23 & 0.37 & 0.28 & 0.29 & 0.26 & 0.45 \\
\hline $\mathbf{B E}^{\mathrm{S}}$ & & & & & & & & & & 0.48 & 0.35 & 0.52 & 0.34 & 0.27 & 0.45 & 0.70 \\
\hline $\mathbf{D K}^{\mathrm{S}}$ & & & & & & & & & & & 0.40 & 0.44 & 0.26 & 0.29 & 0.41 & 0.56 \\
\hline $\mathrm{FI}^{\mathrm{S}}$ & & & & & & & & & & & & 0.34 & 0.25 & 0.27 & 0.44 & 0.59 \\
\hline$I^{S}$ & & & & & & & & & & & & & 0.34 & 0.34 & 0.46 & 0.58 \\
\hline $\mathbf{P T}$ & & & & & & & & & & & & & & 0.23 & 0.20 & 0.34 \\
\hline $\mathbf{J P}^{\mathrm{S}}$ & & & & & & & & & & & & & & & 0.33 & 0.38 \\
\hline $\mathbf{U S}$ & & & & & & & & & & & & & & & & 0.65 \\
\hline $\mathbf{D E}^{\mathbf{B}}$ & -0.01 & 0.03 & -0.02 & 0.04 & -0.05 & -0.01 & -0.02 & 0.03 & 0.03 & 0.03 & -0.06 & -0.04 & -0.06 & -0.02 & 0.02 & 0.02 \\
\hline $\mathbf{F} \mathbf{R}^{\mathbf{B}}$ & -0.02 & 0.12 & -0.08 & 0.06 & -0.04 & 0.04 & -0.01 & 0.03 & 0.07 & 0.03 & -0.04 & -0.04 & -0.12 & -0.06 & 0.02 & 0.02 \\
\hline $\mathbf{U} \mathbf{K}^{\mathbf{B}}$ & -0.02 & 0.05 & 0.15 & 0.06 & -0.01 & 0.04 & 0.03 & 0.02 & 0.03 & 0.02 & 0.01 & 0.05 & -0.01 & 0.00 & 0.06 & 0.03 \\
\hline & 0.06 & 0.07 & 0.07 & 0.23 & 0.05 & 0.11 & 0.09 & 0.06 & 0.08 & 0.11 & 0.05 & 0.06 & 0.00 & 0.02 & 0.04 & 0.11 \\
\hline $\mathbf{N L}^{\mathrm{B}}$ & -0.01 & 0.02 & -0.04 & 0.04 & -0.06 & 0.01 & -0.02 & 0.03 & 0.04 & 0.05 & -0.05 & -0.05 & -0.07 & -0.05 & 0.01 & 0.01 \\
\hline $\mathbf{E S}^{\mathbf{B}}$ & 0.03 & 0.08 & 0.08 & 0.13 & 0.02 & 0.14 & 0.08 & 0.09 & 0.07 & 0.10 & 0.07 & 0.04 & 0.03 & 0.02 & 0.04 & 0.07 \\
\hline $\mathbf{S E}^{\mathbf{B}}$ & 0.06 & 0.10 & 0.06 & 0.14 & 0.03 & 0.13 & 0.20 & 0.08 & 0.08 & 0.09 & 0.07 & 0.04 & 0.05 & 0.02 & 0.05 & 0.09 \\
\hline $\mathbf{A} \mathbf{T}^{\mathbf{B}}$ & -0.01 & 0.04 & 0.05 & 0.08 & -0.03 & 0.06 & 0.02 & 0.08 & 0.07 & 0.06 & 0.00 & 0.04 & 0.00 & 0.00 & 0.02 & 0.03 \\
\hline $\mathbf{D} \mathbf{K}^{\mathbf{B}}$ & 0.08 & 0.13 & 0.09 & 0.14 & 0.06 & 0.16 & 0.08 & 0.08 & 0.18 & 0.26 & 0.04 & 0.11 & 0.05 & 0.05 & 0.06 & 0.13 \\
\hline $\mathbf{I E}^{\mathbf{B}}$ & 0.05 & 0.08 & 0.10 & 0.12 & 0.03 & 0.08 & 0.08 & 0.11 & 0.11 & 0.12 & 0.01 & 0.12 & 0.09 & 0.07 & 0.07 & 0.08 \\
\hline $\mathbf{J P}^{\mathbf{E}}$ & -0.09 & -0.02 & -0.05 & -0.07 & -0.08 & -0.08 & -0.09 & -0.06 & -0.05 & -0.02 & -0.03 & -0.07 & -0.09 & -0.04 & 0.01 & -0.07 \\
\hline $\mathbf{U} \mathbf{S}^{\mathbf{B}}$ & -0.16 & -0.09 & -0.16 & -0.10 & -0.17 & -0.11 & -0.14 & -0.02 & -0.05 & -0.06 & -0.13 & -0.11 & -0.14 & -0.07 & 0.04 & -0.13 \\
\hline
\end{tabular}

\begin{tabular}{lccccccccccc}
\hline & $\mathbf{F R}^{\mathbf{B}}$ & $\mathbf{U K}^{\mathbf{B}}$ & $\mathbf{I T}^{\mathbf{B}}$ & $\mathbf{N L}^{\mathbf{B}}$ & $\mathbf{E S}^{\mathbf{B}}$ & $\mathbf{S E}^{\mathbf{B}}$ & $\mathbf{A T}^{\mathbf{B}}$ & $\mathbf{D K}^{\mathbf{B}}$ & $\mathbf{I E}^{\mathbf{B}}$ & $\mathbf{J P}^{\mathbf{B}}$ & $\mathbf{U S}^{\mathbf{B}}$ \\
$\mathbf{D E}^{\mathbf{B}}$ & 0.73 & 0.59 & 0.44 & 0.92 & 0.42 & 0.53 & 0.79 & 0.62 & 0.60 & 0.26 & 0.55 \\
$\mathbf{F R}^{\mathbf{B}}$ & & 0.55 & 0.41 & 0.76 & 0.41 & 0.49 & 0.62 & 0.54 & 0.52 & 0.22 & 0.58 \\
$\mathbf{U K}^{\mathbf{B}}$ & & & 0.32 & 0.61 & 0.35 & 0.46 & 0.52 & 0.38 & 0.55 & 0.19 & 0.47 \\
$\mathbf{I T}^{\mathbf{B}}$ & & & & 0.47 & 0.46 & 0.47 & 0.48 & 0.40 & 0.40 & 0.06 & 0.28 \\
$\mathbf{N L}^{\mathbf{B}}$ & & & & 0.44 & 0.55 & 0.81 & 0.62 & 0.60 & 0.26 & 0.55 \\
$\mathbf{E S}$ & & & & & & 0.44 & 0.48 & 0.38 & 0.41 & 0.06 & 0.28 \\
$\mathbf{S E}$ & & & & & & & 0.55 & 0.46 & 0.46 & 0.11 & 0.35 \\
$\mathbf{A}$ & & & & & & & 0.59 & 0.59 & 0.20 & 0.46 \\
$\mathbf{D K}$ & & & & & & & & & 0.54 & 0.25 & 0.32 \\
$\mathbf{I E}^{\mathbf{B}}$ & & & & & & & & & & 0.13 & 0.38 \\
$\mathbf{J P}^{\mathbf{B}}$ & & & & & & & & & & & 0.16
\end{tabular}


Table 2b: Return unconditional correlations and standard deviations for the period January 1987 - December 1998

This table reports return unconditional correlations as well as standard deviations (in bold) over the sample period January 9th, 1987 - December 30th, 1998. Correlations and standard deviations are computed on weekly returns of 16 equity market indices and 12 10-year government bonds. The equity indices refer to Austria (AT), Belgium (BE), Denmark (DK), Finland (FI), France (FR), Germany (DE), Ireland (IE), Italy (IT), Japan (JP), the Netherlands (NL), Portugal (PT), Spain (ES), Sweden (SE), the United Kingdom (UK), the United States (US), as well as the Eurostoxx50 (EU). Data on 10-year government bonds are available for all the countries listed above, except Belgium, Finland and Portugal. The superscripts "S" and "B" stand for stocks and bonds, respectively.

\begin{tabular}{|c|c|c|c|c|c|c|c|c|c|c|c|c|c|c|c|c|}
\hline & $\mathrm{DE}^{\mathrm{S}}$ & $\mathbf{F R}^{\mathrm{S}}$ & $\mathbf{U K}^{\mathrm{S}}$ & IT $^{\mathrm{S}}$ & $\mathbf{N L}^{\mathrm{S}}$ & $\mathrm{ES}^{\mathrm{S}}$ & $\mathbf{S E}^{\mathrm{S}}$ & $\mathbf{A T}^{\mathrm{S}}$ & $\mathbf{B E}^{\mathrm{S}}$ & $\mathrm{DK}^{\mathrm{S}}$ & $\mathrm{FI}^{\mathrm{S}}$ & $\mathbf{I E}^{\mathrm{S}}$ & $\mathbf{P T}^{\mathrm{S}}$ & $\mathbf{J P}^{\mathbf{S}}$ & $\mathbf{U S}^{\mathbf{S}}$ & $\mathbf{E U}^{S}$ \\
\hline$\overline{D^{S}}$ & 0.16 & 0.68 & 0.55 & 0.52 & 0.72 & 0.57 & 0.59 & 0.61 & 0.65 & 0.49 & 0.41 & 0.51 & 0.31 & 0.31 & 0.43 & 0.88 \\
\hline $\mathbf{F R}^{\mathrm{S}}$ & & 0.16 & 0.53 & 0.50 & 0.65 & 0.59 & 0.51 & 0.48 & 0.64 & 0.41 & 0.38 & 0.48 & 0.29 & 0.31 & 0.43 & 0.82 \\
\hline $\mathbf{U K}^{\mathbf{S}}$ & & & 0.15 & 0.43 & 0.70 & 0.54 & 0.52 & 0.40 & 0.50 & 0.40 & 0.38 & 0.70 & 0.33 & 0.36 & 0.53 & 0.68 \\
\hline $\mathbf{I T}^{\mathbf{S}}$ & & & & 0.21 & 0.50 & 0.48 & 0.44 & 0.40 & 0.47 & 0.44 & 0.37 & 0.41 & 0.25 & 0.26 & 0.29 & 0.63 \\
\hline $\mathbf{N L}^{\mathrm{S}}$ & & & & & 0.15 & 0.58 & 0.58 & 0.46 & 0.65 & 0.48 & 0.45 & 0.61 & 0.33 & 0.34 & 0.58 & 0.85 \\
\hline $\mathbf{E S}^{\mathbf{S}}$ & & & & & & 0.20 & 0.58 & 0.46 & 0.57 & 0.43 & 0.37 & 0.54 & 0.32 & 0.35 & 0.42 & 0.69 \\
\hline $\mathbf{S E}^{\mathrm{S}}$ & & & & & & & 0.19 & 0.42 & 0.52 & 0.42 & 0.54 & 0.54 & 0.37 & 0.33 & 0.41 & 0.63 \\
\hline $\mathbf{A T} \mathbf{T}^{\mathbf{S}}$ & & & & & & & & 0.18 & 0.48 & 0.35 & 0.33 & 0.40 & 0.29 & 0.31 & 0.27 & 0.56 \\
\hline $\mathbf{B} \mathbf{E}^{\mathbf{S}}$ & & & & & & & & & 0.14 & 0.46 & 0.40 & 0.52 & 0.37 & 0.30 & 0.38 & 0.70 \\
\hline $\mathbf{D K}^{\mathrm{S}}$ & & & & & & & & & & 0.12 & 0.39 & 0.40 & 0.26 & 0.24 & 0.31 & 0.51 \\
\hline $\mathrm{FI}^{\mathrm{S}}$ & & & & & & & & & & & 0.21 & 0.38 & 0.26 & 0.21 & 0.27 & 0.46 \\
\hline $\mathbf{I E}^{\mathrm{S}}$ & & & & & & & & & & & & 0.18 & 0.35 & 0.34 & 0.44 & 0.58 \\
\hline $\mathbf{P T}^{\mathrm{S}}$ & & & & & & & & & & & & & 0.24 & 0.26 & 0.18 & 0.34 \\
\hline$J \mathbf{P}^{\mathrm{S}}$ & & & & & & & & & & & & & & 0.20 & 0.32 & 0.37 \\
\hline $\mathbf{U S}^{\mathbf{S}}$ & & & & & & & & & & & & & & & 0.14 & 0.54 \\
\hline $\mathbf{E} \mathbf{U}^{\mathbf{S}}$ & & & & & & & & & & & & & & & & 0.15 \\
\hline $\mathbf{D E}^{\mathrm{B}}$ & 0.16 & 0.19 & 0.06 & 0.14 & 0.10 & 0.07 & 0.11 & 0.06 & 0.12 & 0.11 & 0.04 & 0.04 & -0.06 & 0.04 & 0.12 & 0.20 \\
\hline$F R^{B}$ & 0.09 & 0.28 & -0.05 & 0.13 & 0.08 & 0.10 & 0.08 & 0.05 & 0.15 & 0.09 & 0.03 & 0.01 & -0.14 & -0.02 & 0.09 & 0.15 \\
\hline $\mathbf{U K}^{\mathrm{B}}$ & 0.05 & 0.15 & 0.26 & 0.13 & 0.10 & 0.08 & 0.11 & 0.04 & 0.08 & 0.07 & 0.07 & 0.12 & -0.01 & 0.05 & 0.12 & 0.13 \\
\hline $\mathbf{I T}^{\mathbf{B}}$ & 0.18 & 0.17 & 0.13 & 0.33 & 0.17 & 0.17 & 0.18 & 0.08 & 0.14 & 0.19 & 0.15 & 0.12 & 0.01 & 0.06 & 0.10 & 0.24 \\
\hline $\mathbf{N L}^{\mathrm{B}}$ & 0.16 & 0.18 & 0.04 & 0.15 & 0.10 & 0.09 & 0.11 & 0.06 & 0.13 & 0.14 & 0.07 & 0.02 & -0.07 & 0.00 & 0.11 & 0.20 \\
\hline $\mathbf{E S}^{\mathbf{B}}$ & 0.14 & 0.20 & 0.15 & 0.21 & 0.14 & 0.21 & 0.17 & 0.11 & 0.14 & 0.18 & 0.20 & 0.11 & 0.05 & 0.06 & 0.10 & 0.20 \\
\hline $\mathbf{S E}^{\mathrm{B}}$ & 0.18 & 0.21 & 0.12 & 0.21 & 0.15 & 0.20 & 0.34 & 0.11 & 0.15 & 0.15 & 0.19 & 0.09 & 0.06 & 0.06 & 0.11 & 0.22 \\
\hline $\mathbf{A} \mathbf{T}^{\mathbf{B}}$ & 0.20 & 0.24 & 0.19 & 0.22 & 0.19 & 0.18 & 0.20 & 0.15 & 0.22 & 0.17 & 0.18 & 0.17 & 0.02 & 0.09 & 0.13 & 0.27 \\
\hline $\mathbf{D K}^{\mathbf{B}}$ & 0.21 & 0.24 & 0.16 & 0.23 & 0.18 & 0.24 & 0.17 & 0.11 & 0.28 & 0.42 & 0.15 & 0.19 & 0.06 & 0.10 & 0.13 & 0.26 \\
\hline $\mathrm{IE}^{\mathrm{B}}$ & 0.21 & 0.23 & 0.21 & 0.22 & 0.19 & 0.17 & 0.21 & 0.14 & 0.21 & 0.22 & 0.12 & 0.23 & 0.11 & 0.15 & 0.17 & 0.25 \\
\hline $\mathbf{J P}^{\mathbf{B}}$ & -0.09 & -0.02 & -0.05 & -0.06 & -0.09 & -0.10 & -0.09 & -0.06 & -0.06 & 0.00 & -0.05 & -0.09 & -0.11 & 0.02 & 0.04 & -0.08 \\
\hline $\mathbf{U S}^{\mathbf{B}}$ & -0.03 & 0.06 & -0.10 & -0.02 & -0.04 & -0.02 & -0.02 & 0.01 & 0.02 & 0.01 & -0.05 & -0.06 & -0.13 & -0.02 & 0.20 & 0.02 \\
\hline
\end{tabular}

\begin{tabular}{lcccccccccccc}
\hline & $\mathbf{D E}^{\mathbf{B}}$ & $\mathbf{F R}^{\mathbf{B}}$ & $\mathbf{U K}^{\mathbf{B}}$ & $\mathbf{I T}^{\mathbf{B}}$ & $\mathbf{N L}^{\mathbf{B}}$ & $\mathbf{E S}^{\mathbf{B}}$ & $\mathbf{S E}^{\mathbf{B}}$ & $\mathbf{A T}^{\mathbf{B}}$ & $\mathbf{D K}^{\mathbf{B}}$ & $\mathbf{I E}^{\mathbf{B}}$ & $\mathbf{J P}^{\mathbf{B}}$ & $\mathbf{U S}^{\mathbf{B}}$ \\
$\mathbf{D E}^{\mathbf{B}}$ & $\mathbf{0 . 0 7}$ & 0.66 & 0.51 & 0.32 & 0.89 & 0.29 & 0.43 & 0.68 & 0.55 & 0.48 & 0.29 & 0.45 \\
$\mathbf{F R}^{\mathbf{B}}$ & & $\mathbf{0 . 1 0}$ & 0.48 & 0.31 & 0.69 & 0.30 & 0.40 & 0.49 & 0.47 & 0.40 & 0.22 & 0.52 \\
$\mathbf{U K}^{\mathbf{B}}$ & & & $\mathbf{0 . 1 1}$ & 0.24 & 0.54 & 0.27 & 0.39 & 0.41 & 0.30 & 0.49 & 0.20 & 0.41 \\
$\mathbf{I T}^{\mathbf{B}}$ & & & & $\mathbf{0 . 1 3}$ & 0.36 & 0.39 & 0.41 & 0.37 & 0.32 & 0.30 & 0.04 & 0.18 \\
$\mathbf{N L}^{\mathbf{B}}$ & & & & & $\mathbf{0 . 0 6}$ & 0.32 & 0.46 & 0.70 & 0.55 & 0.47 & 0.30 & 0.46 \\
$\mathbf{E S}^{\mathbf{B}}$ & & & & & & $\mathbf{0 . 1 3}$ & 0.36 & 0.37 & 0.30 & 0.32 & 0.04 & 0.18 \\
$\mathbf{S E}^{\mathbf{B}}$ & & & & & & $\mathbf{0 . 1 2}$ & 0.45 & 0.38 & 0.36 & 0.09 & 0.26 \\
$\mathbf{A T}^{\mathbf{B}}$ & & & & & & & $\mathbf{0 . 0 5}$ & 0.51 & 0.45 & 0.21 & 0.29 \\
$\mathbf{D K}^{\mathbf{B}}$ & & & & & & & & $\mathbf{0 . 1 0}$ & 0.47 & 0.25 & 0.23 \\
$\mathbf{I E}^{\mathbf{B}}$ & & & & & & & & & $\mathbf{0 . 1 0}$ & 0.12 & 0.27 \\
$\mathbf{J P}^{\mathbf{B}}$ & & & & & & & & & & $\mathbf{0 . 0 8}$ & 0.17 \\
$\mathbf{U S}^{\mathbf{B}}$ & & & & & & & & & & & $\mathbf{0 . 0 9}$
\end{tabular}


Table 2c: Return unconditional correlations and standard deviations for the period January 1992 - December 1998

This table reports return unconditional correlations as well as standard deviations (in bold) over the sample period January 2nd, 1992 - December 30th, 1998. Correlations and standard deviations are computed on weekly returns of 17 equity market indices and 14 10-year government bonds. The equity indices refer to Austria (AT), Belgium (BE), Denmark (DK), Finland (FI), France (FR), Germany (DE), Greece (GR), Ireland (IE), Italy (IT), Japan (JP), the Netherlands (NL), Portugal (PT), Spain (ES), Sweden (SE), the United Kingdom (UK), the United States (US), as well as the Eurostoxx50 (EU). Data on 10-year government bonds are available for all the countries listed above, except Portugal. The superscripts "S" and "B" stand for stocks and bonds, respectively.

\begin{tabular}{|c|c|c|c|c|c|c|c|c|c|c|c|c|c|c|c|c|c|}
\hline & $\mathbf{D E}^{\mathrm{S}}$ & $\mathbf{R}^{\mathrm{S}}$ & $\mathrm{JK}^{\mathrm{S}}$ & $\mathrm{IT}^{\mathrm{S}}$ & $\mathrm{NL}^{\mathrm{S}}$ & $\mathbf{E S}^{\mathbf{S}}$ & $\mathrm{SE}^{\mathrm{S}}$ & $\mathbf{A T}^{\mathrm{S}}$ & $\mathrm{BE}^{\mathrm{S}}$ & $\mathrm{DK}^{\mathrm{S}}$ & $\mathrm{FI}^{\mathrm{S}}$ & $G^{S}$ & $\mathrm{IE}^{\mathrm{S}}$ & $\mathrm{PT}^{\mathrm{S}}$ & $\mathrm{JP}^{\mathrm{S}}$ & $\mathbf{U S}^{\mathbf{S}}$ & $\mathbf{E U}^{\mathbf{S}}$ \\
\hline $\mathbf{E}^{\mathrm{S}}$ & 0.15 & 0.73 & 0.62 & 0.52 & 0.77 & 066 & 0.62 & 0.61 & 0.69 & 0.53 & 0.52 & 0.32 & 0.54 & 0.50 & 0.23 & 0.50 & 0.88 \\
\hline & & 0.15 & 0.66 & 0.50 & 0.75 & 0.69 & 0.57 & 0.52 & 0.65 & 0.42 & 0.48 & 0.35 & 0.53 & 0.48 & 0.26 & 0.49 & 0.88 \\
\hline $\mathrm{S}$ & & & 0.13 & 0.39 & 0.71 & 0.61 & 0.55 & 0.53 & 0.57 & 0.43 & 0.48 & 0.32 & 0.63 & 0.42 & 0.29 & 0.51 & 0.73 \\
\hline & & & & 0.22 & 0.49 & 0.51 & 0.43 & 0.35 & 0.46 & 0.44 & 0.41 & 0.19 & 0.34 & 0.32 & 0.15 & 0.30 & 0.61 \\
\hline $\mathbf{N L}^{\mathbf{s}}$ & & & & & 0.15 & 0.67 & 0.62 & 0.56 & 0.71 & 0.53 & 0.54 & 0.32 & 0.57 & 0.53 & 8 & 0.59 & 0.87 \\
\hline $\mathbf{E S}^{\mathbf{S}}$ & & & & & & 0.18 & 0.65 & 0.51 & 0.60 & 0.45 & 0.45 & 0.33 & 0.54 & 0.48 & 0.28 & 0.48 & 0.77 \\
\hline $\mathrm{SE}^{\mathrm{S}}$ & & & & & & & 0.19 & 0.41 & 0.51 & 0.46 & 0.65 & 0.32 & 0.56 & 0.43 & 0.25 & 0.49 & 0.67 \\
\hline $\mathbf{A}$ & & & & & & & & 0.14 & 0.53 & 0.36 & 0.42 & 0.29 & 0.46 & 0.40 & 0.24 & 0.33 & 0.59 \\
\hline $\mathbf{B E}^{\mathrm{S}}$ & & & & & & & & & 0.13 & 0.49 & 0.48 & 0.31 & 0.52 & 0.48 & 0 & 0.44 & 0.74 \\
\hline $\mathbf{D K}^{\mathrm{S}}$ & & & & & & & & & & 0.12 & 0.47 & 0.26 & 0.42 & 0.40 & 0.15 & 0.30 & 0.52 \\
\hline & & & & & & & & & & & 0.24 & 0.29 & 0.50 & 0.32 & 0.20 & 0.41 & 0.55 \\
\hline CD & & & & & & & & & & & & 0.27 & 0.40 & 0.41 & 0 & 0.28 & 0.34 \\
\hline $\mathrm{IE}^{\mathrm{S}}$ & & & & & & & & & & & & & 0.15 & 0.43 & 0.28 & 0.50 & 0.57 \\
\hline PT & & & & & & & & & & & & & & 0.16 & 0.23 & 0.31 & 0.51 \\
\hline 10 & & & & & & & & & & & & & & & 0 & 0.28 & 0.29 \\
\hline US & & & & & & & & & & & & & & & & 0.12 & 0.58 \\
\hline $\mathbf{F u}$ & & & & & & & & & & & & & & & & & 0.16 \\
\hline $\mathbf{D E}^{\mathbf{B}}$ & 0.20 & 0.26 & 0.21 & 0.21 & 0.16 & 0.18 & 0.19 & 0.13 & 0.16 & 0.15 & 0.11 & 0.01 & 0.19 & 0.00 & 0.01 & 0.14 & 0.27 \\
\hline$F R^{B}$ & 0.22 & 0.39 & 0.25 & 0.31 & 0.20 & 0.29 & 0.19 & 0.15 & 0.24 & 0.25 & 0.18 & 0.04 & 0.23 & 0.04 & 0.01 & 0.12 & 0.33 \\
\hline & 0.16 & 0.25 & 0.38 & 0.19 & 0.18 & 0.19 & 0.14 & 0.13 & 0.13 & 0.19 & 0.14 & 0.07 & 0.23 & 0.05 & 0.03 & 0.13 & 0.25 \\
\hline & 0.29 & 0.35 & 0.24 & 0.49 & 0.25 & 0.31 & 0.29 & 0.21 & 0.27 & 0.31 & 0.27 & 0.07 & 0.23 & 0.13 & 0.09 & 0.17 & 0.36 \\
\hline $\mathbf{N L}^{\mathrm{B}}$ & 0.22 & 0.28 & 0.26 & 0.26 & 0.19 & 0.23 & 0.22 & 0. & 0.21 & 0.23 & 015 & 0.04 & 0.21 & O & 0 & 0.17 & 0.30 \\
\hline $\mathbf{E S}^{\mathbf{B}}$ & 0.32 & 0.37 & 0.32 & 0.30 & 0.27 & 0.44 & 0.35 & 0.23 & 0.28 & 0.33 & 0.23 & 0.09 & 0.27 & 0.15 & 0.07 & 0.19 & 0.38 \\
\hline SE & 0.24 & 0.24 & 0.22 & 0.28 & 0.22 & 0.33 & 0.43 & 0.17 & 0.21 & 0.24 & 0.24 & 0.11 & 0.22 & 0.14 & 0.06 & 0.12 & 0.28 \\
\hline $\mathbf{T}$ & 0.23 & 0.29 & 0.25 & 0.23 & 0.22 & 0.20 & 0.23 & 0.21 & 0.26 & 0.21 & 0.18 & 0.04 & 0.27 & 0.03 & 0.02 & 0.14 & 0.31 \\
\hline $\mathbf{B E}^{\mathrm{I}}$ & 0.20 & 0.27 & 0.25 & 0.27 & 0.20 & 0.23 & 0.21 & 0.13 & 0.23 & 0.23 & 0.20 & 0.00 & 0.21 & 0.02 & -0.01 & 0.12 & 0.28 \\
\hline $\mathbf{D} \mathbf{K}^{\mathbf{B}}$ & 0.24 & 0.31 & 0.24 & 0.29 & 0.21 & 0.30 & 0.25 & 0.17 & 0.29 & 0.40 & 0.25 & 0.02 & 0.23 & 0.10 & 0.03 & 0.08 & 0.31 \\
\hline & 0.18 & 0.19 & 0.23 & 0.19 & 0.17 & 0.23 & 0.33 & 0.18 & 0.18 & 0.25 & 0.32 & 0.12 & 0.24 & 0.15 & 0.08 & 0.11 & 0.21 \\
\hline & 0.27 & 0.32 & 0.29 & 0.28 & 0.25 & 0.29 & 0.23 & 0.21 & 0.27 & 0.35 & 0.18 & 0.06 & 0.32 & 0.11 & 0.11 & 0.22 & 0.32 \\
\hline & -0.10 & -0.10 & -0.09 & -0.13 & -0.14 & -0.17 & -0.09 & -0.03 & -0.10 & -0.07 & -0.05 & -0.07 & -0.05 & -0.12 & -0.20 & -0.06 & -0.14 \\
\hline $\mathbf{U S}$ & -0.01 & 0.05 & 0.03 & 0.02 & 0.01 & 0.02 & 0.03 & 0.00 & 0.03 & 0.09 & 0.03 & -0.02 & 0.06 & -0.04 & 0.03 & 0.23 & 0.07 \\
\hline
\end{tabular}


Table 2c - Continued

\begin{tabular}{|c|c|c|c|c|c|c|c|c|c|c|c|c|c|c|}
\hline & $\mathbf{D E}^{\mathrm{B}}$ & $\mathrm{FR}^{\mathrm{B}}$ & $\mathbf{U K}^{\mathbf{B}}$ & $\mathbf{I T}^{\mathrm{B}}$ & $\mathbf{N L}^{\mathrm{B}}$ & $\mathbf{E S}^{\mathrm{B}}$ & $\mathbf{S E}^{\mathrm{B}}$ & $\mathbf{A T}^{\mathbf{B}}$ & $\mathrm{BE}^{\mathrm{B}}$ & $\mathbf{D K}^{\mathrm{B}}$ & $\mathbf{F I}^{\mathrm{B}}$ & $\mathbf{I E}^{\mathrm{B}}$ & $\mathbf{J} \mathbf{P}^{\mathbf{B}}$ & $\mathbf{U S}^{\mathbf{B}}$ \\
\hline $\mathbf{D E}^{\mathbf{B}}$ & 0.06 & 0.81 & 0.67 & 0.52 & 0.93 & 0.53 & 0.51 & 0.85 & 0.81 & 0.66 & 0.42 & 0.63 & 0.19 & 0.54 \\
\hline$F^{B}{ }^{B}$ & & 0.08 & 0.66 & 0.62 & 0.82 & 0.64 & 0.55 & 0.75 & 0.79 & 0.73 & 0.45 & 0.66 & 0.16 & 0.45 \\
\hline $\mathbf{U K}^{\mathbf{B}}$ & & & 0.10 & 0.42 & 0.70 & 0.51 & 0.43 & 0.58 & 0.66 & 0.51 & 0.41 & 0.64 & 0.13 & 0.46 \\
\hline $\mathbf{I T}^{\mathbf{B}}$ & & & & 0.14 & 0.54 & 0.68 & 0.53 & 0.51 & 0.51 & 0.54 & 0.37 & 0.51 & 0.03 & 0.26 \\
\hline $\mathbf{N L}^{\mathrm{B}}$ & & & & & 0.06 & 0.54 & 0.54 & 0.85 & 0.82 & 0.67 & 0.47 & 0.65 & 0.20 & 0.53 \\
\hline $\mathbf{E S}^{\mathbf{B}}$ & & & & & & 0.12 & 0.53 & 0.49 & 0.54 & 0.60 & 0.44 & 0.68 & 0.04 & 0.28 \\
\hline $\mathrm{SE}^{\mathrm{B}}$ & & & & & & & 0.13 & 0.51 & 0.55 & 0.58 & 0.64 & 0.46 & 0.04 & 0.26 \\
\hline $\mathbf{A} \mathbf{T}^{\mathbf{B}}$ & & & & & & & & 0.06 & 0.78 & 0.69 & 0.47 & 0.61 & 0.20 & 0.40 \\
\hline $\mathbf{B} \mathbf{E}^{\mathbf{B}}$ & & & & & & & & & $\mathbf{0 . 0 7}$ & 0.69 & 0.45 & 0.63 & 0.17 & 0.42 \\
\hline $\mathbf{D K}^{\mathbf{B}}$ & & & & & & & & & & 0.09 & 0.50 & 0.66 & 0.15 & 0.28 \\
\hline $\mathrm{FI}^{\mathrm{B}}$ & & & & & & & & & & & 0.12 & 0.43 & 0.13 & 0.22 \\
\hline $\mathbf{I E}^{\mathbf{B}}$ & & & & & & & & & & & & 0.09 & 0.11 & 0.41 \\
\hline $\mathbf{J P}^{\mathbf{B}}$ & & & & & & & & & & & & & 0.06 & 0.17 \\
\hline $\mathbf{U} \mathbf{S}^{\mathbf{B}}$ & & & & & & & & & & & & & & 0.09 \\
\hline
\end{tabular}


Table 2d: Return unconditional correlations and standard deviations for the period January 1999 - October 2005

This table reports return unconditional correlations as well as standard deviations (in bold) over the sample period January 2nd, 1999 -October 21st, 2005. Correlations and standard deviations are computed on weekly returns of 17 equity market indices and 14 10-year government bonds. The equity indices refer to Austria (AT), Belgium (BE), Denmark (DK), Finland (FI), France (FR), Germany (DE), Greece (GR), Ireland (IE), Italy (IT), Japan (JP), the Netherlands (NL), Portugal (PT), Spain (ES), Sweden (SE), the United Kingdom (UK), the United States (US), as well as the Eurostoxx50 (EU). Data on 10-year government bonds are available for all the countries listed above, except Belgium, Finland and Portugal. The superscripts "S" and "B" stand for stocks and bonds, respectively.

\begin{tabular}{|c|c|c|c|c|c|c|c|c|c|c|c|c|c|c|c|c|c|}
\hline & $\mathrm{DE}^{\mathrm{S}}$ & $\mathbf{F R}^{\mathrm{S}}$ & $\mathbf{U K}^{\mathbf{S}}$ & $\mathbf{I T}^{\mathbf{S}}$ & $\mathrm{NL}^{\mathrm{S}}$ & $\mathbf{E S}^{\mathbf{S}}$ & $\mathbf{S E}^{\mathbf{S}}$ & $\mathbf{A T}^{\mathbf{S}}$ & $\mathbf{B E}^{\mathrm{S}}$ & $\mathrm{DK}^{\mathrm{S}}$ & $\mathrm{FI}^{\mathrm{S}}$ & $G^{S}$ & $\mathrm{IE}^{\mathrm{S}}$ & $\mathbf{P T}^{\mathrm{S}}$ & $\mathrm{JP}^{\mathrm{S}}$ & $\mathbf{U S}^{\mathbf{S}}$ & $\mathbf{E U}^{\mathbf{S}}$ \\
\hline & 0.22 & 0.90 & 0.80 & 0.81 & 0.87 & 0.81 & 0.81 & 0.38 & 0.67 & 0.61 & 0.61 & 0.41 & 0.62 & 0.48 & 0.42 & 0.73 & 0.93 \\
\hline S & & 0.19 & 0.84 & 0.83 & 0.89 & 0.81 & 0.82 & 0.33 & 0.70 & 0.62 & 0.66 & 0.40 & 0.59 & 0.54 & 0.41 & 0.73 & 0.96 \\
\hline $\mathbf{U K}^{\mathrm{S}}$ & & & 0.15 & 0.76 & 0.84 & 0.75 & 0.74 & 0.40 & 0.68 & 0.61 & 0.59 & 0.33 & 0.58 & 0.45 & 0.39 & 0.74 & 0.86 \\
\hline IT $^{\mathrm{S}}$ & & & & 0.19 & 0.80 & 0.79 & 0.72 & 0.36 & 0.61 & 0.61 & 0.53 & 0.38 & 0.60 & 0.50 & 0.39 & 0.63 & 0.83 \\
\hline $\mathbf{N L}^{\mathrm{S}}$ & & & & & 0.21 & 0.79 & 0.73 & 0.37 & 0.77 & 0.63 & 0.56 & 0.38 & 0.60 & 0.41 & 0.37 & 0.68 & 0.93 \\
\hline $\mathbf{E S}^{\mathbf{S}}$ & & & & & & 0.17 & 0.74 & 0.39 & 0.64 & 0.57 & 0.58 & 0.38 & 0.54 & 0.56 & 0.37 & 0.64 & 0.86 \\
\hline $\mathbf{S E}^{\mathbf{S}}$ & & & & & & & 0.20 & 0.29 & 0.52 & 0.62 & 0.72 & 0.36 & 0.49 & 0.52 & 0.43 & 0.70 & 0.81 \\
\hline $\mathbf{A} \mathbf{T}^{\mathrm{S}}$ & & & & & & & & 0.12 & 0.36 & 0.34 & 0.14 & 0.24 & 0.32 & 0.23 & 0.25 & 0.29 & 0.33 \\
\hline $\mathbf{B E}^{\mathrm{S}}$ & & & & & & & & & 0.17 & 0.50 & 0.31 & 0.33 & 0.52 & 0.35 & 0.24 & 0.53 & 0.71 \\
\hline $\mathbf{D K}^{\mathrm{S}}$ & & & & & & & & & & 0.16 & 0.42 & 0.31 & 0.52 & 0.38 & 0.36 & 0.52 & 0.61 \\
\hline $\mathrm{FI}^{\mathrm{S}}$ & & & & & & & & & & & 0.34 & 0.25 & 0.32 & 0.37 & 0.36 & 0.60 & 0.70 \\
\hline $\mathbf{G R}^{\mathrm{S}}$ & & & & & & & & & & & & 0.26 & 0.28 & 0.29 & 0.21 & 0.30 & 0.38 \\
\hline IE & & & & & & & & & & & & & 0.17 & 0.35 & 0.34 & 0.50 & 0.60 \\
\hline $\mathbf{P T}^{\mathrm{S}}$ & & & & & & & & & & & & & & 0.11 & 0.19 & 0.31 & 0.50 \\
\hline $\mathbf{J P}$ & & & & & & & & & & & & & & & 0.20 & 0.34 & 0.41 \\
\hline $\mathbf{U S}^{\mathbf{S}}$ & & & & & & & & & & & & & & & & 0.18 & 0.75 \\
\hline $\mathbf{E} \mathbf{U}^{\mathrm{s}}$ & & & & & & & & & & & & & & & & & 0.21 \\
\hline $\mathbf{D E}^{\mathrm{B}}$ & -0.25 & -0.22 & -0.18 & -0.16 & -0.26 & -0.17 & -0.24 & -0.06 & -0.10 & -0.09 & -0.18 & -0.13 & -0.19 & -0.07 & -0.15 & -0.12 & -0.23 \\
\hline $\mathrm{FR}^{\mathrm{B}}$ & -0.25 & -0.23 & -0.17 & -0.15 & -0.26 & -0.15 & -0.23 & -0.03 & -0.10 & -0.08 & -0.17 & -0.13 & -0.18 & -0.07 & -0.14 & -0.12 & -0.22 \\
\hline 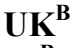 & -0.19 & -0.17 & -0.13 & -0.14 & -0.21 & -0.10 & -0 & 8 & -0.07 & -0.09 & -0.10 & -0.11 & -0.18 & -0.02 & -0.15 & -0.06 & -0.16 \\
\hline & -0.23 & -0.21 & -0.15 & -0.13 & -0.24 & -0.13 & -0.22 & -0.03 & -0.09 & -0.06 & -0.15 & -0.11 & -0.17 & -0.05 & -0.12 & -0.11 & -0.21 \\
\hline & -0.24 & -0.22 & -0.17 & -0.16 & -0.26 & -0.16 & -0.22 & -0.05 & -0.10 & -0.07 & -0.17 & -0.13 & -0.18 & -0.07 & -0.15 & -0.12 & -0.22 \\
\hline $\mathbf{E S}^{\mathbf{B}}$ & -0.25 & -0.23 & -0.17 & -0.15 & -0.27 & -0.15 & -0.23 & -0.03 & -0.13 & -0.08 & -0.17 & -0.14 & -0.20 & -0.06 & -0.14 & -0.13 & -0.23 \\
\hline $\mathbf{S E}^{\mathbf{B}}$ & -0.18 & -0.15 & -0.13 & -0.10 & -0.21 & -0.13 & -0.10 & -0.02 & -0.08 & -0.04 & -0.13 & -0.07 & -0.13 & -0.02 & -0.11 & -0.08 & -0.16 \\
\hline $\mathbf{A} \mathbf{T}^{\mathbf{B}}$ & -0.24 & -0.22 & -0.17 & -0.15 & -0.27 & -0.15 & -0.22 & -0.06 & -0.11 & -0.08 & -0.17 & -0.15 & -0.18 & -0.06 & -0.14 & -0.12 & -0.22 \\
\hline $\mathbf{B E}^{\mathbf{B}}$ & -0.24 & -0.22 & -0.16 & -0.14 & -0.26 & -0.14 & -0.22 & -0.01 & -0.12 & -0.07 & -0.16 & -0.13 & -0.18 & -0.04 & -0.12 & -0.13 & -0.22 \\
\hline $\mathbf{D} \mathbf{K}^{\mathbf{B}}$ & -0.17 & -0.13 & -0.12 & -0.11 & -0.18 & -0.08 & -0.18 & -0.06 & -0.04 & -0.08 & -0.14 & -0.07 & -0.13 & -0.01 & -0.12 & -0.09 & -0.13 \\
\hline $\mathrm{FI}^{\mathrm{B}}$ & -0.23 & -0.21 & -0.17 & -0.14 & -0.25 & -0.15 & -0.21 & -0.05 & -0.10 & -0.06 & -0.17 & -0.13 & -0.17 & -0.06 & -0.13 & -0.11 & -0.21 \\
\hline & -0.24 & -0.23 & -0.17 & -0.15 & -0.25 & -0.17 & -0.22 & -0.03 & -0.12 & -0.06 & -0.17 & -0.13 & -0.18 & -0.07 & -0.14 & -0.13 & -0.22 \\
\hline & -0.11 & -0.03 & -0.06 & -0.09 & -0.09 & -0.04 & -0.09 & -0.07 & -0.04 & -0.07 & -0.01 & -0.06 & -0.04 & -0.02 & -0.22 & -0.04 & -0.05 \\
\hline $\mathbf{U} \mathbf{S}^{\mathbf{B}}$ & -0.36 & -0.33 & -0.28 & -0.27 & -0.34 & -0.28 & -0.35 & -0.10 & -0.18 & -0.15 & -0.23 & -0.20 & -0.22 & -0.19 & -0.16 & -0.18 & -0.33 \\
\hline
\end{tabular}


Table 2d - Continued

\begin{tabular}{|c|c|c|c|c|c|c|c|c|c|c|c|c|c|c|}
\hline & $\mathbf{D E}^{\mathrm{B}}$ & $\mathbf{F R}^{\mathrm{B}}$ & $\mathbf{U K}^{\mathrm{B}}$ & $\mathrm{IT}^{\mathrm{B}}$ & $\mathbf{N L}^{\mathrm{B}}$ & $\mathbf{E S}^{\mathbf{B}}$ & $\mathbf{S E}^{\mathbf{B}}$ & $\mathbf{A T}^{\mathbf{B}}$ & $\mathbf{B E}^{\mathrm{B}}$ & $\mathbf{D K}^{\mathrm{B}}$ & $\mathbf{F I}^{\mathrm{B}}$ & $\mathrm{IE}^{\mathrm{B}}$ & $\mathbf{J} \mathbf{P}^{\mathbf{B}}$ & $\mathbf{U S}^{\mathrm{B}}$ \\
\hline $\mathbf{D E}^{\mathbf{B}}$ & 0.06 & 0.98 & 0.85 & 0.97 & 0.98 & 0.98 & 0.89 & 0.98 & 0.97 & 0.88 & 0.98 & 0.94 & 0.19 & 0.74 \\
\hline$F^{B}$ & & 0.07 & 0.84 & 0.97 & 0.98 & 0.98 & 0.88 & 0.97 & 0.97 & 0.86 & 0.97 & 0.94 & 0.19 & 0.74 \\
\hline $\mathbf{U K}^{\mathrm{B}}$ & & & 0.07 & 0.83 & 0.84 & 0.83 & 0.79 & 0.84 & 0.83 & 0.77 & 0.83 & 0.79 & 0.15 & 0.68 \\
\hline $\mathbf{I T}^{\mathrm{B}}$ & & & & 0.06 & 0.96 & 0.98 & 0.86 & 0.97 & 0.97 & 0.87 & 0.97 & 0.94 & 0.17 & 0.72 \\
\hline $\mathrm{NL}^{\mathrm{B}}$ & & & & & 0.07 & 0.97 & 0.89 & 0.97 & 0.97 & 0.87 & 0.97 & 0.94 & 0.18 & 0.72 \\
\hline $\mathbf{E S}^{\mathbf{B}}$ & & & & & & 0.06 & 0.87 & 0.97 & 0.98 & 0.86 & 0.97 & 0.94 & 0.17 & 0.73 \\
\hline $\mathbf{S E}^{\mathbf{B}}$ & & & & & & & 0.07 & 0.88 & 0.87 & 0.85 & 0.88 & 0.85 & 0.19 & 0.65 \\
\hline $\mathbf{A T}^{\mathbf{B}}$ & & & & & & & & 0.06 & 0.98 & 0.88 & 0.97 & 0.94 & 0.20 & 0.73 \\
\hline $\mathbf{B E}^{\mathbf{B}}$ & & & & & & & & & 0.06 & 0.86 & 0.97 & 0.94 & 0.17 & 0.72 \\
\hline $\mathbf{D K}^{\mathrm{B}}$ & & & & & & & & & & 0.06 & 0.89 & 0.83 & 0.21 & 0.63 \\
\hline $\mathrm{FI}^{\mathrm{B}}$ & & & & & & & & & & & 0.07 & 0.93 & 0.17 & 0.73 \\
\hline $\mathrm{IE}^{\mathrm{B}}$ & & & & & & & & & & & & 0.07 & 0.19 & 0.70 \\
\hline $\mathbf{J P}^{\mathbf{B}}$ & & & & & & & & & & & & & 0.05 & 0.17 \\
\hline $\mathbf{U S}^{\mathbf{B}}$ & & & & & & & & & & & & & & 0.09 \\
\hline
\end{tabular}




\section{Table 3: Univariate GARCH models}

This table reports, for each asset, the selected univariate GARCH specifications and the associated parameter estimates. We choose among the following three univariate GARCH processes:

$$
\begin{aligned}
G A R C H & : h_{i, t}=\alpha_{0}+\alpha_{1} r_{i, t-1}^{2}+\alpha_{2} h_{i, t-1}, \\
E G A R C H & : \ln \left(h_{i, t}\right)=\alpha_{0}+\alpha_{1}\left(\left|v_{i, t-1}\right|-E\left|v_{i, t-1}\right|\right)+\gamma v_{i, t-1}+\alpha_{2} \ln \left(h_{i, t-1}\right), \\
G J R-G A R C H & : h_{i, t}=\alpha_{0}+\alpha_{1} r_{i, t-1}^{2}+\gamma I\left(r_{i, t-1}<0\right) r_{i, t-1}^{2}+\alpha_{2} h_{i, t-1} .
\end{aligned}
$$

We use weekly returns on 16 equity market indices and 12 10-year government bonds. The equity indices refer to Austria (AT), Belgium (BE), Denmark (DK), Finland (FI), France (FR), Germany (DE), Ireland (IE), Italy (IT), Japan (JP), the Netherlands (NL), Portugal (PT), Spain (ES), Sweden (SE), the United Kingdom (UK), the United States (US), as well as the Eurostoxx50 (EU). Data on 10-year government bonds are available for all the countries listed above, except Belgium, Finland and Portugal. The sample covers the period from January 9th, 1987 to October 21st, 2005. The superscripts "S" and "B" stand for

\begin{tabular}{|c|c|c|c|c|c|}
\hline Asset & Selected Model & $\alpha_{0}$ & $\alpha_{1}$ & $\gamma$ & $\alpha_{2}$ \\
\hline$D^{S} E^{S}$ & EGARCH & -0.69 & 0.25 & -0.13 & 0.93 \\
\hline $\mathbf{F R}^{\mathrm{S}}$ & GJR - GARCH & 0.00 & 0.03 & 0.14 & 0.85 \\
\hline $\mathbf{U K}^{\mathbf{S}}$ & GJR - GARCH & 0.00 & 0.02 & 0.19 & 0.87 \\
\hline$I T^{S}$ & EGARCH & -0.44 & 0.25 & -0.05 & 0.97 \\
\hline $\mathbf{N L}^{\mathrm{S}}$ & GJR - GARCH & 0.00 & 0.10 & 0.14 & 0.81 \\
\hline $\mathbf{E S}^{\mathbf{S}}$ & EGARCH & -0.58 & 0.27 & -0.10 & 0.95 \\
\hline $\mathbf{S E}^{\mathrm{S}}$ & EGARCH & -0.77 & 0.27 & -0.12 & 0.92 \\
\hline $\mathbf{A T} \mathbf{T}^{\mathbf{S}}$ & GARCH & 0.00 & 0.13 & & 0.82 \\
\hline $\mathrm{BE}^{\mathrm{S}}$ & GJR - GARCH & 0.00 & 0.10 & 0.25 & 0.70 \\
\hline $\mathbf{D K}^{\mathrm{S}}$ & EGARCH & -0.86 & 0.21 & -0.07 & 0.91 \\
\hline $\mathrm{FI}^{\mathrm{S}}$ & GARCH & 0.00 & 0.11 & & 0.89 \\
\hline $\mathbf{I E}^{\mathrm{S}}$ & EGARCH & -0.75 & 0.27 & -0.09 & 0.93 \\
\hline $\mathbf{P T}^{\mathrm{S}}$ & EGARCH & -0.75 & 0.49 & -0.05 & 0.95 \\
\hline $\mathbf{J P}^{\mathbf{S}}$ & EGARCH & -0.58 & 0.11 & -0.11 & 0.93 \\
\hline $\mathbf{U S} \mathbf{S}^{\mathbf{S}}$ & EGARCH & -0.50 & 0.20 & -0.12 & 0.96 \\
\hline $\mathbf{E} \mathbf{U}^{\mathrm{S}}$ & EGARCH & -0.59 & 0.26 & -0.13 & 0.95 \\
\hline$D_{E^{B}}$ & GARCH & 0.00 & 0.10 & & 0.84 \\
\hline$F R^{B}$ & GJR - GARCH & 0.00 & 0.04 & 0.11 & 0.84 \\
\hline $\mathbf{U K}^{\mathbf{B}}$ & GARCH & 0.00 & 0.11 & & 0.85 \\
\hline $\mathrm{IT}^{\mathrm{B}}$ & EGARCH & -0.64 & 0.34 & -0.04 & 0.95 \\
\hline $\mathbf{N L}^{\mathrm{B}}$ & GARCH & 0.00 & 0.12 & & 0.78 \\
\hline $\mathbf{E S}^{\mathbf{B}}$ & EGARCH & $-2.27^{\mathrm{ns}}$ & 0.32 & -0.12 & 0.75 \\
\hline $\mathbf{S E}^{\mathbf{B}}$ & GARCH & 0.00 & 0.14 & & 0.84 \\
\hline$A T^{B}$ & GARCH & 0.00 & 0.12 & & 0.83 \\
\hline $\mathbf{D K}^{\mathrm{B}}$ & GARCH & 0.00 & 0.11 & & 0.86 \\
\hline $\mathbf{I E}^{\mathrm{B}}$ & GARCH & 0.00 & 0.15 & & 0.81 \\
\hline $\mathbf{J P}^{\mathbf{B}}$ & GARCH & 0.00 & 0.16 & & 0.82 \\
\hline $\mathbf{U S}^{\mathbf{B}}$ & GJR - GARCH & 0.00 & 0.04 & 0.11 & 0.72 \\
\hline
\end{tabular}
stocks and bonds, respectively. All parameters are significant at any conventional level, except those marked with the superscript "ns". 
Table 4: Multivariate DCC GARCH model

This table reports estimate parameter estimates for the DCC GARCH model

$\mathbf{Q}_{t}=\overline{\mathbf{Q}} \odot\left(\iota \iota^{\prime}-\mathbf{a a}^{\prime}-\mathbf{b b}^{\prime}\right)-\overline{\mathbf{H}} \odot \mathbf{g g}^{\prime}+\mathbf{a a}^{\prime} \odot \varepsilon_{t-1} \varepsilon_{t-1}^{\prime}+\mathbf{b b}^{\prime} \odot \mathbf{Q}_{t-1}+\mathbf{g g}^{\prime} \odot \boldsymbol{\eta}_{t-1} \boldsymbol{\eta}_{t-1}^{\prime}$

All parameters are significant at any conventional level, except those marked with the superscript "ns". The log likelihood function is equal to -2330.90.

\begin{tabular}{|c|c|c|c|}
\hline \multirow[t]{2}{*}{ Asset } & \multicolumn{3}{|c|}{ Parameters } \\
\hline & $\mathrm{a}$ & b & g \\
\hline $\mathbf{D E}^{\mathrm{S}}$ & 0.072 & 0.993 & 0.083 \\
\hline $\mathbf{F R}^{\mathrm{S}}$ & 0.089 & 0.993 & 0.102 \\
\hline $\mathbf{U K}^{\mathbf{S}}$ & 0.047 & 0.998 & 0.060 \\
\hline $\mathbf{I T}^{\mathrm{S}}$ & 0.069 & 0.994 & 0.087 \\
\hline $\mathrm{NL}^{\mathrm{S}}$ & 0.061 & 0.994 & 0.087 \\
\hline $\mathbf{E S}^{\mathbf{S}}$ & 0.053 & 0.995 & 0.091 \\
\hline $\mathbf{S E}^{\mathbf{S}}$ & 0.065 & 0.993 & 0.073 \\
\hline $\mathbf{A} \mathbf{T}^{\mathrm{S}}$ & 0.053 & 0.984 & $0.070^{\mathrm{ns}}$ \\
\hline $\mathbf{B E}^{\mathrm{S}}$ & 0.064 & 0.991 & 0.096 \\
\hline DK $^{\mathrm{s}}$ & 0.066 & 0.994 & 0.024 \\
\hline $\mathrm{FI}^{\mathrm{S}}$ & 0.057 & 0.996 & 0.051 \\
\hline $\mathrm{IE}^{\mathrm{S}}$ & 0.041 & 0.995 & 0.045 \\
\hline $\mathbf{P T}^{\mathrm{S}}$ & 0.029 & 0.997 & 0.069 \\
\hline $\mathbf{J P}^{\mathbf{S}}$ & 0.049 & 0.995 & 0.009 \\
\hline $\mathbf{U S}^{\mathbf{S}}$ & 0.048 & 0.996 & 0.053 \\
\hline $\mathbf{E U}^{\mathrm{S}}$ & 0.070 & 0.994 & 0.089 \\
\hline$D^{B}$ & 0.133 & 0.990 & 0.026 \\
\hline $\mathbf{F R}^{\mathbf{B}}$ & 0.142 & 0.989 & 0.034 \\
\hline $\mathbf{U K}^{\mathrm{B}}$ & 0.129 & 0.990 & 0.021 \\
\hline $\mathbf{I T}^{\mathbf{B}}$ & 0.122 & 0.991 & 0.089 \\
\hline $\mathrm{NL}^{\mathrm{B}}$ & 0.138 & 0.990 & 0.018 \\
\hline $\mathbf{E S}^{\mathbf{B}}$ & 0.113 & 0.990 & 0.096 \\
\hline $\mathrm{SE}^{\mathrm{B}}$ & 0.118 & 0.993 & 0.024 \\
\hline $\mathbf{A T}^{\mathbf{B}}$ & 0.131 & 0.990 & 0.024 \\
\hline $\mathrm{DK}^{\mathrm{B}}$ & 0.125 & 0.990 & 0.038 \\
\hline$I^{B}$ & 0.134 & 0.989 & 0.024 \\
\hline $\mathbf{J P}^{\mathbf{B}}$ & 0.060 & 0.985 & -0.018 \\
\hline $\mathbf{U S}^{\mathbf{B}}$ & 0.102 & 0.993 & 0.014 \\
\hline
\end{tabular}


Table 5a: Average probabilities of co-movements for returns on equity market indices - The euro area economies

This table reports for each country pair average probabilities of comovements over two periods. Average probabilities are computed across upper, lower and all the quantile ranges, for $\theta \in(0.05,0.5), \theta \in(0.55,0.95)$, and $\theta \in(0.05,0.95)$, respectively. The first subsample covers the pre-monetary union period (January 1992 to December 1998), while the second sub-sample covers the monetary union period (January 1999 to October 2005). The equity indices refer to Austria (AT), Belgium (BE), Denmark (DK), Finland (FI), France (FR), Germany (DE), Greece (GR), Ireland (IE), Italy (IT), the Netherlands (NL), Portugal (PT), Spain (ES), Sweden (SE) and the United Kingdom (UK).

\begin{tabular}{|c|c|c|c|c|c|c|c|c|c|c|c|c|c|c|}
\hline \multicolumn{15}{|c|}{$\theta \in[0.05,0.5]$} \\
\hline Period & & FR & UK & IT & NL & ES & SE & AT & BE & DK & FI & GR & IE & PT \\
\hline \multirow{13}{*}{$<1999$} & DE & 0.54 & 0.56 & 0.50 & 0.62 & 0.55 & 0.53 & 0.53 & 0.52 & 0.52 & 0.48 & 0.35 & 0.51 & 0.44 \\
\hline & FR & & 0.60 & 0.50 & 0.63 & 0.56 & 0.51 & 0.49 & 0.50 & 0.47 & 0.48 & 0.38 & 0.50 & 0.43 \\
\hline & UK & & & 0.47 & 0.63 & 0.54 & 0.55 & 0.52 & 0.51 & 0.48 & 0.54 & 0.37 & 0.61 & 0.46 \\
\hline & IT & & & & 0.50 & 0.49 & 0.48 & 0.44 & 0.46 & 0.48 & 0.45 & 0.36 & 0.46 & 0.37 \\
\hline & NL & & & & & 0.57 & 0.55 & 0.53 & 0.57 & 0.53 & 0.53 & 0.36 & 0.57 & 0.47 \\
\hline & ES & & & & & & 0.57 & 0.49 & 0.47 & 0.50 & 0.48 & 0.36 & 0.51 & 0.43 \\
\hline & SE & & & & & & & 0.49 & 0.49 & 0.55 & 0.62 & 0.39 & 0.54 & 0.44 \\
\hline & $\mathbf{A T}$ & & & & & & & & 0.50 & 0.47 & 0.51 & 0.35 & 0.49 & 0.41 \\
\hline & BE & & & & & & & & & 0.48 & 0.48 & 0.33 & 0.52 & 0.44 \\
\hline & DK & & & & & & & & & & 0.52 & 0.31 & 0.47 & 0.41 \\
\hline & FI & & & & & & & & & & & 0.36 & 0.49 & 0.44 \\
\hline & GR & & & & & & & & & & & & 0.39 & 0.37 \\
\hline & IE & & & & & & & & & & & & & 0.45 \\
\hline \multirow{13}{*}{$>1999$} & DE & 0.78 & 0.67 & 0.68 & 0.76 & 0.71 & 0.67 & 0.49 & 0.59 & 0.57 & 0.58 & 0.49 & 0.54 & 0.48 \\
\hline & FR & & 0.73 & 0.70 & 0.79 & 0.71 & 0.69 & 0.48 & 0.60 & 0.57 & 0.62 & 0.51 & 0.54 & 0.49 \\
\hline & UK & & & 0.68 & 0.73 & 0.66 & 0.62 & 0.49 & 0.59 & 0.53 & 0.57 & 0.47 & 0.53 & 0.49 \\
\hline & IT & & & & 0.69 & 0.67 & 0.60 & 0.48 & 0.59 & 0.54 & 0.54 & 0.47 & 0.52 & 0.48 \\
\hline & NL & & & & & 0.70 & 0.63 & 0.48 & 0.62 & 0.57 & 0.58 & 0.47 & 0.53 & 0.47 \\
\hline & ES & & & & & & 0.64 & 0.50 & 0.55 & 0.55 & 0.57 & 0.47 & 0.53 & 0.54 \\
\hline & SE & & & & & & & 0.45 & 0.53 & 0.58 & 0.62 & 0.48 & 0.48 & 0.49 \\
\hline & AT & & & & & & & & 0.45 & 0.45 & 0.38 & 0.41 & 0.42 & 0.41 \\
\hline & BE & & & & & & & & & 0.50 & 0.43 & 0.50 & 0.53 & 0.45 \\
\hline & DK & & & & & & & & & & 0.48 & 0.45 & 0.48 & 0.47 \\
\hline & FI & & & & & & & & & & & 0.43 & 0.42 & 0.45 \\
\hline & GR & & & & & & & & & & & & 0.43 & 0.39 \\
\hline & IE & & & & & & & & & & & & & 0.43 \\
\hline
\end{tabular}


Table 5a - Continued

\begin{tabular}{|c|c|c|c|c|c|c|c|c|c|c|c|c|c|c|}
\hline \multicolumn{15}{|c|}{$\theta \in[0.55,0.95]$} \\
\hline Period & & FR & UK & IT & NL & ES & SE & AT & BE & DK & FI & GR & IE & PT \\
\hline \multirow{13}{*}{$<1999$} & DE & 0.56 & 0.50 & 0.42 & 0.58 & 0.46 & 0.51 & 0.49 & 0.57 & 0.47 & 0.46 & 0.33 & 0.45 & 0.41 \\
\hline & FR & & 0.55 & 0.44 & 0.59 & 0.53 & 0.51 & 0.45 & 0.52 & 0.41 & 0.43 & 0.34 & 0.43 & 0.39 \\
\hline & UK & & & 0.40 & 0.55 & 0.50 & 0.52 & 0.46 & 0.48 & 0.46 & 0.46 & 0.34 & 0.55 & 0.37 \\
\hline & IT & & & & 0.40 & 0.45 & 0.43 & 0.36 & 0.42 & 0.40 & 0.42 & 0.29 & 0.38 & 0.35 \\
\hline & NL & & & & & 0.54 & 0.56 & 0.49 & 0.54 & 0.46 & 0.47 & 0.33 & 0.49 & 0.41 \\
\hline & ES & & & & & & 0.52 & 0.41 & 0.45 & 0.43 & 0.45 & 0.31 & 0.44 & 0.39 \\
\hline & SE & & & & & & & 0.39 & 0.46 & 0.42 & 0.58 & 0.31 & 0.46 & 0.38 \\
\hline & AT & & & & & & & & 0.45 & 0.36 & 0.36 & 0.33 & 0.39 & 0.38 \\
\hline & BE & & & & & & & & & 0.46 & 0.45 & 0.33 & 0.44 & 0.43 \\
\hline & DK & & & & & & & & & & 0.41 & 0.33 & 0.44 & 0.40 \\
\hline & FI & & & & & & & & & & & 0.28 & 0.45 & 0.35 \\
\hline & GR & & & & & & & & & & & & 0.36 & 0.36 \\
\hline & IE & & & & & & & & & & & & & 0.40 \\
\hline \multirow{13}{*}{$>1999$} & DE & 0.75 & 0.62 & 0.64 & 0.68 & 0.61 & 0.66 & 0.41 & 0.56 & 0.46 & 0.57 & 0.44 & 0.54 & 0.43 \\
\hline & FR & & 0.69 & 0.65 & 0.74 & 0.67 & 0.67 & 0.39 & 0.56 & 0.48 & 0.61 & 0.41 & 0.51 & 0.44 \\
\hline & UK & & & 0.55 & 0.62 & 0.58 & 0.59 & 0.37 & 0.51 & 0.46 & 0.57 & 0.36 & 0.49 & 0.40 \\
\hline & IT & & & & 0.60 & 0.61 & 0.58 & 0.36 & 0.51 & 0.45 & 0.49 & 0.38 & 0.47 & 0.43 \\
\hline & NL & & & & & 0.60 & 0.58 & 0.40 & 0.57 & 0.50 & 0.51 & 0.42 & 0.52 & 0.40 \\
\hline & ES & & & & & & 0.59 & 0.37 & 0.56 & 0.44 & 0.53 & 0.35 & 0.42 & 0.45 \\
\hline & SE & & & & & & & 0.34 & 0.46 & 0.46 & 0.61 & 0.39 & 0.47 & 0.40 \\
\hline & $\mathbf{A T}$ & & & & & & & & 0.43 & 0.34 & 0.30 & 0.36 & 0.36 & 0.35 \\
\hline & BE & & & & & & & & & 0.43 & 0.43 & 0.35 & 0.46 & 0.41 \\
\hline & DK & & & & & & & & & & 0.40 & 0.36 & 0.41 & 0.34 \\
\hline & FI & & & & & & & & & & & 0.34 & 0.42 & 0.41 \\
\hline & GR & & & & & & & & & & & & 0.39 & 0.35 \\
\hline & IE & & & & & & & & & & & & & 0.39 \\
\hline
\end{tabular}


Table 5a - Continued

\begin{tabular}{|c|c|c|c|c|c|c|c|c|c|c|c|c|c|c|}
\hline \multicolumn{15}{|c|}{$\theta \in[0.05,0.95]$} \\
\hline Period & & FR & UK & IT & NL & ES & SE & AT & $\mathbf{B E}$ & DK & FI & GR & IE & PT \\
\hline \multirow{13}{*}{$<1999$} & $\overline{D E}$ & 0.55 & 0.53 & 0.46 & 0.60 & 0.51 & 0.52 & 0.51 & 0.54 & 0.50 & 0.47 & 0.34 & 0.48 & 0.43 \\
\hline & FR & & 0.58 & 0.47 & 0.61 & 0.54 & 0.51 & 0.47 & 0.51 & 0.44 & 0.46 & 0.36 & 0.47 & 0.41 \\
\hline & UK & & & 0.43 & 0.59 & 0.52 & 0.54 & 0.49 & 0.50 & 0.47 & 0.50 & 0.36 & 0.58 & 0.42 \\
\hline & IT & & & & 0.45 & 0.47 & 0.45 & 0.40 & 0.44 & 0.44 & 0.43 & 0.32 & 0.42 & 0.36 \\
\hline & NL & & & & & 0.56 & 0.55 & 0.51 & 0.56 & 0.49 & 0.50 & 0.34 & 0.53 & 0.44 \\
\hline & ES & & & & & & 0.55 & 0.45 & 0.46 & 0.46 & 0.46 & 0.33 & 0.48 & 0.41 \\
\hline & SE & & & & & & & 0.44 & 0.47 & 0.49 & 0.60 & 0.35 & 0.50 & 0.41 \\
\hline & AT & & & & & & & & 0.48 & 0.42 & 0.44 & 0.34 & 0.44 & 0.40 \\
\hline & BE & & & & & & & & & 0.47 & 0.47 & 0.33 & 0.48 & 0.43 \\
\hline & DK & & & & & & & & & & 0.47 & 0.32 & 0.46 & 0.40 \\
\hline & FI & & & & & & & & & & & 0.32 & 0.47 & 0.40 \\
\hline & GR & & & & & & & & & & & & 0.37 & 0.36 \\
\hline & IE & & & & & & & & & & & & & 0.42 \\
\hline \multirow{13}{*}{$>1999$} & DE & 0.77 & 0.65 & 0.66 & 0.72 & 0.66 & 0.67 & 0.45 & 0.57 & 0.52 & 0.57 & 0.47 & 0.54 & 0.46 \\
\hline & FR & & 0.71 & 0.68 & 0.77 & 0.69 & 0.68 & 0.44 & 0.58 & 0.53 & 0.61 & 0.46 & 0.53 & 0.47 \\
\hline & UK & & & 0.62 & 0.68 & 0.62 & 0.60 & 0.43 & 0.55 & 0.50 & 0.57 & 0.42 & 0.51 & 0.45 \\
\hline & IT & & & & 0.65 & 0.64 & 0.59 & 0.42 & 0.55 & 0.50 & 0.52 & 0.42 & 0.50 & 0.46 \\
\hline & NL & & & & & 0.65 & 0.61 & 0.44 & 0.59 & 0.53 & 0.55 & 0.45 & 0.52 & 0.44 \\
\hline & ES & & & & & & 0.62 & 0.44 & 0.56 & 0.50 & 0.55 & 0.41 & 0.48 & 0.50 \\
\hline & SE & & & & & & & 0.40 & 0.50 & 0.52 & 0.62 & 0.44 & 0.48 & 0.45 \\
\hline & AT & & & & & & & & 0.44 & 0.39 & 0.34 & 0.38 & 0.39 & 0.38 \\
\hline & BE & & & & & & & & & 0.47 & 0.43 & 0.43 & 0.49 & 0.43 \\
\hline & DK & & & & & & & & & & 0.44 & 0.41 & 0.44 & 0.41 \\
\hline & FI & & & & & & & & & & & 0.38 & 0.42 & 0.43 \\
\hline & GR & & & & & & & & & & & & 0.41 & 0.37 \\
\hline & IE & & & & & & & & & & & & & 0.41 \\
\hline
\end{tabular}


Table 5b: Average probabilities of co-movements for returns on equity market indices - The largest euro area economies, Japan and the US

This table reports for each country pair average probabilities of comovements over two periods. Average probabilities are computed across all the quantile ranges, for $\theta \in(0.05$, 0.95). The first sub-sample covers the pre-monetary union period (January 1992 to December 1998), while the second sub-sample covers the monetary union period (January 1999 to October 2005). The equity indices refer to France (FR), Germany (DE), Italy (IT), the Netherlands (NL), Spain (ES), the United Kingdom (UK), Japan (JP) and the United States (US).

\begin{tabular}{|c|l|ccccccc|}
\hline Period & & FR & UK & IT & NL & ES & JP & US \\
\hline \multirow{5}{*}{$<\mathbf{1 9 9 9}$} & DE & 0.55 & 0.53 & 0.46 & 0.60 & 0.51 & 0.37 & 0.43 \\
& FR & & 0.58 & 0.47 & 0.61 & 0.54 & 0.37 & 0.43 \\
& UK & & & 0.43 & 0.59 & 0.52 & 0.40 & 0.45 \\
& IT & & & & 0.45 & 0.47 & 0.35 & 0.36 \\
& NL & & & & & 0.56 & 0.40 & 0.47 \\
& ES & & & & & & 0.38 & 0.41 \\
& JP & & & & & & & 0.37 \\
\hline \multirow{5}{*}{$>\mathbf{1 9 9 9}$} & DE & 0.77 & 0.65 & 0.66 & 0.72 & 0.66 & 0.46 & 0.64 \\
& FR & & 0.71 & 0.68 & 0.77 & 0.69 & 0.45 & 0.65 \\
& UK & & & 0.62 & 0.68 & 0.62 & 0.43 & 0.61 \\
& IT & & & & 0.65 & 0.64 & 0.43 & 0.55 \\
& NL & & & & & 0.65 & 0.43 & 0.59 \\
& ES & & & & & & 0.43 & 0.58 \\
& JP & & & & & & & 0.43 \\
\hline
\end{tabular}


Table 6a: Tests for differences in probabilities of comovements between the pre-euro and the euro periods for returns on equity market indices The euro area economies

This table reports statistics to test whether the average probabilities of comovements between a given country pair for a certain quantile range are different across two sample periods. The test statistic is estimated for $\theta \in(0.05,0.5), \theta \in(0.55,0.95)$ and $\theta \in(0.05,0.95)$. The first sub-sample covers the pre-monetary union period (January 1992 to December 1998), while the second sub-sample covers the monetary union period (January 1999 to October 2005). Standard errors are reported in italics and statistics significant at the $5 \%$ level in bold. The equity indices refer to Austria (AT), Belgium (BE), Denmark (DK), Finland (FI), France (FR), Germany (DE), Greece (GR), Ireland (IE), Italy (IT), the Netherlands (NL), Portugal (PT), Spain (ES), Sweden (SE) and the United Kingdom (UK).

\begin{tabular}{|c|c|c|c|c|c|c|c|c|c|c|c|c|c|}
\hline \multicolumn{14}{|c|}{$\theta \in[0.05,0.5]$} \\
\hline & FR & UK & IT & NL & ES & SE & AT & $\mathbf{B E}$ & DK & FI & GR & IE & PT \\
\hline DE & $\begin{array}{l}\mathbf{2 . 3 8} \\
0.65\end{array}$ & $\begin{array}{l}1.12 \\
0.59\end{array}$ & $\begin{array}{l}\mathbf{1 . 7 9} \\
0.62\end{array}$ & $\begin{array}{l}\mathbf{1 . 3 4} \\
0.64\end{array}$ & $\begin{array}{l}\mathbf{1 . 5 9} \\
0.67\end{array}$ & $\begin{array}{l}\mathbf{1 . 4 5} \\
058\end{array}$ & $\begin{array}{r}-0.49 \\
0.61\end{array}$ & $\begin{array}{l}0.70 \\
0.70\end{array}$ & $\begin{array}{l}0.52 \\
0.57\end{array}$ & $\begin{array}{l}1.04 \\
0.57\end{array}$ & $\begin{array}{l}\mathbf{1 . 3 9} \\
0.54\end{array}$ & $\begin{array}{l}0.31 \\
0.57\end{array}$ & $\begin{array}{l}0.42 \\
0.60\end{array}$ \\
\hline \multirow{2}{*}{ FR } & & 1.30 & 2.02 & 1.60 & 1.51 & 1.77 & -0.11 & 1.06 & 0.99 & 1.39 & 1.36 & 0.36 & 0.64 \\
\hline & & 0.63 & 0.62 & 0.65 & 0.66 & 0.60 & 0.59 & 0.67 & 0.57 & 0.59 & 0.55 & 0.58 & 0.56 \\
\hline \multirow{2}{*}{ UK } & & & 2.16 & 0.97 & 1.21 & 0.72 & -0.31 & 0.75 & 0.45 & 0.35 & 0.95 & -0.79 & 0.38 \\
\hline & & & 0.64 & 0.63 & 0.63 & 0.60 & 0.57 & 0.74 & 0.53 & 0.60 & 0.54 & 0.61 & 0.57 \\
\hline \multirow{2}{*}{ IT } & & & & 1.93 & 1.87 & 1.26 & 0.46 & 1.32 & 0.62 & 0.97 & 1.07 & 0.61 & 1.08 \\
\hline & & & & 0.60 & 0.64 & 0.58 & 0.59 & 0.66 & 0.57 & 0.54 & 0.54 & 0.59 & 0.55 \\
\hline \multirow{2}{*}{ NL } & & & & & 1.29 & 0.82 & -0.52 & 0.46 & 0.41 & 0.55 & 1.11 & -0.42 & -0.01 \\
\hline & & & & & 0.65 & 0.57 & 0.56 & 0.67 & 0.56 & 0.58 & 0.52 & 0.59 & 0.58 \\
\hline \multirow{2}{*}{ ES } & & & & & & 0.65 & 0.04 & 0.83 & 0.50 & 0.91 & 1.16 & 0.18 & 1.07 \\
\hline & & & & & & 0.63 & 0.60 & 0.67 & 0.59 & 0.58 & 0.54 & 0.58 & 0.60 \\
\hline \multirow{2}{*}{ SE } & & & & & & & -0.31 & 0.45 & 0.30 & 0.01 & 0.96 & -0.52 & 0.49 \\
\hline & & & & & & & 0.57 & 0.66 & 0.58 & 0.59 & 0.56 & 0.58 & 0.59 \\
\hline \multirow{2}{*}{ AT } & & & & & & & & -0.50 & -0.28 & -1.25 & 0.59 & -0.73 & -0.01 \\
\hline & & & & & & & & 0.65 & 0.57 & 0.54 & 0.55 & 0.57 & 0.57 \\
\hline \multirow{2}{*}{ BE } & & & & & & & & & 0.22 & -0.52 & 1.65 & 0.07 & 0.03 \\
\hline & & & & & & & & & 0.58 & 0.56 & 0.55 & 0.63 & 0.59 \\
\hline \multirow{2}{*}{ DK } & & & & & & & & & & -0.38 & 1.37 & 0.03 & 0.62 \\
\hline & & & & & & & & & & 0.58 & 0.52 & 0.54 & 0.56 \\
\hline \multirow{2}{*}{ FI } & & & & & & & & & & & 0.65 & -0.69 & 0.13 \\
\hline & & & & & & & & & & & 0.53 & 0.53 & 0.57 \\
\hline \multirow{2}{*}{ GR } & & & & & & & & & & & & 0.38 & 0.22 \\
\hline & & & & & & & & & & & & 0.55 & 0.54 \\
\hline IE & & & & & & & & & & & & & -0.18 \\
\hline & & & & & & & & & & & & & 0.54 \\
\hline
\end{tabular}


Table 6a - Continued

\begin{tabular}{|c|c|c|c|c|c|c|c|c|c|c|c|c|c|}
\hline \multicolumn{14}{|c|}{$\theta \in[0.55,0.95]$} \\
\hline & FR & UK & IT & NL & ES & SE & AT & $\mathbf{B E}$ & DK & FI & GR & IE & PT \\
\hline \multirow{2}{*}{ DE } & 1.72 & 1.10 & 1.98 & 0.93 & 1.36 & 1.33 & -0.71 & -0.16 & -0.12 & 0.92 & 0.96 & 0.82 & 0.19 \\
\hline & 0.59 & 0.57 & 0.54 & 0.57 & 0.52 & 0.55 & 0.50 & 0.59 & 0.55 & 0.57 & 0.52 & 0.55 & 0.54 \\
\hline \multirow{2}{*}{ FR } & & 1.27 & 1.85 & 1.43 & 1.21 & 1.42 & -0.53 & 0.36 & 0.62 & 1.55 & 0.65 & 0.70 & 0.44 \\
\hline & & 0.59 & 0.58 & 0.59 & 0.58 & 0.57 & 0.51 & 0.56 & 0.53 & 0.55 & 0.51 & 0.54 & 0.51 \\
\hline \multirow{2}{*}{ UK } & & & 1.40 & 0.62 & 0.74 & 0.54 & -0.81 & 0.27 & 0.02 & 1.01 & 0.22 & -0.51 & 0.30 \\
\hline & & & 0.53 & 0.55 & 0.53 & 0.55 & 0.49 & 0.55 & 0.52 & 0.55 & 0.52 & 0.58 & 0.50 \\
\hline \multirow{2}{*}{ IT } & & & & 1.86 & 1.45 & 1.41 & 0.00 & 0.74 & 0.46 & 0.69 & 0.81 & 0.81 & 0.74 \\
\hline & & & & 0.53 & 0.55 & 0.56 & 0.48 & 0.56 & 0.52 & 0.54 & 0.50 & 0.51 & 0.50 \\
\hline \multirow{2}{*}{ NL } & & & & & 0.48 & 0.23 & -0.78 & 0.23 & 0.35 & 0.34 & 0.82 & 0.23 & -0.12 \\
\hline & & & & & 0.54 & 0.57 & 0.49 & 0.57 & 0.54 & 0.55 & 0.48 & 0.55 & 0.51 \\
\hline \multirow{2}{*}{ ES } & & & & & & 0.58 & -0.31 & 1.05 & 0.15 & 0.73 & 0.35 & -0.11 & 0.49 \\
\hline & & & & & & 0.56 & 0.44 & 0.54 & 0.52 & 0.54 & 0.45 & 0.50 & 0.50 \\
\hline \multirow{2}{*}{ SE } & & & & & & & -0.47 & 0.08 & 0.29 & 0.29 & 0.76 & 0.04 & 0.23 \\
\hline & & & & & & & 0.44 & 0.52 & 0.51 & 0.58 & 0.48 & 0.52 & 0.49 \\
\hline \multirow{2}{*}{$\mathbf{A T}$} & & & & & & & & -0.18 & -0.26 & -0.53 & 0.28 & -0.27 & -0.30 \\
\hline & & & & & & & & 0.51 & 0.45 & 0.44 & 0.47 & 0.47 & 0.46 \\
\hline \multirow{2}{*}{$\mathbf{B E}$} & & & & & & & & & -0.23 & -0.25 & 0.23 & 0.11 & -0.18 \\
\hline & & & & & & & & & 0.53 & 0.54 & 0.48 & 0.54 & 0.52 \\
\hline \multirow{2}{*}{ DK } & & & & & & & & & & -0.10 & 0.35 & -0.30 & -0.49 \\
\hline & & & & & & & & & & 0.49 & 0.47 & 0.51 & 0.51 \\
\hline \multirow{2}{*}{ FI } & & & & & & & & & & & 0.50 & -0.31 & 0.49 \\
\hline & & & & & & & & & & & 0.47 & 0.56 & 0.52 \\
\hline \multirow{2}{*}{ GR } & & & & & & & & & & & & 0.33 & -0.05 \\
\hline & & & & & & & & & & & & 0.52 & 0.54 \\
\hline \multirow{2}{*}{ IE } & & & & & & & & & & & & & -0.10 \\
\hline & & & & & & & & & & & & & 0.52 \\
\hline
\end{tabular}


Table 6a - Continued

\begin{tabular}{|c|c|c|c|c|c|c|c|c|c|c|c|c|c|}
\hline \multicolumn{14}{|c|}{$\theta \in[0.05,0.95]$} \\
\hline & FR & UK & IT & NL & $\mathbf{E S}$ & SE & $\mathbf{A T}$ & BE & DK & FI & GR & IE & PT \\
\hline \multirow{2}{*}{ DE } & 4.10 & 2.22 & 3.77 & 2.27 & 2.94 & 2.78 & -1.20 & 0.55 & 0.40 & 1.96 & 2.34 & 1.13 & 0.61 \\
\hline & 0.55 & 0.56 & 0.59 & 0.54 & 0.59 & 0.52 & 0.59 & 0.69 & 0.57 & 0.59 & 0.59 & 0.58 & 0.64 \\
\hline \multirow{2}{*}{ FR } & & 2.57 & 3.87 & 3.03 & 2.72 & 3.19 & -0.64 & 1.42 & 1.61 & 2.94 & 2.01 & 1.06 & 1.08 \\
\hline & & 0.55 & 0.60 & 0.53 & 0.59 & 0.55 & 0.59 & 0.63 & 0.57 & 0.59 & 0.59 & 0.57 & 0.59 \\
\hline \multirow{2}{*}{ UK } & & & 3.56 & 1.59 & 1.95 & 1.26 & -1.11 & 1.03 & 0.47 & 1.36 & 1.17 & -1.29 & 0.68 \\
\hline & & & 0.61 & 0.53 & 0.56 & 0.57 & 0.55 & 0.72 & 0.53 & 0.61 & 0.60 & 0.62 & 0.59 \\
\hline \multirow{2}{*}{ IT } & & & & 3.78 & 3.32 & 2.67 & 0.46 & 2.07 & 1.08 & 1.66 & 1.88 & 1.42 & 1.82 \\
\hline & & & & 0.57 & 0.61 & 0.60 & 0.59 & 0.67 & 0.59 & 0.58 & 0.60 & 0.60 & 0.59 \\
\hline \multirow{2}{*}{ NL } & & & & & 1.77 & 1.05 & -1.30 & 0.69 & 0.76 & 0.90 & 1.93 & -0.19 & -0.13 \\
\hline & & & & & 0.57 & 0.54 & 0.55 & 0.62 & 0.55 & 0.59 & 0.54 & 0.59 & 0.60 \\
\hline \multirow{2}{*}{ ES } & & & & & & 1.23 & -0.27 & 1.87 & 0.65 & 1.63 & 1.51 & 0.07 & 1.56 \\
\hline & & & & & & 0.59 & 0.55 & 0.64 & 0.58 & 0.59 & 0.55 & 0.56 & 0.60 \\
\hline \multirow{2}{*}{ SE } & & & & & & & -0.78 & 0.53 & 0.59 & 0.30 & 1.72 & -0.48 & 0.72 \\
\hline & & & & & & & 0.54 & 0.65 & 0.55 & 0.57 & 0.58 & 0.58 & 0.61 \\
\hline \multirow{2}{*}{$\mathbf{A T}$} & & & & & & & & -0.68 & -0.54 & -1.78 & 0.87 & -1.00 & -0.31 \\
\hline & & & & & & & & 0.64 & 0.54 & 0.54 & 0.58 & 0.56 & 0.58 \\
\hline \multirow{2}{*}{$\mathbf{B E}$} & & & & & & & & & -0.01 & -0.77 & 1.88 & 0.18 & -0.15 \\
\hline & & & & & & & & & 0.58 & 0.60 & 0.58 & 0.63 & 0.61 \\
\hline \multirow{2}{*}{ DK } & & & & & & & & & & -0.47 & 1.72 & -0.27 & 0.13 \\
\hline & & & & & & & & & & 0.60 & 0.57 & 0.56 & 0.59 \\
\hline \multirow{2}{*}{ FI } & & & & & & & & & & & 1.15 & -0.99 & 0.61 \\
\hline & & & & & & & & & & & 0.58 & 0.61 & 0.62 \\
\hline \multirow{2}{*}{ GR } & & & & & & & & & & & & 0.71 & 0.16 \\
\hline & & & & & & & & & & & & 0.60 & 0.62 \\
\hline \multirow{2}{*}{ IE } & & & & & & & & & & & & & -0.28 \\
\hline & & & & & & & & & & & & & 0.58 \\
\hline
\end{tabular}


Table 6b: Tests for differences in probabilities of comovements between the pre-euro and the euro periods for returns on equity market indices The euro area largest economies, Japan and the US

This table reports statistics to test whether the average probabilities of comovements between a given country pair for a certain quantile range are different across two sample periods. The test statistic is estimated for $\theta \in(0.05,0.95)$. The first sub-sample covers the pre-monetary union period (January 1992 to December 1998), while the second sub-sample covers the monetary union period (January 1999 to October 2005). Standard errors are reported in italics and statistics significant at the $5 \%$ level in bold. The equity indices refer to France (FR), Germany (DE), Italy (IT), the Netherlands (NL), Spain (ES), the United Kingdom (UK), Japan (JP) and the United States (US).

\begin{tabular}{|c|c|c|c|c|c|c|c|}
\hline & $\overline{F R}$ & $\overline{\text { UK }}$ & IT & NL & ES & JP & US \\
\hline \multirow{2}{*}{ DE } & 4.10 & 2.22 & 3.77 & 2.27 & 2.94 & 1.82 & 4.06 \\
\hline & 0.55 & 0.56 & 0.59 & 0.54 & 0.59 & 0.52 & 0.56 \\
\hline \multirow{2}{*}{ FR } & & 2.57 & 3.87 & 3.03 & 2.72 & 1.61 & 4.18 \\
\hline & & 0.55 & 0.60 & 0.53 & 0.59 & 0.53 & 0.58 \\
\hline \multirow{2}{*}{ UK } & & & 3.56 & 1.59 & 1.95 & 0.64 & 3.04 \\
\hline & & & 0.61 & 0.53 & 0.56 & 0.54 & 0.63 \\
\hline \multirow{2}{*}{ IT } & & & & 3.78 & 3.32 & 1.48 & 3.62 \\
\hline & & & & 0.57 & 0.61 & 0.54 & 0.59 \\
\hline \multirow{2}{*}{ NL } & & & & & 1.77 & 0.49 & 2.25 \\
\hline & & & & & 0.57 & 0.55 & 0.59 \\
\hline \multirow{2}{*}{ ES } & & & & & & 1.04 & 3.19 \\
\hline & & & & & & 0.53 & 0.59 \\
\hline JP & & & & & & & 1.20 \\
\hline & & & & & & & 0.58 \\
\hline
\end{tabular}


Table 7: Average probabilities of comovements and tests for differences in probabilities of comovements between the pre-euro and the euro periods - Returns on equity market indices

This table reports for each country/region pair two items: (i) average probabilities of comovements over two periods; and (ii) statistics to test whether the average probabilities of comovements between a given country/region pair for a certain quantile range are different across two sample periods. Average probabilities and test statistics are computed across upper, lower and all the quantile ranges, for $\theta \in(0.05,0.5), \theta \in(0.55,0.95)$, and $\theta \in(0.05,0.95)$, respectively. The first sub-sample covers the pre-monetary union period (January 1992 to December 1998), while the second sub-sample covers the monetary union period (January 1999 to October 2005). Standard errors are reported in italics and statistics significant at the $5 \%$ level in bold. The equity indices refer to Eurostoxx50 (EU), Japan (JP) and the United States (US).

\begin{tabular}{|c|c|c|c|c|c|}
\hline \multicolumn{6}{|c|}{$\begin{array}{l}\text { Panel A : Average probabilities of comovements over the lower and upper } \\
\text { quantile range }\end{array}$} \\
\hline & \multicolumn{3}{|c|}{$\theta \mathbf{C}[0.05,0.5]$} & \multicolumn{2}{|c|}{$\theta \mathbf{C}[0.55,0.95]$} \\
\hline Period & & $\mathbf{J P}$ & US & JP & US \\
\hline \multirow[t]{2}{*}{$<1999$} & $\mathbf{E} \mathbf{U}$ & 0.44 & 0.45 & 0.34 & 0.49 \\
\hline & JP & & 0.39 & & 0.35 \\
\hline \multirow[t]{2}{*}{$>1999$} & $\mathbf{E} \mathbf{U}$ & 0.49 & 0.68 & 0.40 & 0.63 \\
\hline & JP & & 0.47 & & 0.40 \\
\hline
\end{tabular}

Panel B : Tests for differences in probabilities of comovements between the preeuro and the euro periods over the lower and upper quantile range

\begin{tabular}{lcccc} 
& $\boldsymbol{\theta} \mathbf{\epsilon}[\mathbf{0 . 0 5}, \mathbf{0 . 5}]$ & \multicolumn{1}{c}{$\boldsymbol{\theta} \mathbf{\epsilon}[\mathbf{0 . 5 5}, \mathbf{0 . 9 5}]$} \\
& $\mathbf{J P}$ & $\mathbf{U S}$ & $\mathbf{J P}$ & $\mathbf{U S}$ \\
$\mathbf{E U}$ & 0.49 & $\mathbf{2 . 2 5}$ & 0.48 & $\mathbf{1 . 2 0}$ \\
& 0.57 & 0.60 & 0.44 & 0.55 \\
$\mathbf{J P}$ & & 0.77 & & 0.43 \\
& & 0.58 & & 0.46
\end{tabular}

Panel C : Average probabilities of comovements over the whole quantile range

\begin{tabular}{lccc} 
& & \multicolumn{2}{c}{$\theta \mathbf{C}[\mathbf{0 . 0 5}, \mathbf{0 . 9 5}]$} \\
Period & & JP & US \\
$<\mathbf{1 9 9 9}$ & EU & 0.40 & 0.47 \\
& JP & & 0.37 \\
$>1999$ & EU & 0.45 & 0.65 \\
& JP & & 0.43
\end{tabular}

Panel D : Tests for differences in probabilities of comovements between the pre-euro and the euro periods over the whole quantile range

\begin{tabular}{llr} 
& \multicolumn{1}{c}{$\boldsymbol{\theta} \mathbf{C}[\mathbf{0 . 0 5}, \mathbf{0 . 9 5}]$} \\
& $\mathbf{J P}$ & $\mathbf{U S}$ \\
$\mathbf{E U}$ & 0.97 & $\mathbf{3 . 4 5}$ \\
& 0.54 & 0.56 \\
$\mathbf{J P}$ & & $\mathbf{1 . 2 0}$ \\
& & 0.58 \\
\hline
\end{tabular}


Table 8: Average probabilities of comovements and tests for differences in conditional probabilities of comovements between the pre-euro and the euro periods - Returns on 10-year government bonds

This table reports for each country/region pair two items: (i) average probabilities of comovements over two periods; and (ii) statistics to test whether the average probabilities of comovements between a given country/region pair for a certain quantile range are different across two sample periods. Average probabilities and test statistics are computed across upper, lower and all the quantile ranges, for $\theta \in(0.05,0.5), \theta \in(0.55,0.95)$, and $\theta \in(0.05$, $0.95)$, respectively. The first sub-sample covers the pre-monetary union period (January 1992 to December 1998), while the second sub-sample covers the monetary union period (January 1999 to October 2005). Standard errors are reported in italics and statistics significant at the $5 \%$ level in bold. Ten-year government bonds are for Austria (AT), Belgium (BE), Denmark (DK), Finland (FI), France (FR), Germany (DE), Ireland (IE), Italy (IT), Japan (JP), the Netherlands (NL), Spain (ES), Sweden (SE), the United Kingdom (UK), and the United States (US).

Euro area economies, Japan and the US

\begin{tabular}{|c|c|c|c|c|c|c|c|c|c|c|c|c|c|c|}
\hline \multicolumn{15}{|c|}{$\begin{array}{l}\text { Panel A : Average probabilities of comovements over the lower and upper quantile range } \\
\qquad \boldsymbol{\theta \in C}[\mathbf{0 . 0 5}, \mathbf{0 . 5}]\end{array}$} \\
\hline Period & & FR & UK & IT & NL & ES & SE & AT & $\mathbf{B E}$ & DK & FI & IE & JP & US \\
\hline $1992-98$ & DE & 0.68 & 0.61 & 0.50 & 0.81 & 0.56 & 0.55 & 0.70 & 0.70 & 0.58 & 0.52 & 0.60 & 0.30 & 0.47 \\
\hline 1999-05 & DE & 0.91 & 0.77 & 0.85 & 0.93 & 0.87 & 0.78 & 0.91 & 0.90 & 0.77 & 0.90 & 0.87 & 0.34 & 0.65 \\
\hline \multicolumn{15}{|c|}{$\Theta \in[0.55,0.95]$} \\
\hline $1992-98$ & DE & 0.66 & 0.54 & 0.49 & 0.77 & 0.50 & 0.48 & 0.71 & 0.69 & 0.56 & 0.45 & 0.58 & 0.33 & 0.48 \\
\hline $1999-05$ & DE & 0.90 & 0.75 & 0.85 & 0.85 & 0.83 & 0.71 & 0.85 & 0.87 & 0.73 & 0.86 & 0.88 & 0.34 & 0.58 \\
\hline \multicolumn{15}{|c|}{$\begin{array}{l}\text { Panel B : Test for differences in probabilities of comovements between the pre-euro and the euro periods } \\
\text { over the lower and upper quantile range }\end{array}$} \\
\hline \multicolumn{15}{|c|}{$\theta \in[0.05,0.5]$} \\
\hline & DE & 2.29 & 1.59 & 3.54 & 1.21 & 3.11 & 2.22 & 2.16 & 1.98 & 1.86 & 3.81 & 2.70 & 0.41 & 1.82 \\
\hline & Std & 0.69 & 0.65 & 0.66 & 0.72 & 0.66 & 0.64 & 0.70 & 0.72 & 0.65 & 0.68 & 0.68 & 0.46 & 0.61 \\
\hline \multicolumn{15}{|c|}{$\theta \in[0.55,0.95]$} \\
\hline & DE & 2.15 & 1.85 & 3.24 & 0.73 & 2.95 & 2.09 & 1.26 & 1.58 & 1.54 & 3.66 & 2.74 & 0.11 & 0.91 \\
\hline & Std & 0.64 & 0.62 & 0.58 & 0.64 & 0.56 & 0.57 & 0.60 & 0.66 & 0.58 & 0.58 & 0.60 & 0.49 & 0.61 \\
\hline \multicolumn{15}{|c|}{ Panel C : Average probabilities of comovements over the whole quantile range } \\
\hline $1992-98$ & DE & 0.67 & 0.58 & 0.50 & 0.79 & 0.53 & 0.52 & 0.70 & 0.69 & 0.57 & 0.48 & 0.59 & 0.31 & 0.47 \\
\hline 1999-05 & DE & 0.90 & 0.76 & 0.85 & 0.89 & 0.85 & 0.75 & 0.88 & 0.88 & 0.75 & 0.88 & 0.87 & 0.34 & 0.62 \\
\hline \multicolumn{15}{|c|}{$\begin{array}{l}\text { Panel D : Test for differences in probabilities of comovements between the pre-euro and the euro periods } \\
\text { over the whole quantile range }\end{array}$} \\
\hline \multicolumn{15}{|c|}{$\theta \in[0.05,0.95]$} \\
\hline & DE & 4.44 & 3.43 & 6.79 & 1.94 & 6.06 & 4.31 & 3.42 & 3.55 & 3.39 & 7.47 & 5.44 & 0.52 & 2.73 \\
\hline & Std & 0.51 & 0.57 & 0.53 & 0.47 & 0.51 & 0.55 & 0.45 & 0.56 & 0.53 & 0.55 & 0.50 & 0.54 & 0.63 \\
\hline
\end{tabular}


Table 8 - Continued

The UK and the US

\begin{tabular}{|c|c|c|c|}
\hline \multicolumn{3}{|c|}{$\begin{array}{l}\text { Panel A: Average probabilities of } \\
\text { comovements over the lower and upper } \\
\text { quantile range }\end{array}$} & $\begin{array}{l}\text { Panel C : Average probabilities of } \\
\text { comovements over the whole quantile range } \\
\qquad \boldsymbol{\theta \in C}[\mathbf{0 . 0 5 , 0 . 9 5 ]}\end{array}$ \\
\hline \multicolumn{3}{|c|}{$\theta \in\left[\begin{array}{l}0.05,0.5 \\
0\end{array}\right.$} & \\
\hline Period & & US & US \\
\hline $1992-98$ & UK & 0.49 & 0.48 \\
\hline $1999-05$ & UK & 0.63 & 0.59 \\
\hline \multicolumn{4}{|c|}{$\theta \in[0.55,0.95]$} \\
\hline $1992-98$ & UK & 0.47 & \\
\hline $1999-05$ & UK & 0.54 & \\
\hline \multicolumn{3}{|c|}{$\begin{array}{l}\text { Panel B : Test for differences in probabilities of } \\
\text { comovements between the pre-euro and the } \\
\text { euro periods over the lower and upper quantile } \\
\text { range }\end{array}$} & $\begin{array}{l}\text { Panel D : Test for differences in } \\
\text { probabilities of comovements between the } \\
\text { pre-euro and the euro periods over the } \\
\text { whole quantile range }\end{array}$ \\
\hline & & US & US \\
\hline & UK & 1.34 & 2.04 \\
\hline & Std & 0.63 & 0.71 \\
\hline \multicolumn{4}{|c|}{$\theta \in[0.55,0.95]$} \\
\hline & UK & 0.69 & \\
\hline & Std & 0.67 & \\
\hline
\end{tabular}


Figure 1: Weighted average conditional correlations between returns on equity market indices for euro area economies

This figure plots weighted average conditional correlations between returns on equity market indices for euro area member states. The lines "LARGE", "SMALL", "SMALL_LARGE" and "ALL" indicate average correlations between large, small, small versus large, and all the euro area economies, respectively. The data set covers the period from January 1987 to October 2005. The five largest euro area economies are France, Germany, Italy, the Netherlands and Spain. The small economies included in the analysis are Austria, Belgium, Finland, Ireland and Portugal. The conditional correlation of each euro area country pair is weighted by the fraction of its GDP relative to the total euro area GDP.

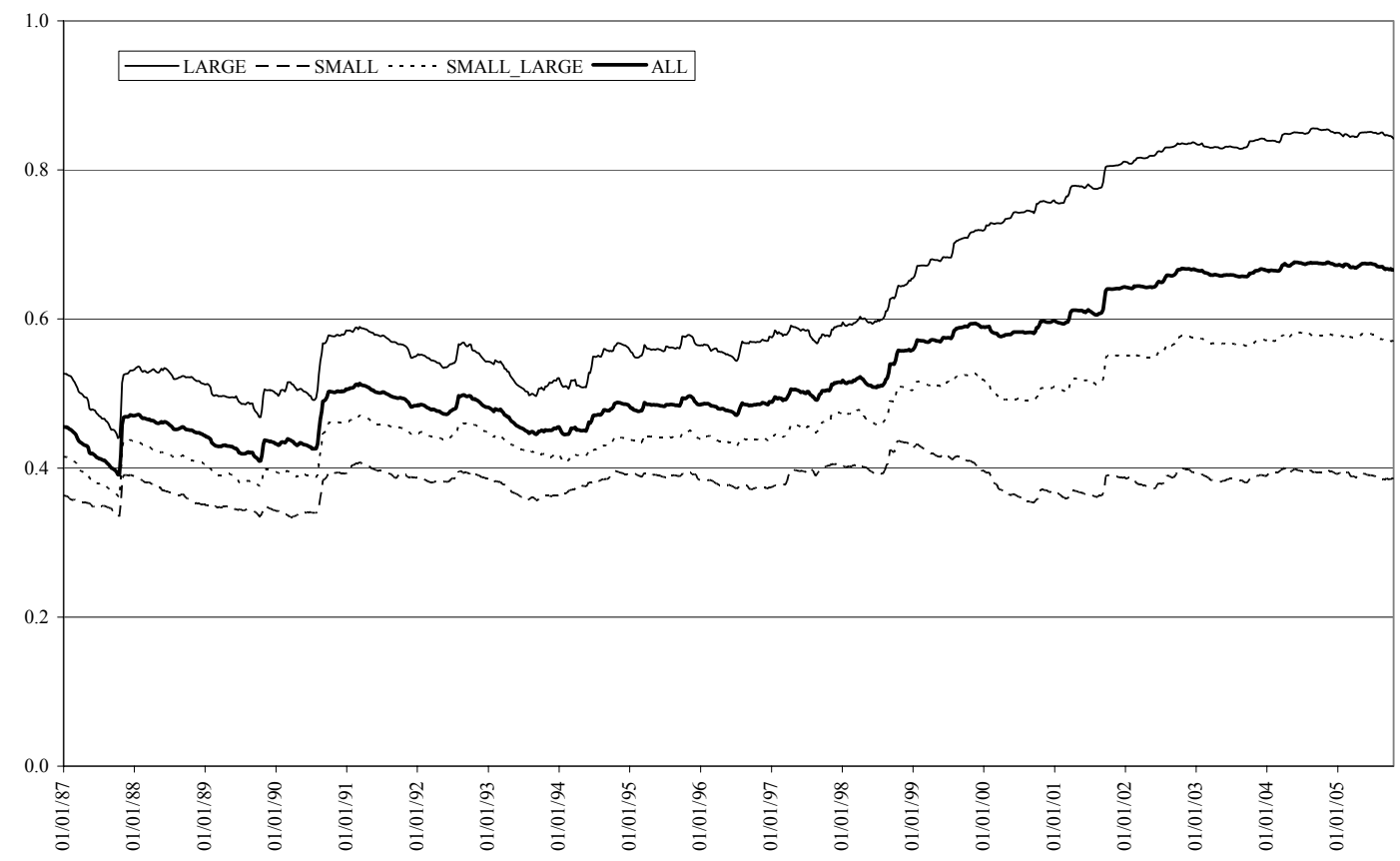


Figure 2: Conditional correlations between returns on equity market indices for the euro area large economies

This figure plots conditional correlations between returns on equity market indices for euro area large member states. The data set covers the period from January 1987 to October 2005. The five largest euro area economies are France (FR), Germany (DE), Italy (IT), the Netherlands (NL) and Spain (ES). For visual convenience, the resulting ten correlation pairs are represented in two different graphs, figure $2 \mathrm{a}$ and $2 \mathrm{~b}$.

Figure $2 a$

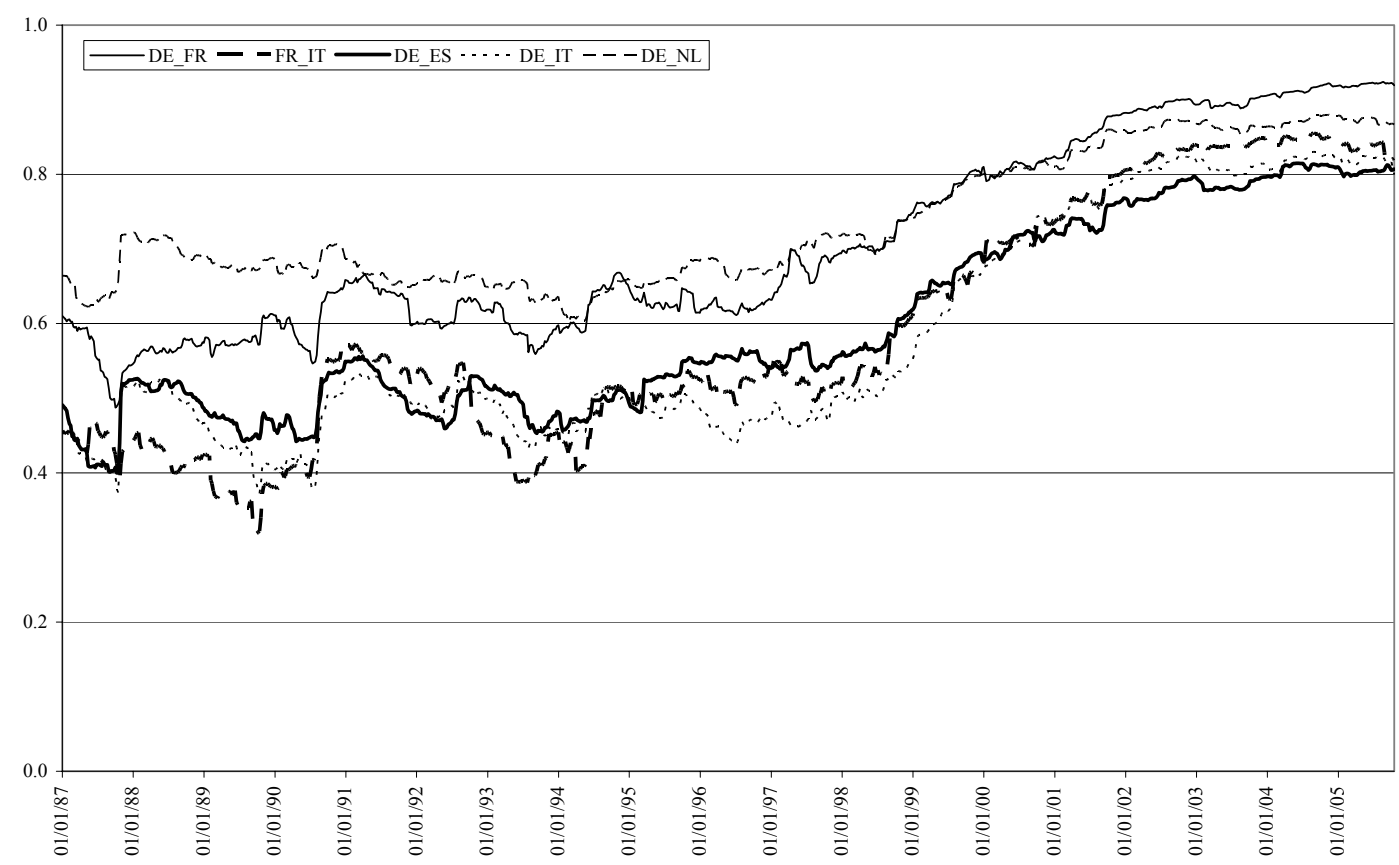

Figure $2 b$

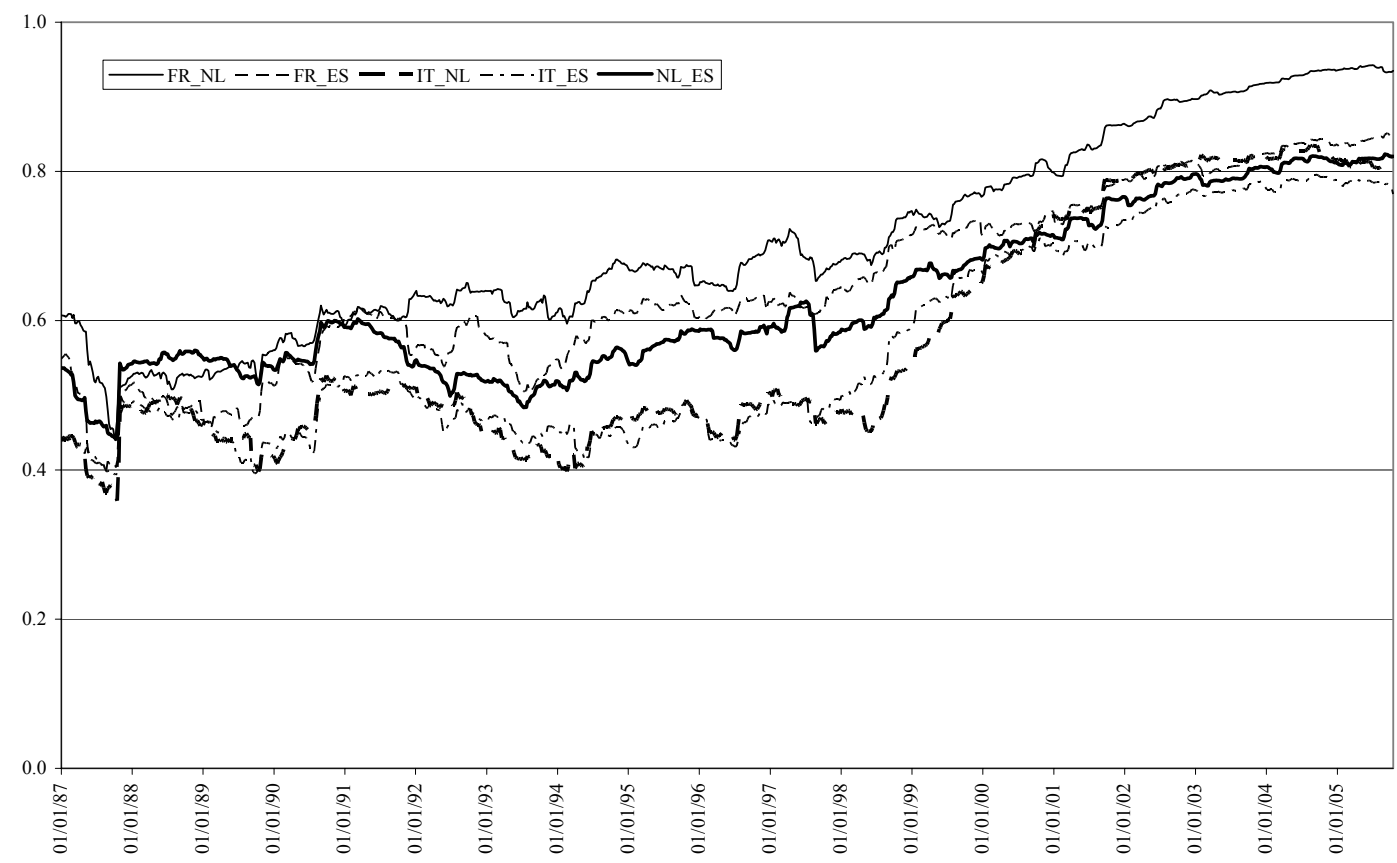


Figure 3: Conditional correlations between returns on equity market indices for euro area small economies

This figure plots conditional correlations between returns on equity market indices for euro area small member states. The data set covers the period from January 1987 to October 2005. The small euro area economies included in the analysis are Austria (AT), Belgium (BE), Finland (FI), Ireland (IE) and Portugal (PT). For visual convenience, the resulting ten correlation pairs are represented in two different graphs, figure 3a and 3b.

Figure $3 a$

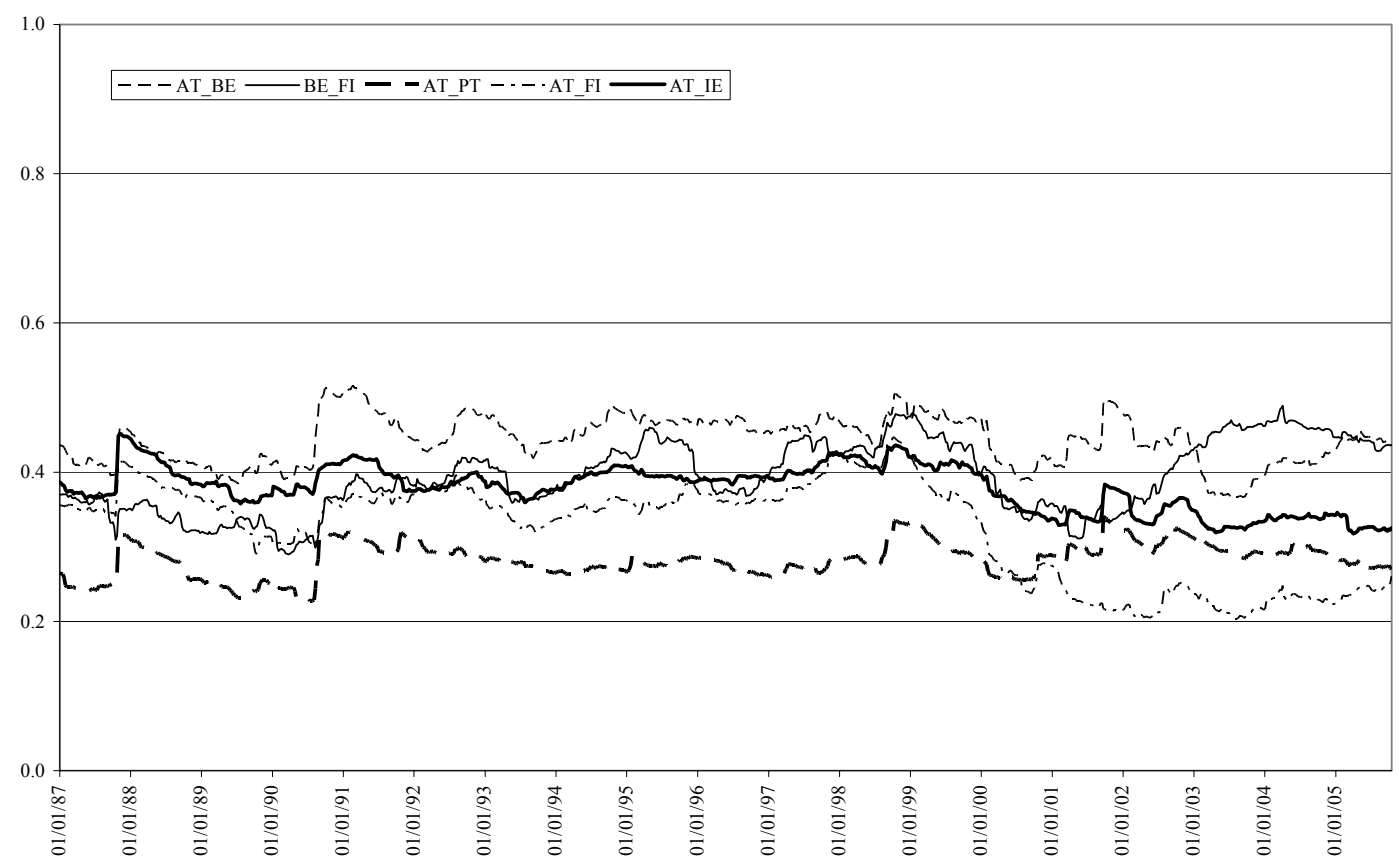

Figure $3 b$

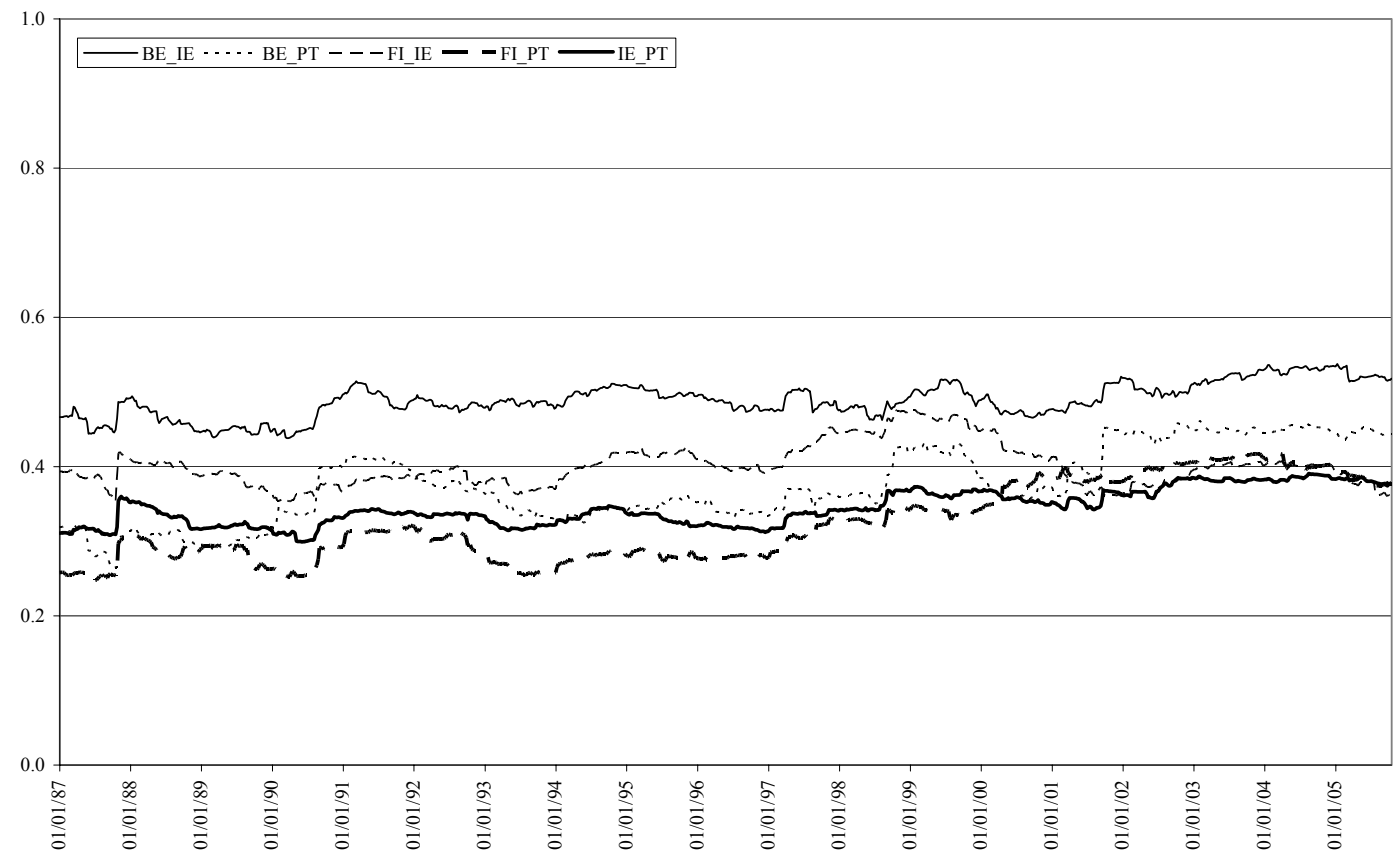


Figure 4: Conditional correlations between returns on equity market indices for euro area small and large economies

This figure plots conditional correlations between returns on equity market indices for selected euro area small and large member states. The data set covers the period from January 1987 to October 2005. The five largest euro area economies are France (FR), Germany (DE), Italy (IT), the Netherlands (NL) and Spain (ES). The small economies included in the analysis are Austria (AT), Belgium (BE), Finland (FI), Ireland (IE) and Portugal (PT). For visual convenience, the resulting ten correlation pairs are represented in two different graphs, figure $4 \mathrm{a}$ and $4 \mathrm{~b}$.

Figure $4 a$

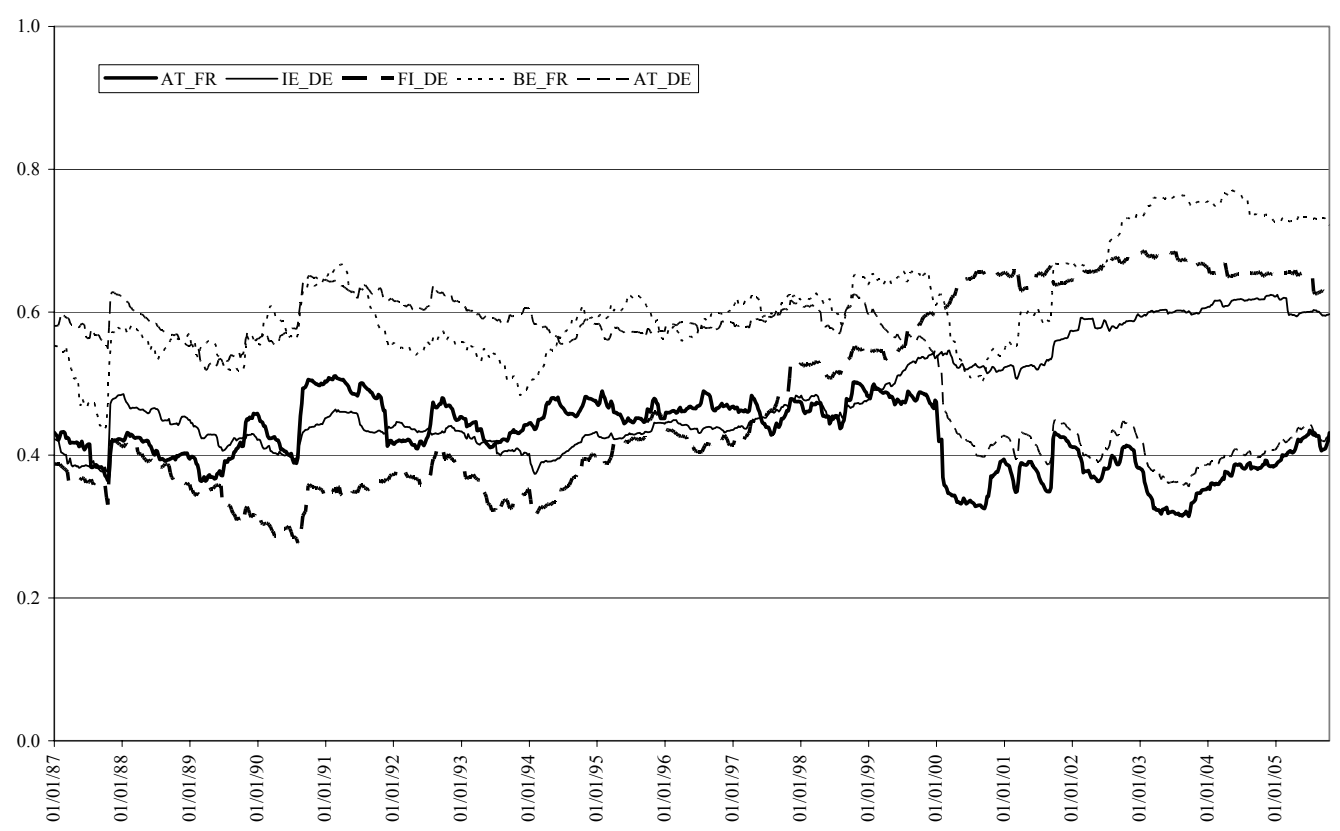

Figure $4 b$

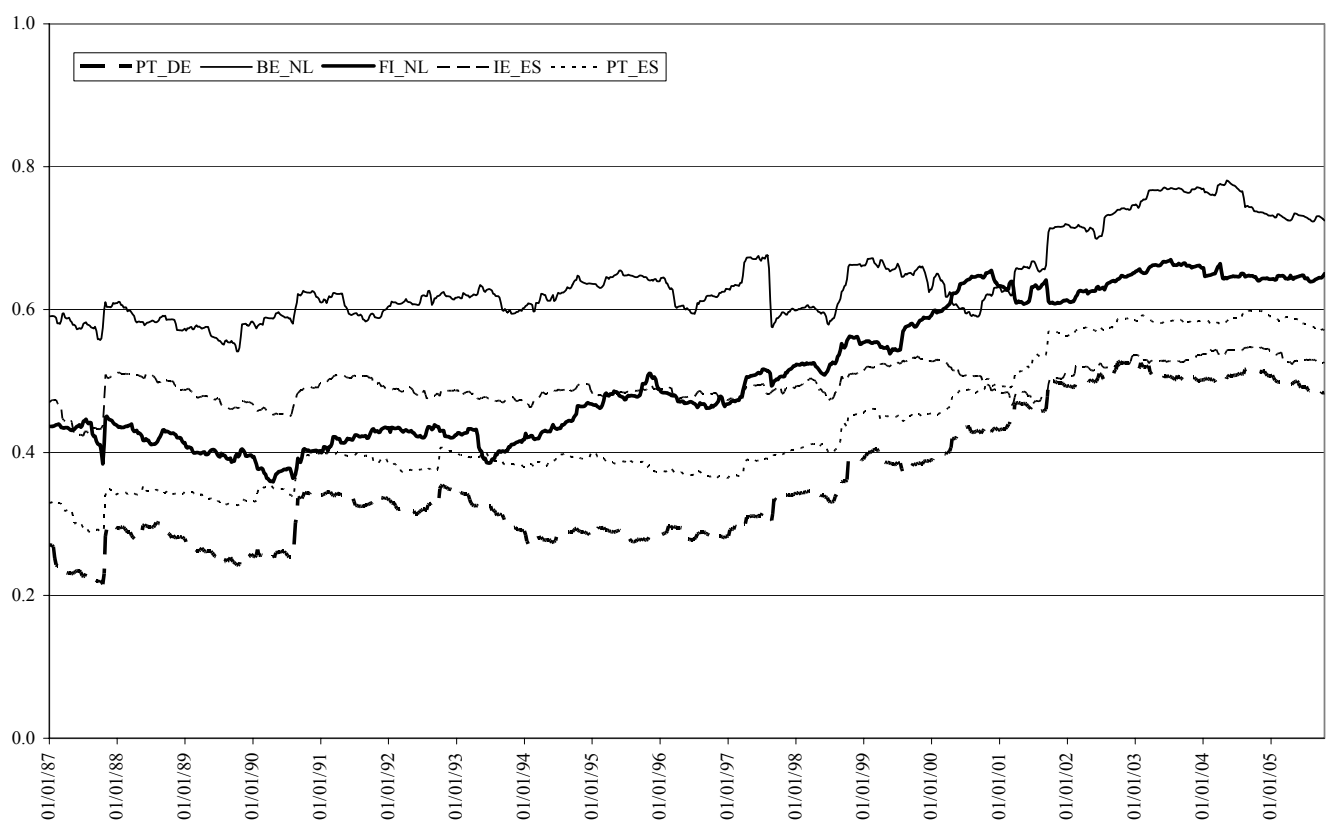


Figure 5: Conditional correlations between returns on Eurostoxx50 and non-euro area equity market indices

This figure plots conditional correlations between returns on Eurostoxx50 and non-euro area equity market indices. The data set covers the period from January 1987 to October 2005. The non euro area countries included in the analysis are Denmark (DK), Japan (JP), Sweden (SE), the United Kingdom (UK) and the United States (US).

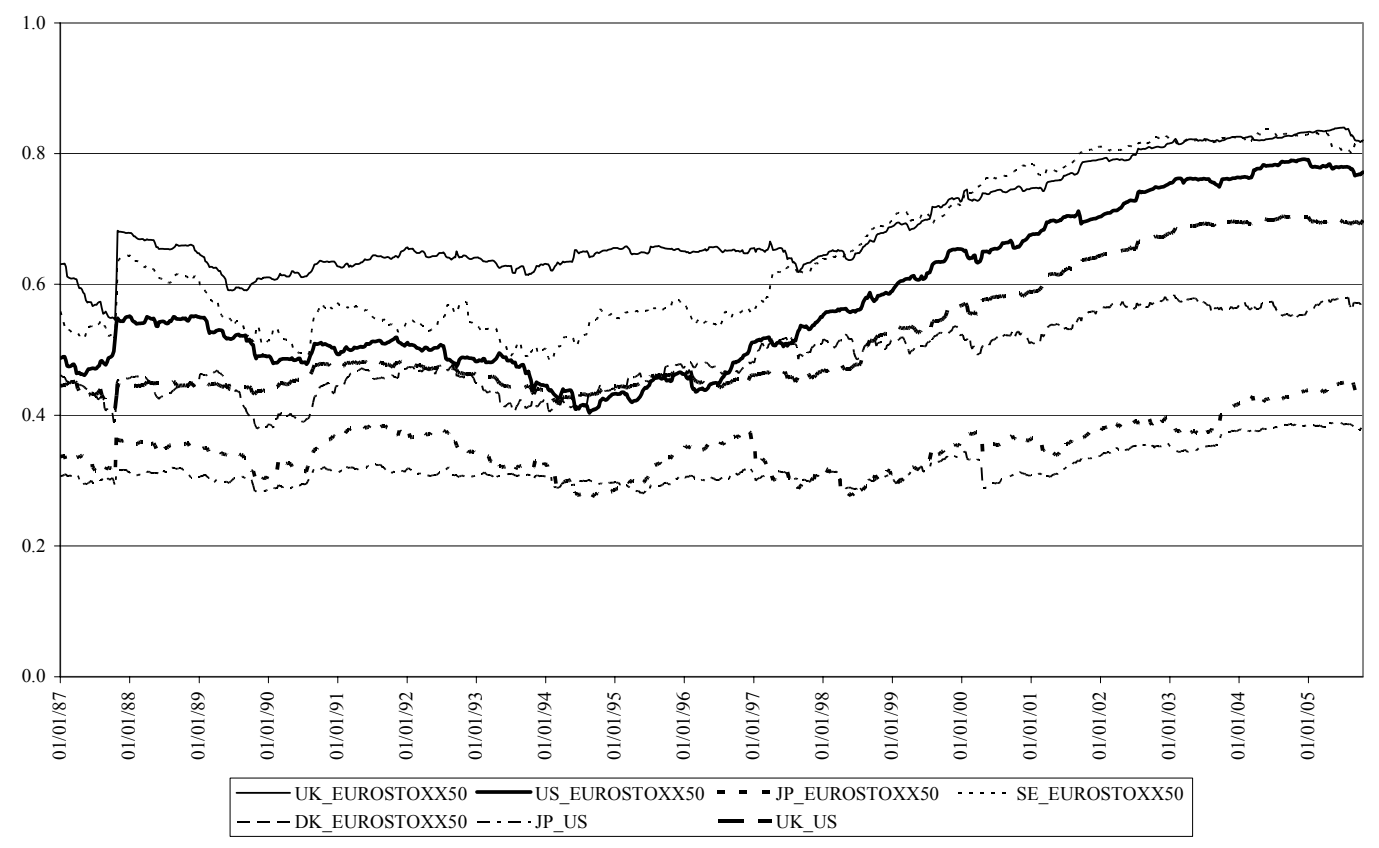


Figure 6: Weighted average conditional correlations between returns on 10-year government bonds for Germany verus other euro area economies

This figure plots weighted average conditional correlations between returns on 10-year government bonds for Germany versus other euro area member states. The lines "LARGE" and "SMALL" indicate average correlations between German versus large and small economy bond returns, respectively, while the line "ALL" stands for average correlations between German and all the other euro area bond returns. The data set covers the period from January 1987 to October 2005. The five largest euro area economies are France, Germany, Italy, the Netherlands and Spain. The small economies included in the analysis are Austria and Ireland. The conditional correlation of each euro area country pair is weighted by the fraction of its GDP relative to the total euro area GDP.

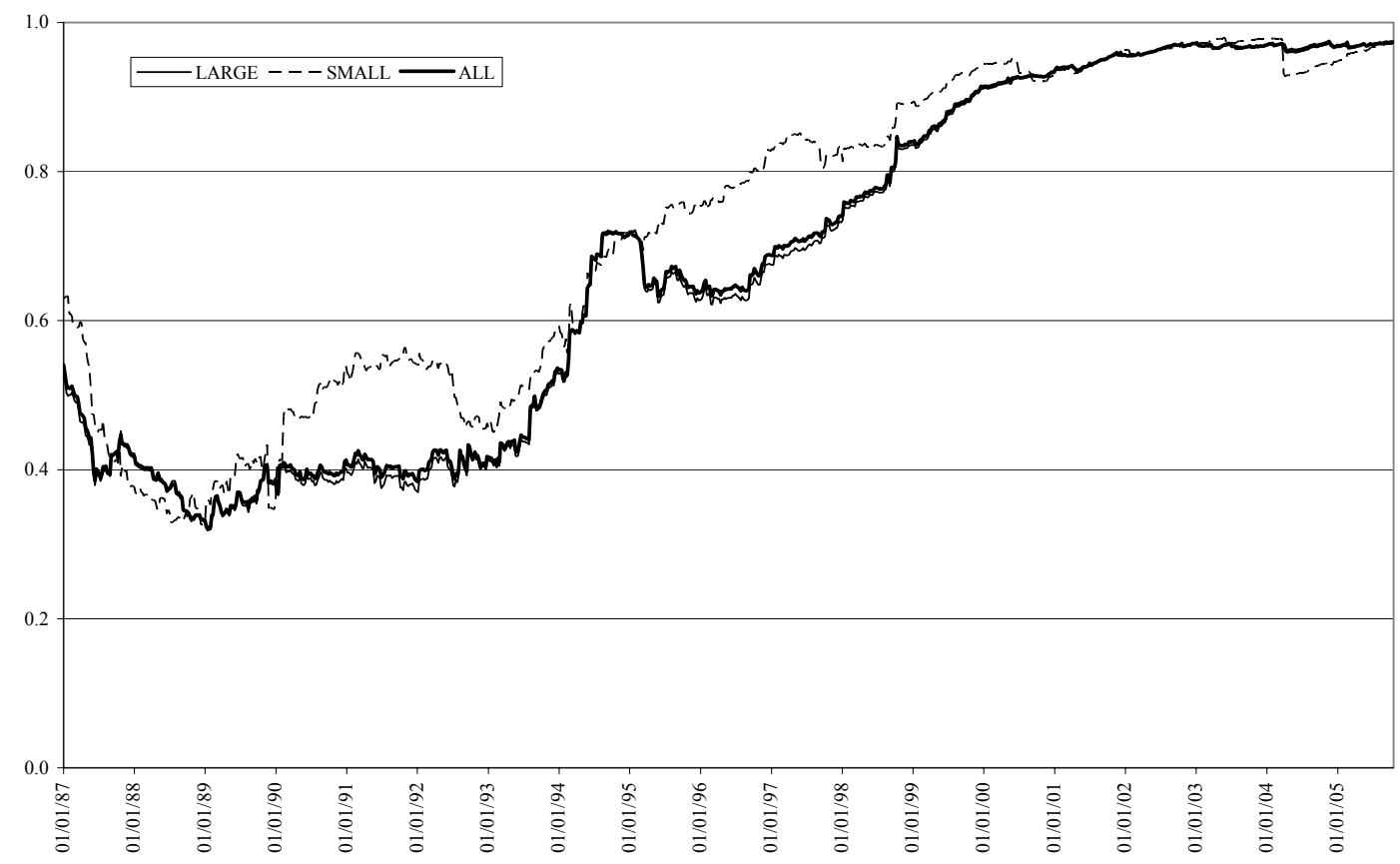


Figure 7: Conditional correlations between returns on on 10-year government bonds for Germany versus other euro area economies

This figure plots conditional correlations between returns on 10-year government bonds for Germany versus other euro area member states. The data set covers the period from January 1987 to October 2005. The countries included in the analysis are Austria (AT), France (FR), Germany (DE), Ireland (IE), Italy (IT), the Netherlands (NL) and Spain (ES).

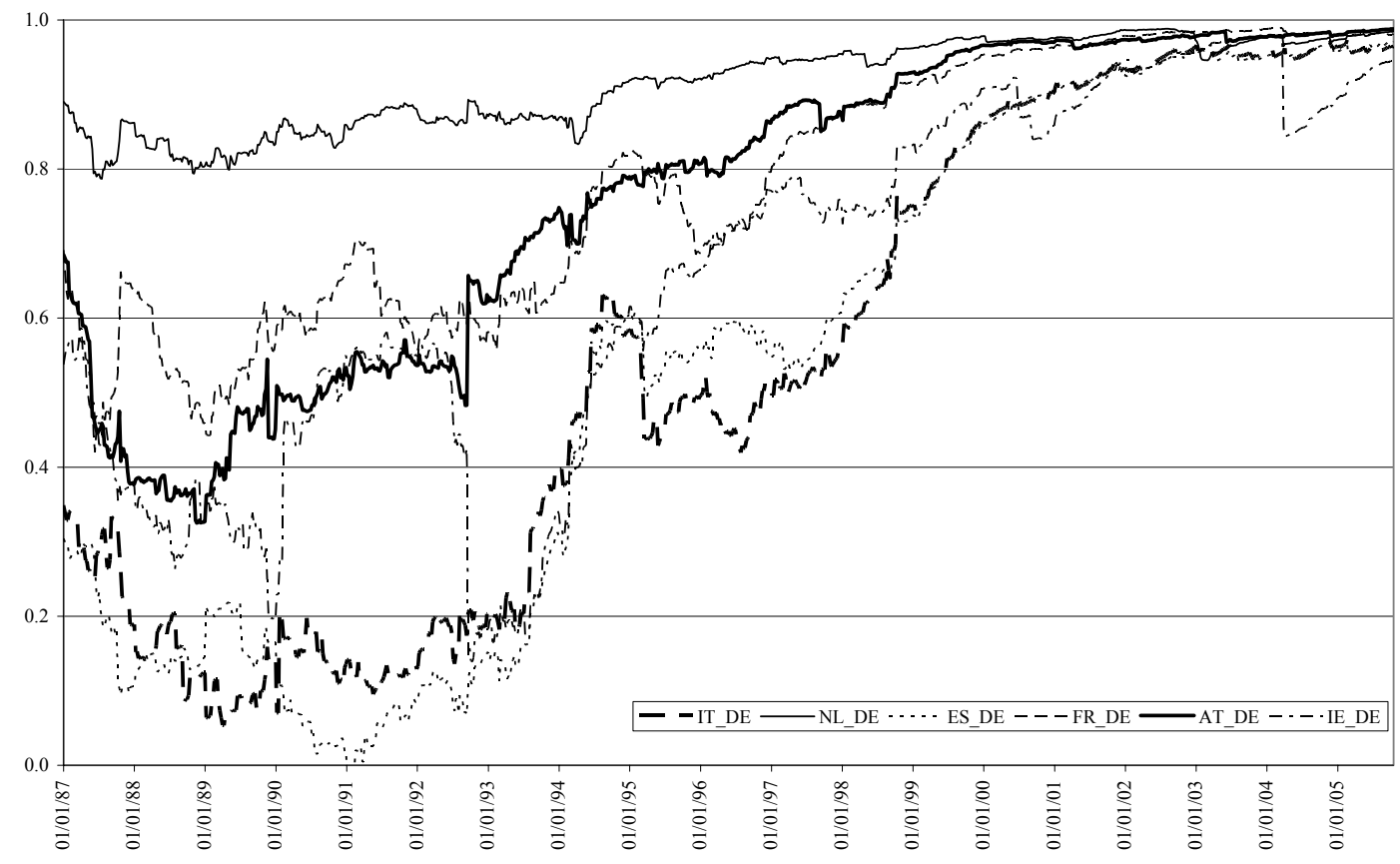


Figure 8: Conditional correlations between returns on 10-year government bonds for Germany and non-euro area economies

This figure plots conditional correlations between returns on 10-year government bonds for Germany versus non-euro area countries. The data set covers the period from January 1987 to October 2005. The non euro area countries included in the analysis are Denmark (DK), Japan (JP), Sweden (SE), the United Kingdom (UK) and the United States (US).

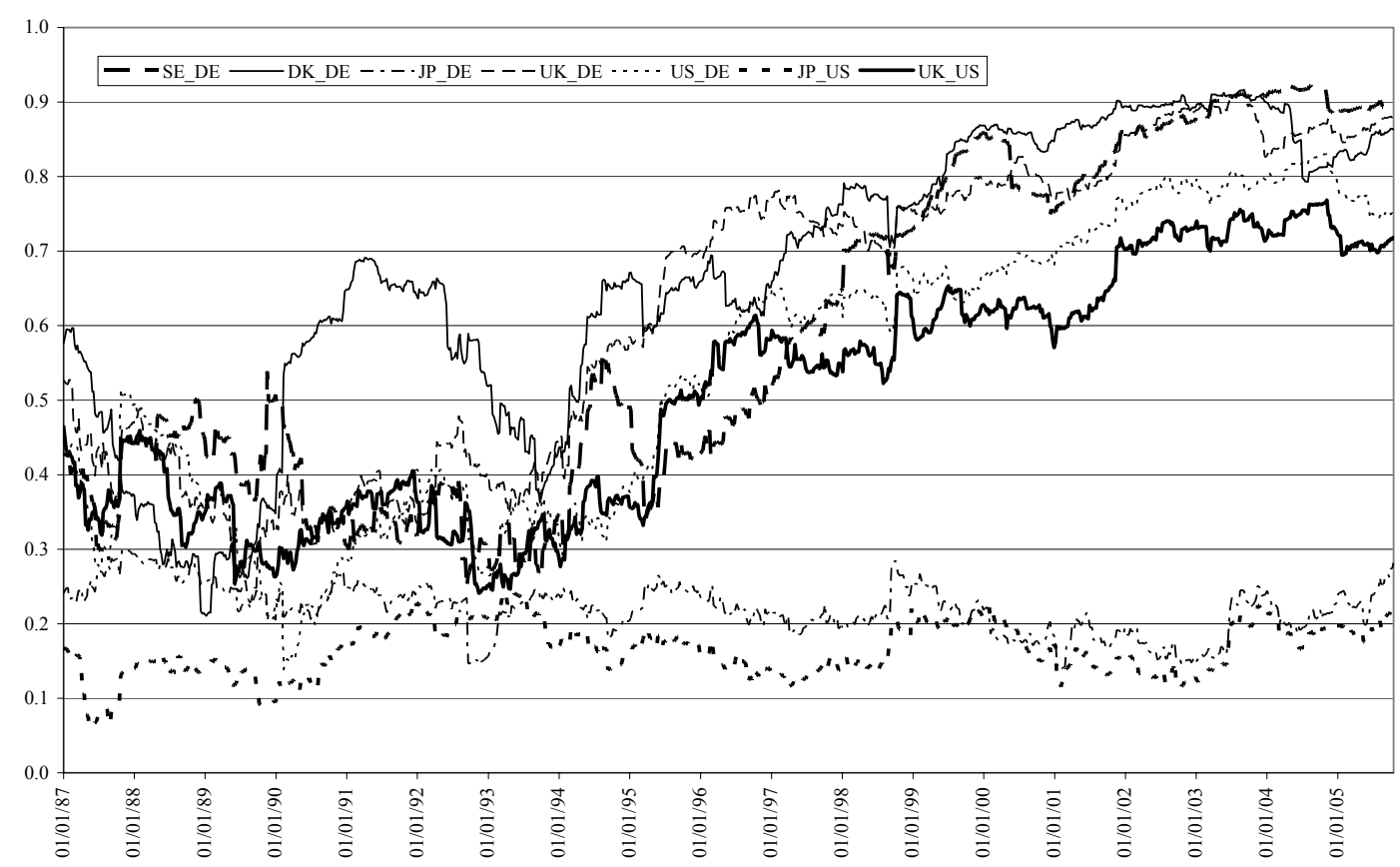


Figure 9: Weighted average conditional volatilities of returns on equity market indices for euro area economies

This figure plots weighted average conditional volatilities of returns on equity market indices for euro area member states. The lines "LARGE", "SMALL" and "ALL" indicate average volatilities of large, small and all the euro area economies, respectively. The data set covers the period from January 1987 to October 2005. The five largest euro area economies are France, Germany, Italy, the Netherlands and Spain. The small economies included in the analysis are Austria, Belgium, Finland, Ireland and Portugal. The conditional volatiltities of each euro area country is weighted by the fraction of its GDP relative to the total euro area GDP.

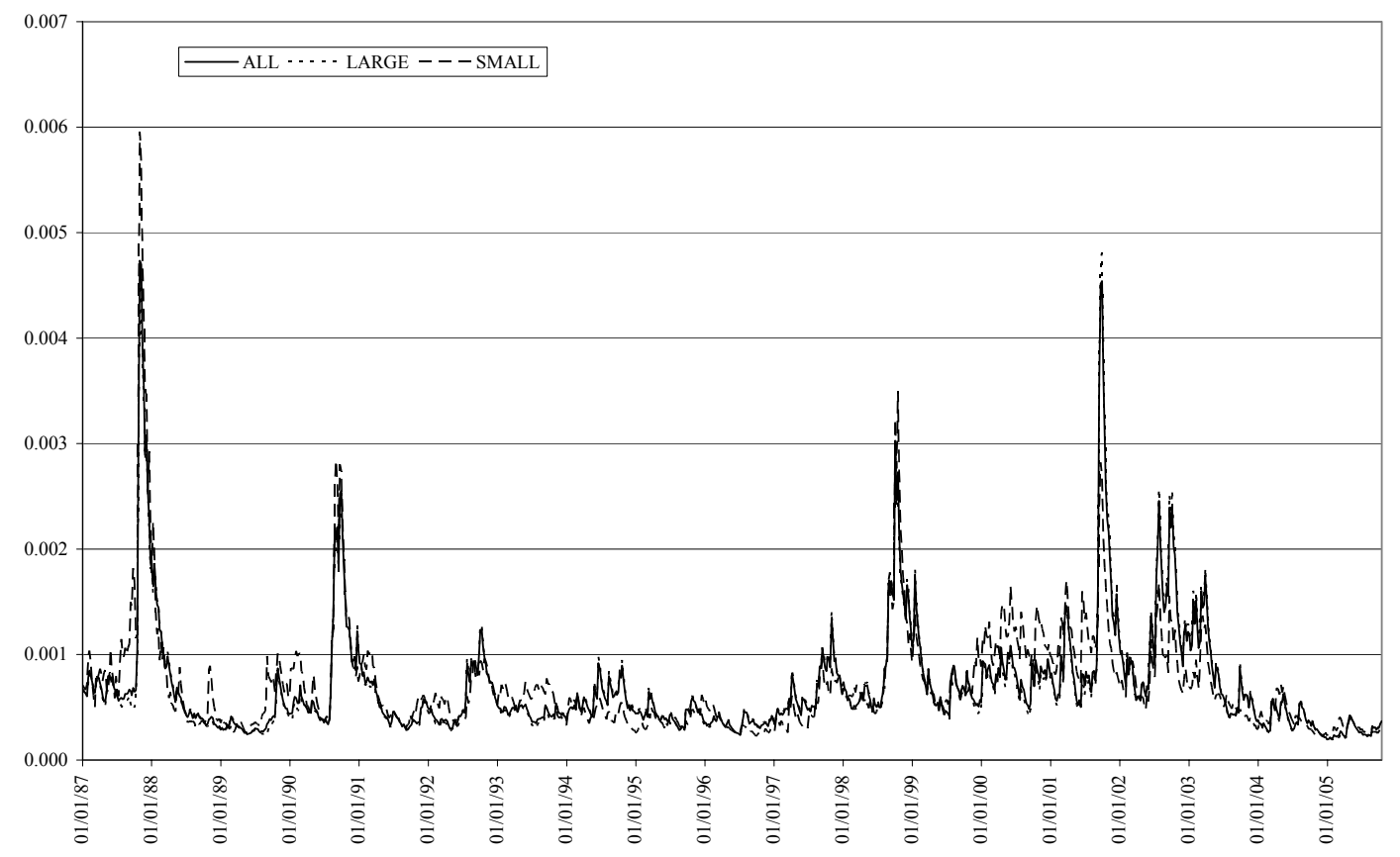


Figure 10: Conditional volatilities of returns on equity market indices for euro area economies

This figure plots conditional volatilities of returns on equity market indices for euro area member states. The data set covers the period from January 1987 to October 2005. The euro area economies included in the analysis are Austria (AT), Belgium (BE), Finland (FI), France (FR), Germany (DE), Ireland (IE), Italy (IT), the Netherlands (NL), Portugal (PT) and Spain (ES). For visual convenience, volatility plots are represented in two different graphs, figure 10a and 10b.

Figure $10 a$

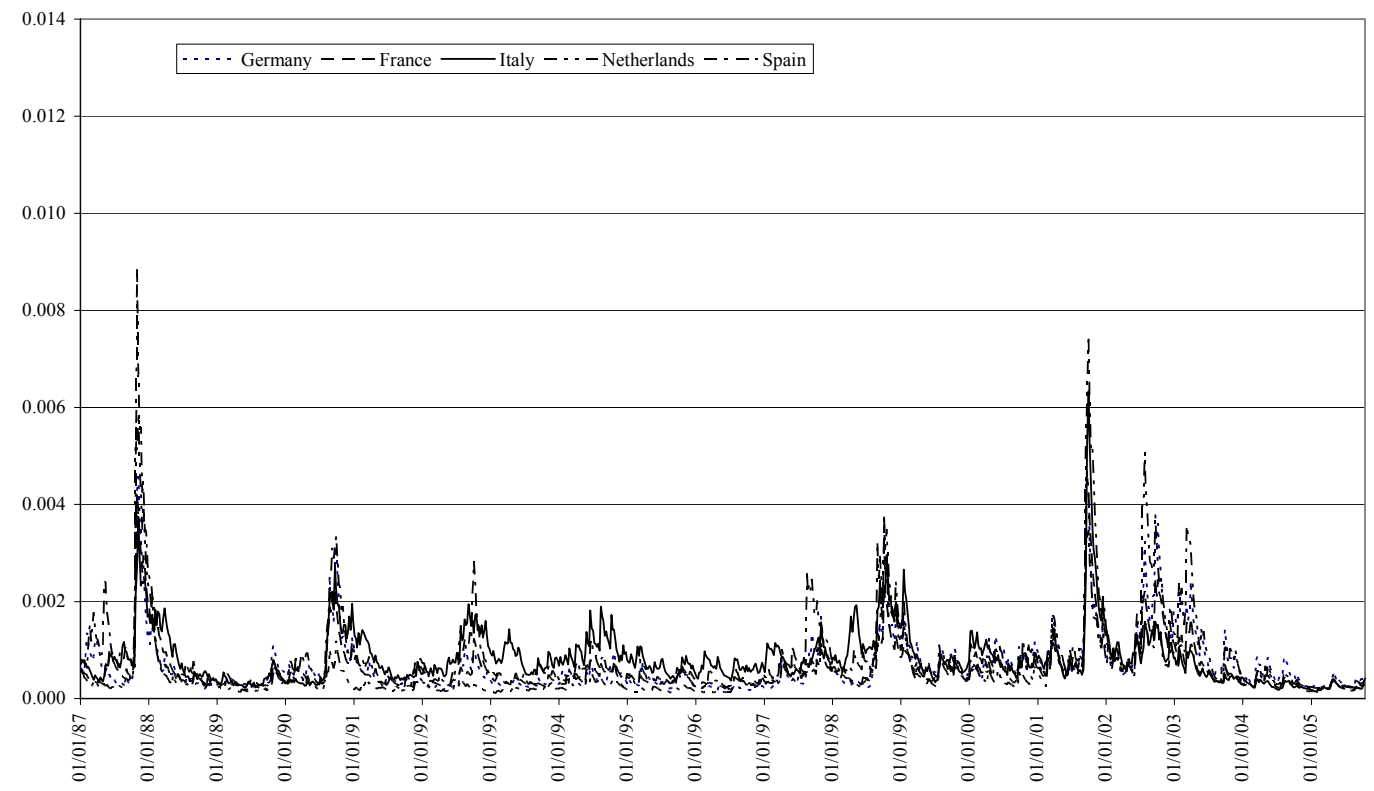

Figure $10 b$

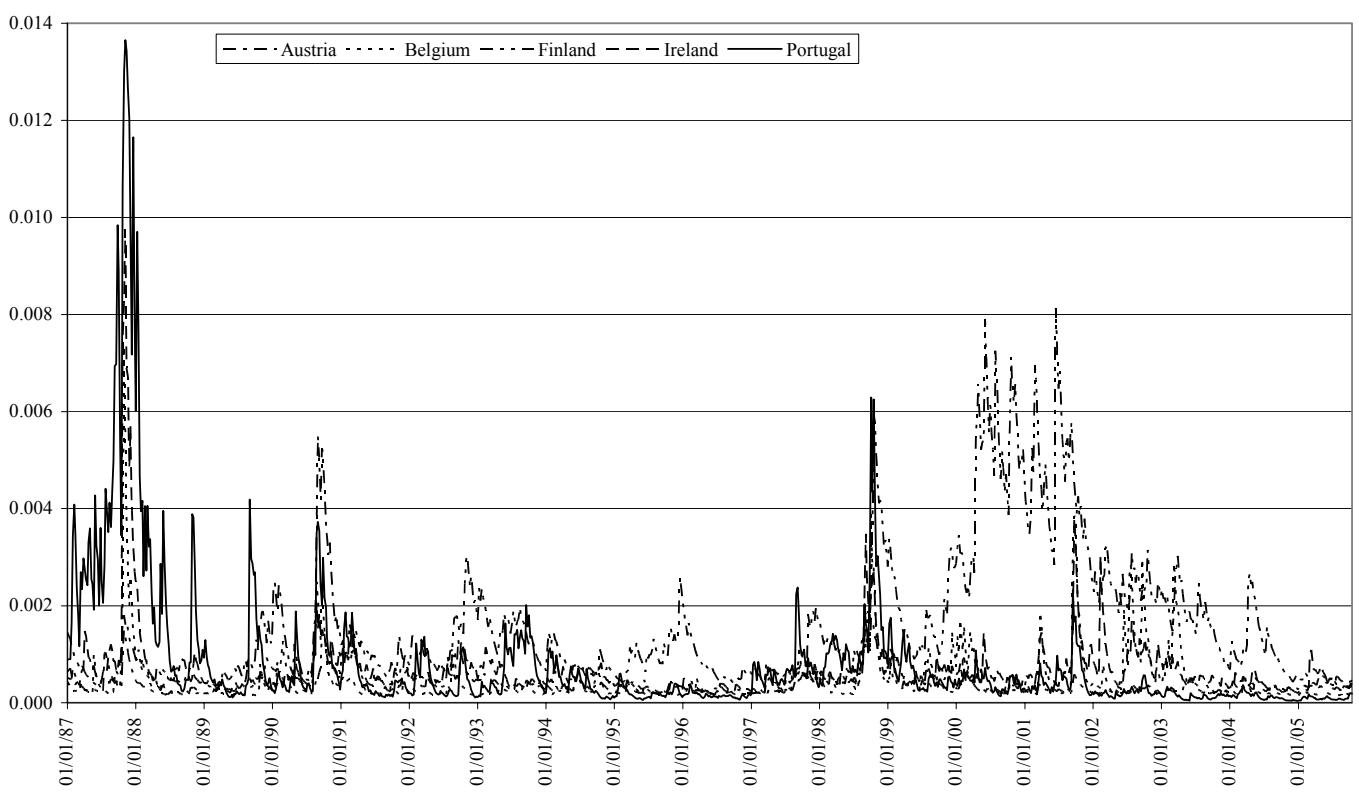


Figure 11: Conditional volatilities of returns on Eurostoxx50 and noneuro area equity market indices

This figure plots conditional volatilities of returns on Eurostoxx 50 and non-euro area equity market indices. The data set covers the period from January 1987 to October 2005. The non euro area countries included in the analysis are Denmark (DK), Japan (JP), Sweden (SE), the United Kingdom (UK) and the United States (US).

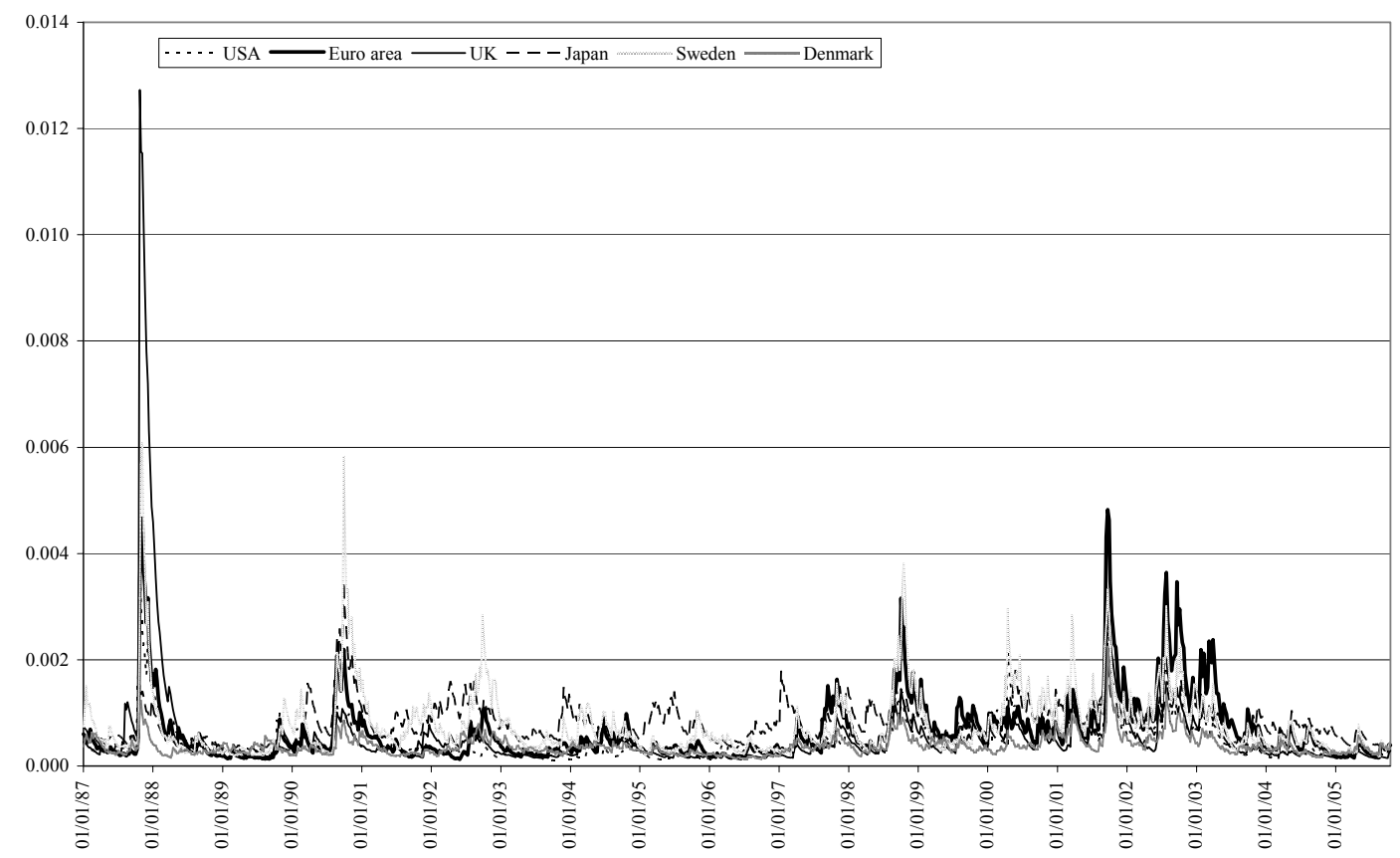


Figure 12: Weighted average conditional volatilities of returns on 10-year government bonds for euro area economies

This figure plots weighted average conditional volatilities of returns on 10-year government bonds for euro area member states. The lines "LARGE", "SMALL" and "ALL" indicate average volatilities of large, small and all the euro area economies, respectively. The data set covers the period from January 1987 to October 2005. The five largest euro area economies are France, Germany, Italy, the Netherlands and Spain. The small economies included in the analysis are Austria and Ireland. The conditional volatilities of each euro area country is weighted by the fraction of its GDP relative to the total euro area GDP.

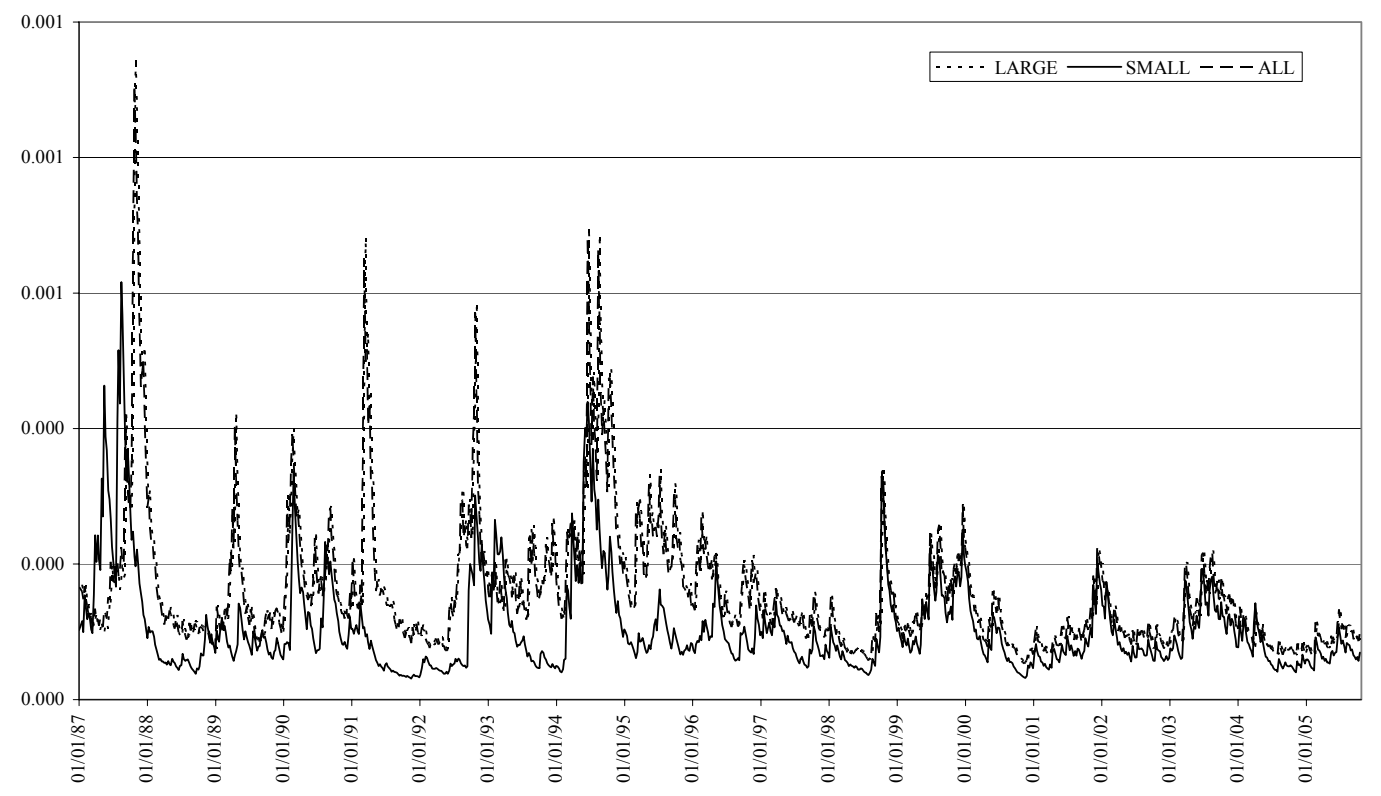


Figure 13: Conditional volatilities of returns on 10-year government bonds for euro area economies

This figure plots conditional volatilities of returns on world government bond markets. The data set covers the period from January 1987 to October 2005. The euro area economies included in the analysis are Austria (AT), France, Germany, Ireland, Italy, the Netherlands, and Spain . For visual convenience, volatility plots are represented in two different graphs, figure 13a and 13b. Figure 13c plots volatiity for Denmark, Japan, the US, the UK, and Sweden.

Figure $13 a$

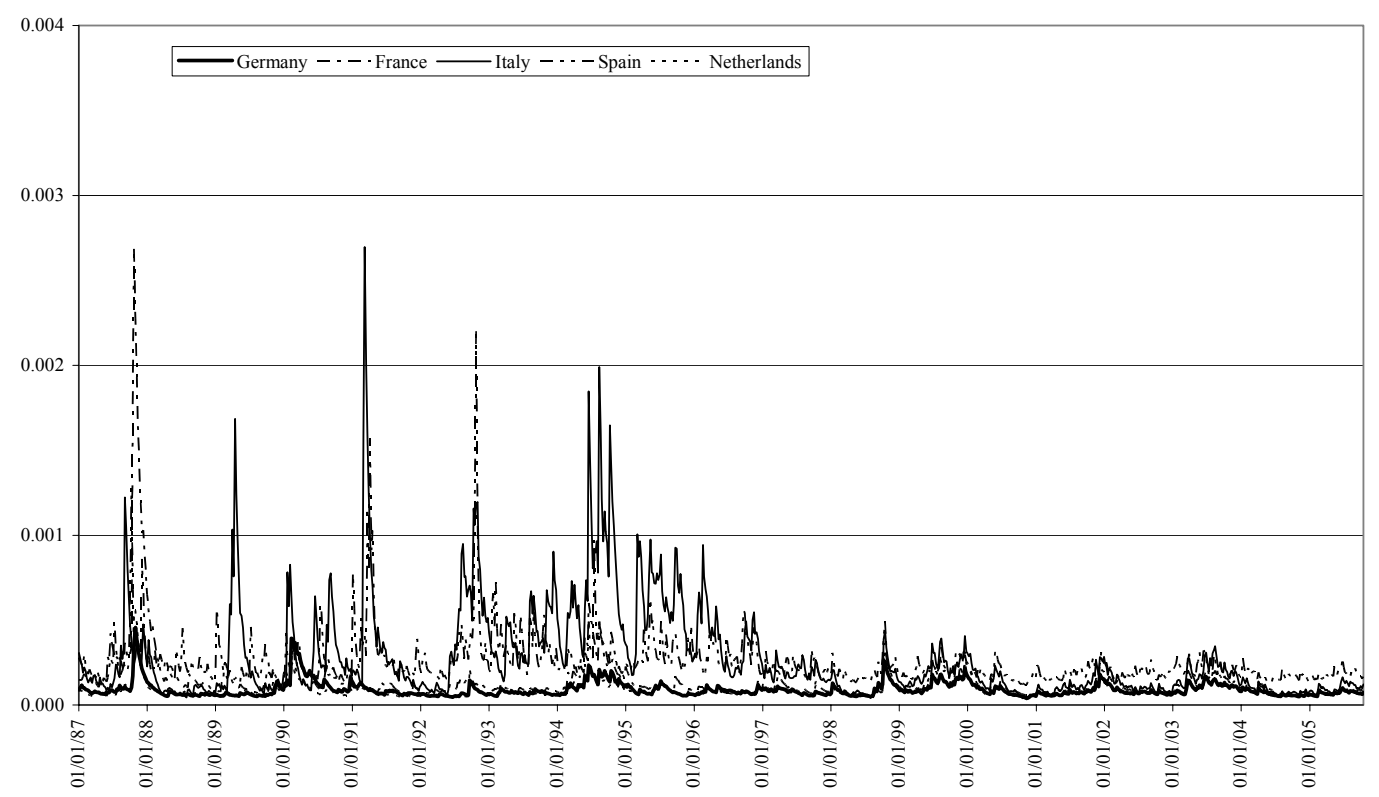

Figure $13 b$

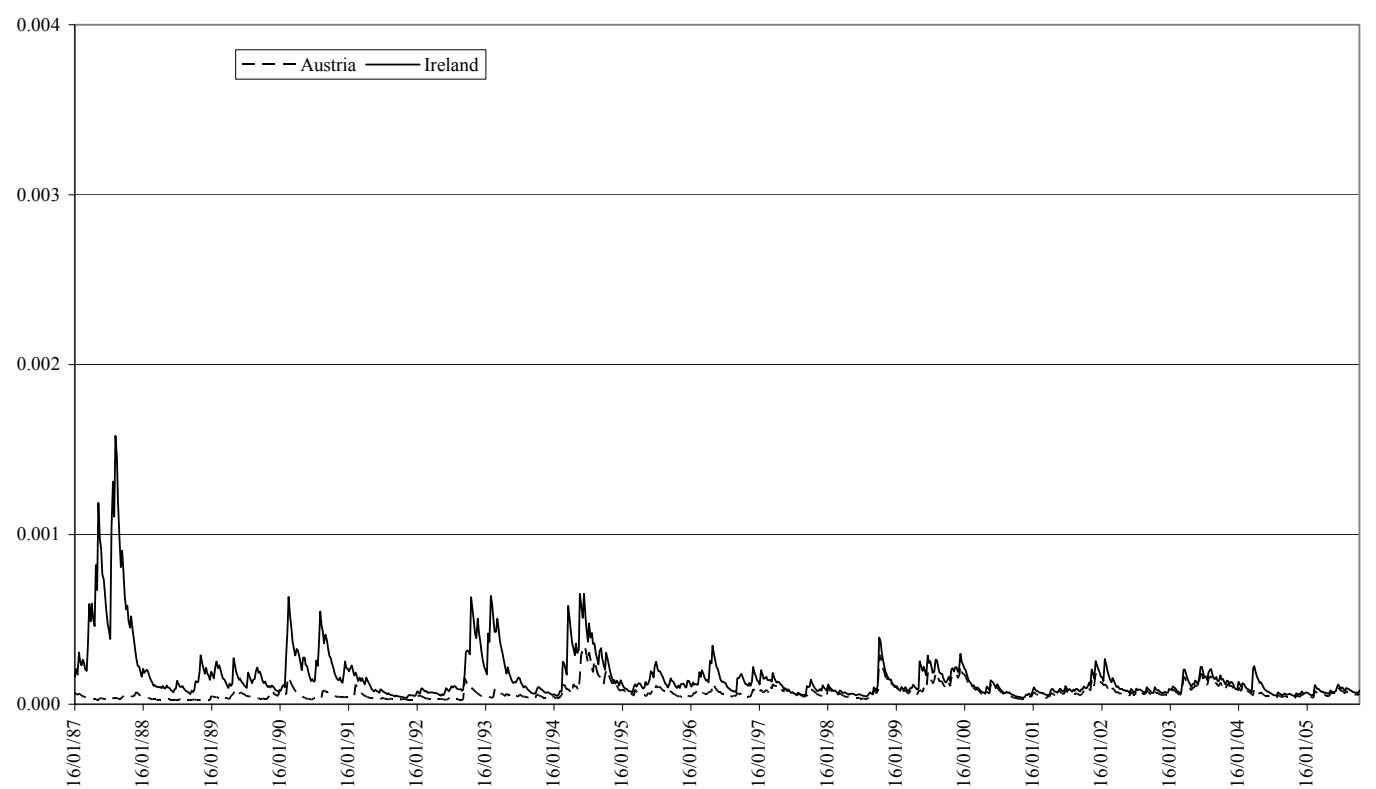


Figure 13 - Continued

Figure $13 \mathrm{c}$

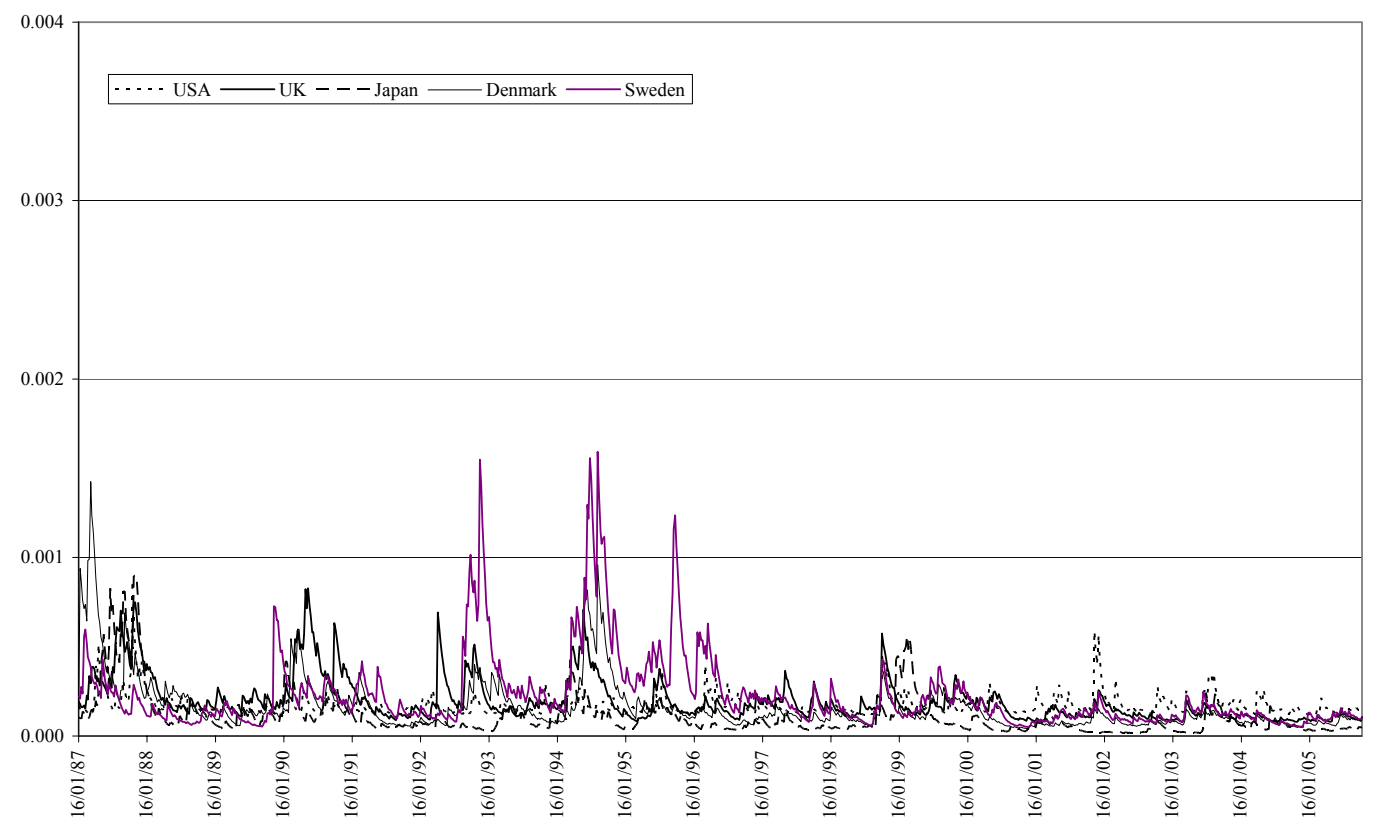




\section{Figure 14: The comovement box}

Figure 14 plots the probability that an asset return $r_{i t}$ falls below (above) its $\theta$-quantile conditional on another asset return $r_{j t}$ being below (above) its $\theta$-quantile, for $\theta<0.5$ $(\theta \geq 0.5)$. The case of perfect positive correlation (co-monotonicity), independence, and perfect negative correlation (counter-monotonicity) are represented.

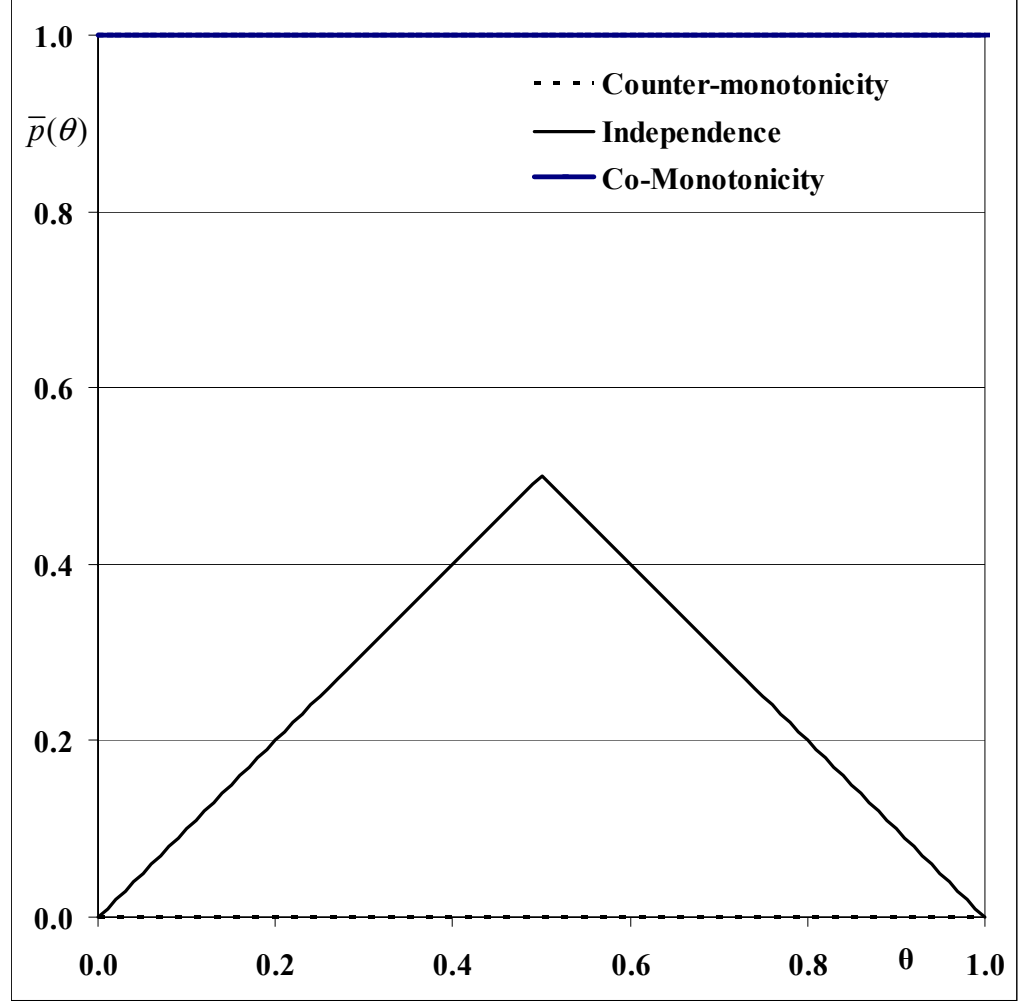


Figure 15: Weighted average probabilities of comovements between returns on equity market indices for the euro area economies

Figures 15a-15d plot weighted average estimated probabilities of comovements between returns on equity market indices for euro area member states over two periods. The first sub-sample covers the pre-monetary union period (January 1992 to December 1998), while the second the monetary union period (December 1999 to October 2005). The five largest euro area economies are France, Germany, Italy, the Netherlands and Spain. The small economies included in the analysis are Austria, Belgium, Finland, Greece, Ireland and Portugal. The probability of comovement of each euro area country pair is weighted by the fraction of its GDP relative to the total euro area GDP.

Figure 15a: All euro area economies

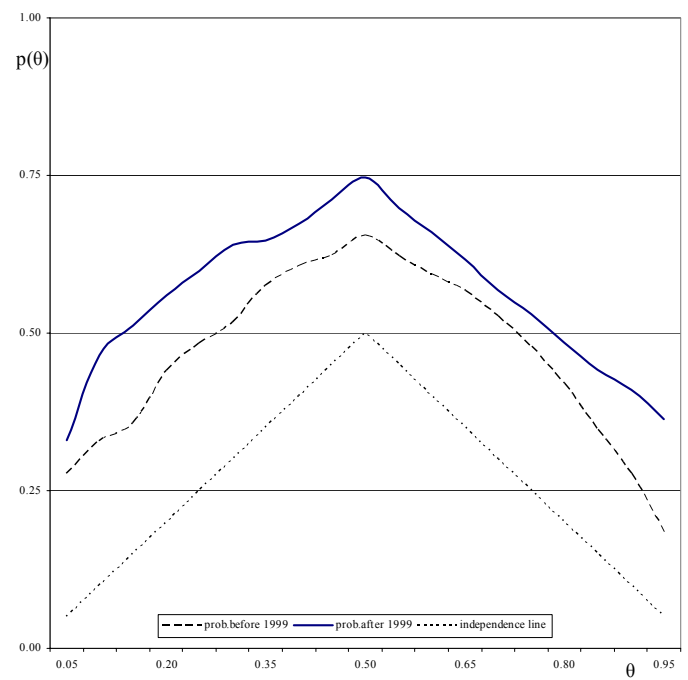

Figure 15c: Small economies

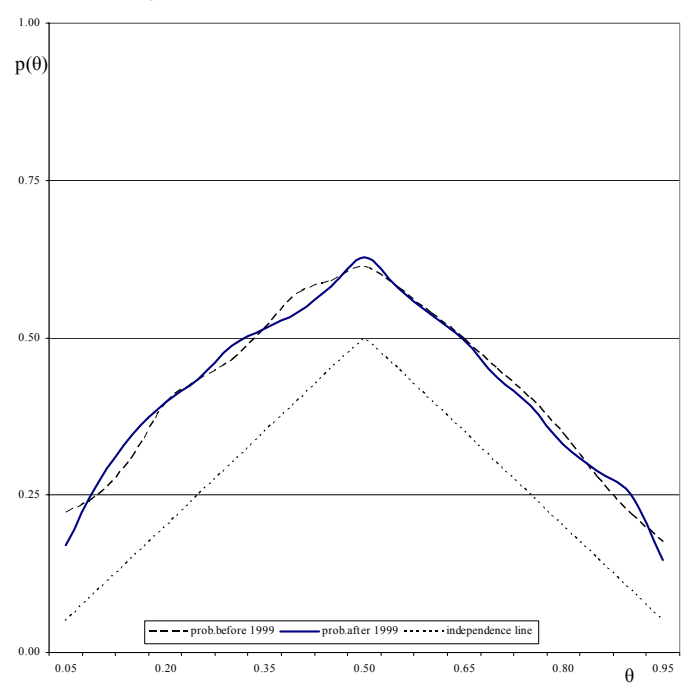

Figure 15b: Five largest economies

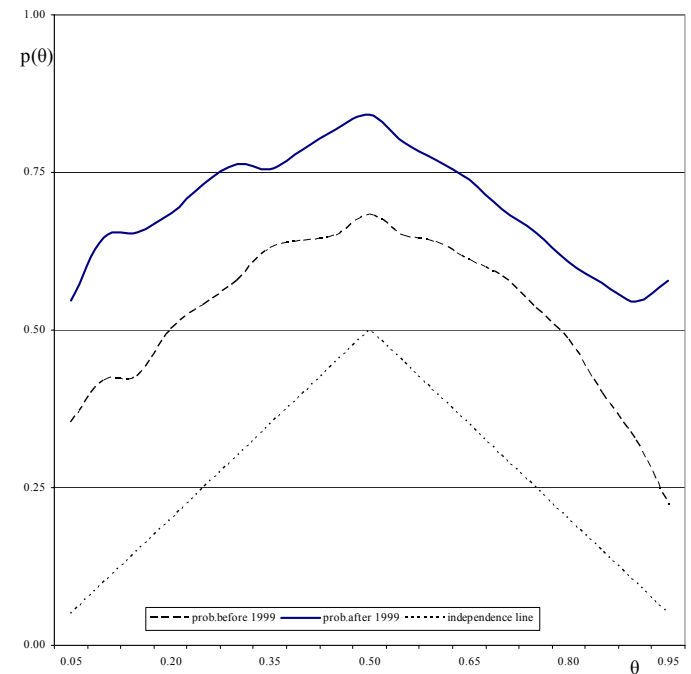

Figure 15d: Small vs. large economies

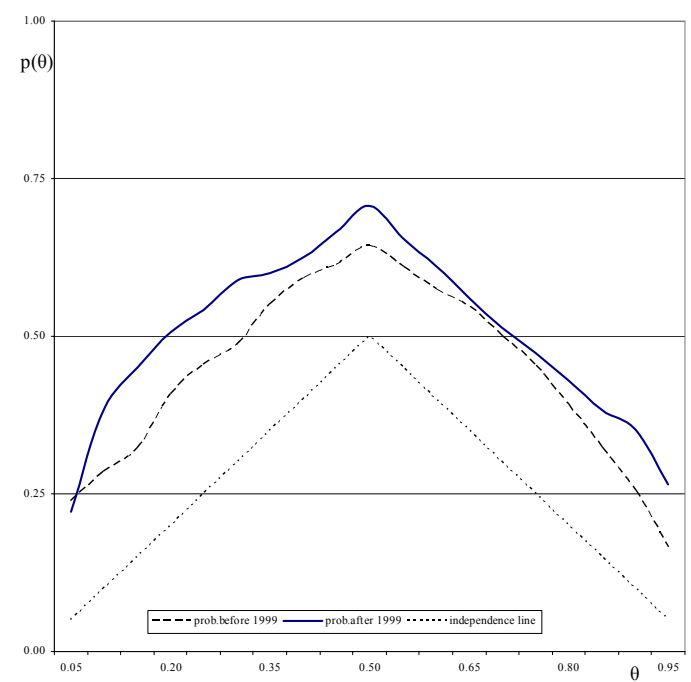


Figure 16: Probabilities of comovements between returns on equity market indices for the large euro area economies

Figures 16a-16j plot the estimated probabilities of comovements between returns on large euro area country pairs equity market indices over two periods. The first sub-sample covers the pre-monetary union period (January 1992 to December 1998), while the second the monetary union period (January 1999 to October 2005). The five largest euro area economies are France, Germany, Italy, the Netherlands and Spain. The thin lines denote the two standard error bounds around the estimated comovement likelihood in the monetary union period, while the dashed lines represent the probability of comovement in the pre-monetary union period.

Figure 16a: France-Germany

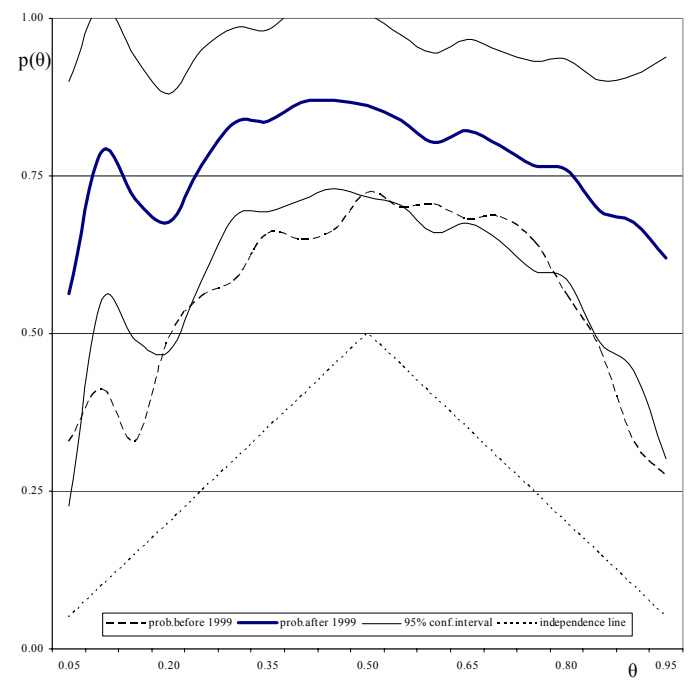

Figure 16c: France-Netherlands

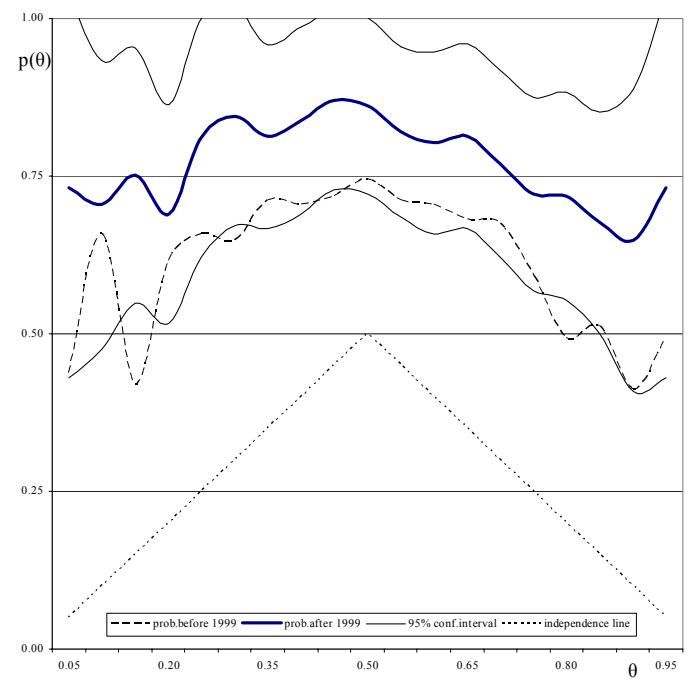

Figure 16b: France-Italy

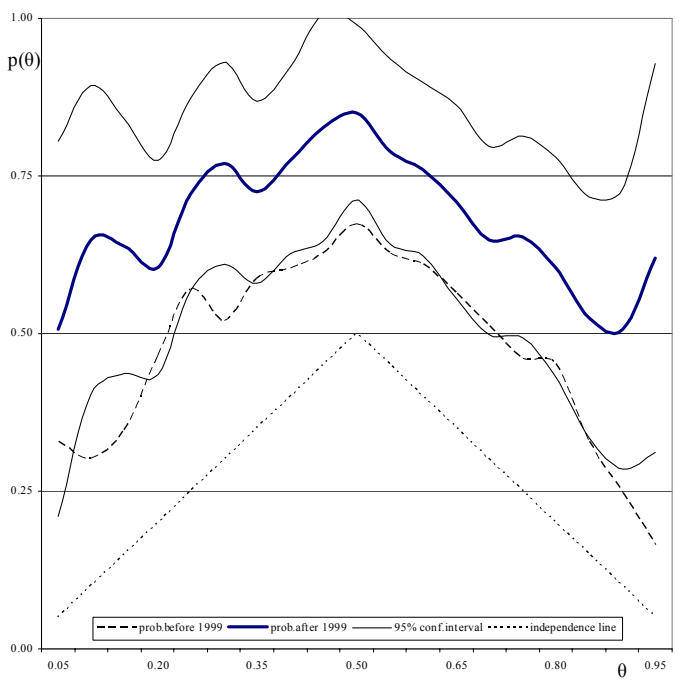

Figure 16d: France-Spain

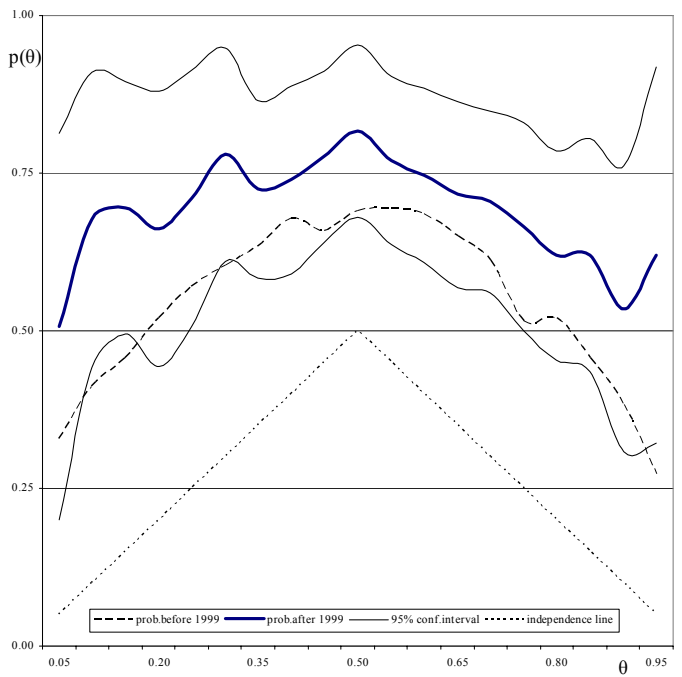




\section{Figure 16 - Continued}

Figure 16e: Germany-Italy

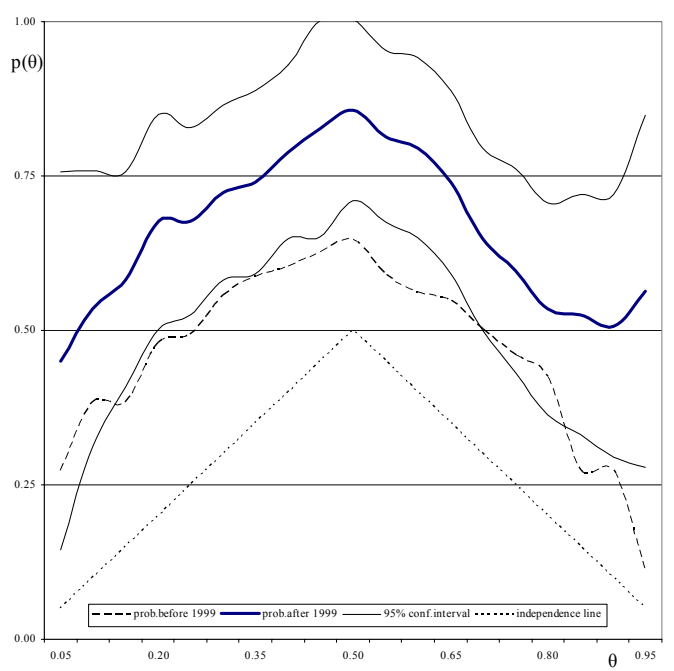

Figure 16g: Germany-Spain

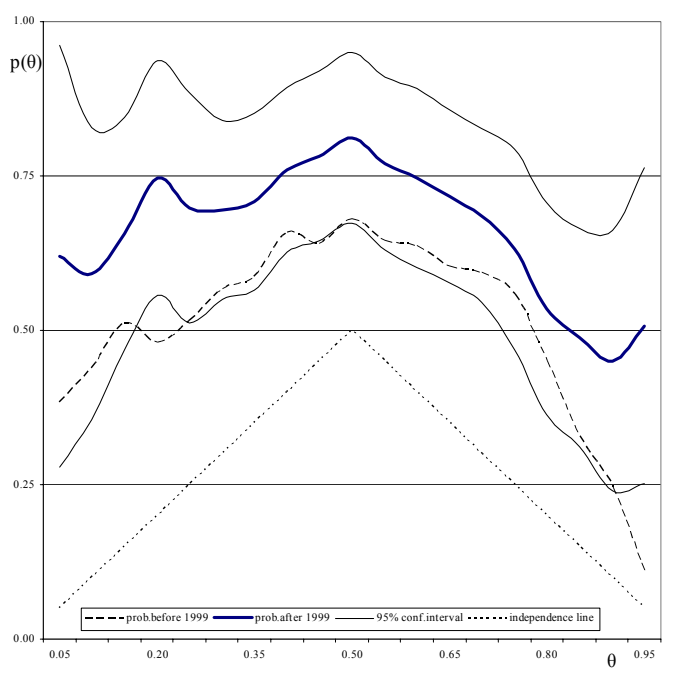

Figure 16i: Italy-Spain

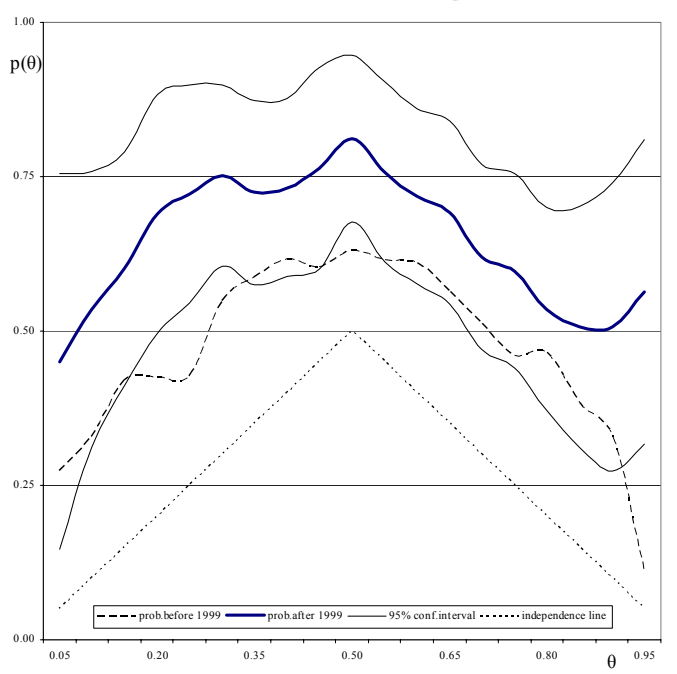

Figure 16f: Germany-Netherlands

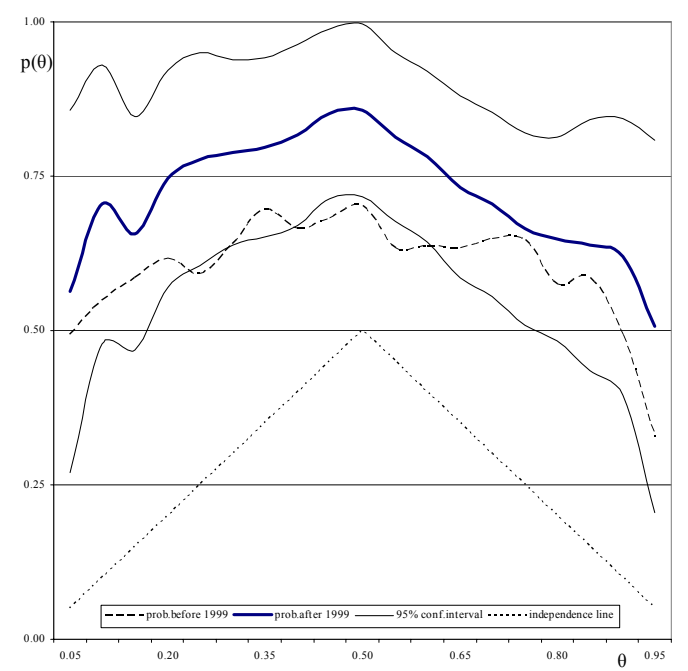

Figure 16h: Italy-Netherlands

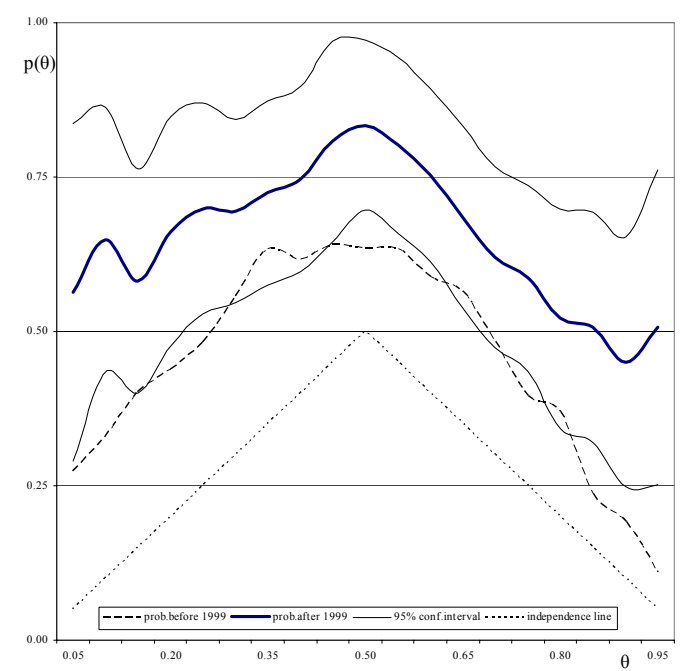

Figure 16j: Spain-Netherlands

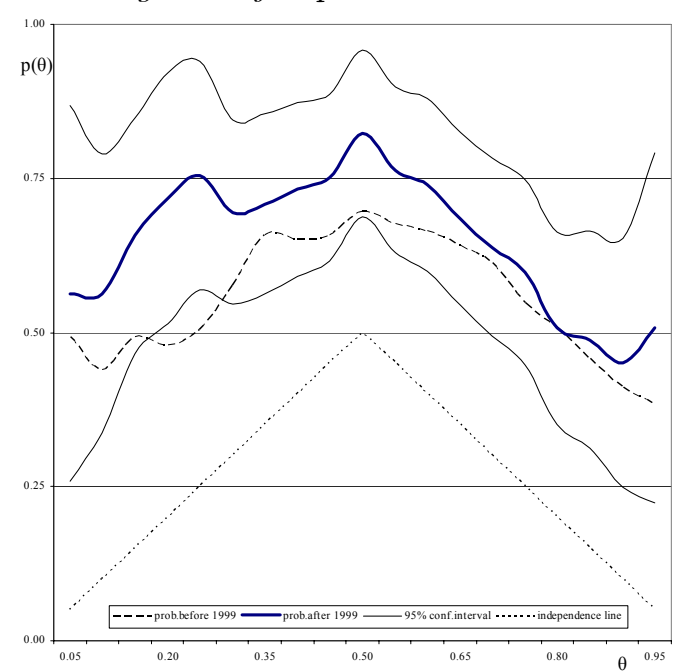


Figure 17: Probabilities of comovements between returns on equity market indices for small euro area economies

Figures 17a-17o plot the estimated probabilities of comovements between returns on small euro area country pairs equity market indices over two periods. The first sub-sample covers the pre-monetary union period (January 1992 to December 1998), while the second the monetary union period (January 1999 to October 2005). The small euro area economies included in the analysis are Austria, Belgium, Finland, Greece, Ireland and Portugal. The thin lines denote the two standard error bounds around the estimated comovement likelihood in the monetary union period, while the dashed lines represent the probability of comovement in the pre-monetary union period.

Figure 17a: Austria-Belgium

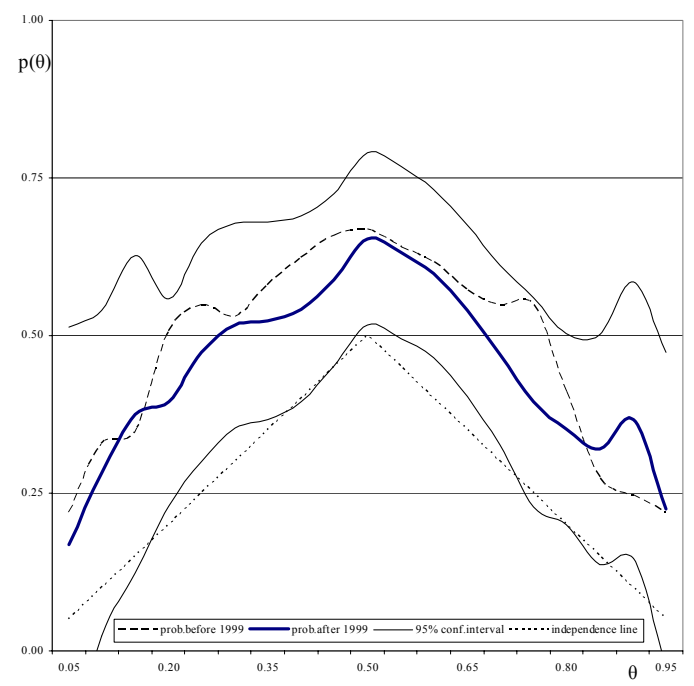

Figure 17c: Austria-Greece

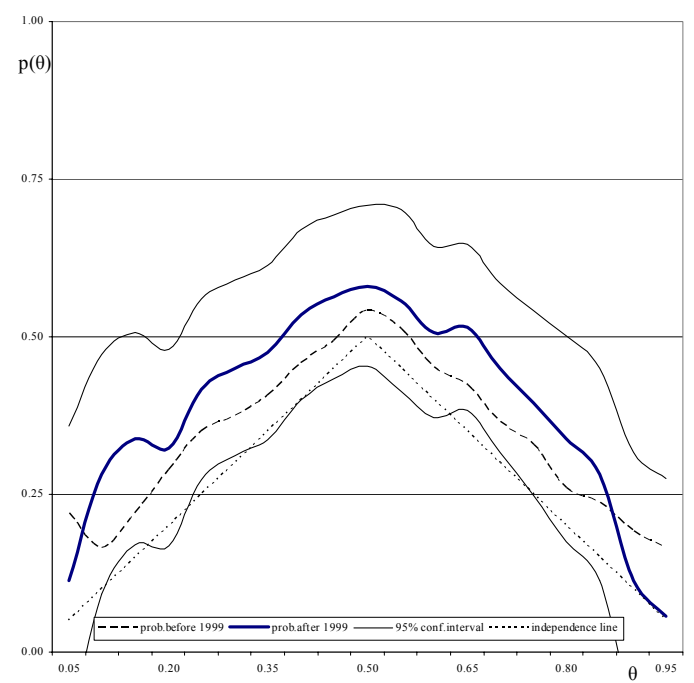

Figure 17b: Austria-Finland

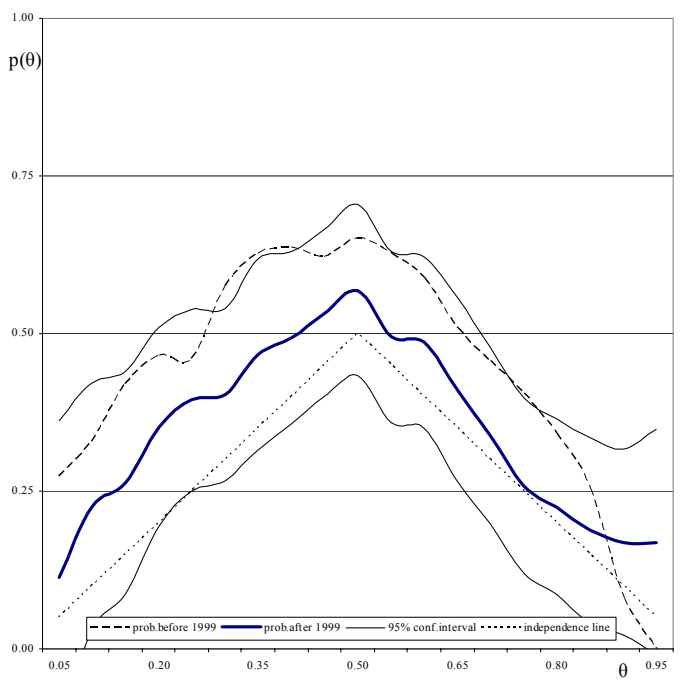

Figure 17d: Austria-Ireland

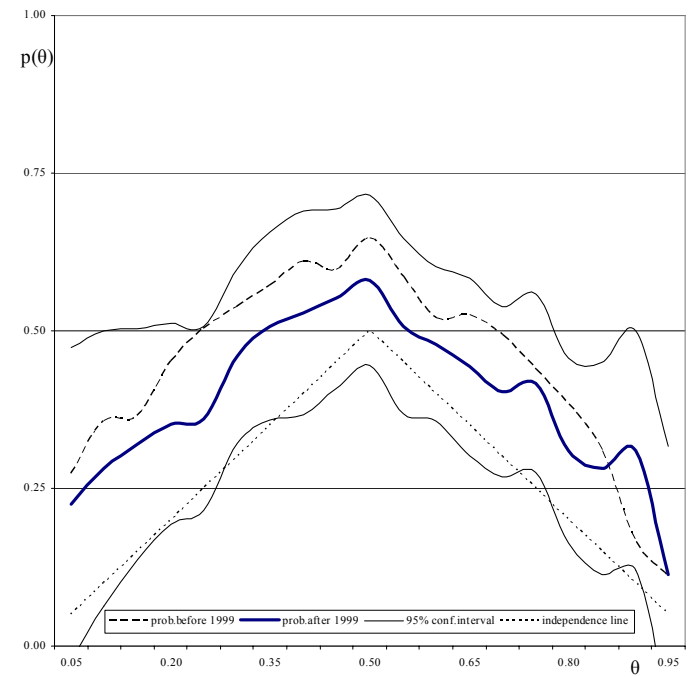


Figure 17 - Continued

Figure 17e: Austria-Portugal

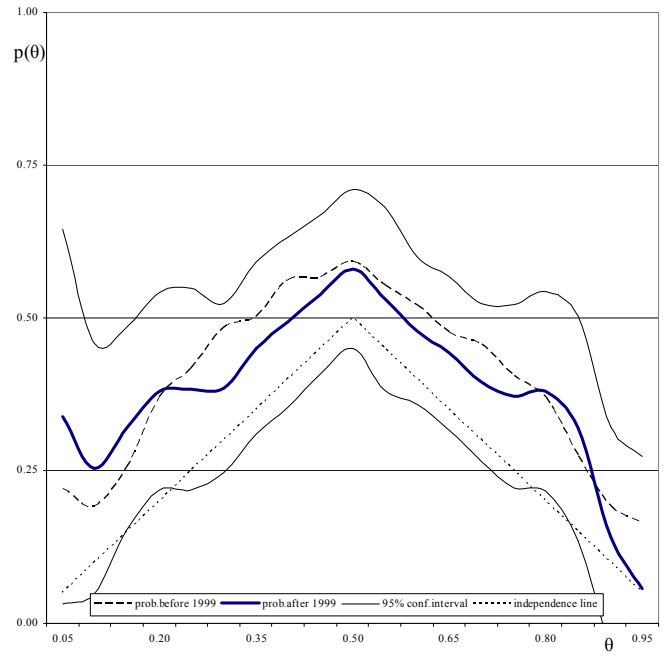

Figure 17g: Belgium-Greece

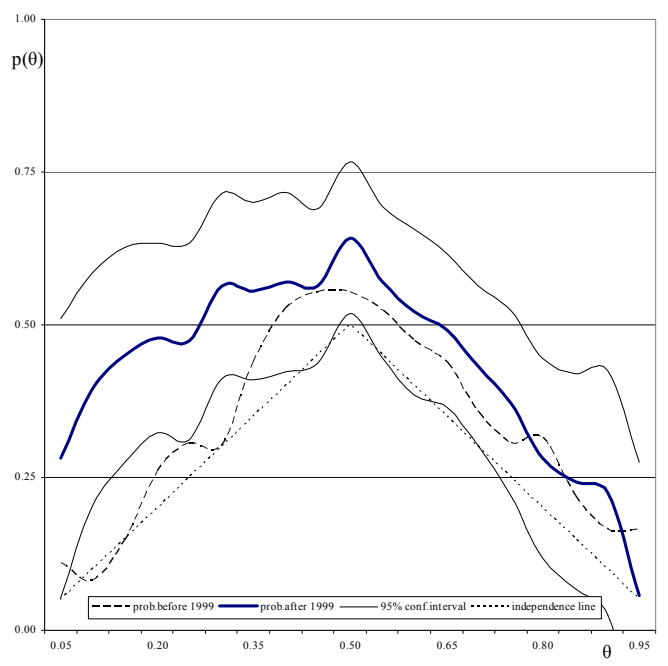

Figure 17i: Belgium-Portugal

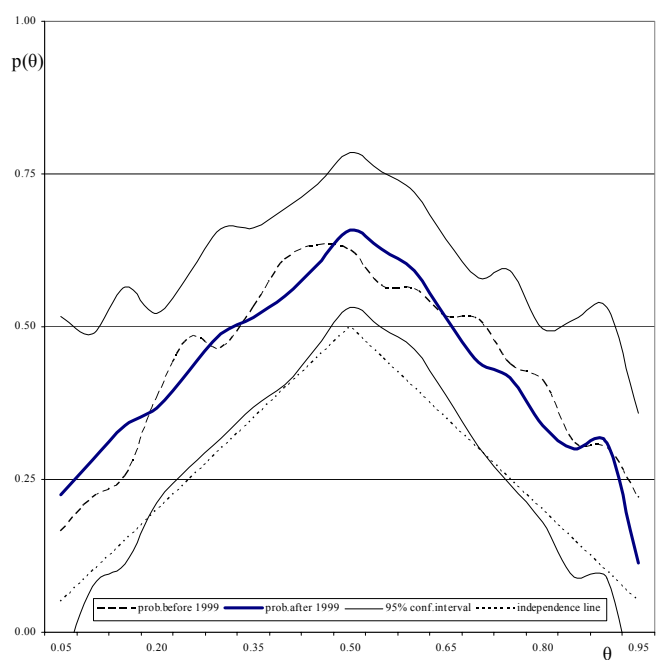

Figure 17f: Belgium-Finland

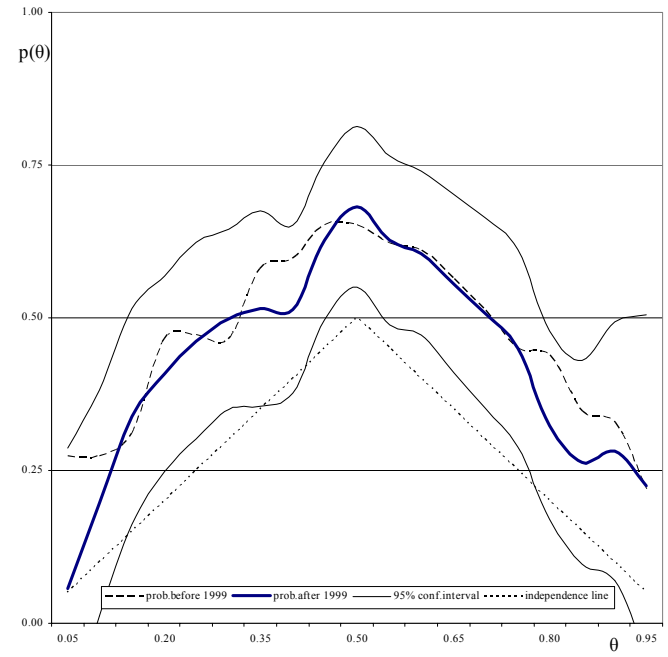

Figure 17h: Belgium-Ireland

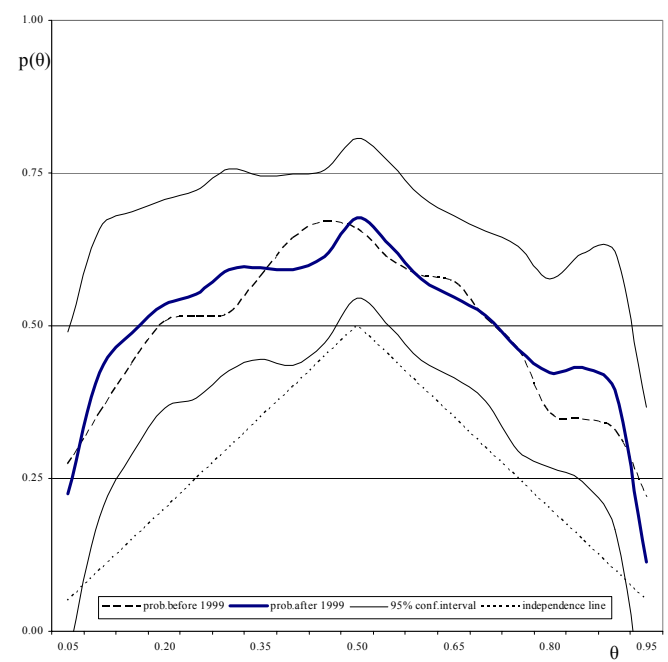

Figure 17j: Finland-Greece

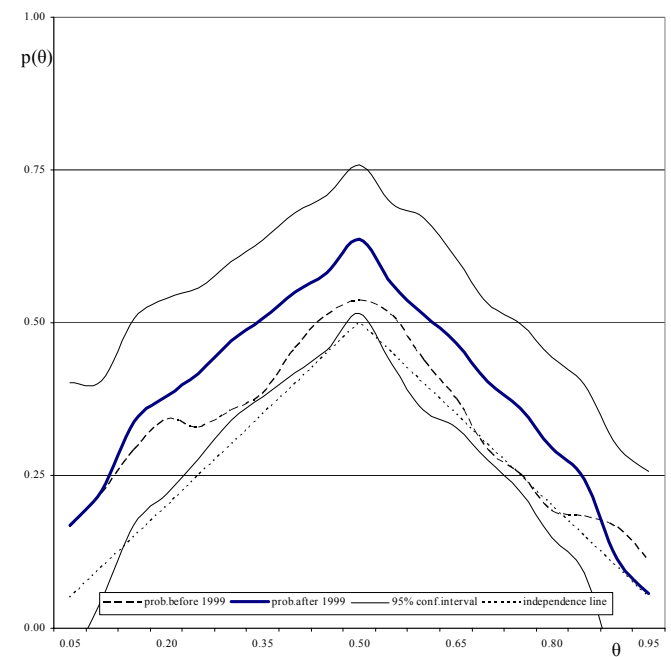


Figure 17 - Continued

Figure 17k: Finland-Ireland

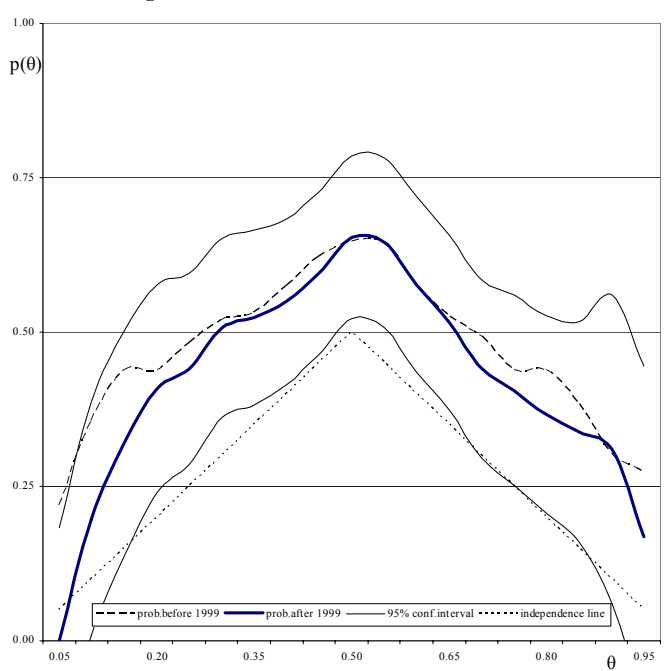

Figure 1\%m: Greece-Ireland

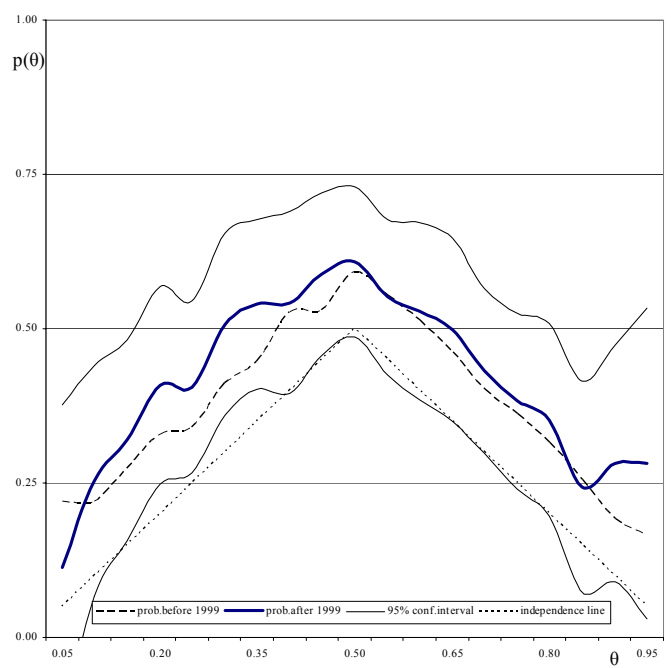

Figure 17o: Ireland-Portugal

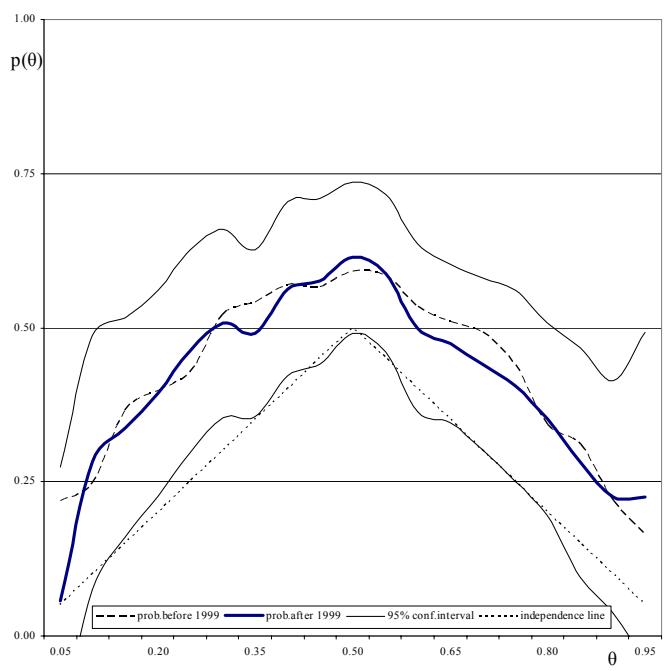

Figure 17l: Finland-Portugal

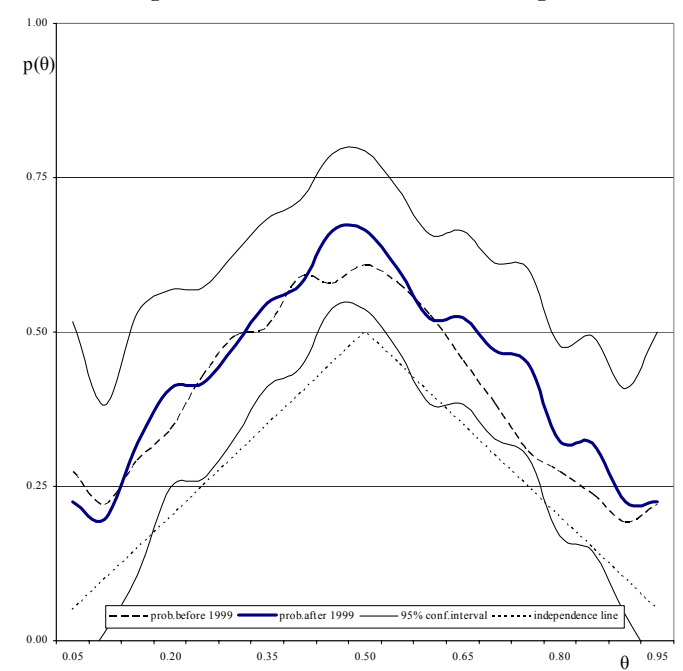

Figure 17n: Greece-Portugal

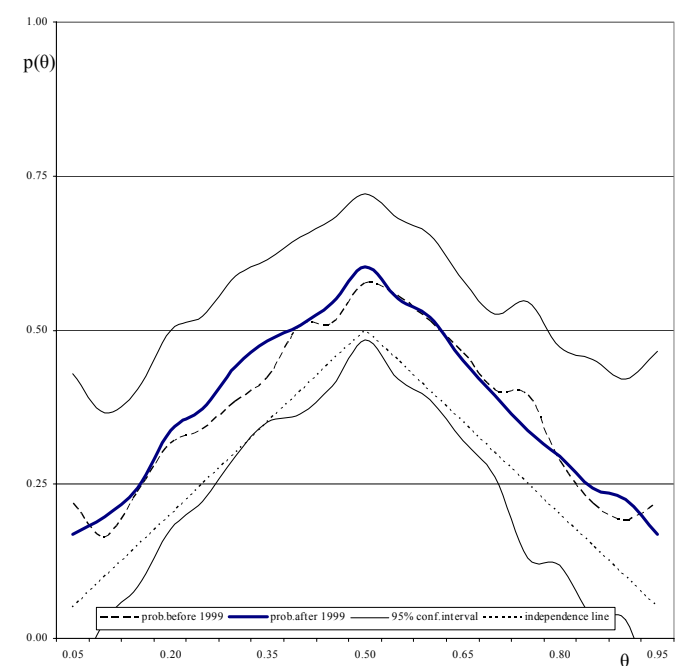


Figure 18: Probabilities of comovements between returns on equity market indices for large and small euro area economies

Figures 18a-18l plot the estimated probabilities of comovements between returns on large and small euro area country pairs equity market indices over two periods. The first subsample covers the pre-monetary union period (January 1992 to December 1998), while the second the monetary union period (January 1999 to October 2005). The five largest euro area economies are France, Germany, Italy, the Netherlands and Spain. The small economies included in the analysis are Austria, Belgium, Finland, Greece, Ireland and Portugal. The thin lines denote the two standard error bounds around the estimated comovement likelihood in the monetary union period, while the dashed lines represent the probability of comovement in the pre-monetary union period.

Figure 18a: Austria-France

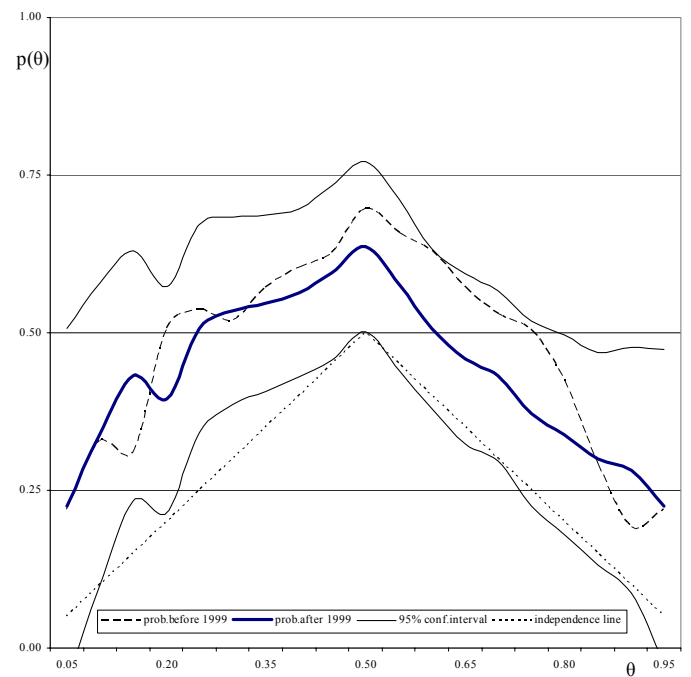

Figure 18c: Belgium-France

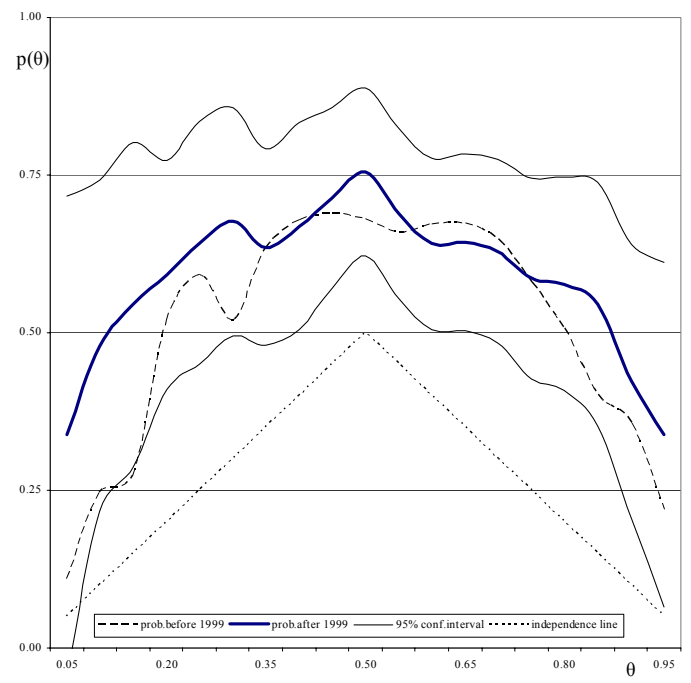

Figure 18b: Austria-Germany

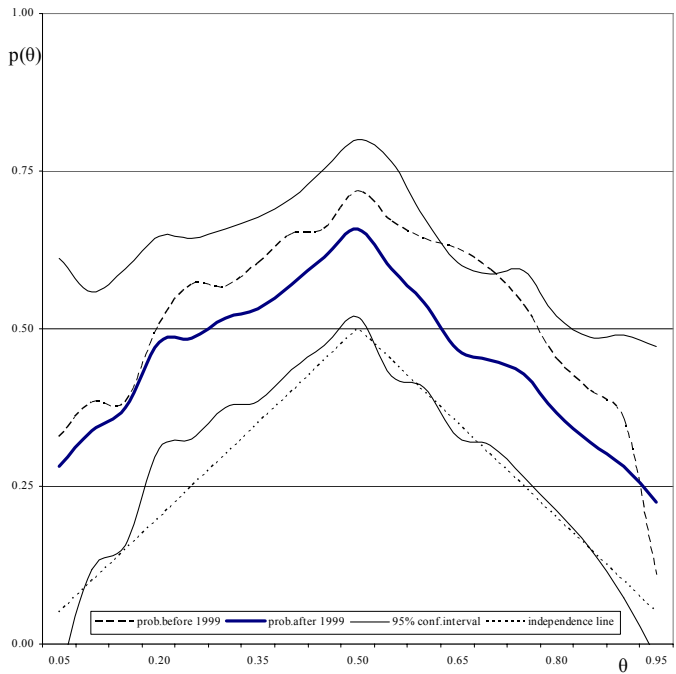

Figure 18d: Belgium-Netherlands

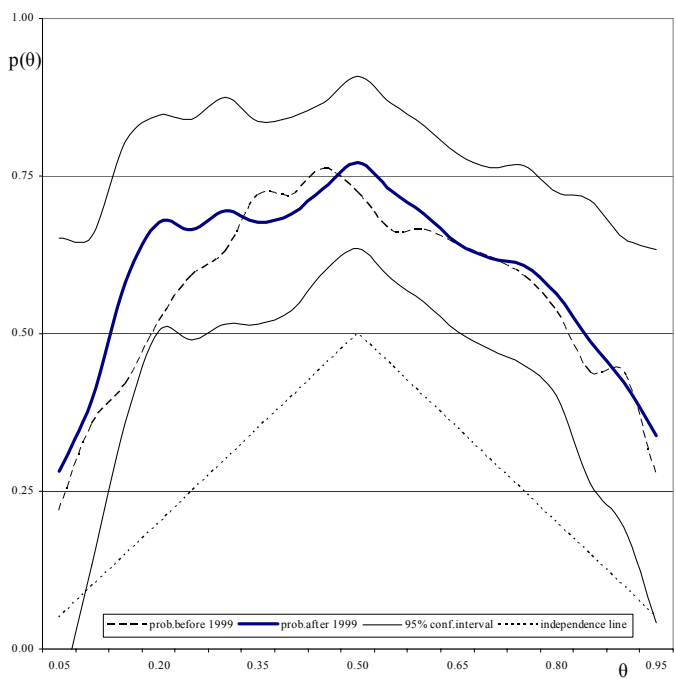


Figure 18 - Continued

Figure 18e: Finland-Germany

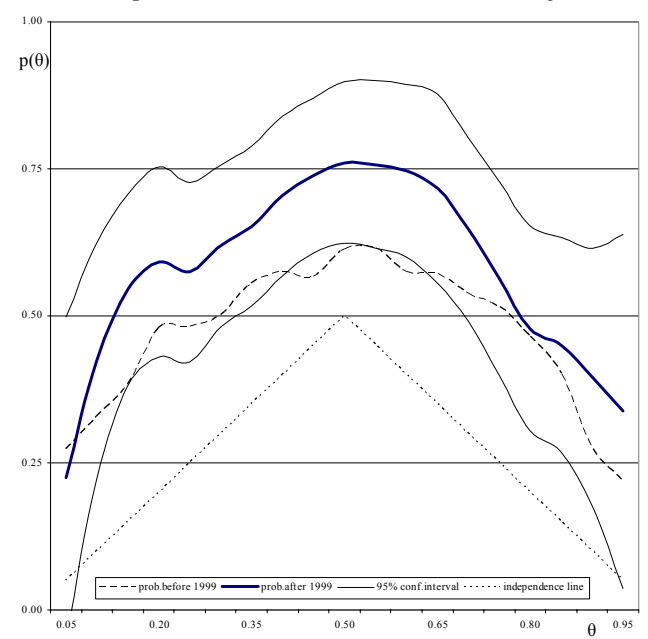

Figure 18g: Greece-France

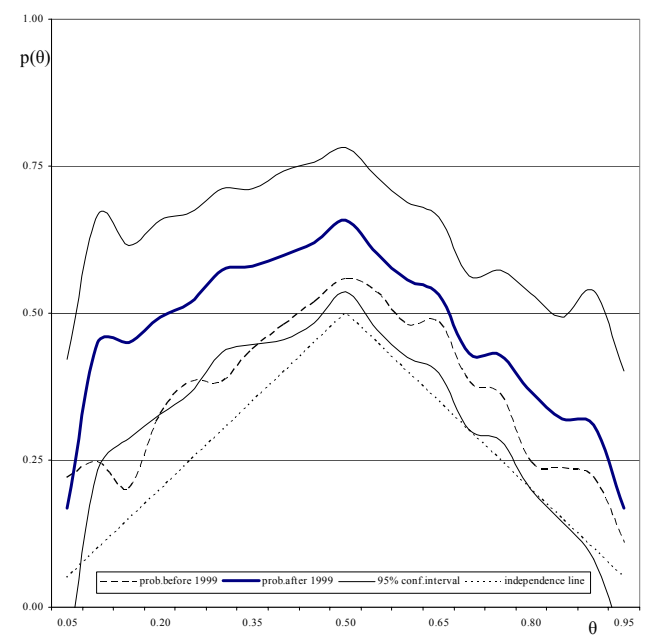

Figure 18i: Ireland-Germany

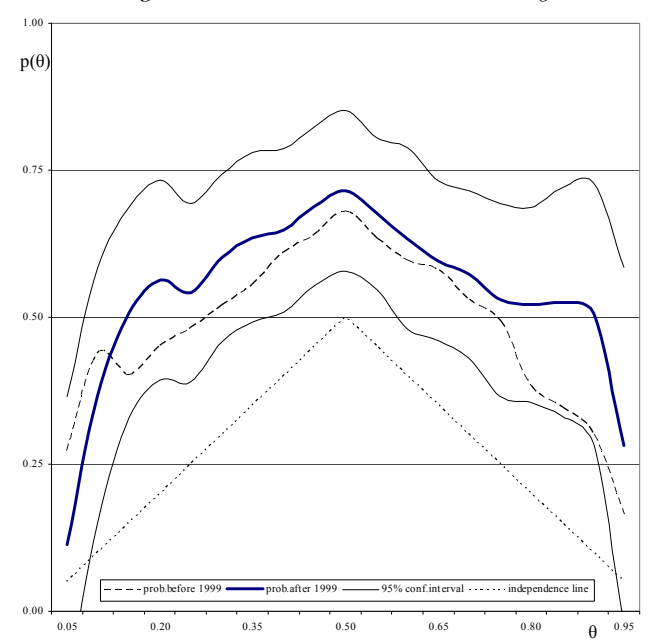

Figure 18f: Finland-Netherlands

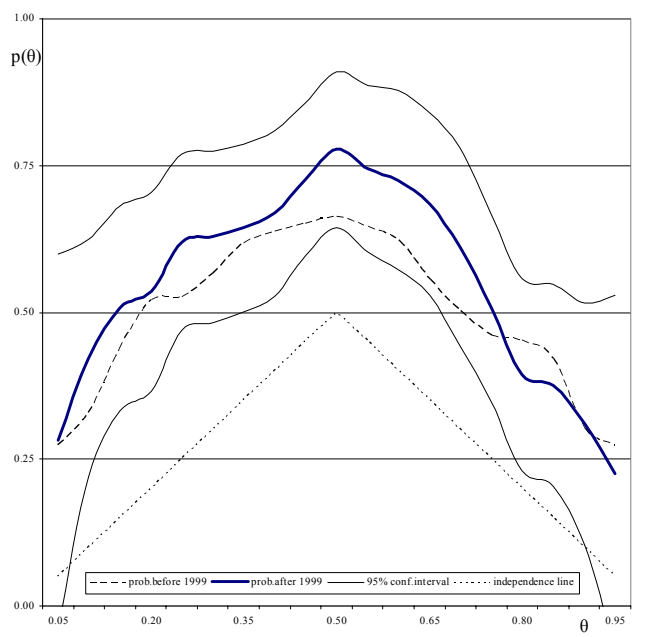

Figure 18h: Greece-Italy

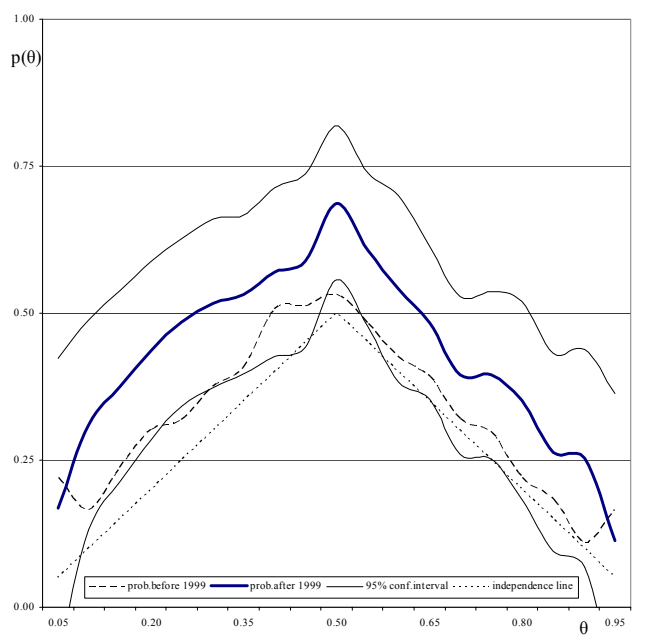

Figure 18j: Ireland-Spain

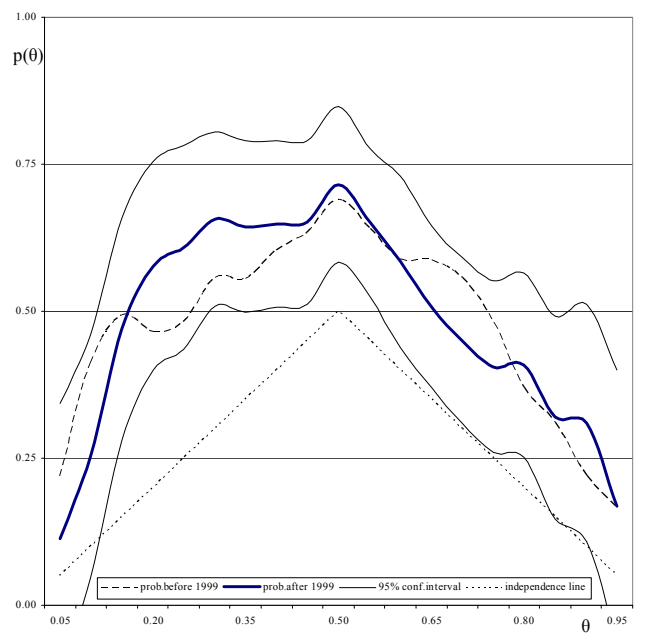


Figure 18 - Continued

Figure 18k: Germany-Portugal

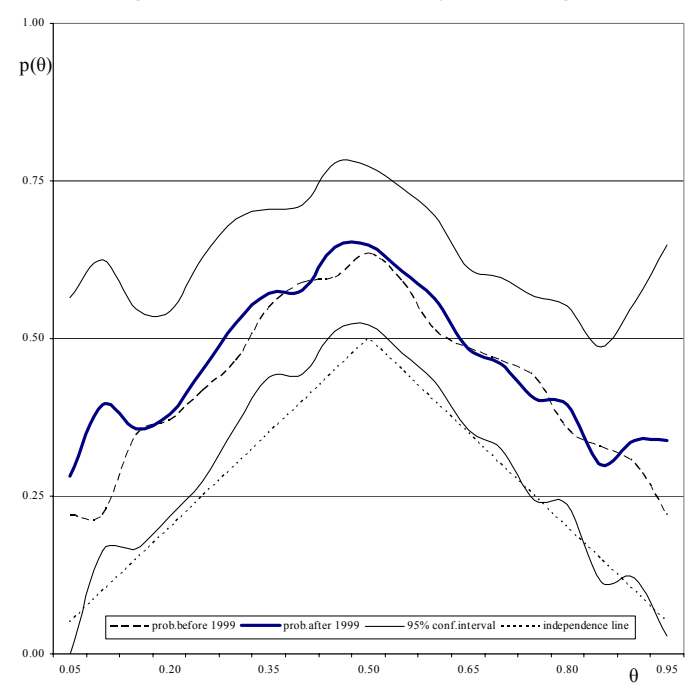

Figure 18l: Spain-Portugal

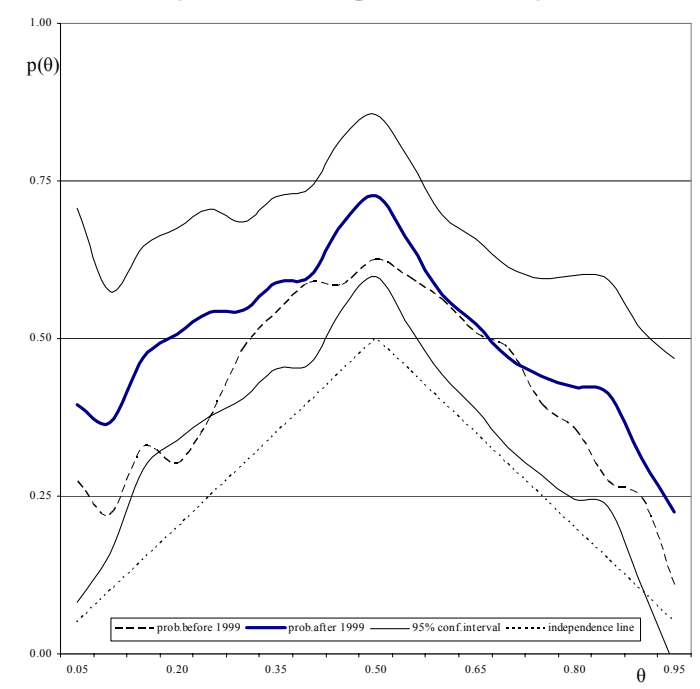


Figure 19: Probabilities of comovements between returns on Eurostoxx50 and non-euro area equity market indices

Figures 19a-19g plot the estimated probabilities of comovements between returns on Eurostoxx50 and non-euro area country pairs equity market indices over two periods. The first sub-sample covers the pre-monetary union period (January 1992 to December 1998), while the second the monetary union period (January 1999 to October 2005). The non euro area countries included in the analysis are Denmark, Japan, Sweden, the United Kingdom and the United States. The thin lines denote the two standard error bounds around the estimated comovement likelihood in the monetary union period, while the dashed lines represent the probability of comovement in the pre-monetary union period.

Figure 19a: Euro area-UK

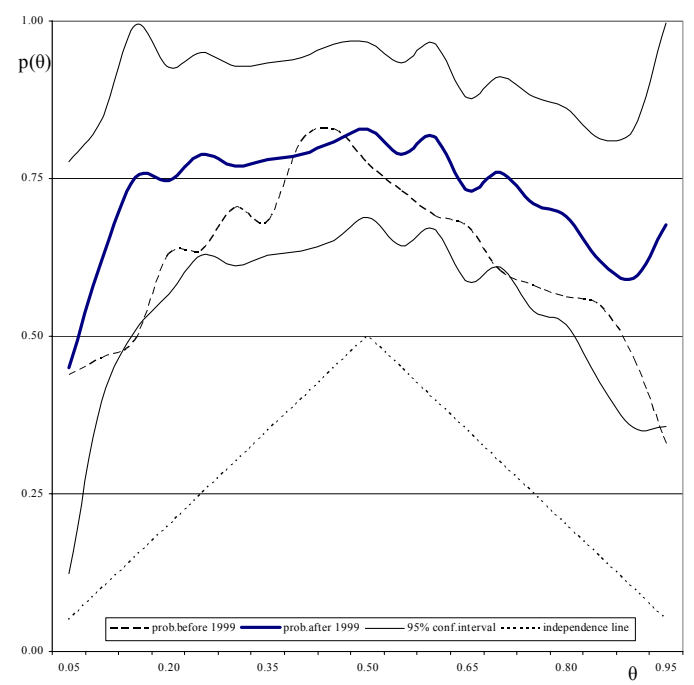

Figure 19c: Euro area-Japan

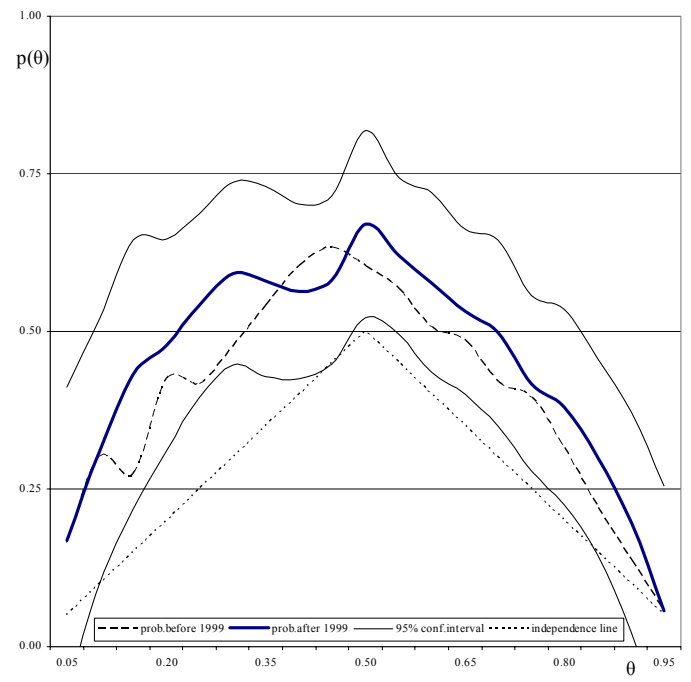

Figure 19b: Euro area-US

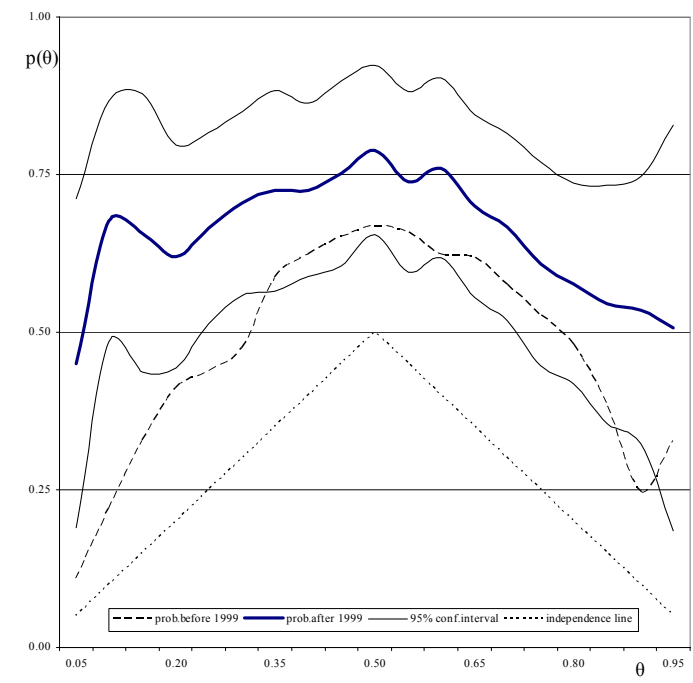

Figure 19d: Euro area-Sweden

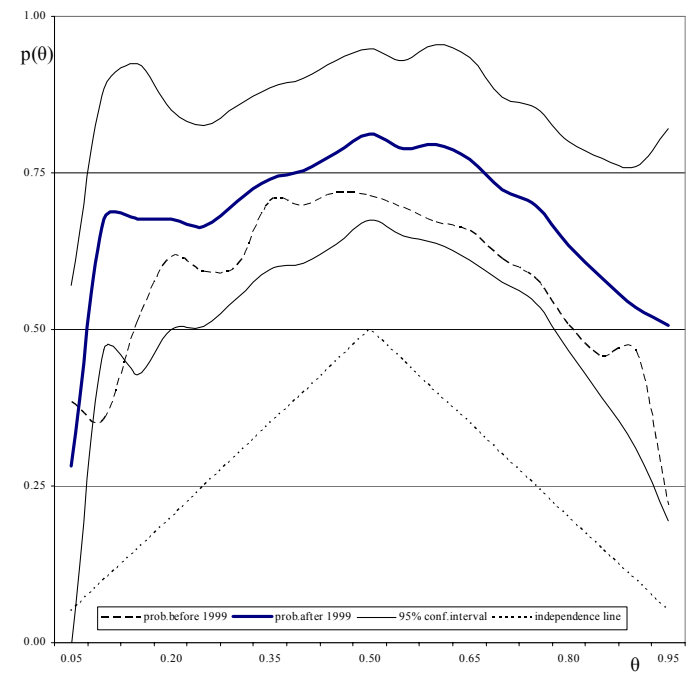


Figure 19 - Continued

Figure 19e: Euro area-Denmark

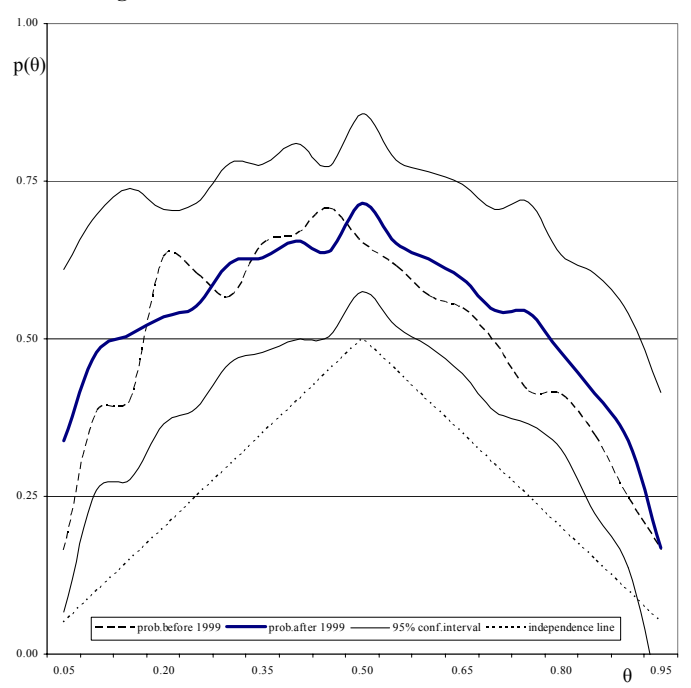

Figure 19g: US-UK

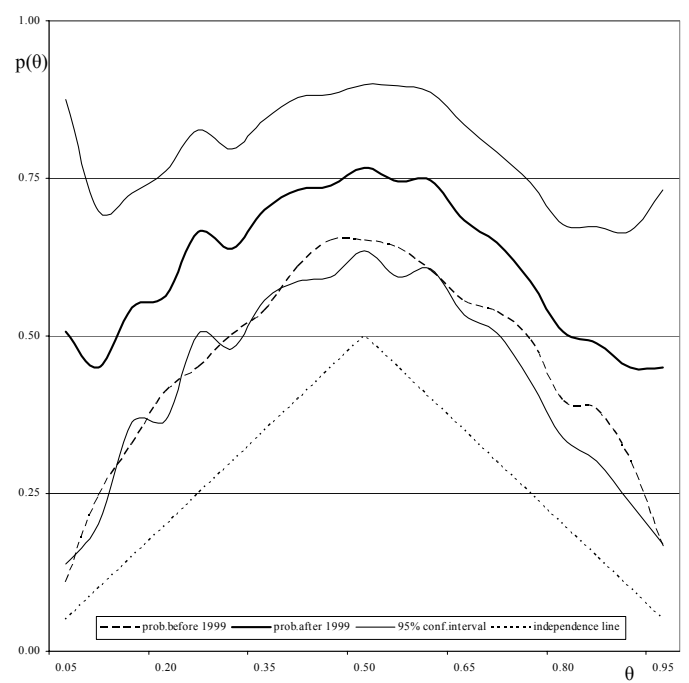

Figure 19f: US-Japan

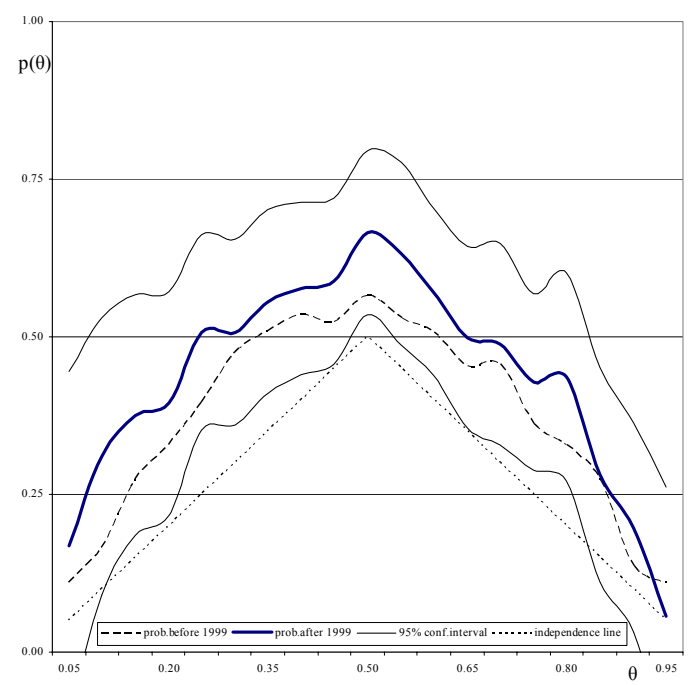


Figure 20: Weighted average probabilities of comovements between returns on 10-year government bonds for Germany verus other euro area economies

Figures 20a-20c plot weighted average estimated probabilities of comovements between returns on 10-year government bonds for Germany versus other euro area member states over two periods. The first sub-sample covers the pre-monetary union period (January 1992 to December 1998), while the second the monetary union period (December 1999 to October 2005). The five largest euro area economies are France, Germany, Italy, the Netherlands and Spain. The small economies included in the analysis are Austria, Belgium, Finland and Ireland. The probability of comovement of each euro area country pair is weighted by the fraction of its GDP relative to the total euro area GDP.

Figure 20a: All euro area economies

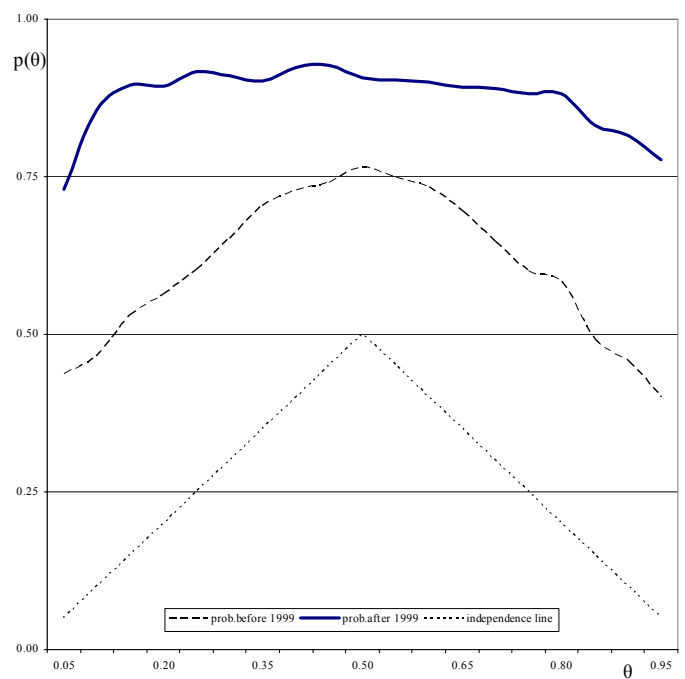

Figure 20c: Small economies

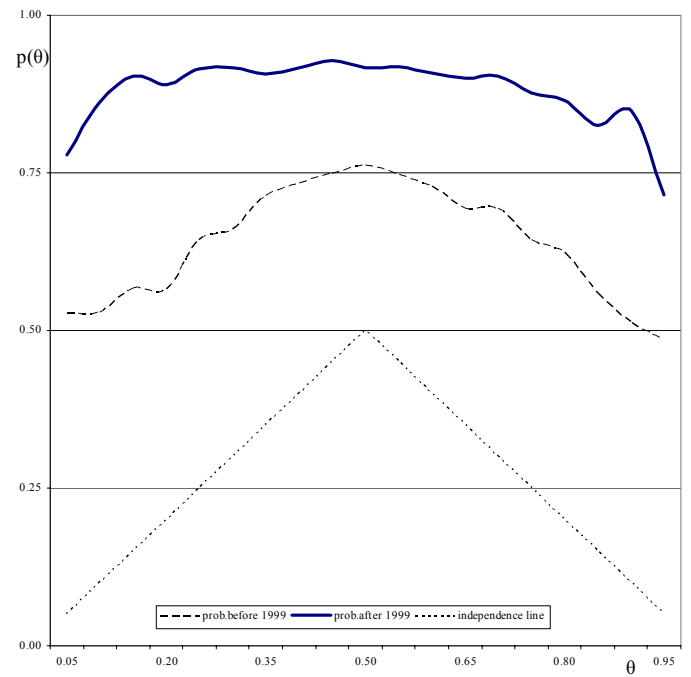

Figure 20b: Five largest economies

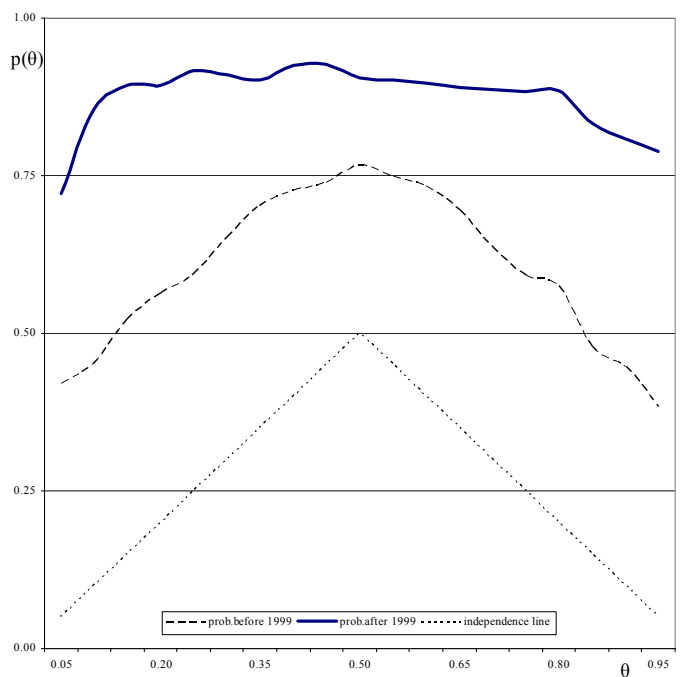


Figure 21: Probabilities of comovements between returns on 10-year government bonds for Germany versus other euro area economies

Figures 21a-21h plot the estimated probabilities of comovements between returns on 10-year government bonds for Germany versus other euro area member states over two periods. The first sub-sample covers the pre-monetary union period (January 1992 to December 1998), while the second the monetary union period (December 1999 to October 2005). The countries included in the analysis are Austria, Belgium, Finland, France, Germany, Ireland, Italy, the Netherlands and Spain. The thin lines denote the two standard error bounds around the estimated comovement likelihood in the monetary union period, while the dashed lines represent the probability of comovement in the pre-monetary union period.

Figure 21a: Germany-Austria

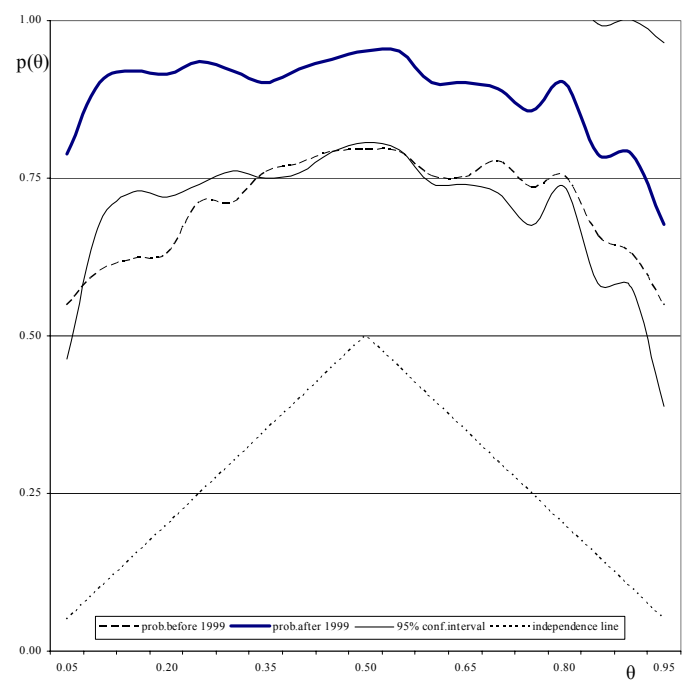

Figure 21c: Germany-Finland

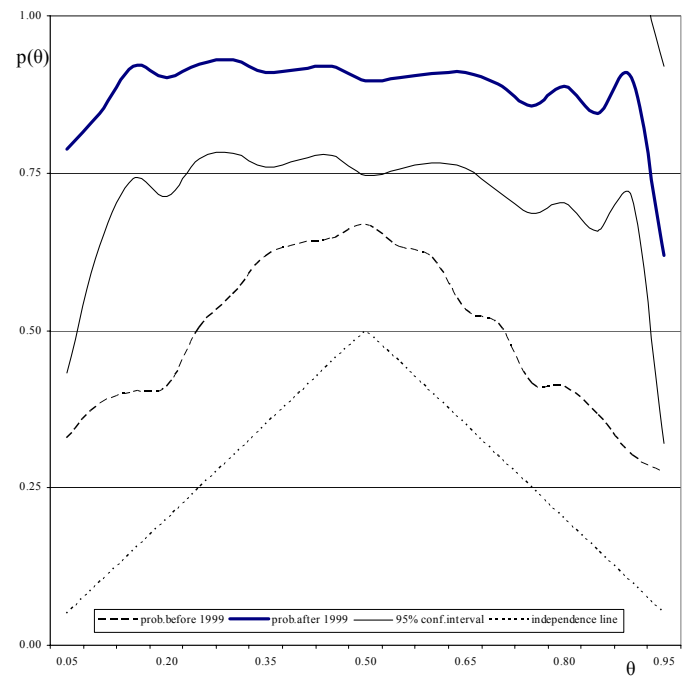

Figure 21b: Germany-Belgium

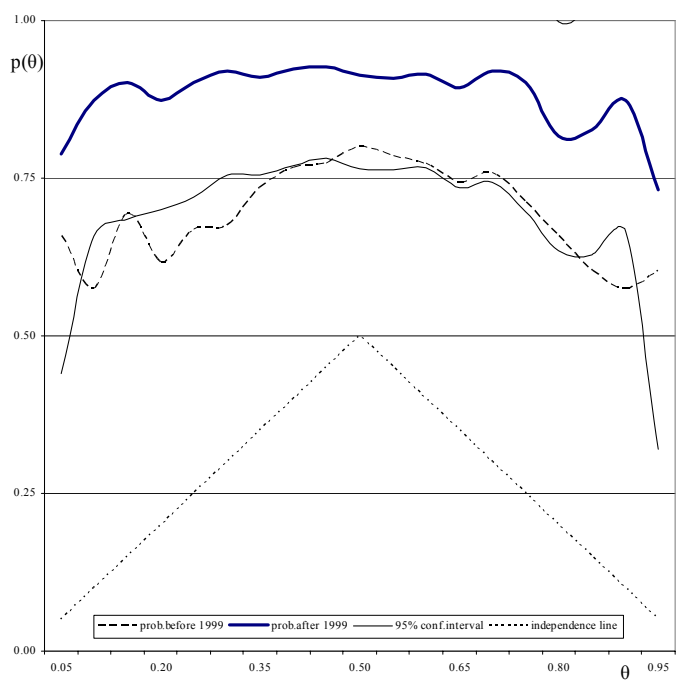

Figure 21d: Germany-France

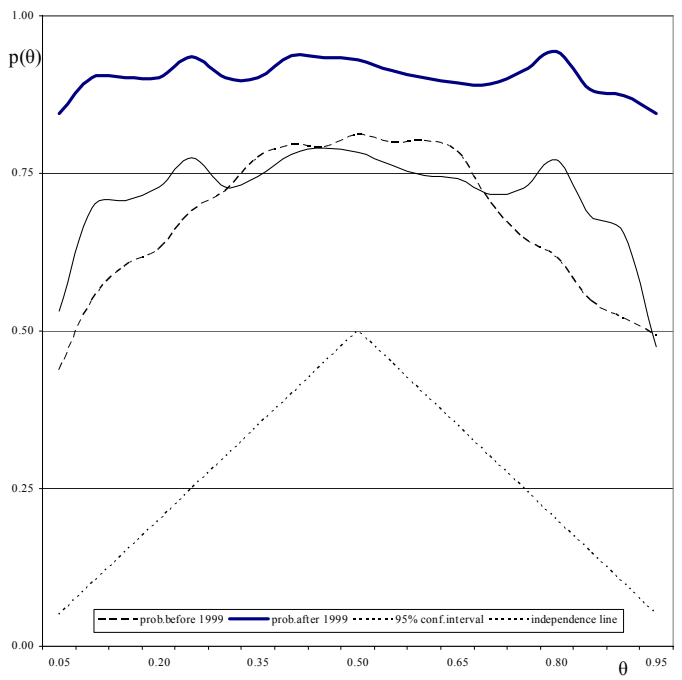


Figure 21 - Continued

Figure 21e: Germany-Ireland

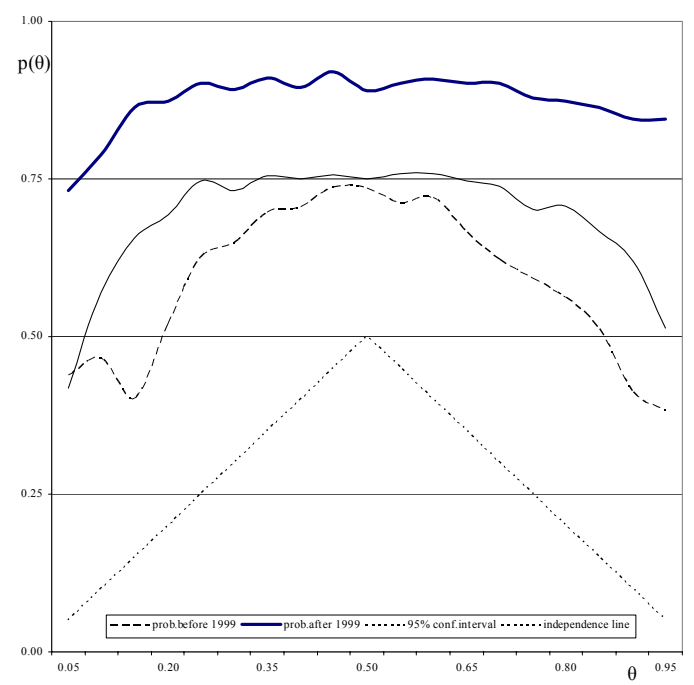

Figure 21g: Germany-Netherlands

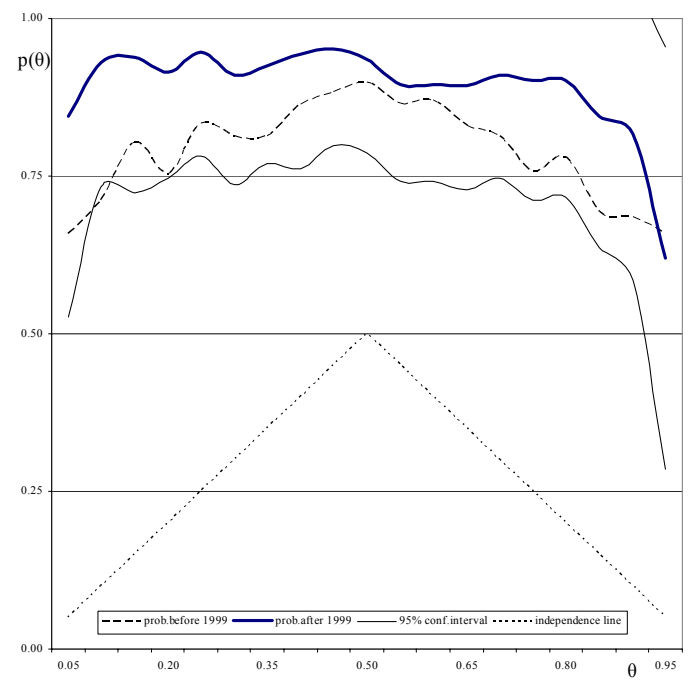

Figure 21f: Germany-Italy

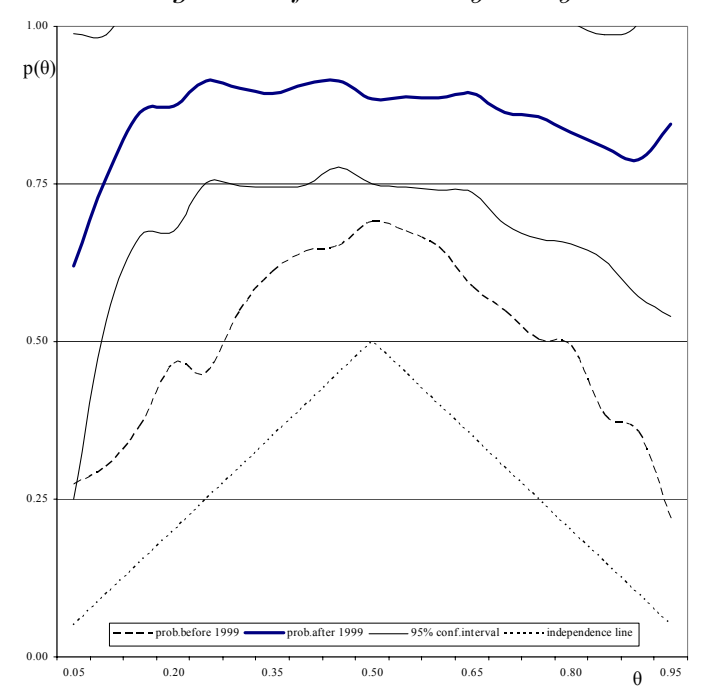

Figure 21h: Germany-Spain

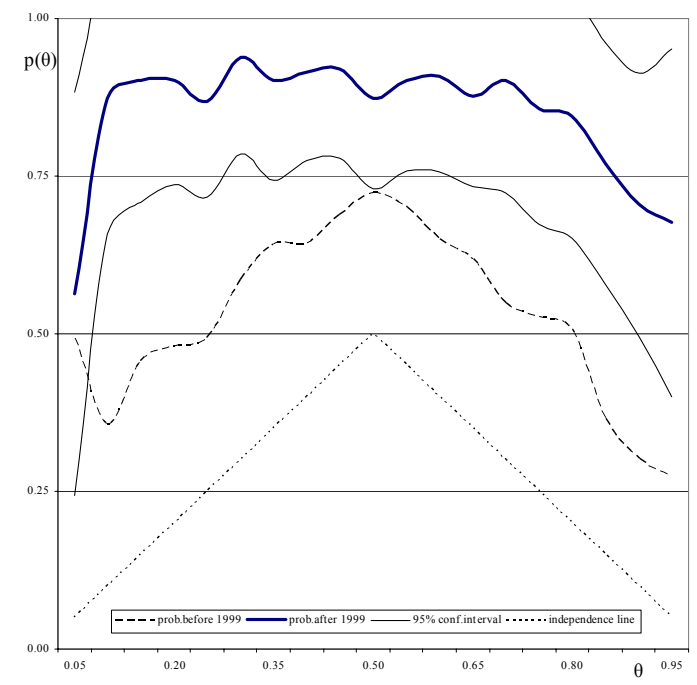


Figure 22: Probabilities of comovements between returns on 10-year government bonds for Germany and non-euro area economies

Figures 22a-22g plot the estimated probabilities of comovements between returns on German and non-euro area country pairs 10-year government bonds over two periods. The first subsample covers the pre-monetary union period (January 1992 to December 1998), while the second the monetary union period (January 1999 to October 2005). The non euro area countries included in the analysis are Denmark, Japan, Sweden, the United Kingdom and the United States. The thin lines denote the two standard error bounds around the estimated comovement likelihood in the monetary union period, while the dashed lines represent the probability of comovement in the pre-monetary union period.

Figure 22a: Germany-UK

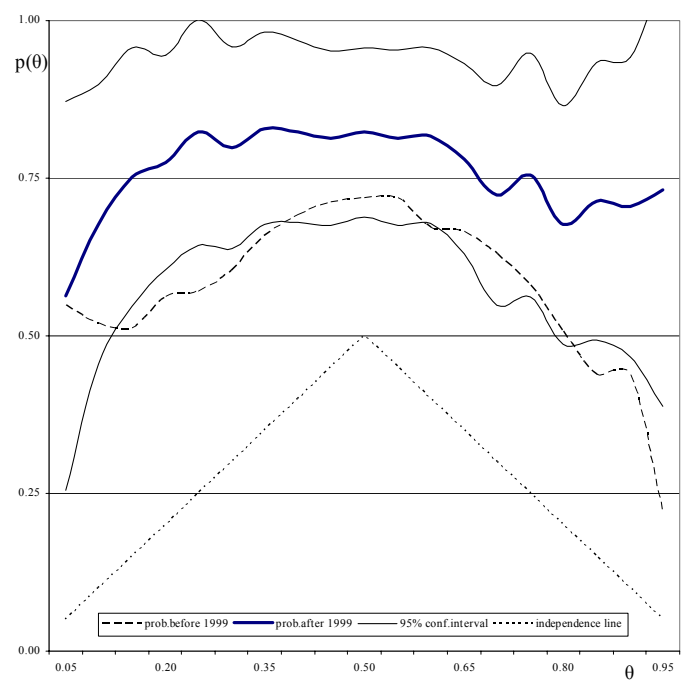

Figure 22c: Germany-Japan

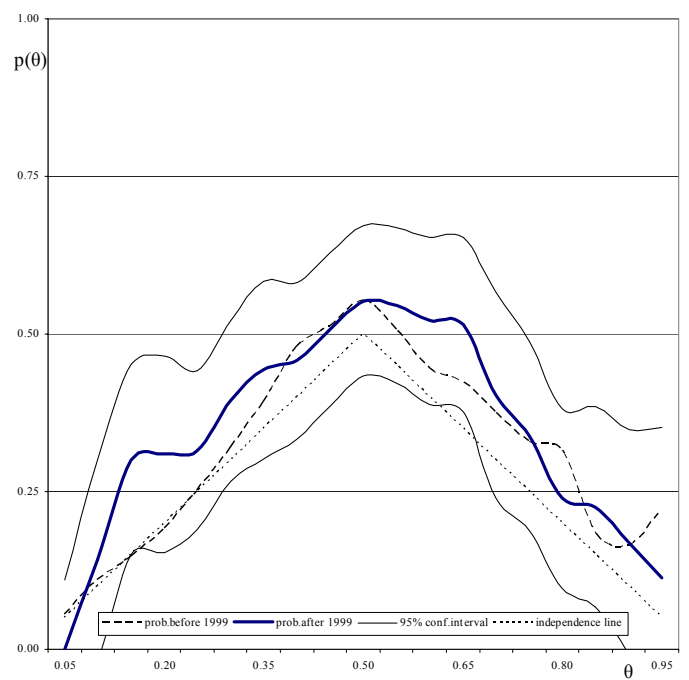

Figure 22b: Germany-US

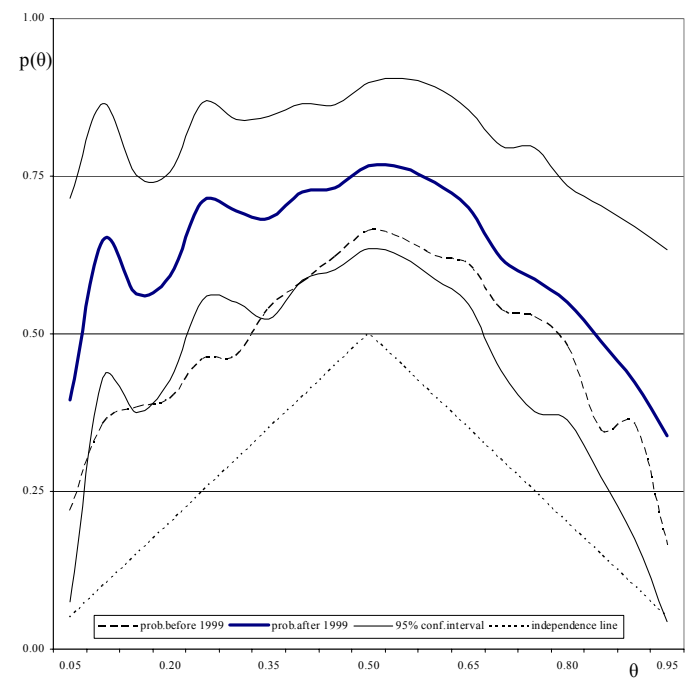

Figure 22d: Germany-Sweden

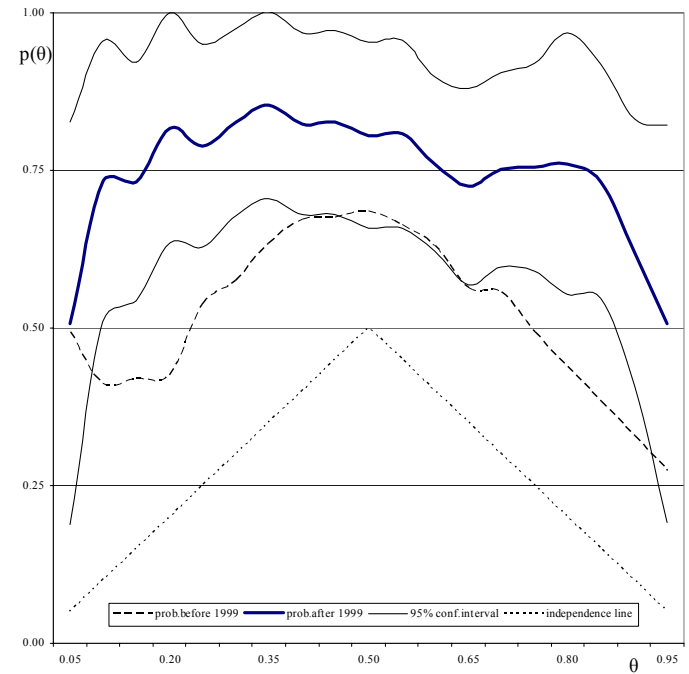


Figure 22 - Continued

Figure 22e: Germany-Denmark

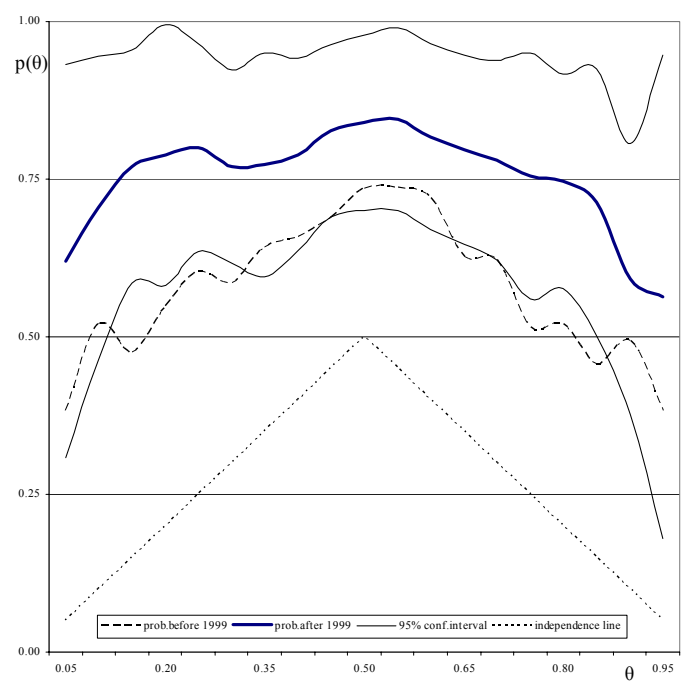

Figure 22g: US-Japan

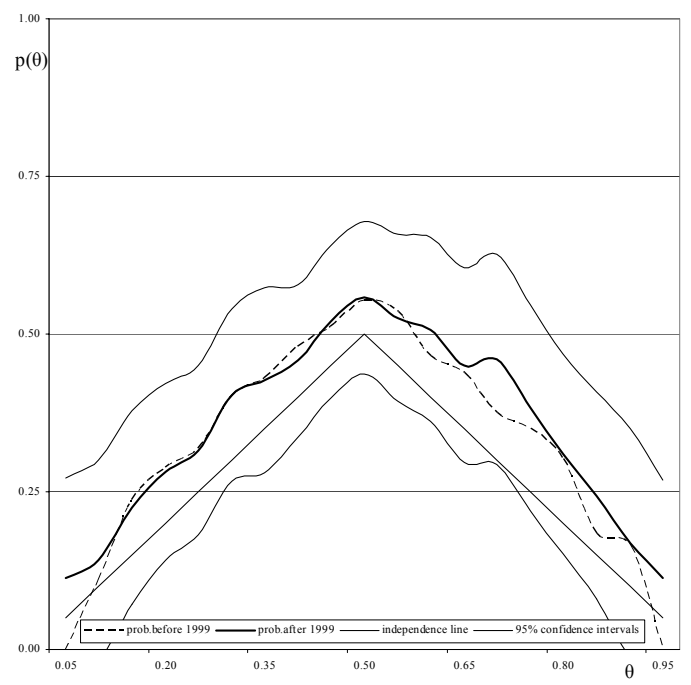

Figure 22f: US-UK

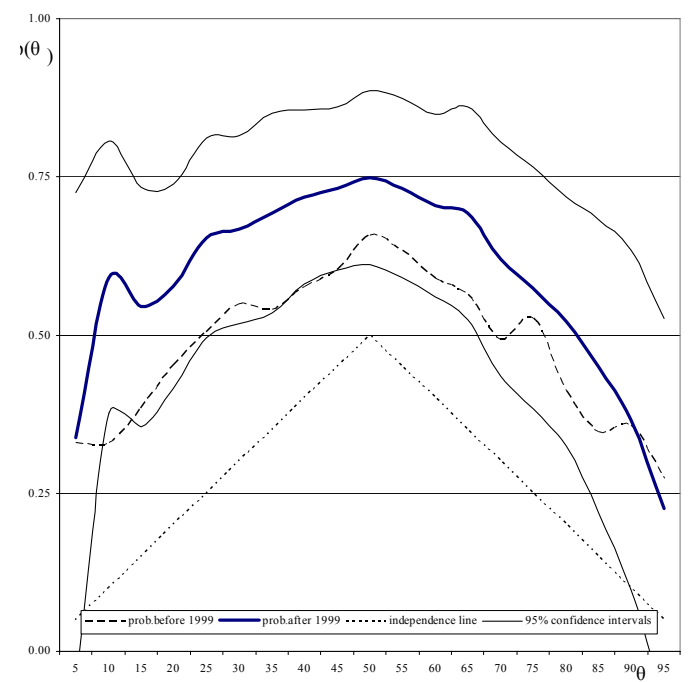


Figure 23: Data used in the estimations

(a) Macro data: Germany for 1975 - 1998; euro area for 1999 - 2004
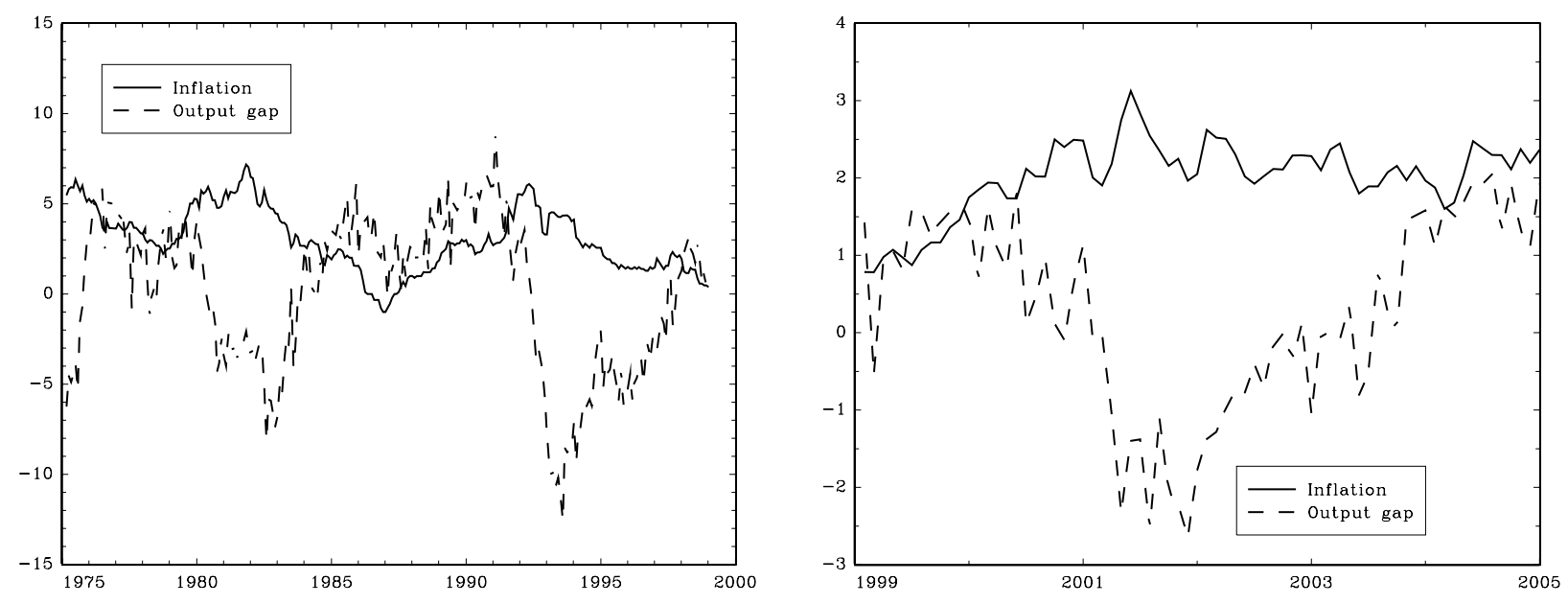

The inflation figures are expressed as percent per year; the output gap is in percent.

(b) Yield data: Germany for 1975 - 1998; euro area for 1999 - 2004
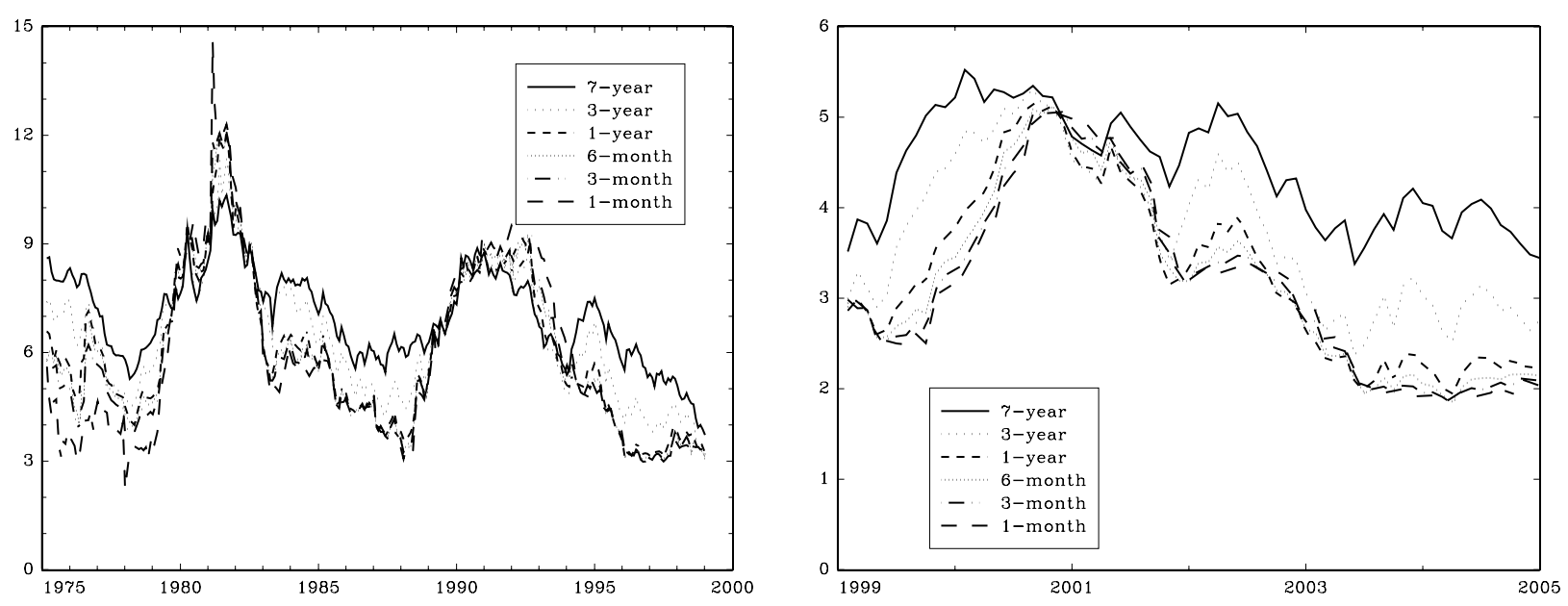

Percent per year. 
Figure 24.1: Impulse response of inflation to a monetary policy shock

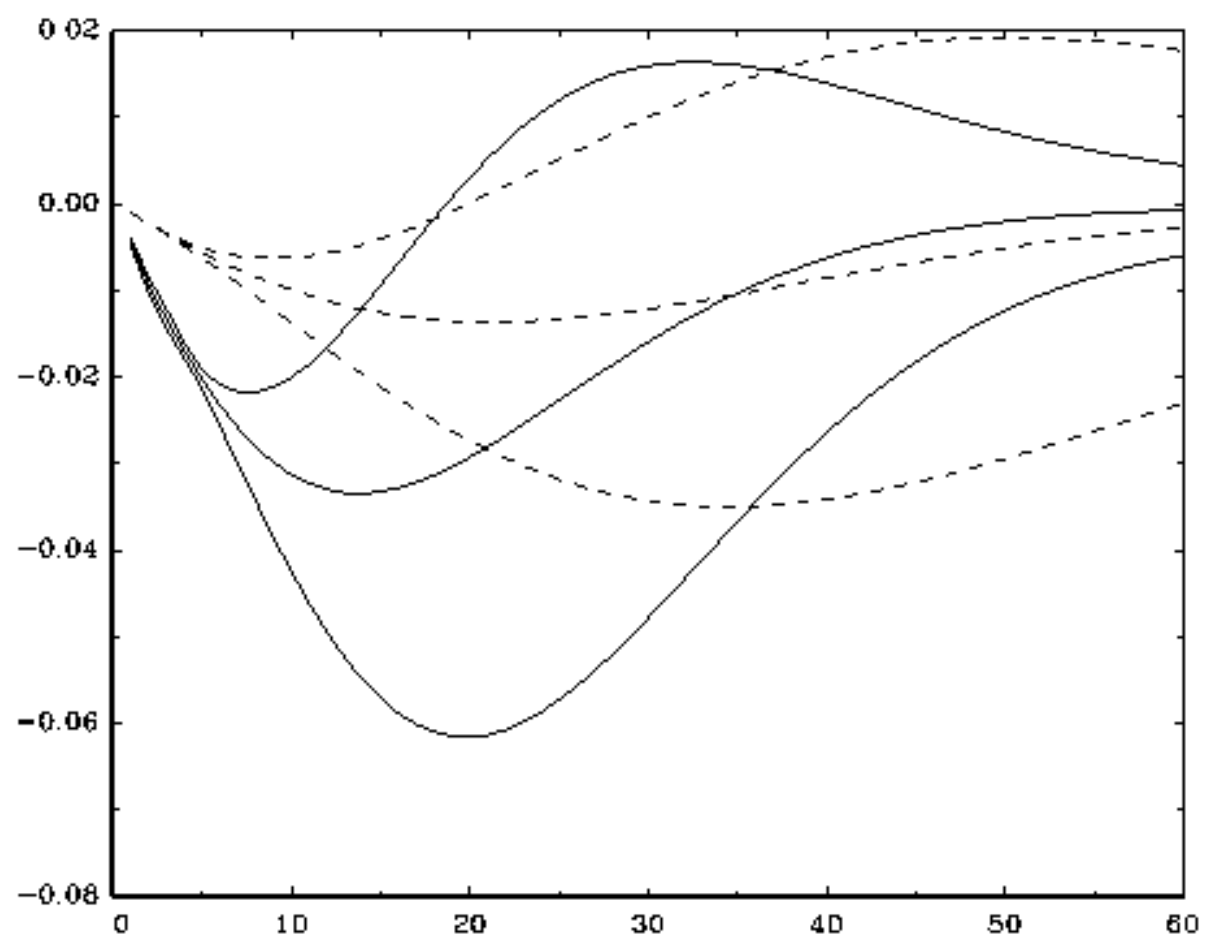

The bold thick line represents the estimated response during the euro period, while the bold dashed line is the response during the pre-euro period. The thinner lines are 95 percent confidence bands. All responses are expressed in annual percentage terms. The short-term interest rate was shocked by one standard deviation (around 48 bps for the pre-euro period; around $16 \mathrm{bps}$ for the euro period). 
Figure 24.2: Term structure of average yield premia

Term structure of average yield premia (annualized)

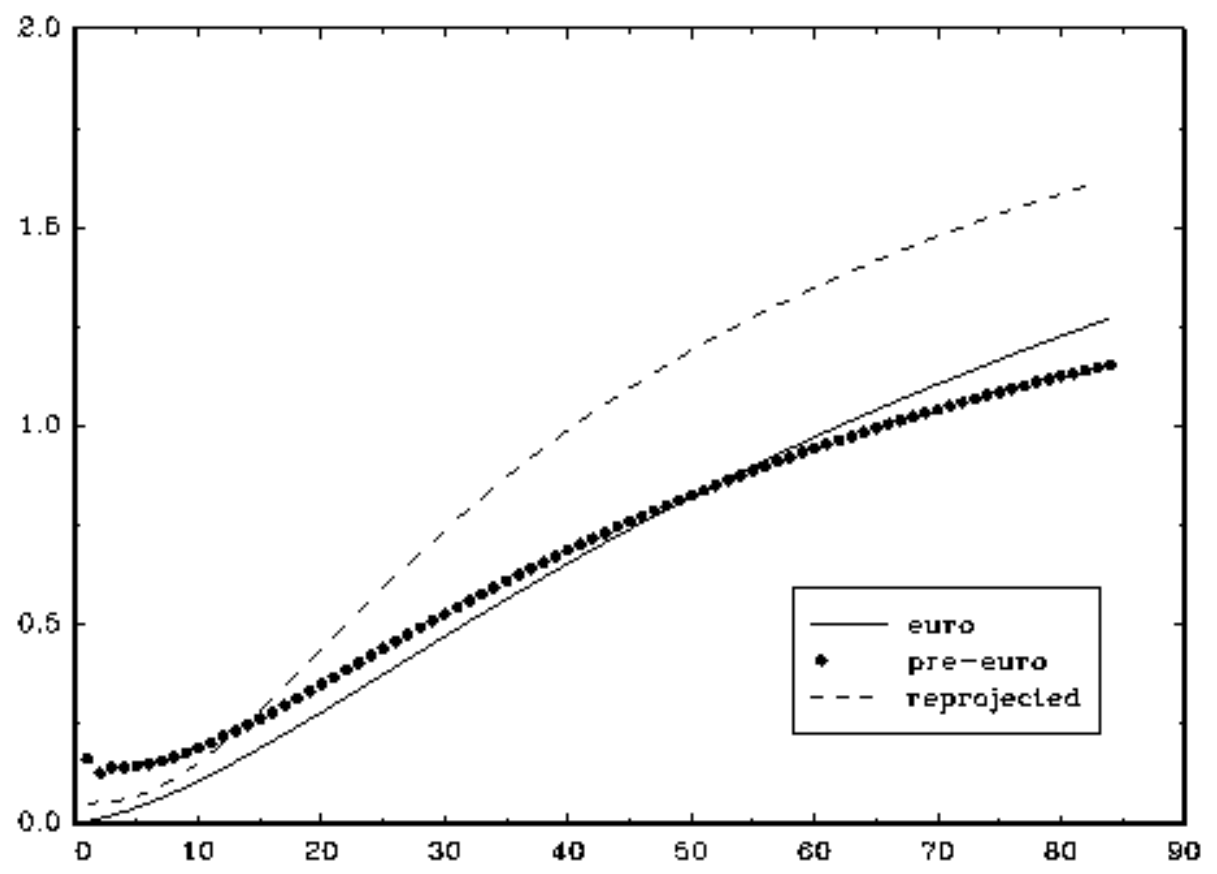

Yield premia are expressed in annual percentage terms. 
Figure 24.3: Initial response of yield premia to an inflation target shock

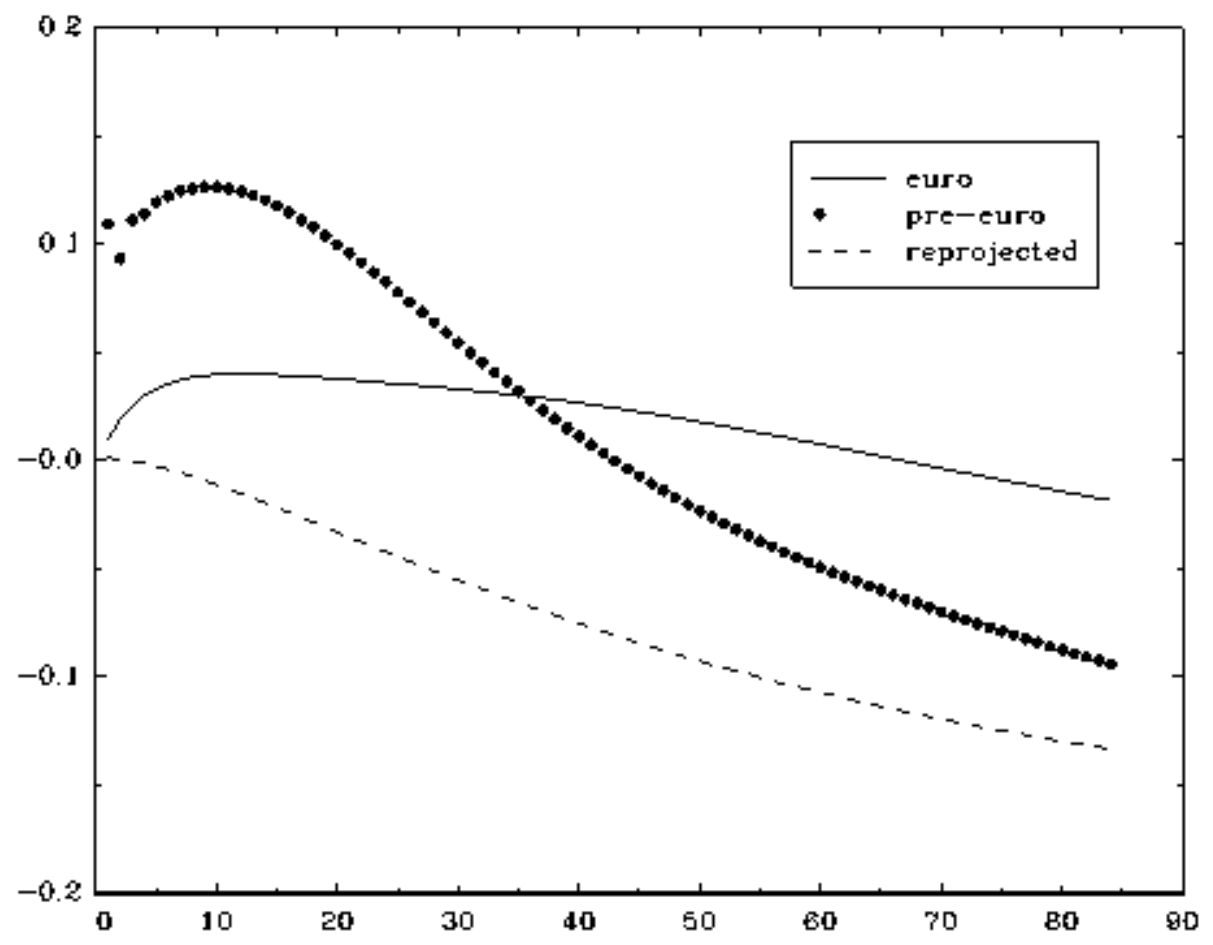

The figure shows the one-month ahead response of the yield premia $\omega_{n}$, at maturities $n$ up to 84 months, to a one standard deviation shock of the inflation target. The premia are expressed in annual percentage terms. 
Figure 24.4: Initial response of yield premia to a monetary policy shock

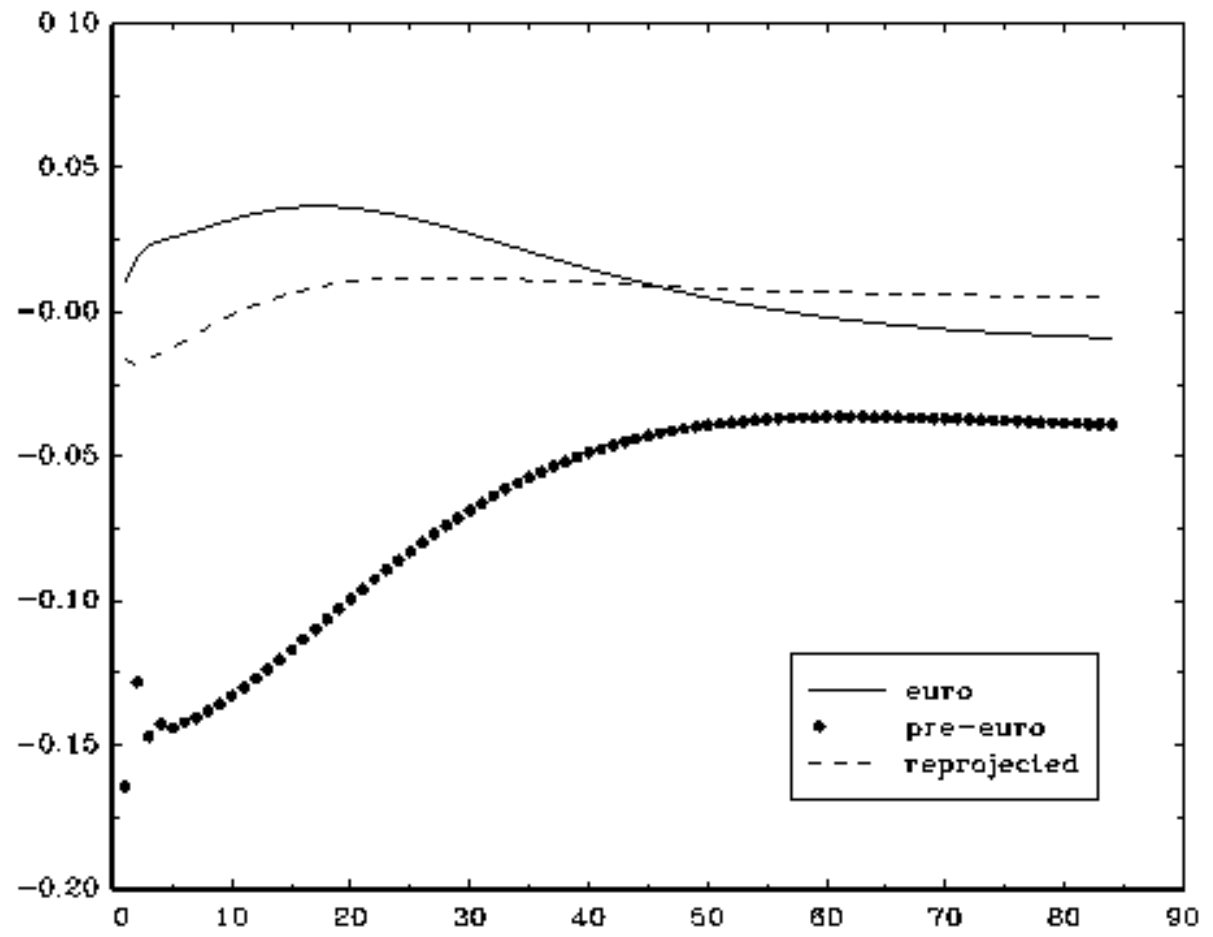

The figure shows the one-month ahead response of the yield premia $\omega_{n}$, at maturities $n$ up to 84 months, to a one standard deviation monetary policy shock. The premia are expressed in annual percentage terms. 
Figure 24.5: Initial response of yield premia to an inflation shock

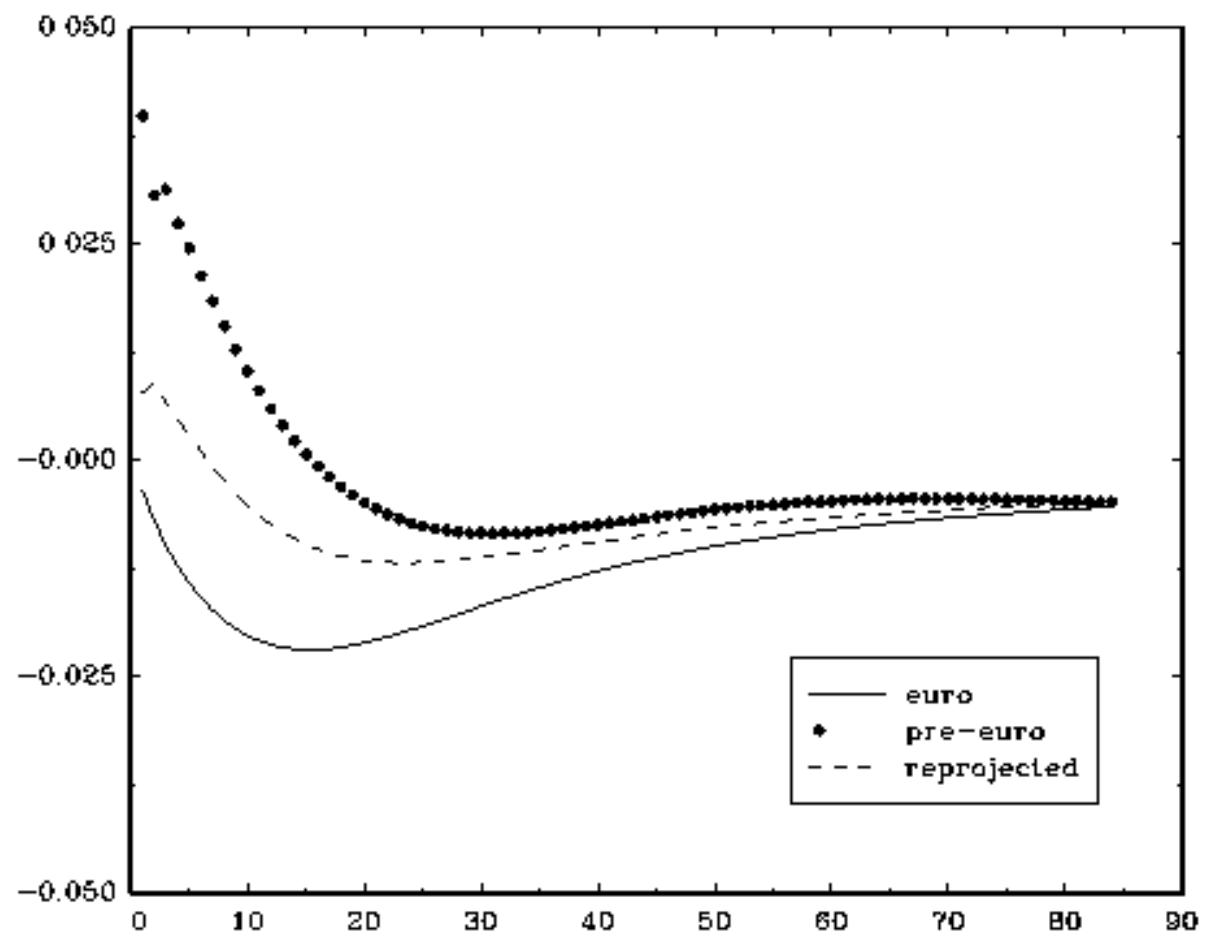

The figure shows the one-month ahead response of the yield premia $\omega_{n}$, at maturities $n$ up to 84 months, to a one standard deviation inflation shock. The premia are expressed in annual percentage terms. 
Figure 24.6: Initial response of yield premia to an output gap shock

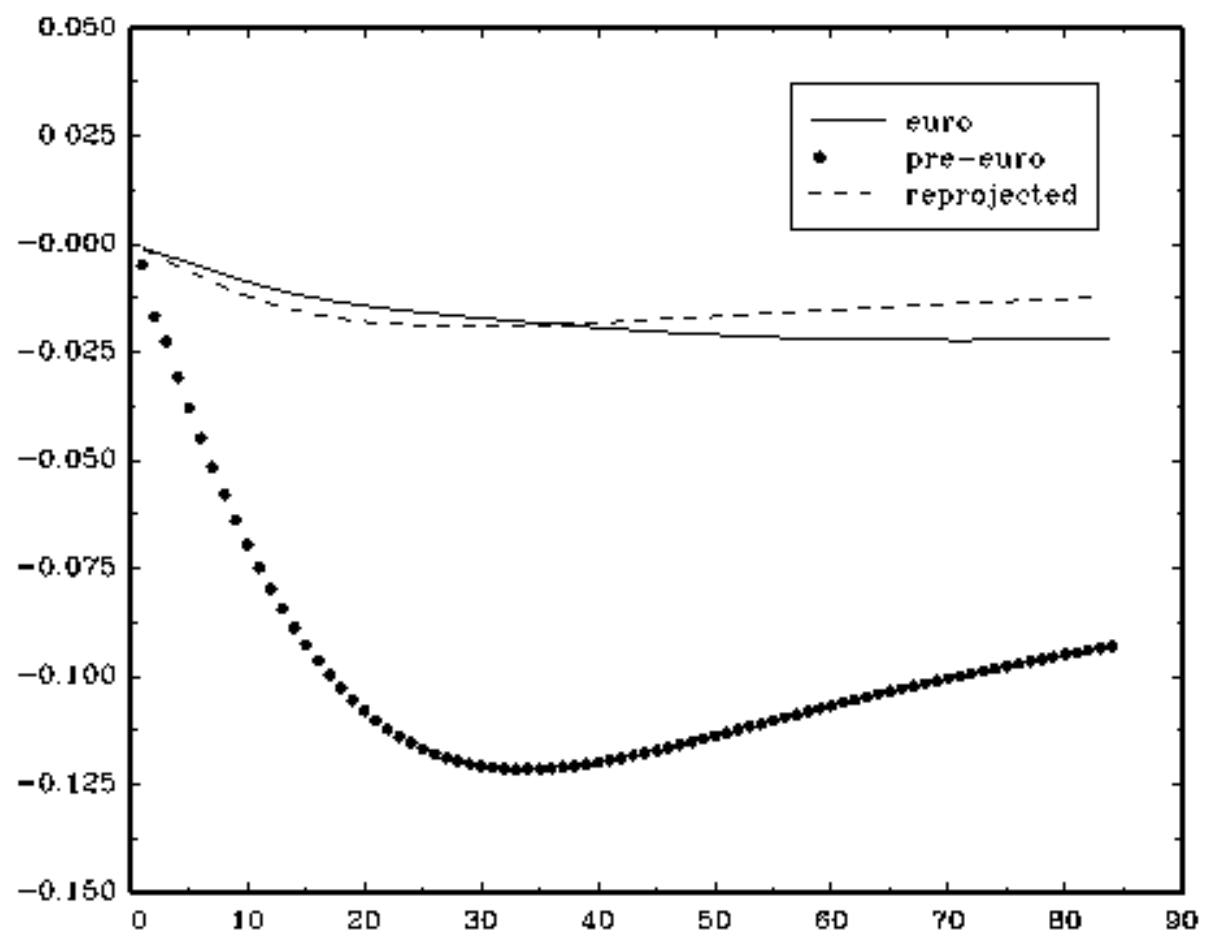

The figure shows the one-month ahead response of the yield premia $\omega_{n}$, at maturities $n$ up to 84 months, to a one standard deviation output gap shock. The premia are expressed in annual percentage terms. 
Figure 24.7: Estimated yield premia and components of premia: pre-euro period

De-meaned 1-year premium
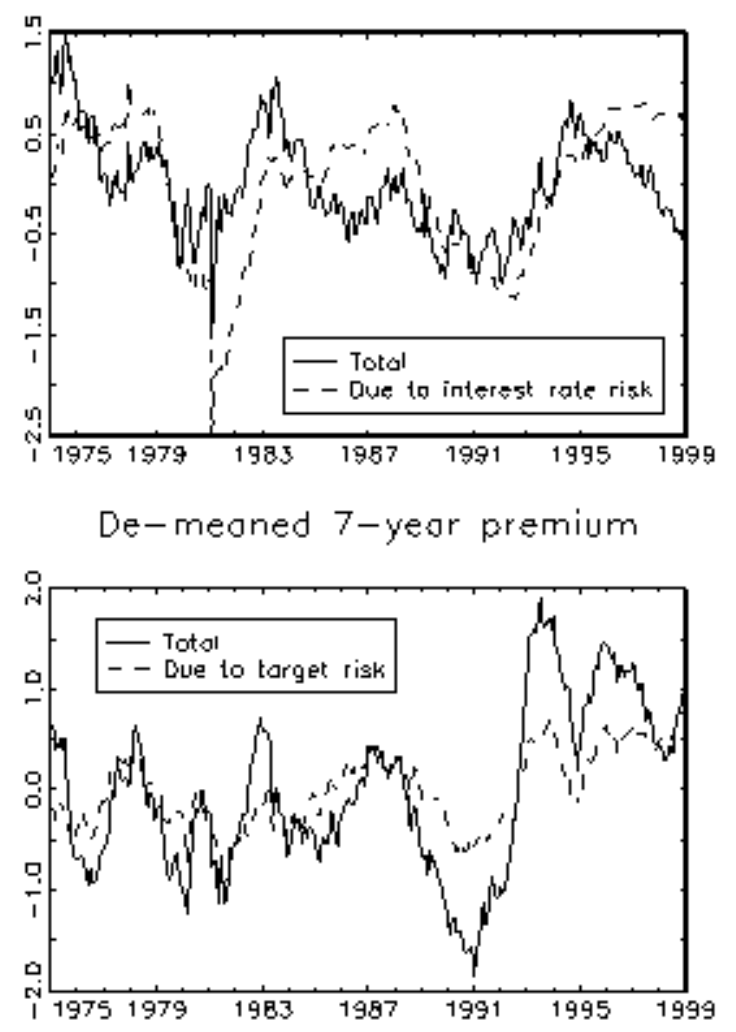

De-meaned 1-yeor premium
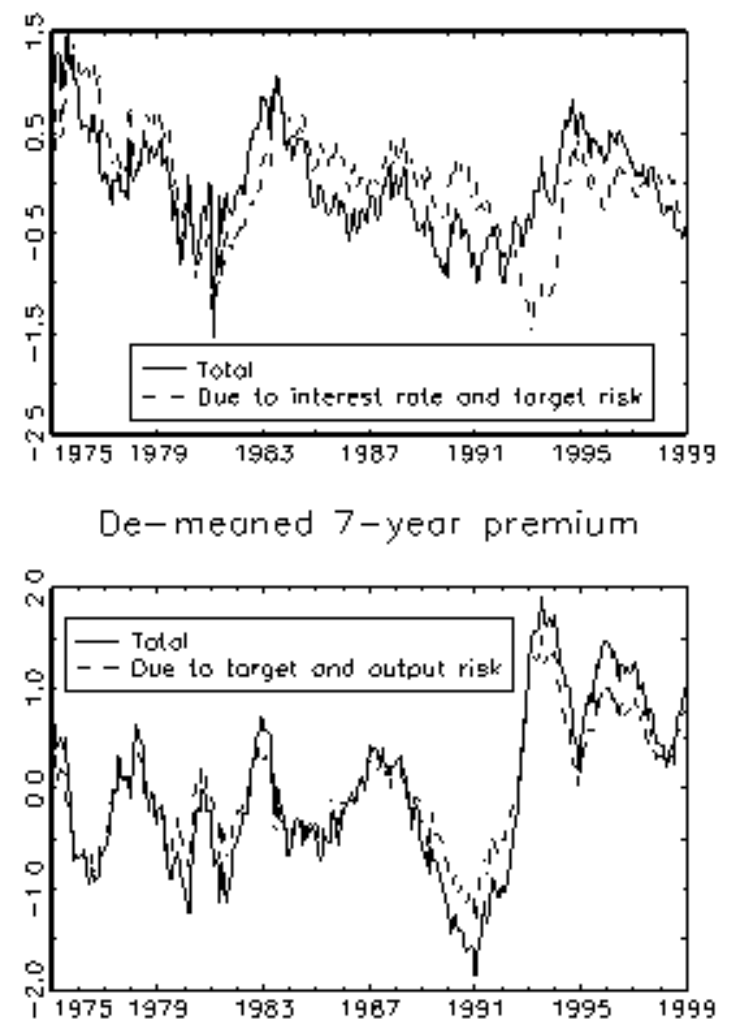

The solid lines are the estimated (de-meaned) yield premiums $\omega_{n}$ during the 1975-1998 sample periods, for maturities $n=12$ and 84 months, expressed in annual percentage terms. The dashed lines show the portions of the premia that are due to selected macro factors or combinations of such factors. 
Figure 24.8: Estimated yield premia and components of premia: euro period

De-meaned 1-year premium
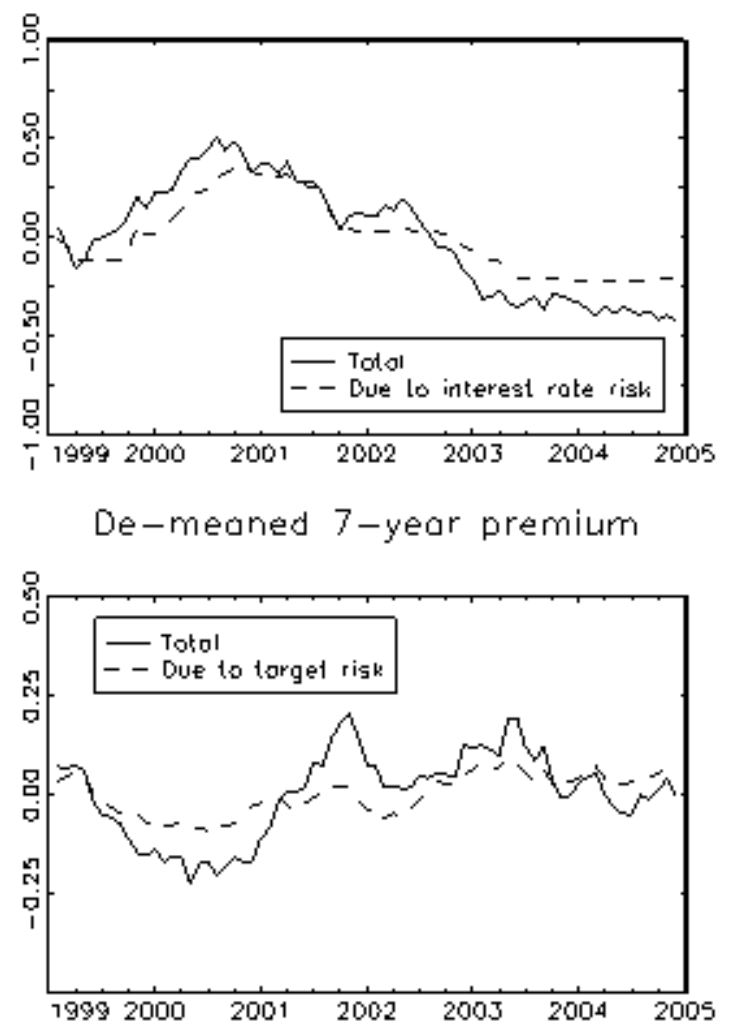

De-meaned 1-year premium

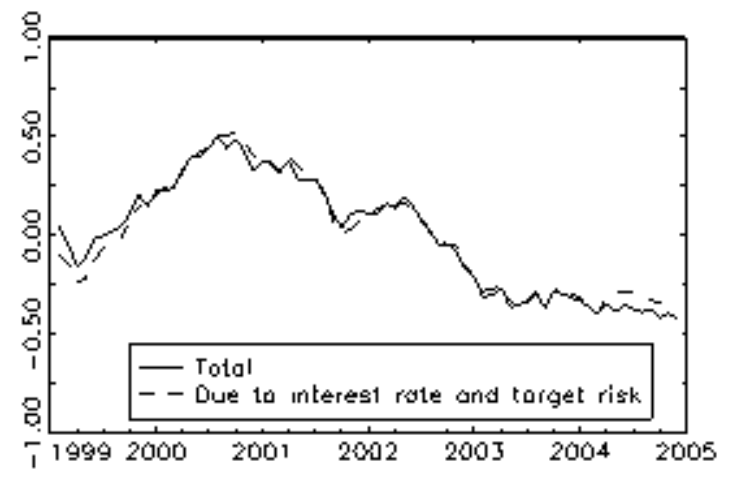

De-meoned 7 -yeor premium

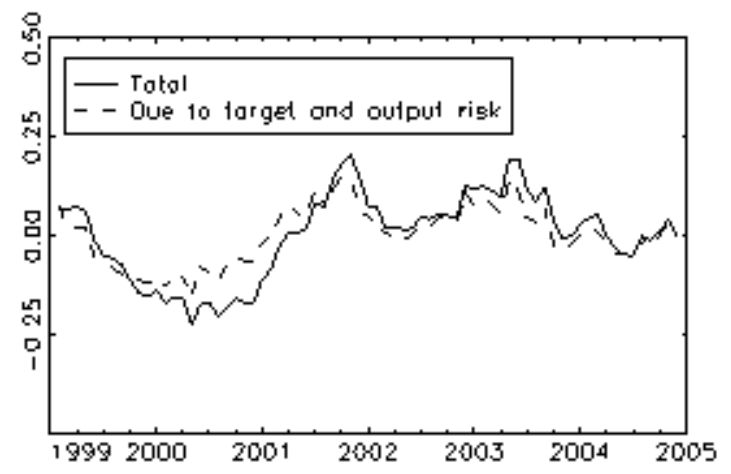

The solid lines are the estimated (de-meaned) yield premiums $\omega_{n}$ during the 1999-2004 sample periods, for maturities $n=12$ and 84 months, expressed in annual percentage terms. The dashed lines show the portions of the premia that are due to selected macro factors or combinations of such factors. 


\section{Xavier Vives}

\section{IESE, INSEAD and ICREA-UPF}

Why has the integration of the European banking sector been so much slower than that in the securities markets?

This is an open issue which this presentation will discuss.

Let us start with some history of the economic thought on the matter. The expectations in the Cecchini Report (1988) of convergence to lowest prices in financial services in Europe as a result of the Single Market Programme (SPM) in a seamless market where the Law of One Price would prevail were ill founded because the banking sector is imperfectly competitive and not contestable. The main characteristics that imply imperfect competition are the presence of switching costs, asymmetric information, reputation and institutional barriers to entry. Nevertheless, the Single Market Programme represents a credible commitment to the liberalization of the banking and financial sector in Europe. ${ }^{1}$

My view in 1991 was that the most important effect of the integration would be a change of the focal point of banks' strategies from collusion and regulatory capture to competition. Nevertheless, this competition would be imperfect owing to the presence of important barriers to entry, and this would yield an upper bound for the integration benefits lower than the competitive benchmark. The banking system would remain segmented with different degrees of competition, and the benefits of integration in a single market would be unevenly distributed. Furthermore, mergers, acquisitions and cross-participation agreements would tend to soften competition. ${ }^{2}$

The view of a CEPR report in 1999 was that financial markets in the European Union were fundamentally segmented: "On the supply side - savings behaviour - is the "home bias" of European households. On the demand side - the behaviour of firms - one needs to understand why European corporations stay clear of the bond market and typically 
borrow from banks”. Furthermore, we thought that there was still room for an increase in competition in the banking sector, even though there had been some increase during the 1990s. Regarding domestic mergers, we evaluated that there were limited benefits of diversification for banks in the European Union. ${ }^{3}$

In regard to the impact of the euro I conjectured ${ }^{4}$ that the most important effect of the single currency would be the deepening and expansion of financial markets, as market solutions would become more attractive than intermediated solutions. Moreover, the euro would reduce the segmentation in retail banking, although it would not eliminate it as barriers in retail, differences in preferences and culture between countries and regulatory restrictions would imply a small degree of cross border penetration. In addition, political obstacles to cross-border banking mergers were in place. There are some examples to illustrate this, like the problems BBVA had in Italy with Unicredito, BSCH in Portugal with Champalimaud, or the protectionist attitude of the French authorities in the triangular battle BNP-SG-Paribas. I concluded that there was a need to establish and consolidate an active domestic and EU-wide competition policy which would limit local market power and the promotion of national champions which are too big to fail.

\section{The transformation of the banking sector}

The size of the banking firm is important again because there has been a long-term development from investment in bricks (branches) to investment in information technology, specialized human capital and financial engineering, as well as the need to diversify. Concentration in the banking sector in the different European national markets has increased mostly because of domestic mergers. These have predominated because they have helped to cut costs reducing branching overlaps, allowed to increase or maintain market power, prevent a hostile takeover, or form a financial conglomerate. Cross-border mergers in Europe have been not so common because they face some obstacles that are not present in the US market. Among them: there are more limited economies of international diversification, the existence of labour market rigidities, differences in language, regulation and corporate culture in the different markets, and 
political interference to foster national champions. With increased integration of European banking the time for cross border mergers may have come. These may develop to acquire local expertise and to access high margin deposits or diversify, at the same time that size is gained to compete in the global market segments. Cross-border regional mergers constitute an intermediary step in this direction (like the ones occurred between the Scandinavian countries and the Benelux in the late 90s). There are recent examples of cross border mergers (SCH taking over Abbey or ABN Amro and BBVA trying with Antonveneta and BNL respectively).

\section{Integration of European Banking - The Way Forward ${ }^{5}$}

The report stresses the variable level of integration in banking. This has been high in wholesale banking and in certain areas of corporate finance, whereas only modest in relationship aspects of banking. Integration has been low in retail banking, and patchy and heavily dependent on foreign financial institutions in the accession countries. For the most part, integration has been greatest where economic theory predicts it to be so. In this sense, care needs to be taken not to attempt to correct perceived low levels of integration through excessive harmonization of regulation in areas in which only modest amounts of integration can be expected. However, the report rejects the use of arguments about ownership and relationship banking to justify the retention of artificial barriers to integration.

Which is then the optimal level of integration? A first attempt to answer this question is to be aware that integration is not an end in itself, as a naïve integration goal could lead to unwarranted harmonization. The key objective is to improve the access to financial services, and that may lead to uneven degrees of integration. What is more, the adaptation to local preferences may imply the use of efficient discrimination.

Regarding barriers to entry, we need to distinguish between regulatory and nonregulatory ones. Regulatory barriers can take the form of restrictions, like limitations on the proportion of overseas securities that pension funds allow to hold; regulatory 
hurdles to opening foreign branches and subsidiaries or to takeovers; discrimination against foreign providers; non-discriminatory but different regulation for foreign providers. Non-regulatory barriers to entry relate to national patterns of savings and borrowings, proximity of savers to borrowers and brand loyalty.

The measurement of the degree of integration is not a straightforward task. Integration is driven by the euro, the Financial Sector Assessment Programme (FSAP), and by improvements in information technology and globalization. Disentangling the effects of each of these factors is not easy. Moreover, they impact differently across member States.

Retail markets remains regional since proximity to clients, access to information and long term relationships are key competitive drivers. However, deregulation has had indirect effects as market structures converge through domestic consolidation and expansion beyond commercial banking like in the insurance market. Cross border bank transactions have increased, particularly after the introduction of the euro, and more branches are opened abroad even though the subsidiary form remains important. Crossborder mergers and de novo entry remain marginal.

Theoretical predictions in corporate finance predict that information problems are more serious in equity that in debt finance as a consequence of the greater information sensitivity of equity finance. They also predict that the participation of a large number of investors requires information to be more widely available in public securities than in private capital markets. As a result, we should expect more integration in finance for large than small firms, in market sources than intermediated finance, in public than private transactions and more integration in debt than equity. The predictions imply therefore that financial integration should be most in evidence in public debt markets, least in private equity markets, and somewhere in between in private debt and public equity markets. The results point out that the degree of integration is highly variable. Integration is more pronounced in the public corporate bond issuance, but still 
significant in the public equity market activity. In both cases however, there is more integration at the large end of the market. Integration is largely absent from bank lending to SMEs; in private equity is significant, while it is only modest in syndicated bank lending. Those two last results are at apparently at odds with the theoretical predictions. Investment banking integration has also occurred largely on the back of penetration of European markets by US banks, which have injected a greater degree of competition and efficiency in the new issue process to the benefit of European corporations.

Accession countries have had similar results. Real integration has outpaced financial integration, which remains uneven and partial across countries. Most of the progress has occurred in banking and in the Baltic area and integration has been achieved through ownership of West European banks. However, equity and bond markets remain weak and illiquid. Lastly, the access of SMEs to capital markets may be facilitated by a modern banking sector, but bringing down overall risk levels remains a key policy priority.

From these results there are some policy implications we could derive. Integration occurs where comparative benefits are greatest, so the failure to achieve integration in certain areas like in retail banking reflects mostly inherent impediments. For instance, the main deficiency in relation to SME, and in particular in the high tech sector, may not be due to the failure to integrate bank lending but due to the failure in developing capabilities to manage early stage equity finance. The key bottleneck is the limited managerial expertise and entrepreneurial capability and not a lack of funds.

\footnotetext{
${ }^{1}$ See Vives, “Banking Competition and European Integration” in European Financial Integration, A. Giovannini and C. Mayer, editors, Cambridge University Press, 1991.

${ }^{2}$ See Vives, “Banking Competition and European Integration” in European Financial Integration, A. Giovannini and C. Mayer, editors, Cambridge University Press, 1991.

3 “Monitoring European Integration: The Fututre of European Banking”, J.P. Danthine, F. Giavazzi, E.L. von Thadden and X. Vives, CEPR 1999

${ }^{4}$ Vives, X., "Restructuring Financial Regulation in the European Monetary Union”, Journal of Financial Services Research, 2001

5 “Monitoring European Deregulation” by P. Fulghieri, P. Pita Barros, J.Gual, C.Mayer, E.Berglöf, and X.Vives, CEPR 2005.
} 
Financial Integration Session: The Impact of the Euro on Financial Markets

Bruno Gerard, Norwegian School of Management-BI and Tias Business School, Tilburg University

In this discussion, I will first briefly describe some of the different concepts of market integration found in the economic and finance literature and relate them to the most striking results in the main presentation in this session. I will then discuss some additional evidence about the effect of the adoption of the single currency on the portfolio choices of bond and equity investors. In particular, I will highlight the impact of the introduction of the Euro on the risks of pan-european portfolios as well as on changes in composition and holdings of international portfolios. I conclude by pointing to some unresolved issues that warrant further study.

Several definitions of market integration can be found in the economic and finance literature. For example financial economists say that markets are integrated when only common risk factors are priced in assets returns and that market are (partially) segmented when local risk factors also determine equilibrium returns. Another, more general definition relates market and economic integration to a strengthening of the financial and real linkages between economies. Typically tests of the first definition of market integration require sophisticated asset pricing tests, while tests of the second definition are usually conducted by investigating the changes in the correlations across countries between selected economic variables and financial asset returns.

As groups of countries adopt common financial regulatory frameworks and economic policies, one expects the impact of common factors on domestic assets returns to increase. Hence the transition to the single currency within the EMU should be accompanied by an increase in co-movements in assets cash flows and therefore in the returns on the financial claims: increased co-movements in equity and bond returns are consistent with increased economic integration and interdependence. However economic integration and interdependence is not necessary equivalent to financial market integration, as trade barriers may be removed while restrictions to financial flows may remain in place, whether these restrictions stem from explicit barriers or remaining regulatory differences across markets or from more subtle differences in transaction costs, information availability and risk for foreign and domestic investors.

The extent to which drastic structural changes like the adoption of the single currency lead to increased financial market integration can be evaluated by assessing whether financial assets offer similar risk return trade-offs across borders. However asset pricing based tests of changes in degree of market integration are notably difficult to conduct. Alternatively investigating the extent to which investor's actual portfolio investment decisions respond to changes in the economic environment like the disappearance of intra-EMU currency risk and the increased transparency and lower transactions costs that ensued, provides direct evidence of the changes in the degree of effective market segmentation faced by investors. Evidence of decreased home bias, and increased investments in assets from countries with lower costs in term of risk, information or 
transactions, would all suggest the disappearance of implicit or explicit barriers to crossborder investments and increased financial market integration.

The paper of Cappiello, Hordahl, Kadareja and Manganelli investigates mostly the impact of the introduction of the single currency on the co-movements of financial asset returns within and outside the Euro-zone. It provides very exhaustive and interesting evidence about the changes in co-movements across equity and fixed income markets over the seven years preceding the adoption of the Euro and the seven years following it. To put the evidence in perspective, I summarized the correlations data provided in Table 2 as follows. I group countries into regions and average cross-country returns correlations for each asset class within and across regions. For example.0.49 (top left-most cell) is the average cross country equity correlation among EMU countries during the pre-Euro period.

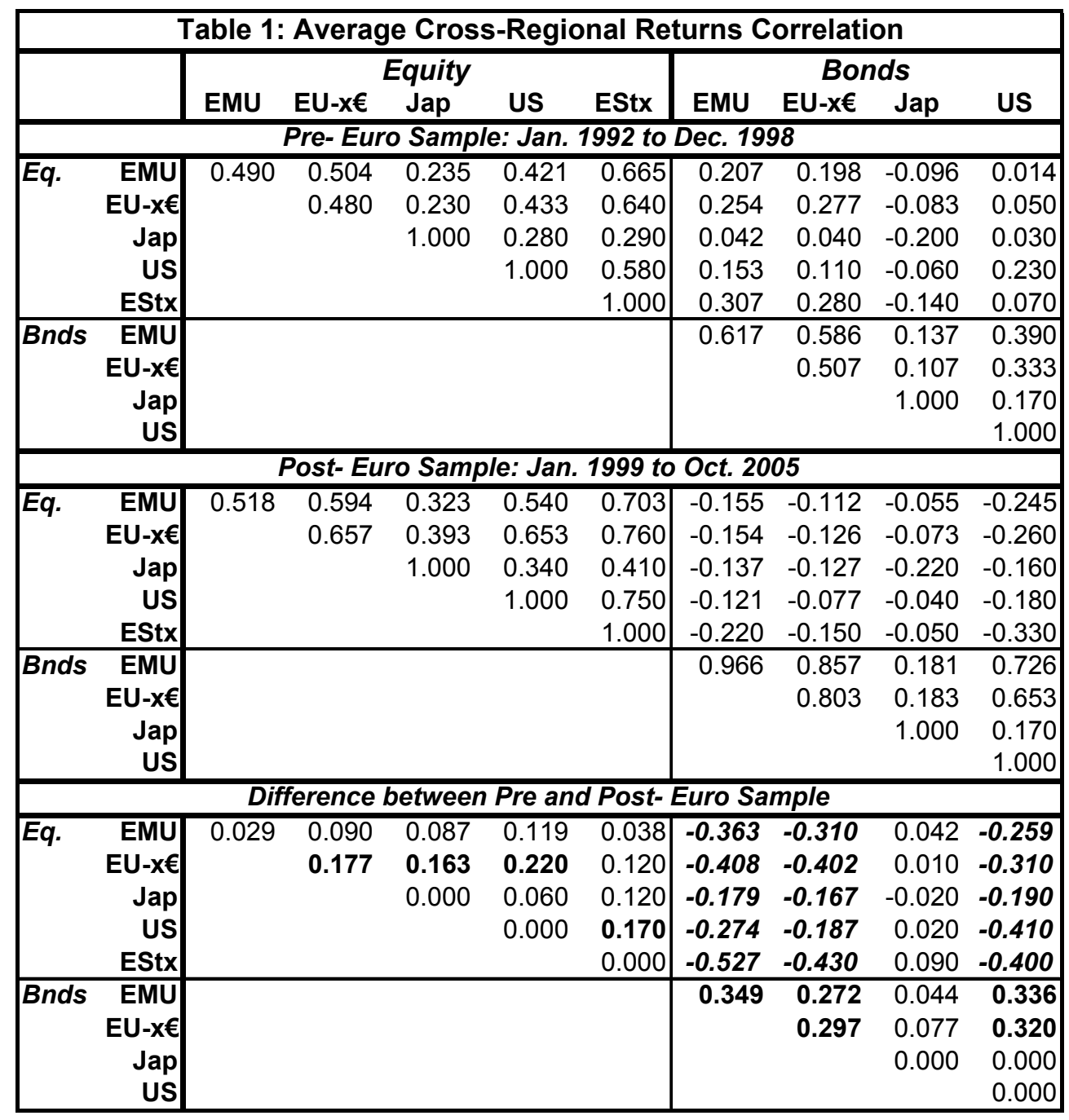

The striking results from this comparison is that although one observe an across-theboard increase in returns correlations within asset classes, it is of similar magnitude 
within and outside the Euro-zone: surprisingly equity returns correlations increase more between EU countries not part of the Euro-zone than between Euro-zone equity markets. The most dramatic evidence of increased integration in the Euro-zone is observed in bond markets where the average cross-country return correlation increases from 0.62 prior to 1999 to 0.97 after the adoption of the Euro. However, increases in correlations of the same magnitude are observed between US and non-Euro EU bond markets. The only exception is Japan. Lastly note that one also observe a uniform decrease in the correlations between equity and bond markets over the post-Euro period.

Further evidence about the changes in equity markets and equity returns characteristics induced by the adoption of the single currency can be elicited from a careful study of country and industry portfolios within the Euro zone (see Eiling, Gerard, and de Roon, 2005 , for the full details). We investigate the 11 Euro-zone countries equity index portfolios and 10 Euro-zone regional industry portfolios over the period starting in April 1990 and ending in September 2003. We conduct our investigations over three subsamples, the pre-convergence period from April 1990 to December 1994; the convergence period, form February 1995 to December 1998, and the Euro period, from February 1999 to September 2003; as well as over 60-month rolling windows.

Figure 1 provides a snapshot of the results of our analysis and documents the striking changes in the structure of international equity returns in the Euro-zone. Both industry and country returns have become more volatile, but the increase in Euro-wide industry volatility has been substantially larger, in absolute and in relative terms. In terms of comovements, while cross-country correlations have increased, cross-industry correlations have decreased substantially. This suggests increasing homogeneity of industry structures across countries. Simultaneously Euro-wide industries become increasingly heterogeneous. Moevoer, while the level of country return idiosyncratic volatility has remained relatively stable over time, in contrast, Euro-wide industry idiosyncratic risk has more than doubled over the sample period. Our results suggest a clear shift in the structure of Euro-zone equity returns that coincides with the introduction of the Euro. Whereas in the beginning of the 90 s individual country returns were more volatile but less correlated than industry returns, the opposite is true following the adoption of the single currency.

Figure 1: Country and industry portfolio returns characteristics

A. Monthly returns standard deviation (\%)

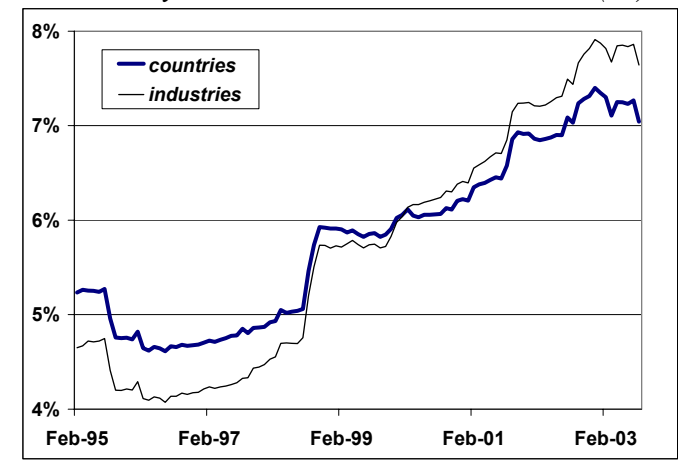

C. Monthly returns idiosyncratic risk

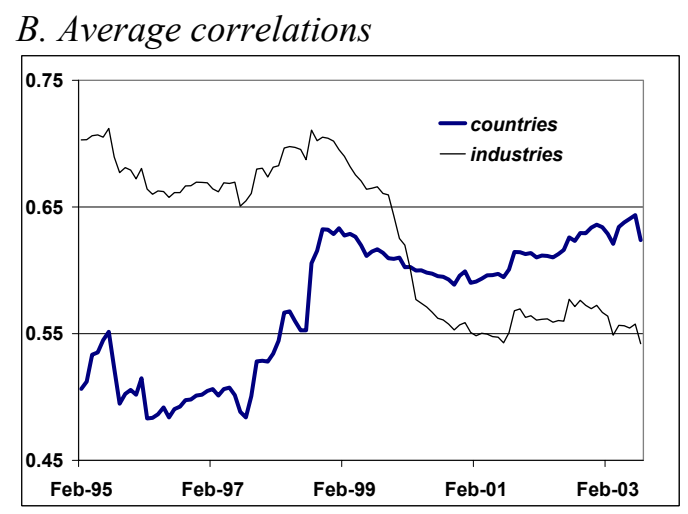

D. Systematic risk as percent of total risk 

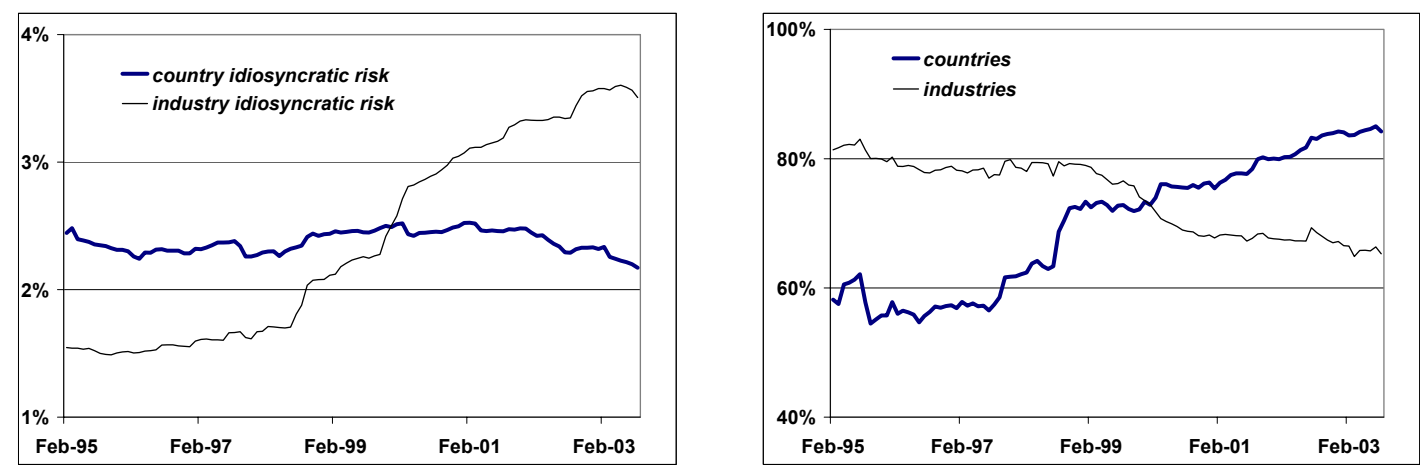

The large increase in Euro-wide industry idiosyncratic risk has substantially enhanced the benefits from holding portfolios optimally diversified across industries within the Eurozone rather than a single Euro-zone industry portfolio, as illustrated in Figure 2. The benefits of optimal diversification across pan-European industry portfolios increase from $5.2 \%$ per annum in the second half of the 1990 s to $9.7 \%$ p.a. after the introduction of the single currency. On the other hand, our findings suggest that Euro-countries have become less specialized in terms of their industry structure, which implies that countries are increasingly diversified across local industries. Hence, in contrast to the gains from crossindustry diversification, the benefits in terms of risk-adjusted returns from optimally diversifying across EMU countries have decreased steadily from $8 \%$ in the early nineties to below $6 \%$ p.a. following the adoption of the Euro. Similar patterns emerge when examining the risk reduction benefits of cross-country or cross-industry diversification

These results emphasize that the gains from international diversification remain highly significant, even within a group of closely linked economies like the Euro-zone, which have experienced not only monetary and economic convergence, but also industrial homogenization. Furthermore, our results show that investing in a single Euro-wide industry has become considerably more risky over the last decade, and provides little of the benefits that international diversification has to offer: not only should investors get out of one country, they should also diversify out of a single Euro-wide industry portfolio.

Figure 2: Euro-zone Diversification Benefits

\section{A. Risk reduction}

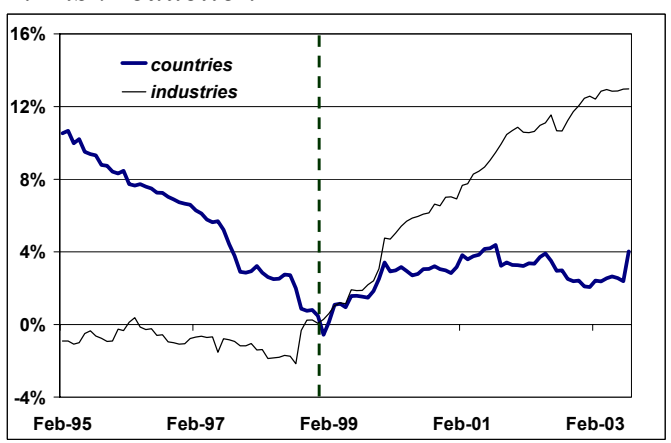

\section{B. Returns gains}

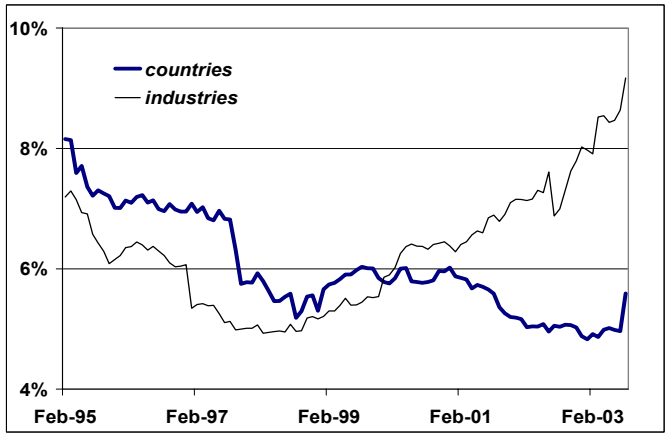


Our analysis of the changes in the structure of country and industry returns within the Euro-zone leads to the following conclusions. On one hand the evidence pertaining to country market portfolio returns is consistent with enhanced market integration, as we document increased correlations between country equity market portfolios, and an increased systematic regional component in total country equity risk. The evidence of decreased benefits of cross-country diversification within the Euro-zone is also consistent with increased integration as it reflects the increased importance of common risk factors across Euro-zone national equity markets. On the other hand, the increased total and idiosyncratic volatility of Euro-zone industry portfolios reflects increased homogeneity within industries and increased heterogeneity across industries. This would be consistent with increased joint cross-border trading of stocks within a given industry, that would have been facilitated by the increased transparency and decreased trading costs induced by the single currency. As a consequence the benefits of diversifying across industries have increased substantially in the post Euro-period.

Further evidence about the effect of the adoption of the single currency in decreasing market segmentation and removing explicit or implicit impediments to cross border investment flows can be gathered from an investigation of the changes over time in the composition of aggregate investment portfolios across countries (see De Santis and Gerard, 2006). We investigate the determinants of international portfolio reallocation for the 30 largest world economies over the period spanning 1997 to 2001 and evaluate the effects of the adoption of the euro on international allocation of equity and fixed income portfolios. We first assess whether the degree of home bias has changed over the 4 year period. We then investigate whether the introduction of the single currency has induced a portfolio reallocation towards euro area countries, within the euro area or among all countries.

Figure 3 and Table 2 summarize some of the main results of our investigation. We document a significant decrease in home bias over the 1997 to 2001 period, both for equity and bond portfolios. We also find that the decline in home bias was on average significantly more pronounced for euro area member states, and more so for fixed income than for equity portfolios. On average the share of foreign assets increase by 7 and $8 \%$ of total equity and bond portfolio respectively for non-EMU countries and by 14 and $28 \%$ for EMU countries.

Figure 3: Changes in international portfolio composition from 1997 to 2001

\section{A: Decline in Home Bias}

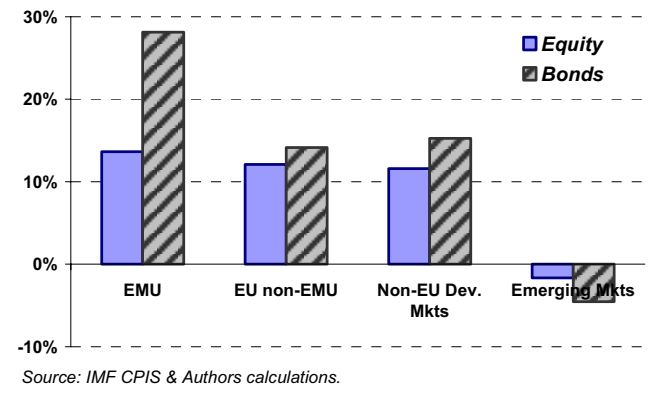

B: Changes in Share of EMU Assets

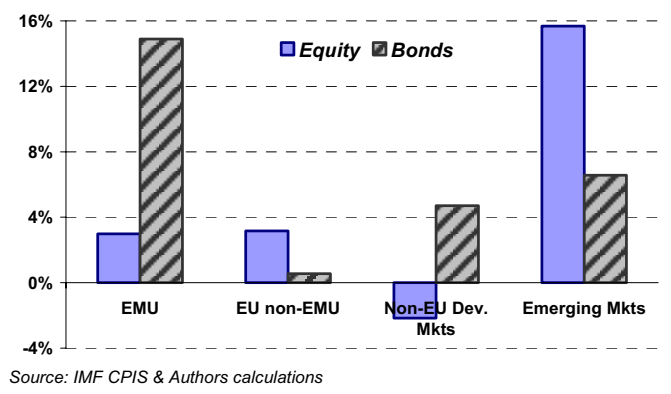


Moreover we document also a significant increase in the share of EMU assets in international portfolios. The reallocation of international fixed income portfolios of EMU countries towards other EMU countries is particularly large at about $15 \%$ of total portfolio. The re-allocation of euro investors portfolio to EMU assets is robust even after controlling for a large set of potential confounding variables suggested by finance theory. To a large extend these effects can be attributed to the single currency, and the enhanced regional financial integration among euro area member states that ensued by easing market access in both equity and bonds markets.

\begin{tabular}{|c|c|c|c|c|}
\hline \multicolumn{5}{|c|}{ Table 2: 1997-2001 Changes in } \\
\hline & \multicolumn{2}{|c|}{ Foreign Holdings } & \multicolumn{2}{|c|}{ EMU asset Allocation } \\
\hline & $\begin{array}{l}\text { Equity } \\
\text { Portfolio }\end{array}$ & $\begin{array}{l}\text { Bond } \\
\text { Portfolio }\end{array}$ & $\begin{array}{l}\text { Equity } \\
\text { Portfolio }\end{array}$ & $\begin{array}{l}\text { Bond } \\
\text { Portfolio }\end{array}$ \\
\hline Overall Average & $0.092 * * *$ & $0.148 * * *$ & $0.042 * *$ & $0.081^{* * *}$ \\
\hline Non-EMU Mkts & $0.070 * * *$ & $0.082 * * *$ & $0.049 * * *$ & $0.047^{* * *}$ \\
\hline EMU Mkts & $0.136 * * *$ & $0.281^{* * *}$ & $0.030 * *$ & $0.149 * * *$ \\
\hline Diff. (EMU, Non-EMU) & $0.066 * *$ & $0.200 * * *$ & -0.019 & $0.102^{* * *}$ \\
\hline
\end{tabular}

To conclude, investor's revealed preferences disclosed in their portfolio holdings and rebalancing decisions suggest that the EMU adoption has improved financial risk sharing in Euro-zone, and enhanced cross-border holdings, which is positive evidence of reduced market segmentation. These effects have been significantly stronger for bond than for equity portfolios. This may not be surprising as bond portfolio returns are proportionally more affected by transaction costs, and currency risk, which have been significantly reduced or eliminated by the adoption of the single currency.

Overall the evidence of significant increases in co-movements across Euro-zone equity and fixed income markets, of substantial increases in allocations to EMU assets across all international investors and of significant lager re-allocation to EMU assets by Euro-zone investors suggests that the adoption of the single currency has led to increased financial market integration and decreased trading costs in the Euro zone. However the evidence is still preliminary and incomplete. Finance researchers, market participants and policy makers would surely welcome more evidence about the impact of the adoption of the Euro on portfolio flows and on the link between international trade and portfolio flows as well as on the changes in the exposures of financial asset to regional versus local or global risk factors.

\section{References:}

Lorenzo Cappiello, Peter Hördahl, Arjan Kadareja and Simone Manganelli, Feb. 2006, The Impact of the Euro on Financial Markets, ECB Working paper.

Roberto De Santis and Bruno Gerard, Feb. 2006, Financial Integration, International Portfolio Choice and the European Monetary Union, ECB Working paper.

Esther Eiling, Bruno Gerard, and Frans de Roon, Dec 2005, International Diversification in the Euro-zone: The Increasing Riskiness of Industry Portfolios, Working paper, CentER, University of Tilburg. 


\section{European Central Bank Working Paper Series}

For a complete list of Working Papers published by the ECB, please visit the ECB's website (http://www.ecb.int)

559 "When did unsystematic monetary policy have an effect on inflation?" by B. Mojon, December 2005.

560 "The determinants of 'domestic' original sin in emerging market economies" by A. Mehl and J. Reynaud, December 2005.

56I "Price setting in German manufacturing: new evidence from new survey data" by H. Stahl, December 2005.

562 "The price setting behaviour of Portuguese firms: evidence from survey data" by F. Martins, December 2005.

563 "Sticky prices in the euro area: a summary of new micro evidence" by L. J. Álvarez, E. Dhyne, M. M. Hoeberichts, C. Kwapil, H. Le Bihan, P. Lünnemann, F. Martins, R. Sabbatini, H. Stahl, P. Vermeulen and J. Vilmunen, December 2005.

564 "Forecasting the central bank's inflation objective is a good rule of thumb" by M. Diron and B. Mojon, December 2005.

565 "The timing of central bank communication" by M. Ehrmann and M. Fratzscher, December 2005.

566 "Real versus financial frictions to capital investment" by N. Bayraktar, P. Sakellaris and P. Vermeulen, December 2005.

567 "Is time ripe for a currency union in emerging East Asia? The role of monetary stabilisation" by M. Sánchez, December 2005.

568 "Exploring the international linkages of the euro area: a global VAR analysis" by S. Dées, F. di Mauro, M. H. Pesaran and L. V. Smith, December 2005.

569 "Towards European monetary integration: the evolution of currency risk premium as a measure for monetary convergence prior to the implementation of currency unions" by F. González and S. Launonen, December 2005.

570 "Household debt sustainability: what explains household non-performing loans? An empirical analysis" by L. Rinaldi and A. Sanchis-Arellano, January 2006.

57I "Are emerging market currency crises predictable? A test" by T. A. Peltonen, January 2006.

572 "Information, habits, and consumption behavior: evidence from micro data" by M. Kuismanen and L. Pistaferri, January 2006.

573 "Credit chains and the propagation of financial distress" by F. Boissay, January 2006. 
574 "Inflation convergence and divergence within the European Monetary Union" by F. Busetti, L. Forni, A. Harvey and F. Venditti, January 2006.

575 "Growth in euro area labour quality" by G. Schwerdt and J. Turunen, January 2006.

576 “Debt stabilizing fiscal rules” by P. Michel, L. von Thadden and J.-P. Vidal, January 2006.

577 "Distortionary taxation, debt, and the price level” by A. Schabert and L. von Thadden, January 2006.

578 "Forecasting ECB monetary policy: accuracy is (still) a matter of geography" by H. Berger, M. Ehrmann and M. Fratzscher, January 2006.

579 "A disaggregated framework for the analysis of structural developments in public finances" by J. Kremer, C. Rodrigues Braz, T. Brosens, G. Langenus, S. Momigliano and M. Spolander, January 2006.

580 "Bank interest rate pass-through in the euro area: a cross country comparison" by C. K. Sørensen and T. Werner, January 2006.

581 "Public sector efficiency for new EU Member States and emerging markets" by A. Afonso, L. Schuknecht and V. Tanzi, January 2006.

582 "What accounts for the changes in U.S. fiscal policy transmission?" by F. O. Bilbiie, A. Meier and G. J. Müller, January 2006.

583 "Back to square one: identification issues in DSGE models" by F. Canova and L. Sala, January 2006.

584 “A new theory of forecasting” by S. Manganelli, January 2006.

585 "Are specific skills an obstacle to labor market adjustment? Theory and an application to the EU enlargement” by A. Lamo, J. Messina and E. Wasmer, February 2006.

586 "A method to generate structural impulse-responses for measuring the effects of shocks in structural macro models" by A. Beyer and R. E. A. Farmer, February 2006.

587 “Determinants of business cycle synchronisation across euro area countries” by U. Böwer and C. Guillemineau, February 2006.

588 "Rational inattention, inflation developments and perceptions after the euro cash changeover" by M. Ehrmann, February 2006.

589 "Forecasting economic aggregates by disaggregates" by D. F. Hendry and K. Hubrich, February 2006.

590 "The pecking order of cross-border investment" by C. Daude and M. Fratzscher, February 2006.

591 "Cointegration in panel data with breaks and cross-section dependence" by A. Banerjee and J. L. Carrion-i-Silvestre, February 2006. 
592 "Non-linear dynamics in the euro area demand for MI" by A. Calza and A. Zaghini, February 2006.

593 “Robustifying learnability” by R. J. Tetlow and P. von zur Muehlen, February 2006.

594 “The euro's trade effects" by R. Baldwin, comments by J. A. Frankel and J. Melitz, March 2006

595 "Trends and cycles in the euro area: how much heterogeneity and should we worry about it?" by D. Giannone and L. Reichlin, comments by B. E. Sørensen and M. McCarthy, March 2006.

596 "The effects of EMU on structural reforms in labour and product markets" by R. Duval and J. Elmeskov, comments by S. Nickell and J. F. Jimeno, March 2006.

597 “Price setting and inflation persistence: did EMU matter?" by I. Angeloni, L. Aucremanne, M. Ciccarelli, comments by W. T. Dickens and T. Yates, March 2006.

598 "The impact of the euro on financial markets" by L. Cappiello, P. Hördahl, A. Kadareja and S. Manganelli, comments by X. Vives and B. Gerard, March 2006. 
